INSTITUTO DE PESQUISAS ENERGÉTICAS E NUCLEARES

Autarquia Associada à Universidade de São Paulo

\title{
ESTUDO DA FORMAÇÃO DE NANOGÉIS E MICROGÉIS DE POLIPROPILENO MODIFICADO POR RADIAÇÃO GAMA E INCORPORAÇÃO DE NANOPARTÍCULAS D E PRATA VISANDO À AÇÃO BIOCIDA
}

\section{Washington Luiz Oliani}

Tese apresentada como parte dos requisitos para obtenção do Grau de Doutor em Ciências na Área de Tecnologia Nuclear - Materiais

Orientador:

Dr. Humberto Gracher Riella

Co-orientador:

Dra Duclerc Fernandes Parra

\section{Versão Corrigida}

Versão Original disponível no IPEN 
"Imagine que, no inclemente inverno russo, os frágeis botões dos uniformes do exército napoleônico se desintegrassem, contribuindo para sua derrota. Quando a temperatura cai, o reluzente estanho metálico começa a se tornar frível e a se esboroar num pó cínza e não metálico - continua sendo estanho, mas com forma estrutural diferente. Teria acontecido isso com os botões de estanho do exército francês? $\mathcal{E} m$ Borisov, um observador descreveu o exército como "uma multidão de fantasmas vestidos com roupa de mulher, retalhos de tapete ou sobretudos queimados e esburacados". Estavam os homens de Napoleão, quando os botões de seus uniformes se desintegraram, tão debilitados e gélidos que não tinham mais condições de atuar como soldados? Será que, à falta de botões, passaram a ter de usar as mãos para prender e segurar as roupas, $e$ não mais para carregar as armas?" Penny Le Couteur e Jay Burreson - Os Botões de $\mathcal{N a p o l e a ̃ o ~ ( 2 0 0 3 ) . ~}$

"A penicilina cura os homens, mas é o vinho que os torna felizes" Alexander Fleming

"But I am not afraid to consider the final question as to whether, ultimately - in the great future - we can arrange the atoms the way we want; the very atoms, all the way down!" - Richard Feynman, There's Plenty of Room at the Bottom (1959).

Aos meus pais, José Oliani e lara Lucena Oliani, pelo incentivo e formação. A minha esposa Ivete $\mathrm{H}$. da $\mathrm{S}$. Oliani e filha Cibele Oliani, pelo apoio incondicional. 


\section{AGRADECIMENTOS}

Ao Dr. Humberto Gracher Riella e a Dra Duclerc Fernandes Parra, pela orientação e pelo apoio cientifico.

Ao Dr. Ademar Benévolo Lugão, pelo apoio prestado durante todos estes anos, tanto no mestrado quanto no doutorado.

A meus colegas do CQMA-IPEN: Sizue O. Rogero, Patricia Ponce, Antonio J. C. Brant, Natália Naime, Mara Tânia S. Alcântara, Edson Takeshi, Sandra Scagliusi, Elisabeth Carvalho Leite Cardoso, Sandra R. Scagliusi, Maria José A. Oliveira, Pedro L. Forster, Hélio F. R. Ferreto, Luiz Gustavo H. Komatsu e em especial ao Dr. Luis Filipe Carvalho Pedroso de Lima pelo convívio, incentivo, assim como o amigo Henrique Perez Ferreira pelo apoio e suporte técnico na elaboração dos gráficos.

Ao Sr. Eleosmar Gasparin, do Laboratório de Polímeros - Centro de Química e Meio Ambiente (CQMA), pelas análises térmicas realizadas.

Ao Sr. Nelson Rodrigues Bueno (CQMA), pela operação da extrusora.

A todos os colegas do CQMA-IPEN.

Aos colegas Glaucio, Larissa, Flavia, Celso e Nildemar, IPEN-CCTM, Centro de Ciências e Tecnologia de Materiais, pelas análises de microscopia eletrônica de varredura e transmissão.

LNLS - LNNano pelo apoio técnico dos Srs. Vinicius e Lucas, com treinamento e experimentos utilizando o equipamento de microscopia de força atômica (MFA).

Ao Dr. Nilton Erbet Lincopan Huenuman e Priscila Martins dos Santos do ICB/USP, Instituto de Ciências Biológicas, obrigado pelo apoio e disposição em ajudar através da realização dos ensaios bacteriológicos e a Raquel Piletti da UNESC pelos ensaios biológicos. 
A MSc. Sizue O. Rogero do Laboratório de Biomateriais Poliméricos CQMA/IPEN, pelos Testes de Citotoxicidade.

À Empresa Brasileira de Radiações CBE/EMBRARAD pela irradiação das amostras de polipropileno.

A CAPES - Projeto Pró-Engenharias nº 01/2007 pela bolsa concedida. 


\section{ESTUDO DA FORMAÇÃO DE NANOGÉIS E MICROGÉIS DE POLIPROPILENO MODIFICADO POR RADIAÇÃO GAMA E INCORPORAÇÃO DE NANOPARTÍCULAS DE PRATA VISANDO À AÇÃO BIOCIDA}

\section{Washington Luiz Oliani}

\section{RESUMO}

A parte inicial deste estudo consistiu da síntese de HMSPP (Polipropileno com Alta Resistência do Fundido) também chamado polipropileno modificado por irradiação gama, a partir de iPP (polipropileno isotático) em presença de acetileno sob pressão de $110 \mathrm{kPa}$ e irradiado com $\gamma$ (gama) de fonte de ${ }^{60} \mathrm{Co}$ nas doses de 5; 12,5 e $20 \mathrm{kGy}$. A fração gel das amostras foi determinada pela extração de componentes solúveis em xileno. A parte solúvel das amostras foi decantada com deposição do gel em lâminas de vidro, até total volatilização do xileno à temperatura ambiente de $25^{\circ} \mathrm{C}$. À parte solúvel da amostra com 12,5 kGy adicionaram-se nanopartículas de prata (NPsAg) nas proporções de: 0,25; 0,5; 1,0; 2,0 e 4,0\% em massa. Estas amostras foram caracterizadas por: microscopia eletrônica de varredura e espectroscopia de energia dispersiva (MEV/EDS), espectroscopia no infravermelho (FTIR), microscopia eletrônica de varredura com emissão de campo (MEV-EC), microscopia de força atômica (MFA), calorimetria exploratória diferencial (DSC), difração de raios $X$ (DRX), redução da unidade formadora de colônias (UFC) (\%) e teste de citotoxicidade. Neste estudo da 
morfologia, observou-se a formação de microgéis de polipropileno na ordem crescente PP 5 kGy < PP 12,5 kGy < 20 kGy. Constatou-se a existência de estruturas nanométricas de géis de polipropileno (nanogéis e nanofibras) nas amostras de PP 12,5 kGy e PP 20 kGy. Os nanogéis são formações reticuladas, ramificadas, e emaranhadas, nucleadas em regiões de incidência de alta concentração de energia (spurs) em uma amostra irradiada.

Nos testes de avaliação da atividade bactericida dos géis com NPsAg observou-se eficiência biocida para E. coli e S. aureus a partir de 1\% de NPsAg e no teste de citotoxicidade as amostras foram caracterizadas como não citotóxicas para células de mamíferos.

Em uma segunda etapa deste trabalho foram produzidos filmes da blenda de iPP e PP modificado (50/50) em uma extrusora de dupla rosca. Adicionou-se ao processamento NPsAg nas proporções de: 0,1; 0,25; 0,5; 1,0; 1,0 PVP; 2,0 e 4,0\% em massa. Os filmes foram caracterizados por: calorimetria exploratória diferencial (DSC), análise de termogravimetria (TGA), difração de raios $X(D R X)$, microscopia eletrônica de varredura (MEV), espectroscopia de energia dispersiva (EDS), espectroscopia de ultravioleta-visível (UV-Vis), microscopia eletrônica de transmissão (MET), redução da unidade formadora de colônias (UFC) (\%), teste de sensibilidade a antimicrobianos por disco de difusão e teste de citotoxicidade. Os filmes analisados apresentaram pontos de aglomeração de prata e regiões com distribuição homogênea das partículas. O efeito bactericida com a interação entre a prata, e E. coli, P. aeruginosa e $S$. aureus foi constatado para o filme de PP 1\%NPsAg PVP Poli(N-vinil-2pirrolidona). No teste de difusão o resultado obtido para PP 1\% NPsAg PVP foi 100\% positivo com essas bactérias. Os filmes não são considerados citotóxicos para células de mamíferos. 


\title{
STUDY ON THE FORMATION OF THE NANOGEL AND MICROGELS POLYPROPYLENE MODIFIED BY GAMMA RADIATION AND INCORPORATION OF SILVER NANOPARTICLES TO BIOCIDE ACTIVITY
}

\section{Washington Luiz Oliani}

\begin{abstract}
The study consists of the synthesis of HMSPP (polypropylene with high melt strength), also called polypropylene modified by gamma irradiation from iPP (isotactic polypropylene) in presence of acetylene at $110 \mathrm{kPa}$ pressure and irradiated with $\gamma$ of ${ }^{60} \mathrm{Co}$ source at doses of 5, 12.5 and $20 \mathrm{kGy}$. The gel fraction of the samples was determined by extracting in xylene. The soluble portion of the samples was decanted to deposition on glass substrate until complete volatilization of xylene at room temperature of $25{ }^{\circ} \mathrm{C}$. On the soluble portion of 12.5 kGy irradiated sample were added silver nanoparticles (AgNPs) in proportions of $0.25,0.5,1.0,2.0$ and $4.0 \mathrm{wt} \%$. These gel samples were characterized by: scanning electron microscopy/energy dispersive spectroscopy (SEM / EDS), infrared spectroscopy (FTIR), scanning electron microscopy with field emission (FE-SEM), atomic force microscopy (AFM), differential scanning calorimetry (DSC), X-ray diffraction (XRD), reduction of colony forming unit (CFU) (\%) and cytotoxicity assay. In this study of the morphology, it has been observed the formation of microgels in polypropylene increasing with the dose PP $5 \mathrm{kGy}<$ PP 12.5 kGy < 20 kGy. Nanoscale structures of gels polypropylene (nanogels and nanofibers) were found in samples of PP 12.5 kGy and $20 \mathrm{kGy}$. The nanogels are
\end{abstract}


formation of crosslinking, branching and entanglement that are nucleated in regions of high energy concentration (spurs) of one irradiated sample.

Efficiency in tests of bactericide activity of the gels with AgNPs was observed versus E. coli and S. aureus from 1\% AgNPs and non cytotoxicity were characterized in those samples for mammalian cells.

In a second stage of this work films of the blend of PP and modified PP (50/50) were produced in a twin screw extruder. AgNPs were added to the extrusion processing in proportions of $0.1 ; 0.25 ; 0.5 ; 1.0 ; 1.0$ PVP; 2.0 and 4.0 $w t \%$. The films obtained were characterized by differential scanning calorimetry (DSC), thermogravimetry analysis (TGA), X-ray diffraction (XRD), scanning electron microscopy (SEM), energy dispersive spectroscopy (EDS), ultravioletvisible spectroscopy (UV-Vis), transmission electron microscopy (TEM), reduction of colony forming unit (CFU) (\%), antimicrobial susceptibility testing by disk diffusion and cytotoxicity assay. The films analyzed showed agglomeration of silver points and regions with homogeneous distribution of the particles. The bactericide effect with the interaction between silver and E. coli, P. aeruginosa and S. aureus was found for PP film 1\% NPsAg Polyvinylpyrrolidone (PVP). In the diffusion test for PP 1\% AgNPs (PVP) was obtained 100\%positive result for those bacteria. The films were not cytotoxic to mammalian cells. 
1 INTRODUÇÃO

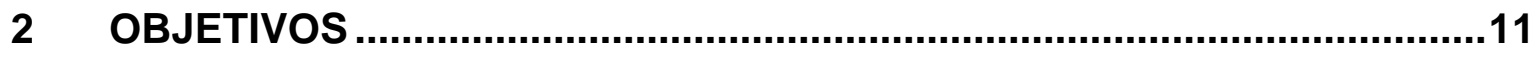

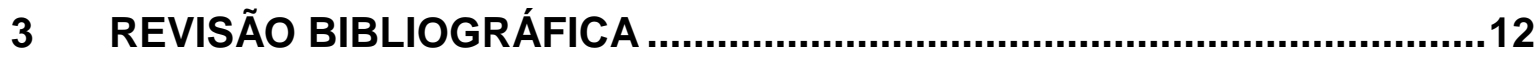

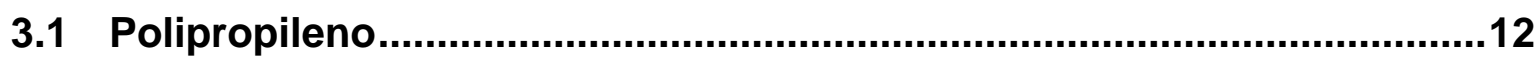

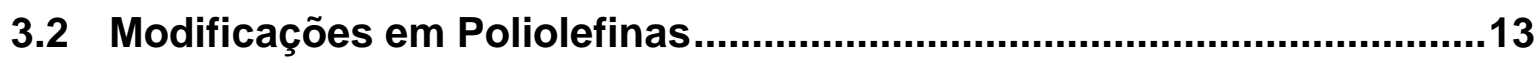

3.2.1 Irradiação do polipropileno.....................................................................................17

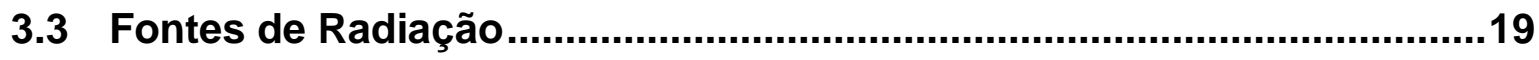

3.3.1 Radiação por Feixe de Elétrons ..............................................................................20

3.3.2 Radiação por Raios Gama...................................................................................22

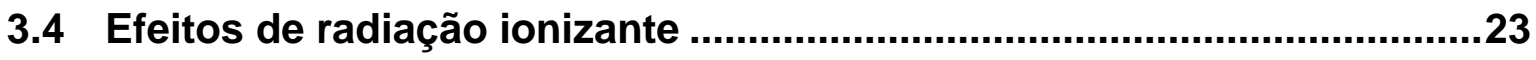

3.4.1 Absorção fotoelétrica ...........................................................................................2

3.4.2 Efeito Compton ...............................................................................................................24

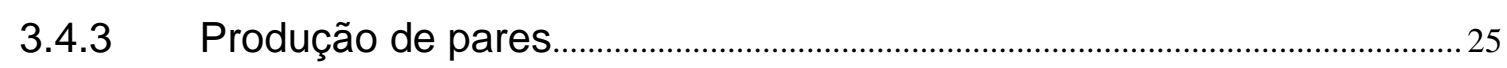

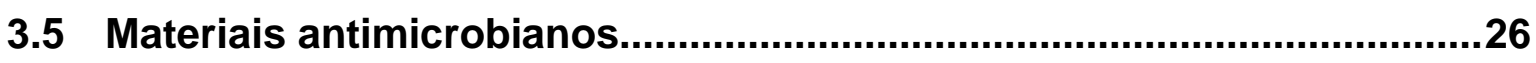

3.5.1 Resistência a Antibióticos........................................................................................2 28

3.6 Aspectos Históricos e Ação Biocida da Prata ........................................31

3.7 História das Nanopartículas de Prata .....................................................33

3.8 Processamento de Polímeros com NPsAg ................................................35

3.9 Mecanismo de ação das nanopartículas de prata …..............................40

3.10 Algumas aplicações das NPsAg nos seres humanos.............................41

3.11 Aspectos ambientais das nanopartículas de prata ................................42

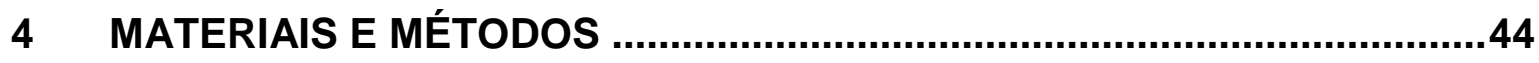




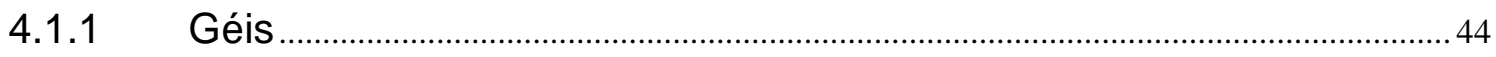

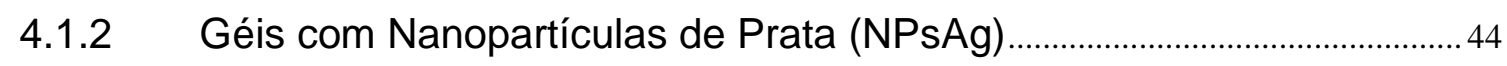

4.1.3 Filmes de Polipropileno com Nanopartículas de Prata (NPsAg) ............ 46

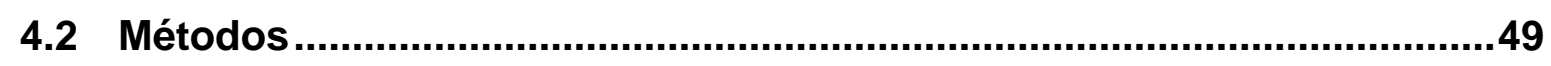

4.2.1 Fração Gel/ Fração Sol e Índice de Fluidez do Fundido (MFI) ................. 49

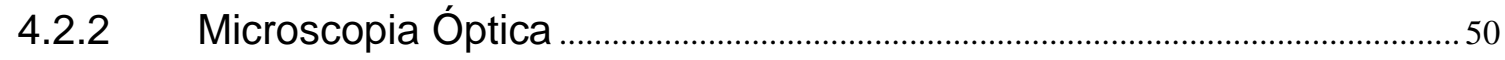

4.2.3 Microscopia Eletrônica de Varredura (MEV) e Table Top (MEV/EDS)

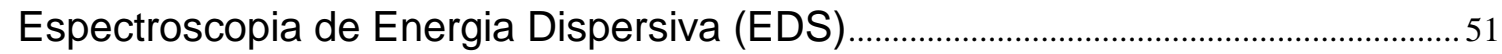

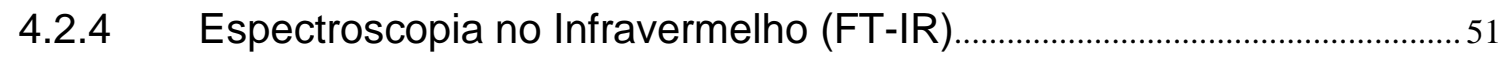

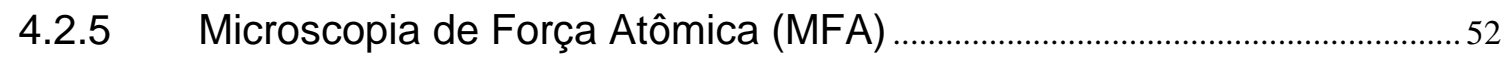

4.2.6 Microscopia Eletrônica de Varredura com Emissão de Campo

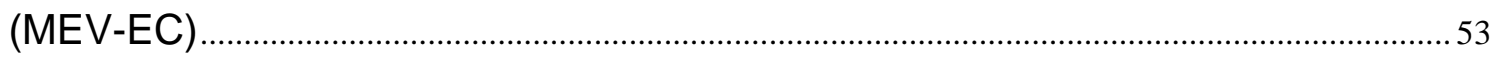

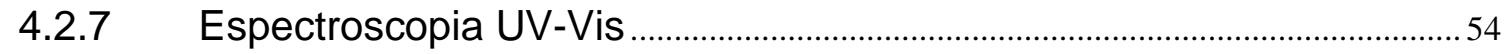

4.2.8 Microscopia Eletrônica de Transmissão (MET) e Ultramicrótomo.......... 54

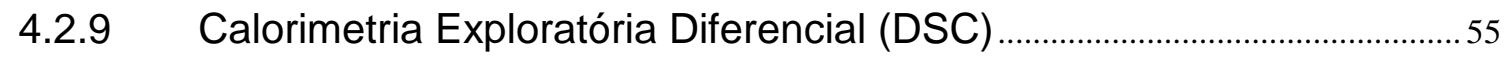

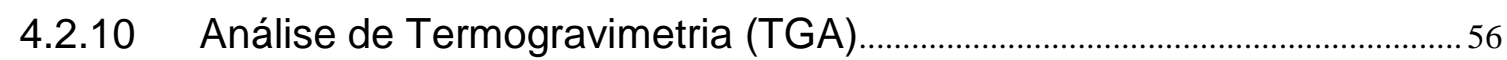

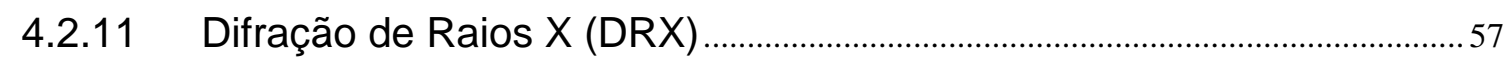

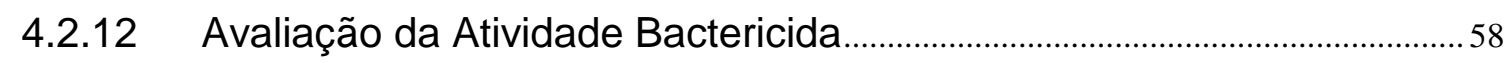

$5 \quad$ RESULTADOS E DISCUSSÃO .........................................................62

5.1 Géis de Polipropileno .....................................................................62

5.1.1 Fração Gel/Fração Sol e Índice de Fluidez do Fundido (MFI).................. 62

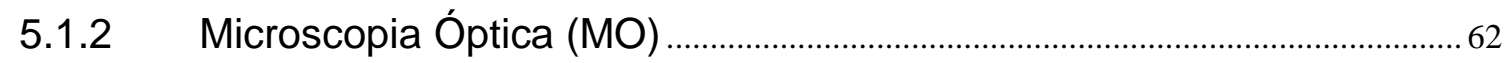

5.1.3 Microscopia Eletrônica de Varredura (MEV) da Fração Gel/Fração

Sol $\quad 64$

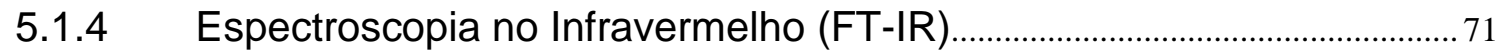

5.1.5 Microscopia Eletrônica de Varredura com Emissão de Campo

(MEV-EC) 72

5.1.6 Calorimetria Exploratória Diferencial (DSC) ................................................... 74

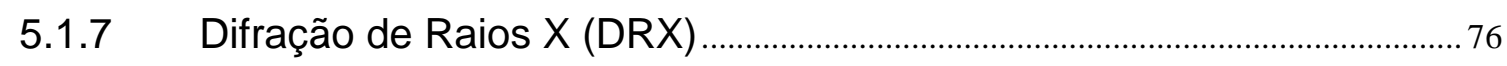


5.2 Géis com Nanopartículas de Prata (NPsAg) .77

5.2.1 Microscopia Eletrônica de Varredura da Fração Sol e Espectroscopia de Energia Dispersiva.

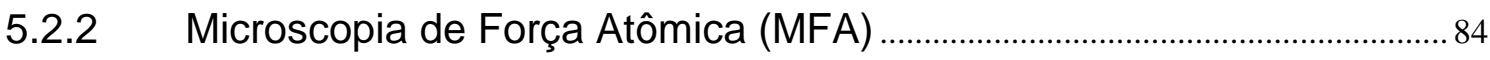

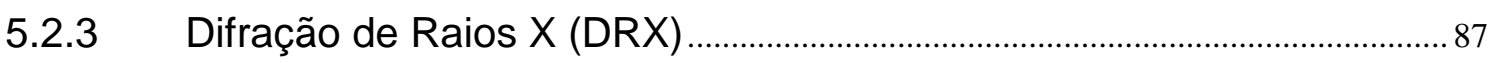

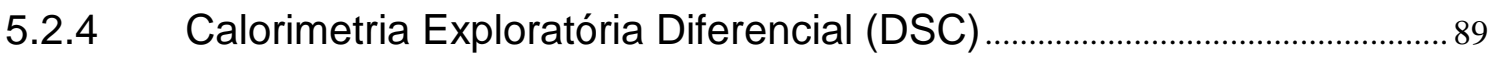

5.2.5 Teste de ação bactericida nos géis com NPsAg ........................................... 91

\subsection{Filmes de Polipropileno com Nanopartículas de Prata (NPsAg) -}

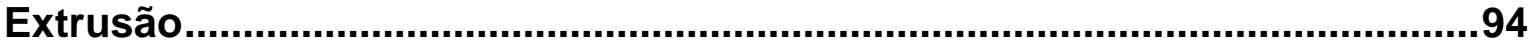

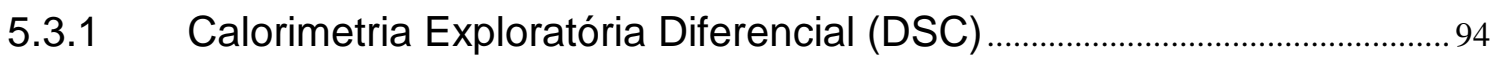

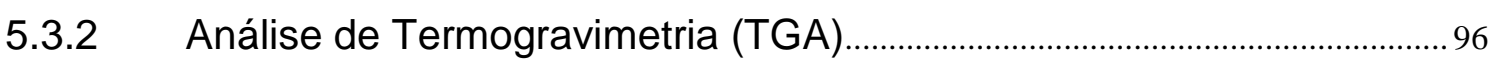

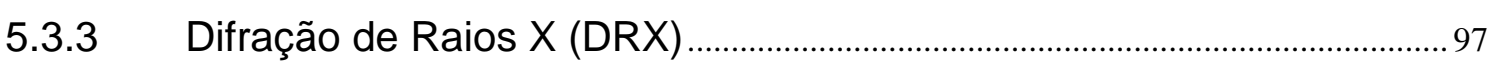

5.3.4 Microscopia Eletrônica de Varredura (MEV) e EDS ....................................... 99

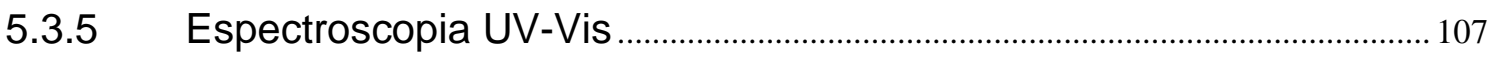

5.3.6 Microscopia Eletrônica de Transmissão (TEM) ………………………......... 108

5.3.7 Teste de ação bactericida nos filmes de PP-NPsAg ..................................... 109

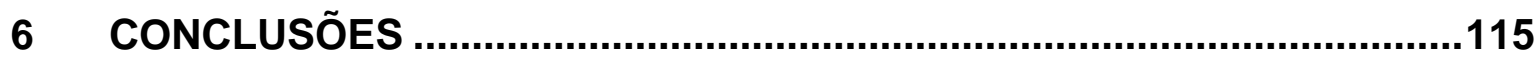

REFERÊNCIAS BIBLIOGRÁFICAS.........................................................117 


\section{ÍNDICE DE FIGURAS}

FIGURA 1- Principais Resinas Termoplásticas Consumidas no Brasil (2011). Fonte: ABIPLAST ${ }^{3}$ 1

FIGURA 2- Balanço de oferta e demanda de PP no Brasil. Fonte: ABIQUIM ${ }^{4} \ldots . . .2$ FIGURA 3 - Cadeias poliméricas: a) Linear, $(b-c)$ ramificadas, e $(d-e)$ reticuladas ${ }^{23-36}$ 4

FIGURA 4 - Escala de comprimento para a classificação de nanopartículas ${ }^{46} \ldots . . .5$ FIGURA 5 - Extensão das escalas nano, micro e macro dos diversos materiais e alcance de algumas técnicas de observação ${ }^{48}$

FIGURA 6 - Esquema do processo de formação de nanopartículas metálicas ${ }^{50-52} 8$ FIGURA 7 - Representação das configurações estereoespecíficas do polipropileno: (a) Isotático; (b) Sindiotático; (c) Atático ${ }^{73-77}$. .13

FIGURA 8 - Esquema da modificação em poliolefinas ${ }^{81,82}$.................................15

FIGURA 9 - Reações oxidativas induzidas por irradiação em polímeros ${ }^{83-89}$.......16

FIGURA 10 - Mecanismo de foto-oxidação do polipropileno ${ }^{90}$.............................18

FIGURA 11 - Desenho tradicional de uma unidade aceleradora de elétrons de alta energia $^{97}$.

FIGURA 12 - Esquema representativo da unidade de irradiação gama por ${ }^{60} \mathrm{Co}{ }^{96}$

FIGURA 13 - Diagrama esquemático do Efeito Compton ${ }^{100-102}$ .25

FIGURA 14 - Produção de pares ${ }^{103}$ .26

FIGURA 15 - Estrutura do biocida da família do bisfenol, Triclosan ${ }^{29}$ ou Irgasan DP300R - Ciba-Geigy ${ }^{109-111}$

FIGURA 16 - (A) Instrumentos dentários em prata do século XVIII ${ }^{117}$; (B) Urna gigante de prata em Diwan-i-klas: que conserva a água sagrada do rio Ganges ${ }^{117}$ 
FIGURA 17- Cálice de Licurgo (A) que apresenta diferentes colorações em função da luz refletida ou $(B)$ transmitida devido à presença de NPs metálicas ${ }^{121-}$ 123

FIGURA 18 - Microscopia eletrônica de transmissão (TEM) de uma liga prataouro, partícula dentro do vidro do Cálice de Lycurgus ${ }^{122,123}$ 34

FIGURA 19 - Estrutura típica casca-núcleo de NPsAg (com diferentes formatos de prata), que podem ser liberadas para o ambiente ${ }^{134}$ .36

FIGURA 20 - Diferentes maneiras de ação da prata na célula bacteriana ${ }^{166}$ .41

FIGURA 21 - Aplicações da prata (lado direito) e de nanopartículas de prata NPsAg (lado esquerdo) em medicina ${ }^{174}$

FIGURA 22 - Fluxograma das atividades da etapa experimental (géis de polipropileno com NPsAg) .45

FIGURA 23 - (A-B) Extrusora co-rotatória Haake; (C) Extrusão da mistura na forma de macarrão; (D) Nanocompósito de polipropileno com NPsAg na forma de grãos

FIGURA 24 - Fluxograma das atividades da etapa experimental (filmes de polipropileno com NPsAg)... .48

FIGURA 25 - (A) Sistema de balões acoplados a destiladores de refluxo; (B) Plastômetro da Ceast. .50

FIGURA 26 - Microscópio óptico Olympus BX51, com luz polarizada .50

FIGURA 27 - (A) Microscopia Eletrônica de Varredura (MEV), equipamento marca EDAX Philips modelo XL-30 (B) Table Top (MEV/EDS), equipamento marca Hitachi modelo TM 3000 51

FIGURA 28 - Aparelho da Thermo Nicolet, modelo 380 FT-IR .52

FIGURA 29 - Microscópio de Força Atômica (MFA) Nanoscope III A .53

FIGURA 30 - Microscópio eletrônico de varredura com emissão de campo (MEVEC), JEOL FE-SEM, JSM-6701F .54 
FIGURA 31 - (A) Microscópio eletrônico de transmissão (MET) equipamento da marca JEOL, modelo JEM 2100F (B) Ultramicrótomo Leica EM FC6...................55

FIGURA 32 - Equipamento da Mettler Toledo DSC 822 …...............................56

FIGURA 33 - Equipamento da marca Mettler-Toledo - TGA/SDTA 851...............57

FIGURA 34 - (A) Difratômetro de Raios X marca Rigaku (B) Visão interna do

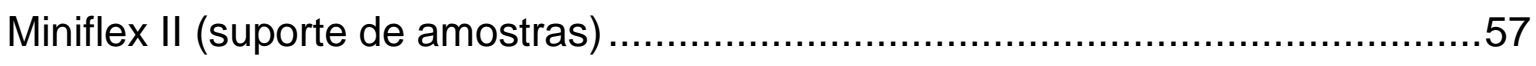

FIGURA 35 - Fotomicrografias obtidas por MO de géis de polipropileno: A) Pristine, B) PP 5 kGy, C) PP 12,5 kGy e D) PP 20 kGy, escala=100 rm ............63 FIGURA 36 - MEV de géis de polipropileno em tela de aço inoxidável: A) iPP, B) 5 kGy, C) PP 12,5 kGy e D) 20 kGy. Índice (1) barra de 100 m; índice (2) barra

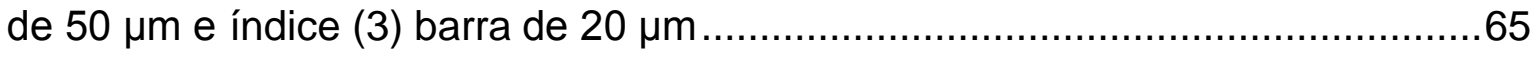
FIGURA 37 - MEV de géis de polipropileno em tela de aço inoxidável: $A_{2}$ ) iPP, barra de $\left.50 \mu \mathrm{m} ; B_{2}\right) 5 \mathrm{kGy}$, barra de $20 \mu \mathrm{m} ; \mathrm{C}_{2}$ ) PP 12,5 kGy, barra de $20 \mu \mathrm{m}$ e $\mathrm{D}_{2}$ ) $20 \mathrm{kGy}$, barra de $20 \mu \mathrm{m}$ .66

FIGURA 38 - MEV de géis de polipropileno em substrato de vidro: E) iPP, F) PP 5

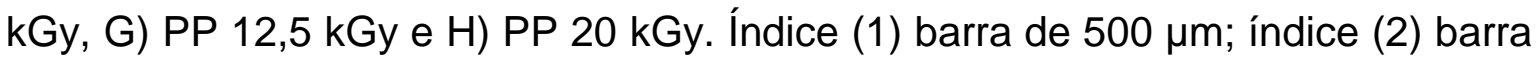
de $50 \mu \mathrm{m}$ e índice (3) barra de $20 \mu \mathrm{m}$ 68

FIGURA 39 - MEV de géis de polipropileno em substrato de vidro: I) iPP, J) PP 5 kGy, K) PP 12,5 kGy e L) PP 20 kGy. Índice (1) barra de $100 \mu \mathrm{m}$; índice (2) barra

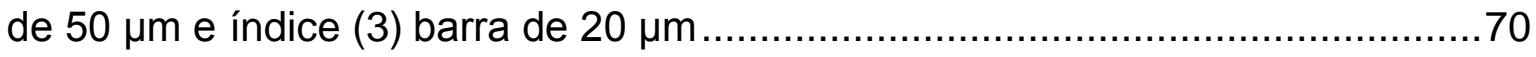

FIGURA 40 - Espectros de FTIR-ATR, de géis de polipropileno...........................71

FIGURA 41 - Imagem MEV-EC em amostra de Gel de iPP. A) barra de $10 \mu \mathrm{m}$ e B) $1 \mu \mathrm{m}$ .72

FIGURA 42 - Imagens MEV-EC da formação de nanogéis em filmes finos de polipropileno, Fs = fração solúvel do PP modificado. C) Microgéis de PP 12,5 kGy, barra de escala $=10 \mu \mathrm{m} ; \mathrm{D})$ Nanogéis de PP $20 \mathrm{kGy}$, barra de escala $=100 \mathrm{~nm}$; E) Nanofibras de PP 12,5 kGy, barra de escala $=100 \mathrm{~nm}$; F) Nanogéis de PP 12,5 kGy, barra de escala $=100 \mathrm{~nm}$ .73 
FIGURA 43 - DSC curvas de cristalização do Gel iPP; Gel PP 5kGy; Gel PP $12,5 \mathrm{kGy}$ e Gel PP 20kGy (resfriamento), aquecimento a $10^{\circ} \mathrm{C} \mathrm{min}^{-1}$ .74

FIGURA 44 - DSC de Gel de PP obtido com diferentes doses de irradiação, no decurso da fusão no reaquecimento, aquecimento a $10^{\circ} \mathrm{C} \min ^{-1}$ .75

FIGURA 45 - Difração de Raios-X de gel de polipropileno e gel PP 12,5 kGy......77 FIGURA 46 - Micrografia de géis de polipropileno (12,5 kGy) e espectro de EDS de géis de polipropileno sem prata .78 FIGURA 47 - Micrografia de géis de polipropileno com NPSAg e espectro de EDS de PP Gel 0,25\%NPsAg 79 FIGURA 48 - Micrografia de géis de polipropileno com NPSAg e espectro de EDS de PP Gel 0,5\%NPsAg .80 FIGURA 49 - Micrografia de géis de polipropileno com NPSAg e espectro de EDS de PP Gel 1\%NPsAg

FIGURA 50 - Micrografia de géis de polipropileno com NPSAg e espectro de EDS de PP Gel 2\%NPsAg

FIGURA 51 - Micrografia de géis de polipropileno com NPsAg e espectro de EDS de PP Gel 4\%NPsAg .83

FIGURA 52 - Imagem 3D de MFA de PP Gel 20 kGy com NPsAg.... .84 FIGURA 53 - Imagem de MFA obtida através do modo contato intermitente de PP Gel 20 kGy com NPsAg .85

FIGURA 54 - Imagem 3D de MFA de PP Gel 12,5 kGy com NPsAg..... .86 FIGURA 55 - Imagem de MFA obtida por modo contato intermitente de PP Gel 12,5 kGy com NPsAg. .86

FIGURA 56 - Difração de raios X em PPGel-AgNPs .88

FIGURA 57 - Curvas de DSC (segunda fusão) de PPGel 12,5 kGy e PPGel 12,5 kGy-NPsAg com diferentes porcentagens em massa de prata, aquecimento $10^{\circ} \mathrm{C}$ $\min ^{-1}$ .90 
FIGURA 58 - Porcentagem (\%) de micro-organismos sobreviventes frente a E.coli e S.aureus em diferentes amostras de géis com NPsAg

FIGURA 59 - Curvas de viabilidade celular das amostras de PPGel-NPsAg pela incorporação do vermelho neutro.

FIGURA 60 - Filmes de polipropileno com nanopartículas de prata em diferentes proporções

FIGURA 61 - Curvas de DSC de filmes de PP 12,5 kGy e PP-NPsAg com diferentes porcentagens em peso de prata (segunda fusão), aquecimento a $10^{\circ} \mathrm{C}$ $\min ^{-1}$ .95

FIGURA 62 - Curvas de perda de massa em atmosfera inerte de filmes de PPNPsAg, taxa de aquecimento de $10^{\circ} \mathrm{C} \mathrm{min}^{-1}$

FIGURA 63 - Difratogramas de Raios-X (DRX) em filmes de polipropileno PP 12,5 kGy e nanocompósitos de PP com NPsAg.

FIGURA 64 - Micrografia do filme de polipropileno e espectro de EDS do filme de polipropileno sem prata

FIGURA 65 - Micrografia do filme de polipropileno com NPsAg e espectro de EDS do filme de PP $0,25 \%$ NPsAg. 100

FIGURA 66 - Micrografia do filme de polipropileno com NPsAg e espectro de EDS do filme de PP 0,1\%NPsAg. 101

FIGURA 67 - Micrografia do filme de polipropileno com NPsAg e espectro de EDS do filme de PP 0,5\%NPsAg. 102

FIGURA 68 - Micrografia do filme de polipropileno com NPsAg e espectro de EDS do filme de PP 1\%NPsAg .103

FIGURA 69 - Micrografia do filme de polipropileno com NPSAg e espectro de EDS do filme de PP 1\%NPsAg com PVP. 104

FIGURA 70 - Micrografia do filme de polipropileno com NPsAg e espectro de EDS do filme de PP $2 \%$ NPsAg 105

FIGURA 71 - Micrografia do filme de polipropileno com NPsAg e espectro de EDS do filme de PP 4\%NPsAg .106 
FIGURA 72 - Espectro de absorção no UV-Vis da solução de PVP com nanopartículas de prata (PVP com 1\% NPsAg) ….......................................107 FIGURA 73 - Imagens obtidas por MET de amostras de filmes de PP 1\%NPsAg 108

FIGURA 74 - Porcentagem de micro-organismos sobreviventes (\%) frente a $E$. coli e S. aureus 109

FIGURA 75 - Teste de sensibilidade a antimicrobianos por disco de difusão em amostra de filme de PP com 1\%NPsAg 111

FIGURA 76 - Teste de proliferação em meio de ágar em amostra de filme de PP e PP 1\%NPsAg, controle positivo e negativo. 112

FIGURA 77 Curvas de viabilidade celular dos filmes de polipropileno contendo 0,1 e $1 \%$ de NPsAg pela incorporação do vermelho neutro 113

FIGURA 78 - Curvas de viabilidade celular dos filmes de polipropileno variando-se entre 2 e $4 \%$ de NPsAg pela incorporação do vermelho neutro. 114 


\section{ÍNDICE DE TABELAS}

TABELA 1 - Data em que um antibiótico tornou-se disponível e quando a resistência a bactérias foi relatada ${ }^{113}$ .29

TABELA 2 - Polímeros com nanopartículas de prata com atividade mediante uma larga faixa de bactérias

TABELA 3- Contribuição da pesquisa brasileira referente ao estudo com nanopartículas de prata e algumas aplicações 39

TABELA 4 - Conteúdo de gel e índice de fluidez das amostras de iPP e PP modificado 62

TABELA 5 - Valores obtidos na análise de DSC, temperatura de cristalização $\left(T_{C}\right)$, temperatura de fusão $\left(T_{m 2}\right)$ e cristalinidade $\left(X_{C}\right)( \pm 5 \%)$, das amostras de géis de iPP e PP modificado .75

TABELA 6 - Valores obtidos na análise de DSC em amostras de PPGel-NPsAg 90 TABELA 7- Valores obtidos da análise de DSC em amostras de filmes extrudados de PP-NPsAg .95 


\section{LISTA DE ABREVIAÇÕES E SÍMBOLOS}

\begin{tabular}{|c|c|}
\hline iPP & Polipropileno isotático \\
\hline PEAD & Polietileno de Alta Densidade \\
\hline PVC & Poli(cloreto de vinila) \\
\hline PEBD & Polietileno de Baixa Densidade \\
\hline PEBDL & Polietileno Linear de Baixa Densidade \\
\hline PET & Poli(tereftalato de etileno) \\
\hline PS & Poliestireno \\
\hline PE & Polietileno \\
\hline EVA & Copoli(etileno-acetato de vinila) \\
\hline EPS & Poliestireno Expandido \\
\hline PA 6 & Poliamida 6 \\
\hline ABIPLAST & Associação Brasileira da Indústria do Plástico \\
\hline ABIQUIM & Associação Brasileira da Indústria Química \\
\hline HMSPP & Polipropileno com Alta Resistência do Fundido \\
\hline IUPAC & União Internacional de Química Pura e Aplicada \\
\hline AFM & Microscopia de Força Atômica \\
\hline NPsAg & Nanopartículas de Prata \\
\hline TCS & Triclosan \\
\hline MRSA & Staphylococcus Aureus Resistente a Meticilina \\
\hline PVP & Polivinilpirrolidona \\
\hline AO & Ácido Oléico \\
\hline NTC & Nanotubo de Carbono \\
\hline DNA & Ácido Desoxiribonucléico \\
\hline NCS & Nanocolóide de Prata \\
\hline $\mathrm{Pg} \mathrm{mg}^{-1}$ & Picograma por Miligrama \\
\hline $\mathrm{nm}$ & Nanômetro \\
\hline $\mathrm{Nm}$ & Nanomol \\
\hline $\mathrm{kPa}$ & Quilo Pascal \\
\hline
\end{tabular}




\begin{tabular}{|c|c|}
\hline kGy & Quilo Gray \\
\hline$M_{w}$ & Massa molar aparente \\
\hline$\gamma$ rays & Raios Gama \\
\hline rpm & Rotação por minuto \\
\hline MFI & Índice de Fluidez do Fundido \\
\hline MEV & Microscopia Eletrônica de Varredura \\
\hline EDS & Espectroscopia de Energia Dispersiva \\
\hline FT-IR & Infravermelho por Transformada de Fourier \\
\hline MFA & Microscopia de Força Atômica \\
\hline MEV-EC & Microscopia Eletrônica de Varredura com Emissão de Campo \\
\hline UV-Vis & Ultravioleta no Visível \\
\hline MET & Microscopia Eletrônica de Transmissão \\
\hline DSC & Calorimetria Exploratória Diferencial \\
\hline TGA & Análise de Termogravimetria \\
\hline $\mathrm{DRX}$ & Difração de Raio X \\
\hline UFC & Unidade Formadora de Colônia \\
\hline CITO & Citotoxicidade \\
\hline ATCC & American Type Culture Collection \\
\hline$\beta$ fase & Fase Beta \\
\hline HIV & Vírus da Imunodeficiência Humana \\
\hline STM & Microscopia de Tunelamento por Varredura \\
\hline M & Monômero Funcional \\
\hline $\mathrm{PH}$ & Polímero \\
\hline $\mathrm{P} \bullet$ & Radical Alquila \\
\hline $\mathrm{PO}_{2} \mathrm{H}$ & Peróxido \\
\hline $\mathrm{HO} \bullet$ & Radical Hidroxila \\
\hline O• & Radical Alcoxila \\
\hline $\mathrm{kW}$ & Quilowatt \\
\hline $\mathrm{mA}$ & Miliampere \\
\hline kV & Quilovolt \\
\hline J & Joule \\
\hline${ }^{60} \mathrm{Co}$ & Cobalto Sessenta \\
\hline
\end{tabular}




$\begin{array}{ll}\text { MeV } & \text { Mega Elétron Volt } \\ \text { hv } & \text { Energia do Fóton Incidente } \\ \mathrm{E}_{\mathrm{c}} & \text { Energia Cinética do Elétron } \\ \mathrm{E}_{\mathrm{b}} & \text { Energia de Ligação do Elétron } \\ \text { CCTM } & \text { Centro de Ciência e Tecnologia de Materiais } \\ \text { CIETEC } & \text { Centro de Inovação, Empreendedorismo e Tecnologia da } \\ & \text { Universidade de São Paulo } \\ \Delta H_{f} & \text { Entalpia de Fusão da Amostra } \\ \Delta H_{0} & \text { Entalpia de Fusão Padrão } \\ \text { MHA } & \text { Ágar Müeller-Hinton } \\ \text { ANVISA } & \text { Agência Nacional de Vigilância Sanitária } \\ \text { NCCLS } & \text { National Commitee for Clinical Laboratory Standard } \\ \text { CPI 5 } & \text { Antibiótico Ciprofloxacina } \\ \text { dg min } & \text { Decigrama por Minuto } \\ T_{C} & \text { Temperatura de Cristalização } \\ T_{m 2} & \text { Temperatura de Fusão no segundo aquecimento } \\ \mathrm{X}_{\mathrm{C}} & \text { Cristalinidade } \\ \mathrm{RMN} & \text { Ressonância Magnética Nuclear } \\ \theta & \text { Ângulo teta }\end{array}$




\section{INTRODUÇÃo}

O iPP (polipropileno isotático) de notável importância econômica é um termoplástico semicristalino que apresenta fase amorfa e cristalina e é amplamente utilizado em muitas áreas, tais como eletrodomésticos, automóveis, construção, embalagens e outras aplicações industriais, não só pelo equilíbrio de propriedades físicas, químicas e mecânicas, mas também devido à sua compatibilidade ambiental enquanto não-tóxico e de fácil reciclagem e, também, baixo custo ${ }^{1}$. Recentemente nanocompósitos de iPP com inclusões nanométricas atraíram a atenção devido à grande importância científica e tecnológica. Em comparação com os compósitos convencionais os nanocompósitos de polipropileno apresentam processabilidade e desempenho diferentes, que são consideravelmente afetados pela cristalização da matriz polímerica ${ }^{2}$.

A FIG. 1 apresenta a produção das principais resinas termoplásticas consumidas no Brasil em 2011, destacando-se o polipropileno, com 25\% deste montante, seguido do PEAD com $21 \%$ e, logo após, o PVC com $16 \%$.

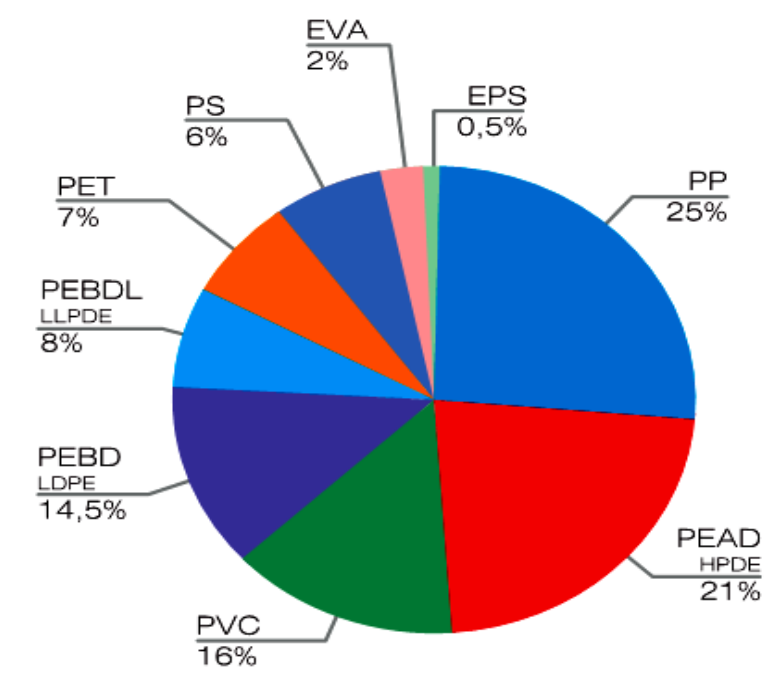

FIGURA 1- Principais Resinas Termoplásticas Consumidas no Brasil (2011). Fonte: ABIPLAST ${ }^{3}$ 
A FIG. 2 apresenta o balanço da oferta e da demanda de PP no Brasil onde são expostos, em mil toneladas, a capacidade de produção brasileira da resina, a produção efetiva, as importações, exportações e o consumo brasileiro aparente no período de 2001 até 2010. O consumo aparente corresponde ao volume produzido mais o volume importado menos o volume exportado, ABIQUIM ${ }^{4}$.

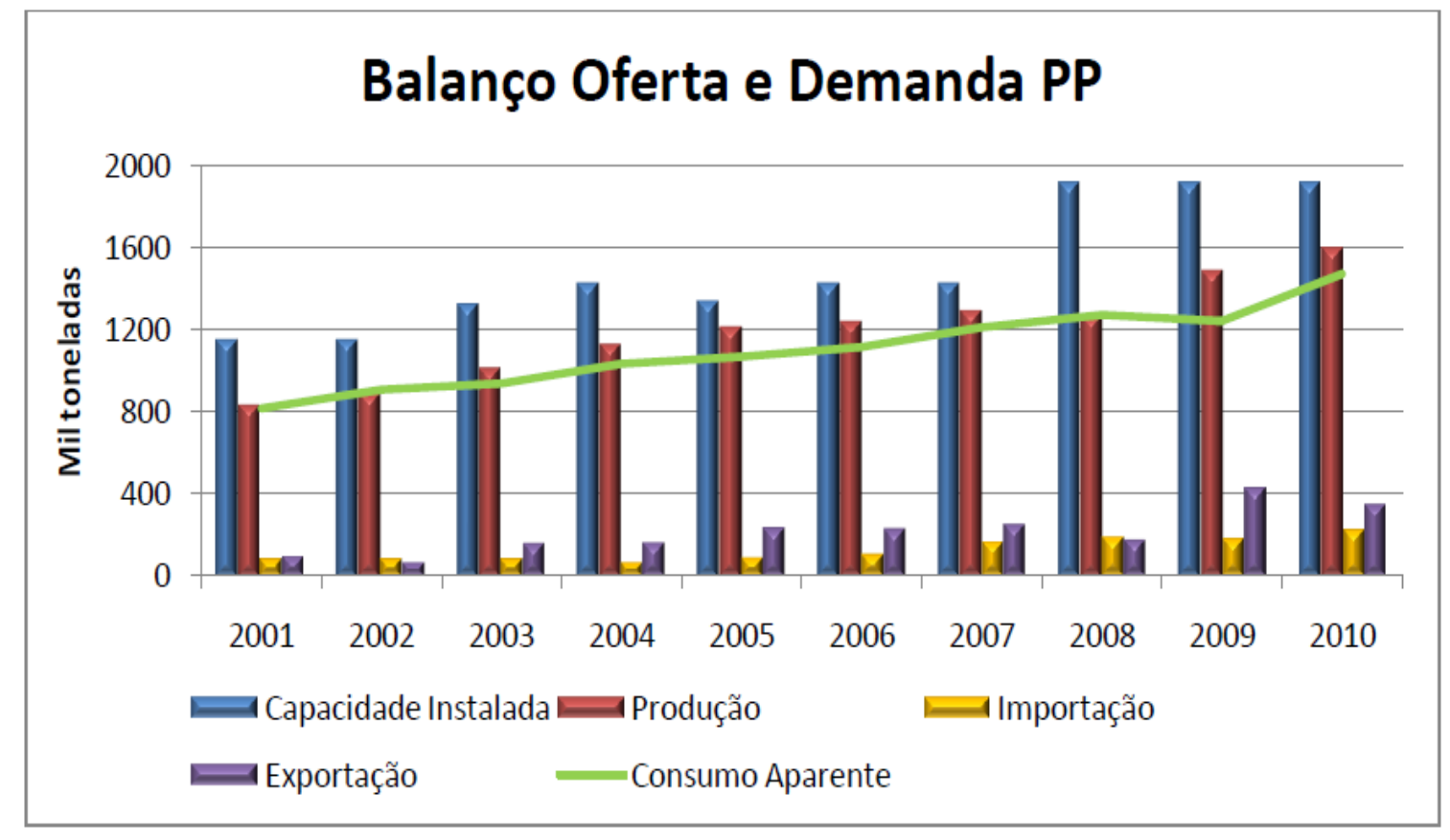

FIGURA 2- Balanço de oferta e demanda de PP no Brasil. Fonte: ABIQUIM ${ }^{4}$

O iPP é o mais comum entre os PP's comercializados, apresenta cadeias apolares essencialmente lineares devido ao seu processo de polimerização que utiliza catalisadores do tipo Ziegler-Natta ${ }^{5,6}$ e metalocênicos ${ }^{7}$. O iPP possui uma morfologia de cristais predominantemente conhecida como, forma- $\alpha$ ou fase- $\alpha$. Além dessa forma cristalina $\alpha$ existem outras, menos presentes, mas que são também formas cristalinas primárias: forma- $\beta$ e forma- ${ }^{8}$. Estes processos não permitem a produção de PP ramificado ${ }^{9}$.

A linearidade das cadeias do iPP confere a este, baixa resistência do fundido (geralmente medida pela força tênsil) o que significa uma resistência ao estiramento fraca durante o processo de elongação. Esta característica limita o 
uso do iPP em processos que demandam um estiramento alto como, por exemplo, na produção de filmes soprados, produção de espumas, extrusão de revestimentos, produção de peças livres de tensões residuais entre outras. A inclusão de enxertos de ramificações longas confere a esse polímero, melhorias da sua viscosidade extensional, no estado fundido, resultando no polipropileno com alta resistência do fundido ${ }^{10}$, cujo acrônimo é HMSPP. O aumento da resistência do fundido ou viscosidade elongacional do polímero fundido, se deve ao aumento da densidade de emaranhamentos nas macromoléculas ${ }^{11}$. Este emaranhamento pode ser resultado da presença e da quantidade de ramificações na cadeia do material e da reticulação entre cadeias ${ }^{12}$.

O grupo de polímeros do IPEN, coordenado pelo Dr. Lugão, desenvolveu o HMSPP pelo processo denominado "Processo IPEN", baseado na enxertia de cadeias ramificadas longas no PP usando acetileno como promotor de reticulação via processo de irradiação ${ }^{13,14}$. As doses utilizadas inicialmente para a síntese do HMSPP foram de 12,5 kGy e $20 \mathrm{kGy}{ }^{7}$, sendo experimentada posteriormente uma dose menor de $5 \mathrm{kGy}^{15}$. O iPP é sensível ao intemperismo em razão da presença de carbono terciário cuja abstração, facilitada pela menor energia de ligação que o torna mais lábil, induz a cisão de cadeias. Na irradiação do $\mathrm{PP}$, radicais são criados e estes podem reagir com o oxigênio. Os radicais gerados pela irradiação do PP são: alquila, polienila e peroxídico ${ }^{16}$. A enxertia utilizando-se o acetileno apresenta uma primeira etapa de formação de radicais e reação de ramificação e, por elevação de temperatura, recombinação de radicais livres residuais com a aniquilação destes radicais. É possível constatar a presença de grupos vínilicos na estrutura molecular do PP modificado. O HMSPP é objeto de investigação quanto a sua estabilidade e enquanto matriz para adição de materiais inorgânicos. Com o intuito de avaliar a estabilidade deste polímero, HMSPP, estudou-se a degradação em condições ambientais e acelerada em laboratório, com a simulação de condições reais de uso ${ }^{17}$.

Quando polímeros são submetidos à radiação ionizante em geral reações de reticulação e cisão de cadeias também são observadas, FIG. 3. Estes processos levam à formação de gel insolúvel se a reticulação for predominante 
sobre a cisão ${ }^{18,19}$. A reticulação intermolecular entre grupos vinilícos e centros de radicais localizados em diferentes macromoléculas produzem ligações cruzadas $^{20,21}$, que são responsáveis, pela agregação de macromoléculas, o que leva à formação de microgéis ${ }^{21}$. Considera-se que durante a reticulação formamse estruturas de microgéis e nanogéis poliméricos.

Polímeros absorvem a energia da radiação ionizante de forma heterogênea. Na região amorfa, ocorre uma variedade de tamanhos de spurs, região com alta concentração de energia ${ }^{22}$, que sugere a formação de pontos de nucleação onde são criados os nanogéis.

(a)

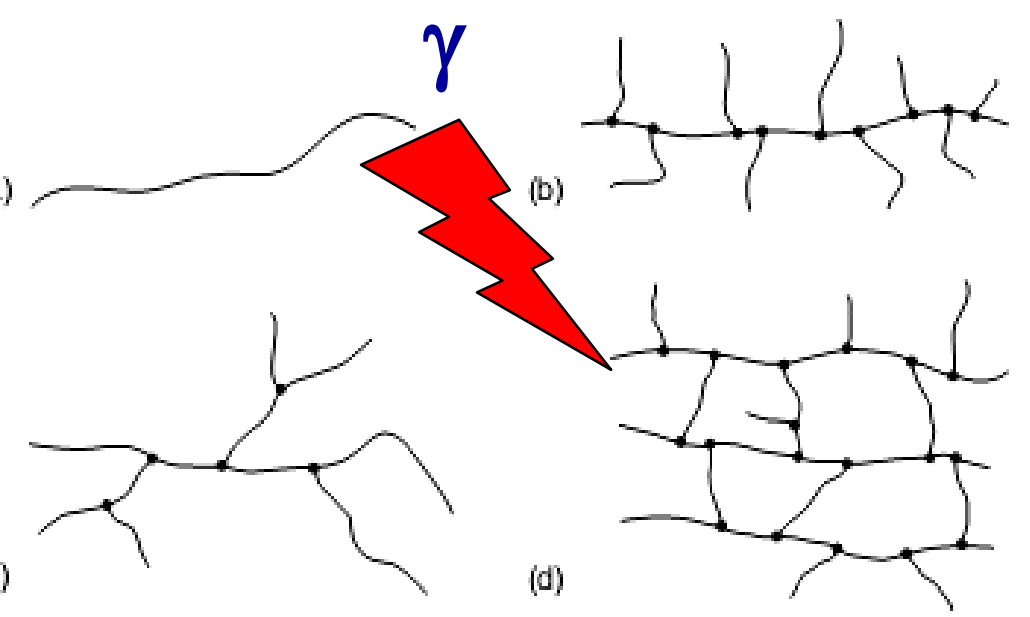

(c)

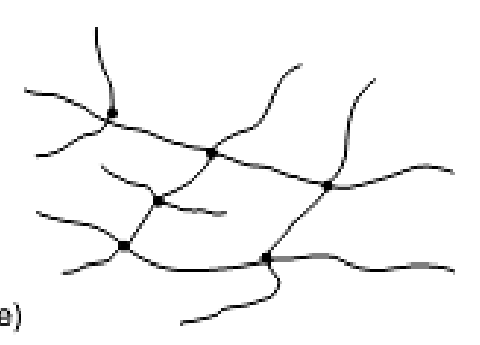

FIGURA 3 - Cadeias poliméricas: a) Linear, (b - c) ramificadas, e (d - e) reticuladas ${ }^{23-36}$ 
O polipropileno enquanto polímero modificado se presta a estudos de matrizes nanotecnológicas com propriedades diferenciadas. O domínio da nanotecnologia encontra-se compreendido entre 0,1 e $100 \mathrm{~nm}$, região onde as propriedades dos materiais são determinadas e podem ser controladas $^{37-41}$. A nanotecnologia é a aplicação do método científico com objetivos práticos e comerciais $^{42}$. Os nanocompósitos são compostos em que a interface domina as propriedades do material devido ao pequeno tamanho dos componentes $100 \mathrm{~nm}$ ou menor ${ }^{43}$. Conforme definição, nanocompósito ${ }^{44}$ é um material constituído por duas fases no qual a fase dispersa apresenta dimensão da ordem de nanômetros $\left(10^{-9} \mathrm{~m}\right)$ ou, conforme definição da IUPAC ${ }^{45}$, é um compósito em que a menor fase tem dimensão da ordem de nanômetros.

Considerando-se o nanomundo "nanoworld", alguns exemplos de tais estruturas estão representados na FIG. 4, diâmetro do fio de cabelo, células vermelhas do sangue, bactéria (E.coli), vírus (HIV), e moléculas (hemoglobina ou buckminsterfullerene $\mathrm{C}_{60}$ ).

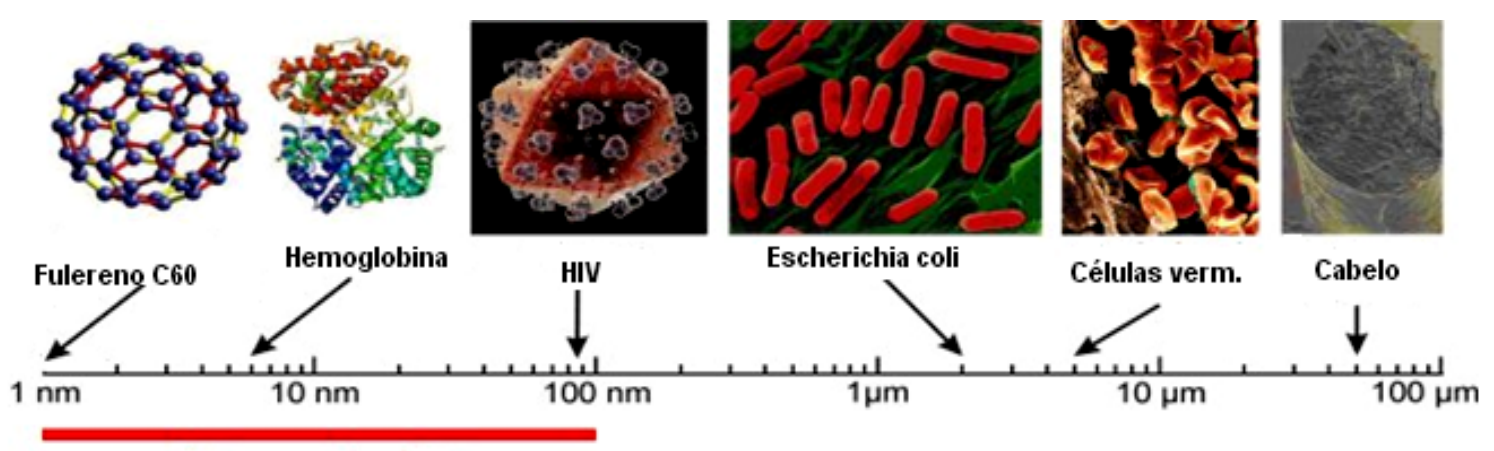

Nanomateriais

FIGURA 4 - Escala de comprimento para a classificação de nanopartículas ${ }^{46}$

A dimensão menor ou igual a $100 \mathrm{~nm}$ é tipicamente de nanopartículas que apresentam, em consequência de seu tamanho pequeno, uma grande área superficial com o que se espera um comportamento de reatividade diferenciada ${ }^{46}$.

Entre as técnicas de microscopia as de varredura por tunelamento (STM) e microscopia de força atômica (AFM) têm sido de contribuição relevante 
para a construção da nanociência ${ }^{47}$. A FIG. 5 ilustra a extensão aproximada da escala nano, micro-escala e macro-escala, o tamanho de estruturas típicas e a evolução da microscopia.
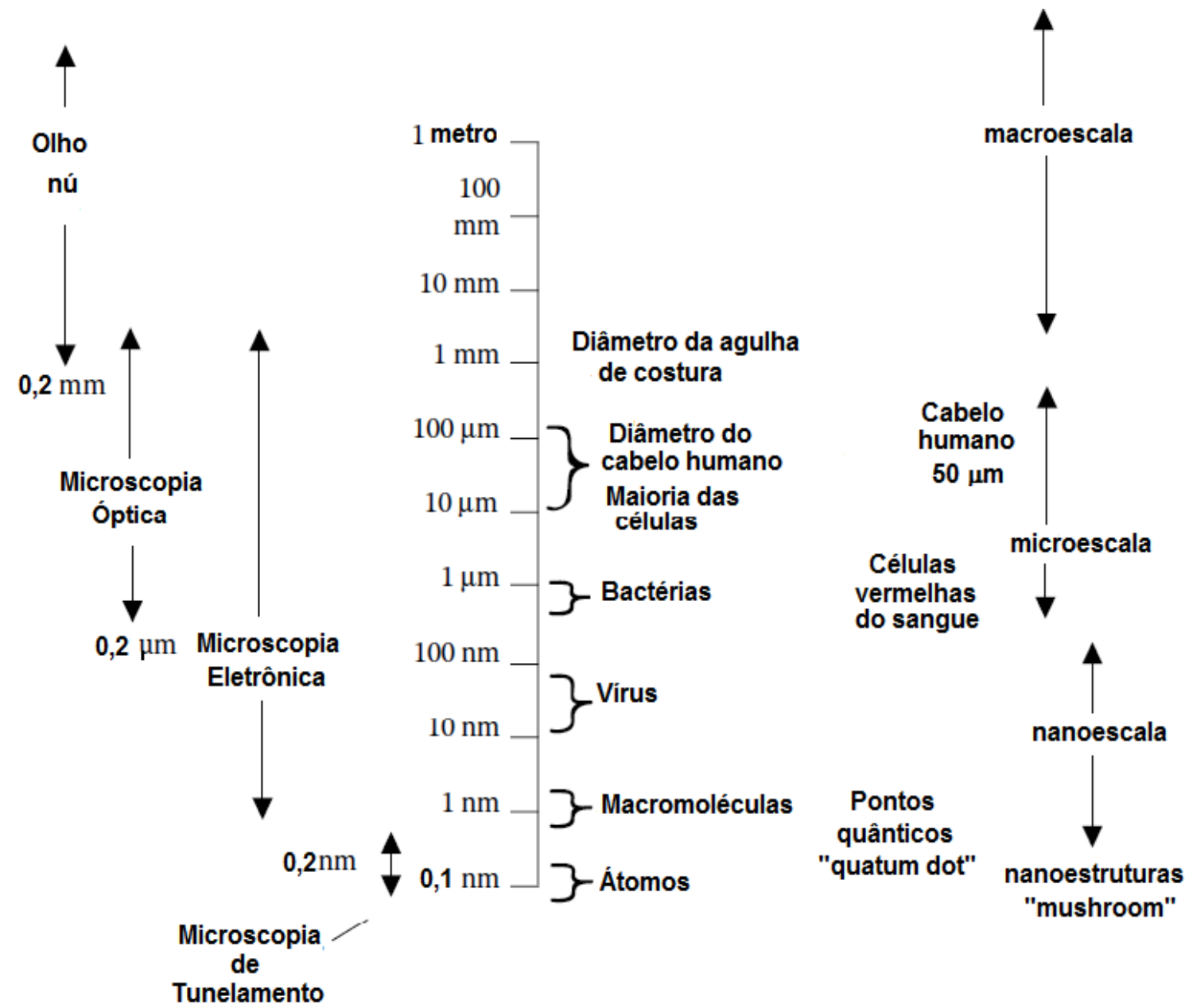

FIGURA 5 - Extensão das escalas nano, micro e macro dos diversos materiais e alcance de algumas técnicas de observação ${ }^{48}$

Nanocompósitos poliméricos são constituídos de uma matriz polimérica adicionada de material inorgânico em escala nanométrica (nanocarga), e, devido ao elevado contato interfacial entre o polímero e a nanocarga, uma morfologia diferente é gerada na interface. A dispersão em nanoescala do material inorgânico é relatada como sendo muito mais uniforme, no caso de polímeros polares, resultando assim a melhoria das propriedades dos compósitos. No entanto, a dispersão de nanocargas em poliolefinas em razão de suas naturezas 
não é simples devido à ausência de interação evidente entre as fases orgânica e inorgânica ${ }^{49}$.

Conforme mecanismo geral de formação de nanopartículas metálicas, FIG. 6, a redução de precursores do metal (moléculas ou íons) resulta na formação de átomos, os quais são insolúveis no meio de dispersão com a formação de embriões (aglomerados). Tais embriões estão em equilíbrio com os átomos do metal. Quando os embriões (clusters/aglomerados) atingem um estado crítico, representado por partículas estáveis e insolúveis, há a formação de núcleos nanométricos. A partir destes núcleos desenvolvem-se nanopartículas primárias que são caracterizadas por terem alta energia livre e continuam a crescer. São três os mecanismos representados na FIG. 6 que mostram o crescimento de nanopartículas primárias, resultando em nanopartículas metálicas.

1) Crescimento por difusão de átomos; 2) Crescimento por agregação (coalescência) de núcleos pré-formados e/ou nanopartículas e 3) Crescimento autocatalítico onde o núcleo metálico serve como um catalisador para a redução do precursor metálico ${ }^{50}$. 


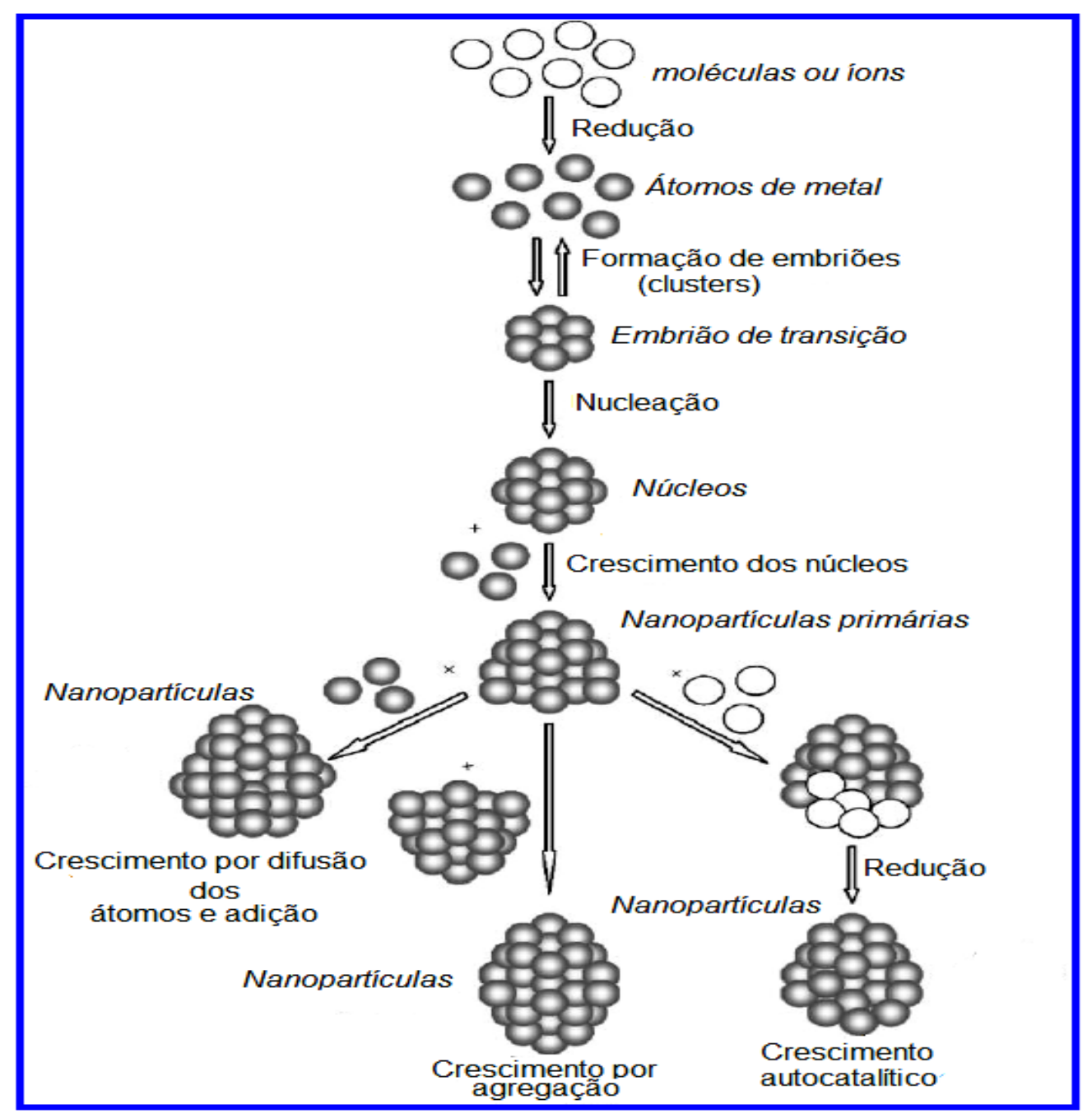

FIGURA 6 - Esquema do processo de formação de nanopartículas metálicas ${ }^{50-52}$

As nanopartículas metálicas tendem a se agregar com o tempo ou mesmo a partir de pequenas perturbações, devido à alta energia superficial, e esta é uma das dificuldades de se trabalhar com esses sistemas ${ }^{50-52}$. As nanopartículas de metais e óxidos de metais, incorporadas à matriz polimérica têm sido intensamente investigadas ${ }^{28}$. Dentre os metais a utilização de prata em polímeros é relativamente recente $e^{53-59}$.

A prata é usada desde tempos antigos, sob a forma de metal de prata, nitrato de prata e sulfadiazina de prata para o tratamento de queimaduras, feridas e várias infecções bacterianas. Mas, devido ao aparecimento de vários antibióticos o uso destes compostos de prata foi diminuindo gradativamente. Com 
o advento da nanotecnologia ocorreu um impulso substancial no século XX devido à capacidade de manipulação dos metais em seu tamanho nanométrico, o que mudou drasticamente as propriedades físicas, químicas e ópticas destes metais. A prata metálica nanoparticulada propiciou um extraordinário efeito como agente antimicrobiano, motivo pelo qual escolhemos a nanoprata para este trabalho. $O$ uso de nanopartículas de prata é importante no combate às bactérias patogénicas, pois, muitas desenvolvem resistência contra diversos antibióticos. Por isso, as nanopartículas de prata surgiram como uma interessante alternativa para aplicação médica que vai desde curativos à base de prata, dispositivos de revestimento medicinais, catéteres ${ }^{60}$, assim como, em filtros para purificação de água, revestimento interno de máquinas de lavar roupa, geladeiras, têxtil, etc ${ }^{61}$.

As propriedades fungitóxicas de sais metálicos foram inicialmente investigadas por Wutrich (1892), e posteriormente, Wober (1920). Com base nestes estudos, Horsfall em $1956^{62}$ estabeleceu a seguinte ordem de fungitoxicidade para os metais:

$$
\mathrm{Ag}>\mathrm{Hg}>\mathrm{Cu}>\mathrm{Cd}>\mathrm{Ni}>\mathrm{Pb}>\mathrm{Co}>\mathrm{Au}>\mathrm{Zn}>\mathrm{Fe}>\mathrm{Mn}>\mathrm{Mo}>\mathrm{Sn}
$$

Além da prata, muitos outros metais possuem propriedades bactericidas, como observado na escala de atividade contra micro$\operatorname{organismos}^{62-70}$.

Pode-se concluir que a prata dependendo da sua quantidade é o metal que apresenta a maior ação e menor toxicidade para as células animais.

Os biocidas orgânicos apresentam aplicações limitadas, devido à baixa resistência ao calor, alta decomposição, tempo de vida curta e alta toxicidade. Como atividade de pesquisa e desenvolvimento de um produto polimérico com atividade antimicrobiana, optou-se por utilizar um polímero de alto consumo (commodity polymer) o polipropileno. Este polímero quando modificado por irradiação e acetileno apresenta cadeias longas e ramificadas, propiciando a ampliação de aplicações industriais. Para o processamento por extrusão, utilizou- 
se um biocida inorgânico (nanoprata), cujo ponto de fusão é de $962{ }^{\circ} \mathrm{C}$. A inserção de nanopartículas de prata que apresentam eficácia biocida, alto ponto de fusão, baixa toxicidade para células humanas é pouco relatada na literatura sob o aspecto de resistência bacteriana, o que torna o seu estudo atraente para a pesquisa em nanociência.

Deve-se destacar a originalidade deste trabalho ao fato de se estudar a formação de microgéis e nanogéis de polipropileno com "alta resistência ao fluxo do fundido" obtido por irradiação gama, que possibilita enxertar ramificações de cadeias longas na cadeia principal. Também é inovadora a inserção de nanopartículas de prata no polipropileno de cadeias longas e ramificadas, pelo processo de extrusão que foi realizado pela primeira vez desde a síntese pelo grupo de polímeros do IPEN. 
2 OBJETIVOS

Os objetivos deste trabalho são, estudar a formação de nanogéis e microgéis de polipropileno modificado por radiação gama e, pela incorporação de nanopartículas de prata (NPsAg), propiciando a ação biocida. 


\section{REVISÃO BIBLIOGRÁFICA}

\subsection{Polipropileno}

A invenção do PP foi quase simultânea nos EUA e na Europa. Hoje, o PP é o termoplástico "commodity" de maior volume produzido no mundo. Em 1953, o Prof. Giulio Natta na Politécnica de Milão, Itália, promoveu um importante avanço na pesquisa e desenvolvimento do PP, concomitantemente Prof. Karl Ziegler do Instituto Max Planck de Química o fez na Alemanha. Prof. Ziegler descobriu que o tetracloreto de titânio pode catalisar a polimerização estereoespecífica de polietileno. Com a ajuda financeira de uma grande empresa química italiana, Montecatini mais tarde Montedison, o Prof. Natta com o Prof. Ziegler estenderam a descoberta para o desenvolvimento de PP isotático, o qual a Montecatini foi a primeira a produzir em escala industrial em 1957, em sua fábrica de Ferrara $^{71}$.

O PP tem competido fortemente com os demais termoplásticos, pois apresenta estruturas químicas baseadas na estereorregularidade, em grau e distribuição. Suas propriedades mecânicas são dependentes da relação entre fases cristalina e amorfa. Existem várias possibilidades de comportamento mecânico para o PP, que vão desde flexível, semiflexível até rígido. O PP com ramificações é constante foco de desenvolvimento, principalmente para aplicação na fabricação de filmes para os quais é importante a resistência durante o estiramento do fundido ${ }^{72}$.

O PP forma esferulitos, cujo tamanho depende da cinética de cristalização (tempo, temperatura) à qual este foi submetido. Eles são constituídos de agregados de cristalitos (lamelares) que crescem a partir de um ponto ou núcleo, formando uma interface plana. O grupo metila $\left(\mathrm{CH}_{3}\right)$ do PP pode formar 
diferentes configurações estereoespecíficas (taticidade do polímero): isotática, sindiotática e atática ${ }^{72}$, como mostrado na FIG. 7.
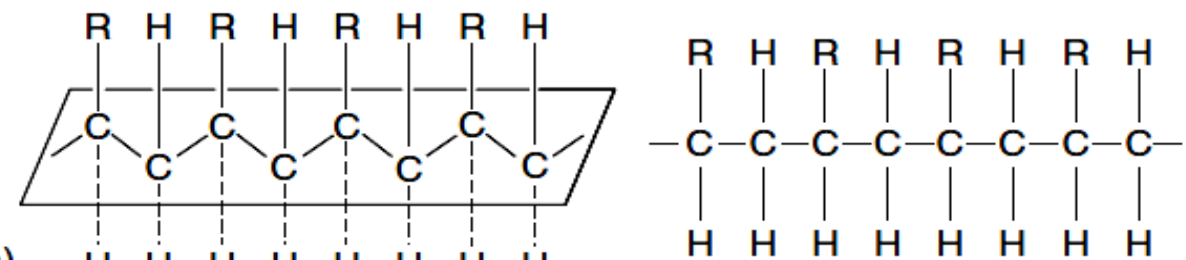

(a)
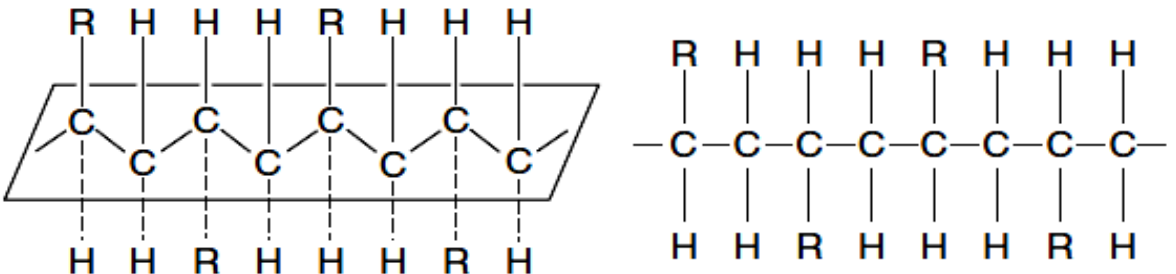

(b)

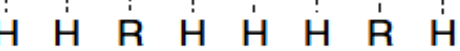

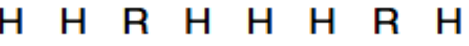
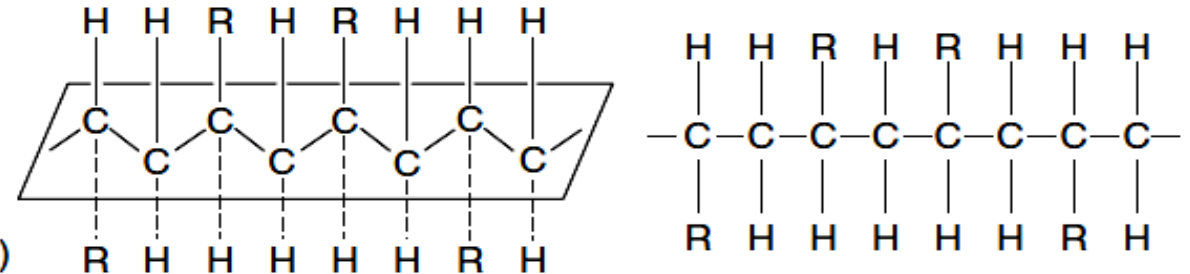

(c) $\mathrm{R} \mathrm{H} \mathrm{H} \mathrm{H} \mathrm{H} \mathrm{H} \mathrm{R} \mathrm{H}$

FIGURA 7 - Representação das configurações estereoespecíficas do polipropileno: (a) Isotático; (b) Sindiotático; (c) Atático ${ }^{73-77}$.

Conforme De-Paoli ${ }^{78}$ no caso do polipropileno isotático, devido à presença de ramificações aumentará o número de átomos de carbono terciário que possui ligações $\mathrm{C}-\mathrm{H}$ com energia de ligação fraca, o que decorre em uma região suscetível ao início de degradação deste polímero.

\subsection{Modificações em Poliolefinas}

Em 1986 Busfield e Appleby ${ }^{79}$ estudaram a formação de reticulações no PP em presença de acetileno por irradiação. Neste trabalho foram avaliadas as propriedades físicas, mecânicas e térmicas dos filmes de polipropileno, assim como o teor de gel, que aumenta consideravelmente com a reticulação, tornando- 
se mais acentuado quando as amostras passam pelo processo de recozimento (annealing).

Matsuda et al. ${ }^{80}$ estudaram a transição sol-gel de polipropileno isotático (iPP) em solventes orgânicos e verificaram a estrutura dos géis composta por esferulitos em contato uns com os outros, sendo estas estruturas cristalinas interligadas. Isto indica que estes esferulitos e as interligações (tie molecules) com estruturas cristalinas formam uma rede tridimensional na forma de microgel.

O esquema com reações de polimerização e funcionalização de radicais, FIG. 8, mostra a enxertia de um monômero funcional (M) na cadeia principal da poliolefina por geração de um macroradical, e sucessivas conversões em um não radical pela inserção de um grupo polar por combinação de reações de enxertia e de transferência. A utilização de radicais geralmente a alta temperatura, torna o processo não seletivo e com limitada especificidade. Pelo ponto de vista mecanístico, a parte mais importante das reações é determinada pela reatividade e estabilidade dos diferentes radicais formados. O radical primário (formado pela decomposição do iniciador, $\mathrm{K}_{\mathrm{d}}$ ) pode gerar um macroradical por abstração de hidrogênio a partir da cadeia principal da poliolefina $\left(\mathrm{K}_{\mathrm{H}}\right)$, pode iniciar o homopolimerização livre do agente de funcionalização $\left(\mathrm{K}_{\mathrm{pi}}\right)$ e/ou degradação $\left(\mathrm{K}_{\mathrm{D}}\right)$. O macroradical gerado por $\mathrm{K}_{H}$ pode gerar um macroradical funcionalizado por enxertia do monômero polar $\left(\mathrm{K}_{\mathrm{gi}}\right)$, pode também produzir ramificação/reticulação e/ou degradação de macromoléculas por acoplamento $\left(K_{C}\right)$ e reações de cisão $\left(K_{S}\right)$. O macroradical funcionalizado pode gerar um produto funcionalizado pela reação de transferência de hidrogênio $\left(\mathrm{K}_{\mathrm{Ht}}\right)$, e propagar o monômero da reação de homopolimerização por enxertia (Kgp) ${ }^{81,82}$. 


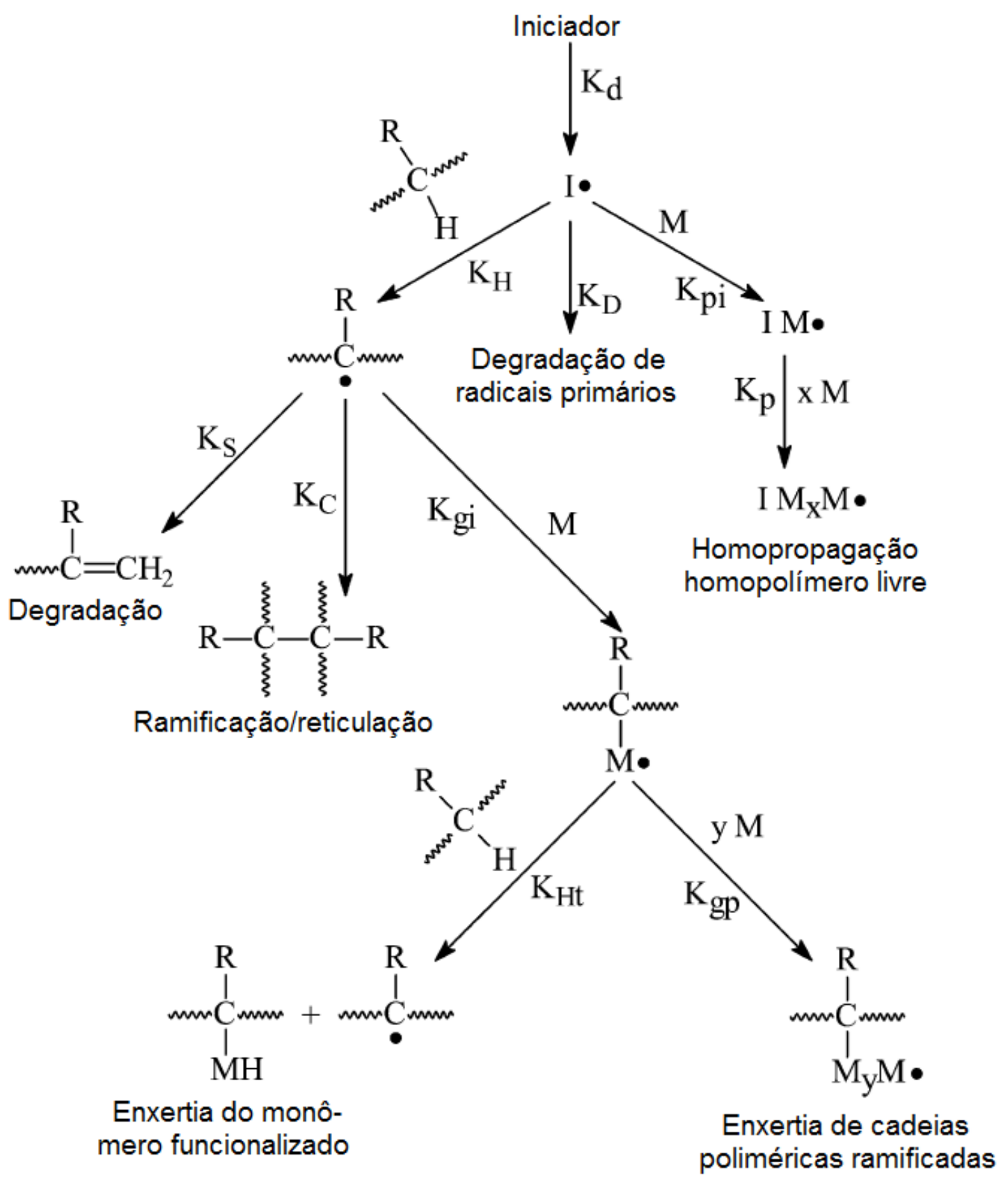

FIGURA 8 - Esquema da modificação em poliolefinas ${ }^{81,82}$

De acordo com De-Paoli ${ }^{78}$ as modificações químicas mais evidentes que ocorrem em polímeros pela ação da radiação de alta energia são: formação de produtos voláteis de baixa massa molar, ligações duplas $\mathrm{C}=\mathrm{C}$ conjugadas ou não, quebra da cadeia principal e reticulação. O produto volátil mais comum em poliolefinas é o hidrogênio ou os produtos resultantes da decomposição dos 
substituintes. A formação de produtos voláteis, Chapiro ${ }^{83}$ indica que, para 0 polipropileno, além de hidrogênio haverá a formação de gás metano.

De-Paoli ${ }^{78}$ indica três aspectos que devem ser considerados quando se discutem os efeitos da radiação de alta energia em polímeros: a dose de radiação por unidade de tempo e de área, a temperatura e a presença ou não de oxigênio. A dose vai determinar o teor de radicais livres formados em função do tempo e isso vai influenciar na ocorrência de cisão de cadeias ou reticulação. A maior ou menor mobilidade dos macroradicais formados favorecerá ou evitará a recombinação. Neste caso, a associação da radiação com o aquecimento aumentará a mobilidade dos radicais livres e as recombinações. A presença de oxigênio levará a processos oxidativos. Dependendo da dose e do material, a degradação por radiação de alta energia provocará predominantemente quebra da cadeia principal ou reticulação. Indiretamente isso dependerá do teor e do tipo de radicais livres formados e de sua mobilidade.

O mecanismo do processo oxidativo está bem relatado na literatura e envolve reações de iniciação, propagação e terminação, que estão exemplificadas na FIG. 9.

Iniciação:

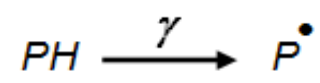

Propagação:
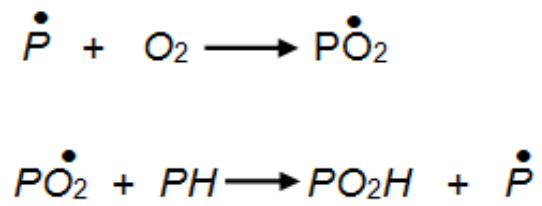

Terminação: $\quad \mathrm{PO}_{2}+\mathrm{P}_{2} \longrightarrow$ Produtos inativos $+\mathrm{O}_{2}$

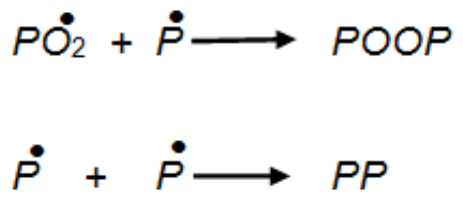

FIGURA 9 - Reações oxidativas induzidas por irradiação em polímeros ${ }^{83-89}$ 
Um esquema com as reações induzidas por irradiação está representado na FIG. 9. O radical alquila $\left(\mathrm{P}^{\bullet}\right)$ formado pela abstração de hidrogênio da cadeia principal do polímero constitue a espécie reativa primária da cadeia que conduz à degradação. O oxigênio pode reagir com um radical alquila formando o radical peroxila, com abstração do hidrogênio e produzindo hidroperóxido por propagação. O mecanismo de terminação forma produtos oxidados, ramificações e reticulação. No caso do processo de irradiação com raios gama ou feixe de elétrons, as transformações dependem preferenciamente da estrutura do polímero e das condições de tratamento usadas anteriormente, durante e após o processo de irradiação ${ }^{84-86}$.

\subsubsection{Irradiação do polipropileno}

Estudos a respeito dos efeitos da radiação gama sob vácuo no polipropileno foram analisados por Spadaro et al. ${ }^{30}$. Foi possível prever os efeitos da irradiação, sob a hipótese de que as principais reações que envolvem a evolução de radicais livres, gerados pelas interações dos raios gama com o polipropileno, são as seguintes: cisão- $\beta$, adição de radicais livres com a formação de duplas ligações e reações de terminação. Por intermédio de equações cinéticas e balanço da relação entre a dependência de radicais livres e concentração de duplas ligações nos parâmetros de irradiação foi possível determinar os radicais e os efeitos da concentração de duplas ligações na estrutura molecular final do polipropileno irradiado.

A FIG. 10 mostra o mecanismo de foto-oxidação do polipropileno isotático. 


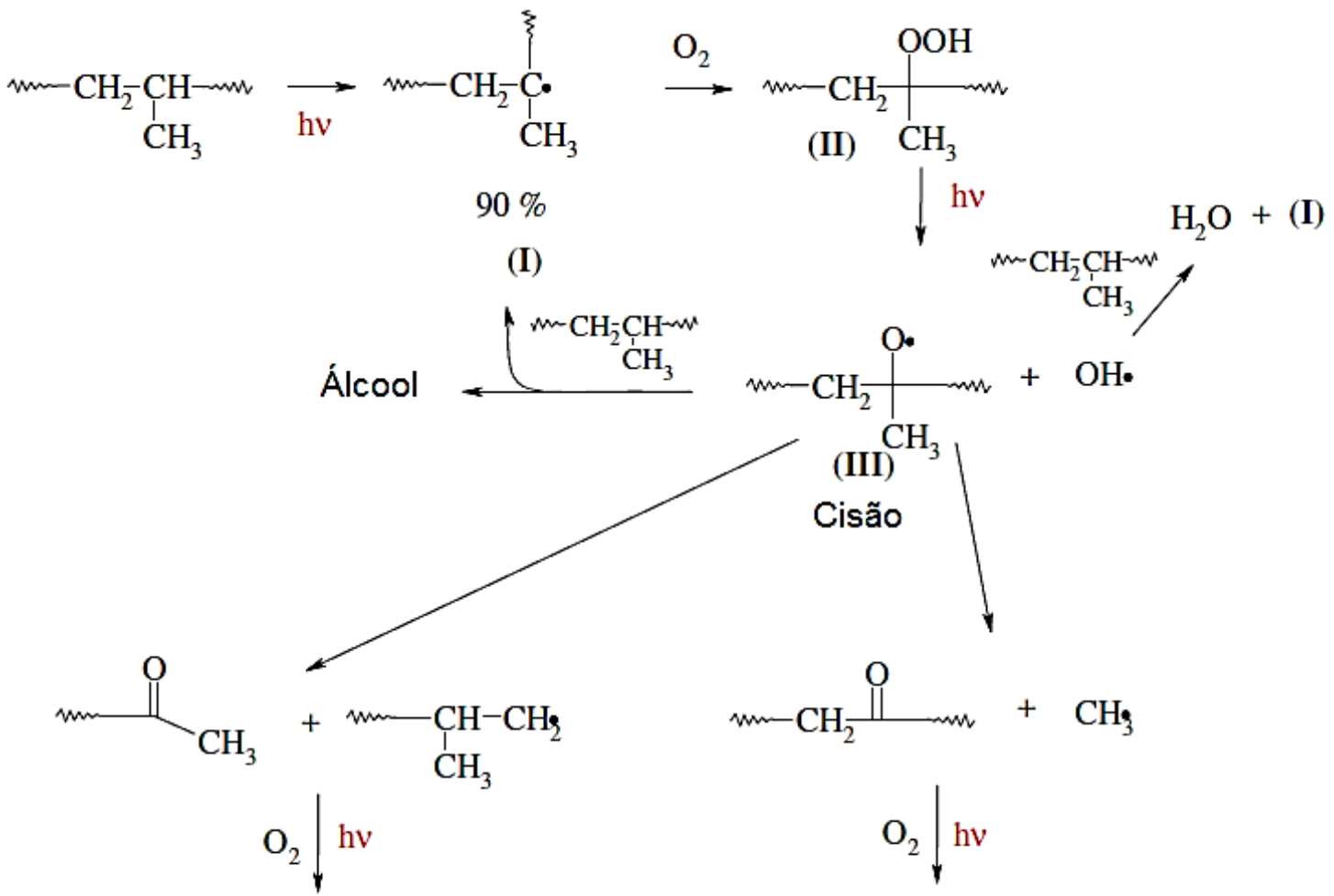

Ácidos, Ésteres, Perésteres, Lactonas

FIGURA 10 - Mecanismo de foto-oxidação do polipropileno ${ }^{90}$

O principal produto resultante da interação da radiação UV com o oxigênio é o hidroperóxido terciário (II) que prevalece ao hidroperóxido secundário em uma proporção em torno de 9-1. Hidroperóxidos terciários decompõem-se produzindo radicais alcoxi (III) e hidroxi (HO•). Estes radicais podem abstrair o hidrogênio da cadeia principal do polímero e propagar a reação de oxidação da cadeia. Os radicais alcoxi (III) podem também sofrer cisão- $\beta$ com a cisão da ligação carbono-carbono quer no segmento principal do polímero ou entre os segmentos e a ligação metila. As sucessivas oxidações dos diversos produtos que são formados continua com a produção de ácidos carboxílicos, ésteres, lactonas, perésteres como evidenciado pela presença da banda $1800-1600 \mathrm{~cm}^{-1}$ referente a grupos carbonilas ${ }^{90}$.

Bernstein et al. ${ }^{91}$ estudaram os mecanismos de degradação oxidativa do polipropileno irradiado com radiação gama. Neste trabalho, foi elaborada uma análise dos produtos de degradação voláteis com a marcação do PP por 
espectrometria de massa, utilisando-se a análise detalhada por FT-IR em estudo da fase sólida de produtos oxidados, e dados adicionais por um longo período pós-irradiação utilizando-se o $\mathrm{RMN}$ com ${ }^{13} \mathrm{C}$. Foram examinados de forma abrangente os resultados das análises integradas à datação, incluindo as origens e mecanismos dos produtos de oxidação de PP. No mecanismo do PP ocorre a cisão de cadeias com formação de metil cetona, aldeídos, ácidos, peróxidos, estruturas derivadas de grupos carbonílicos e diversos produtos volátes, tais como: acetona, metil-isobutil-cetona, isobutano e metil acetato ${ }^{91}$.

Com base nos resultados obtidos, o mecanismo do polipropileno ${ }^{91}$, podemos argumentar que estes resultados se assemelham ao mecanismo de foto-oxidação do polipropileno apresentado na FIG. 10.

A irradiação do polipropileno em presença de gás acetileno promove a ocorrência de degradação, reticulação e/ou ramificação das cadeias carbônicas. Em diversas publicações do nosso grupo de polímeros ${ }^{92,93}$ os resultados obtidos foram de reticulação e/ou ramificação do polipropileno, sendo que esta síntese visou a obtenção de um polímero com cadeias ramificadas longas. No entanto não há na literatura um estudo detalhado do mecanismo de reações da modificação de PP por irradiação em acetileno.

\subsection{Fontes de Radiação}

A radiação ionizante pode ser dividida em direta e indiretamente ionizante, para a compreensão de efeitos biológicos. Muitos tipos de partículas de radiação são diretamente ionizantes isto é, possuem energia cinética adequada para perturbar diretamente a estrutura atômica do meio absorvente podendo produzir danos químicos e biológicos nas moléculas. Em contraste, radiações electromagnéticas, ou seja, os raios- $X$ e raios- $\gamma$ são ionizantes porque elas não produzem danos químicos e biológicos em si, mas produzem elétrons secundários (partículas carregadas) após a absorção de energia no material ${ }^{94}$, que consiste no efeito Compton. 
A radiação eletromagnética inclui ondas de rádio, microondas, luz visível, luz ultravioleta, raios-X e raios- $\gamma$. Estas ondas são caracterizadas essencialmente por sua energia que varia inversamente ao comprimento de onda. Elas dão uma idéia de como os pacotes de energia (quanta) se deslocam e desta forma são chamados de fótons ${ }^{94}$.

Quando a radiação gama passa através de um material, uma complexa série de eventos ocorre, envolvendo combinações de efeito fotoelétrico, espalhamento Compton e formação de pares, cuja importância relativa dos três efeitos depende da energia de raios gama e do material ${ }^{95}$.

As fontes de radiação mais usadas são ${ }^{60} \mathrm{Co}$ (radiação gama) e os aceleradores (feixes de elétrons). A escolha de uma determinada fonte de radiação depende da natureza e do tipo de objeto a ser irradiado. Materiais gasosos podem ser irradiados com sucesso usando-se qualquer tipo de radiação ionizante, mas a irradiação de massas líquidas ou amostras sólidas requer uma radiação mais penetrante como a radiação gama ou feixe de elétrons energéticos. As radiações menos penetrantes como $\alpha, \beta$ ou elétrons de baixa energia, podem ser usadas se se pretende irradiar a camada superficial da amostra. Em algumas circunstâncias, a perda de energia, ao atravessar o meio, é importante e influenciará na seleção da fonte de radiação ${ }^{96}$.

\subsubsection{Radiação por Feixe de Elétrons}

O processo de radiação por feixe de elétrons é amplamente empregado para modificação de polímeros. Na FIG. 11, temos a representação de uma unidade para obtenção de feixe de elétrons de alta energia. A energia do feixe de elétrons é o produto de voltagem pela corrente do feixe de elétrons, expressa em kW $(1 \mathrm{~kW}=10 \mathrm{~mA} \times 100 \mathrm{kV})^{96}$.

A corrente do feixe de elétrons que é o número de elétrons por segundo emitido pelo cátodo e é medida em $\mathrm{mA}\left(1 \mathrm{~mA}=6,25 \times 10^{15}\right.$ elétrons por segundo) unidade de corrente. A dose absorvida é um meio de avaliação da 
energia da radiação ionizante absorvida por unidade de massa do material processado. A unidade de dose absorvida é 1 Gray (Gy) $=1 \mathrm{~J} \mathrm{~kg}^{-1}$ e a taxa de dose é a dose absorvida por unidade de tempo, expressa em Gy s $\mathrm{s}^{-1}=\mathrm{J} \mathrm{kg}^{-1} \mathrm{~s}^{-1}$. Uma constante de aceleração de voltagem é proporcional à corrente do feixe de elétrons ${ }^{97}$.

Em polietileno os efeitos da irradiação por feixe de elétrons são: evolução de hidrogênio e formação de reticulações C-C. A reticulação processase, principalmente, na região amorfa e na interface das duas fases. Como exemplo, tanto o PEBD quanto o PE linear possuem um grupo vinílico terminal e em baixa dose de radiação esse grupo favorece o aumento do peso molecular pela formação de ligações $-Y$ com radicais alquila produzidos pela radiação.

Quando o PP é exposto à radiação ionizante, radicais livres são formados devido às mudanças químicas. O PP é altamente cristalino e os radicais criados nesta fase têm pouca mobilidade, consequentemente, podem estar pouco disponíveis para reações em um longo período de tempo ${ }^{97,98}$.

Sob radiação de alta energia, feixe de elétrons, a possibilidade de formação de radical no grupo metila pendente conduz à reticulação. Entretanto, se o radical for formado na cadeia principal, o final da cadeia poderá reagir com o hidrogênio, causando cisão irreversível. Embora os processos de cisão de cadeia e reticulação ocorram simultaneamente o efeito global é a perda de resistência mecânica do polímero ${ }^{98,99}$. 


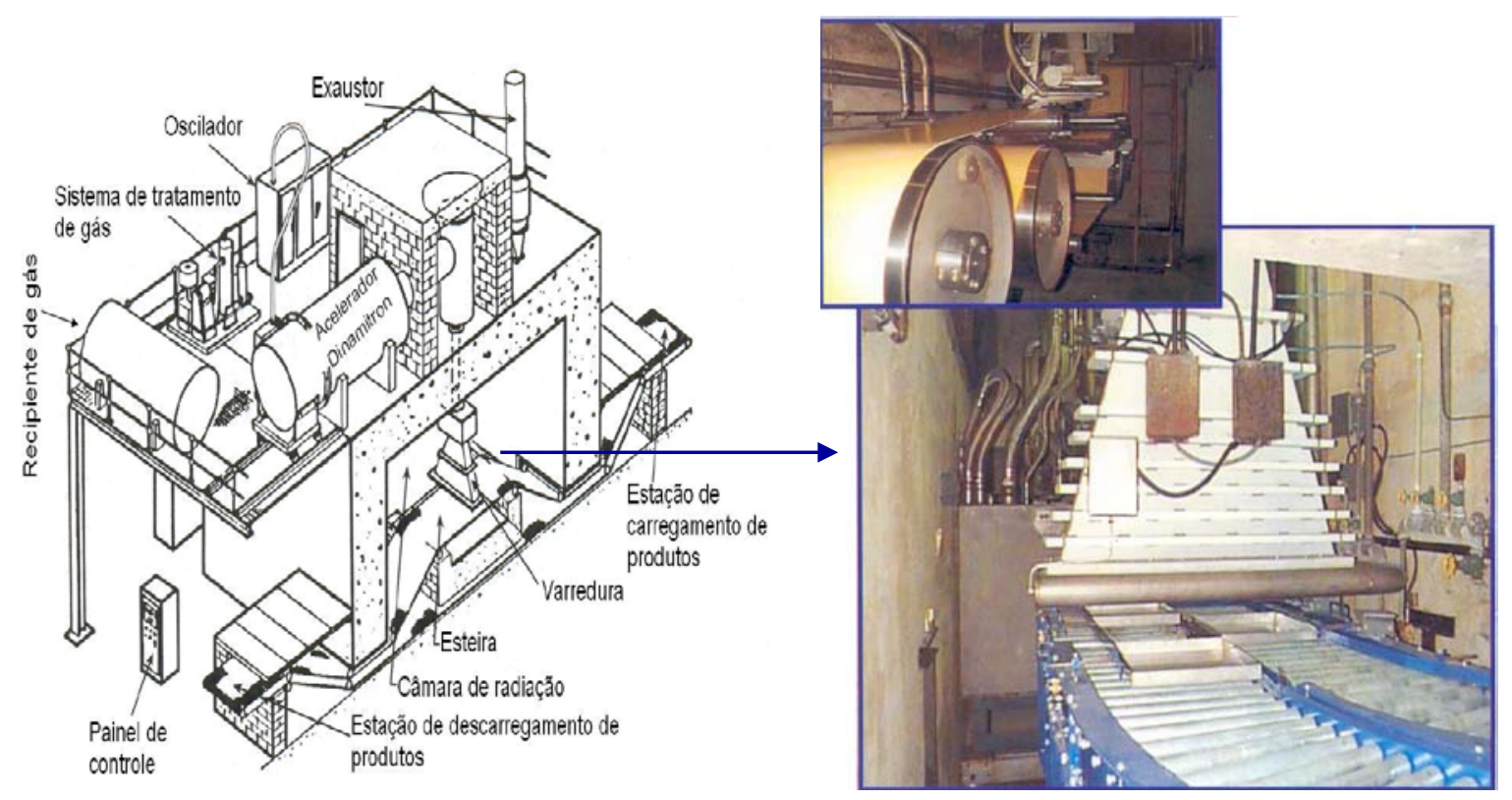

FIGURA 11 - Desenho tradicional de uma unidade aceleradora de elétrons de alta energia ${ }^{97}$.

\subsubsection{Radiação por Raios Gama}

Raios $\gamma$ são ondas eletromagnéticas de alta energia da mesma natureza da luz visível ou ultravioleta, porém de menor comprimento de onda $(\lambda)$. São gerados por núcleos de isótopos radioativos naturais, sendo que o mais usado é o ${ }^{60} \mathrm{Co}$, devido à sua meia-vida de 5,3 anos e facilidade de preparação.

$\mathrm{Na}$ unidade de irradiação, a fonte de ${ }^{60}$ Co emite raios $\gamma$, FIG. 12, com uma energia média de 1,25 MeV, que, interagindo com o polímero, provocam alterações na sua estrutura. Quando o polímero é irradiado pode-se ter a cisão da cadeia principal com a formação de radicais livres. Os radicais livres são átomos que têm um ou mais elétrons sem par e estão disponíveis para formar as ligações químicas. Esses radicais podem se recombinar, reagir com o oxigênio do ar ou promover a reticulação entre as cadeias poliméricas. Se o polímero irradiado for um sólido, os radicais livres podem ficar aprisionados por um tempo considerável após a irradiação e poderão causar, algum tempo depois, transformações químicas no polímero ${ }^{95}$. 


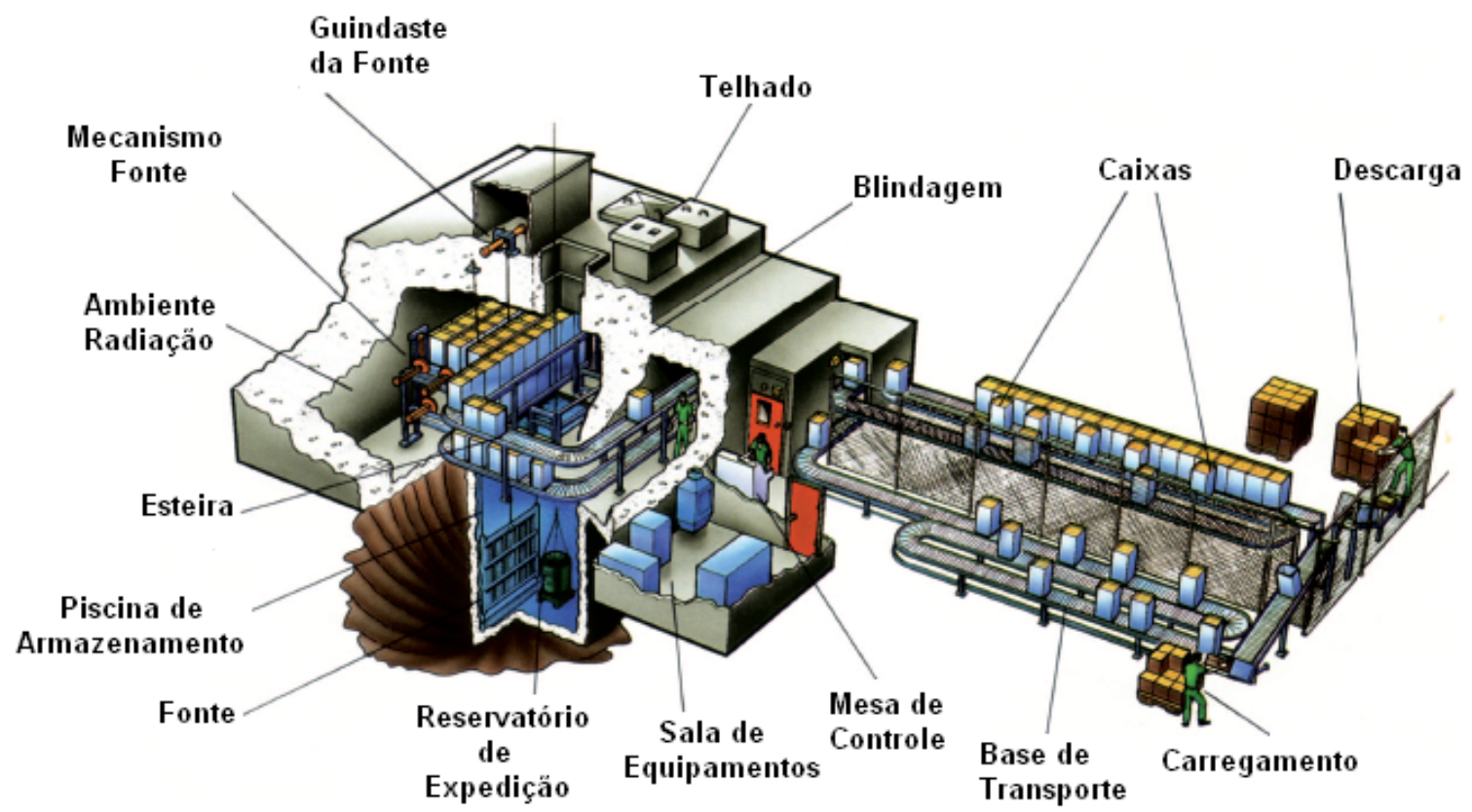

FIGURA 12 - Esquema representativo da unidade de irradiação gama por ${ }^{60} \mathrm{Co}{ }^{96}$

\subsection{Efeitos de radiação ionizante}

\subsubsection{Absorção fotoelétrica}

$\mathrm{Na}$ absorção fotoelétrica, o fóton interage com um elétron da camada interna de energia do átomo de média absorção e transfere esta energia para o elétron expelido a partir da camada atômica ocupada. O fóton incidente desaparece e a energia transferida é usada para superar a energia de ligação do elétron e o restante aparece como energia cinética do foto-elétron resultante. Assim, a energia cinética do foto-elétron ejetado é igual a energia do fóton incidente menos a energia de ligação dos elétrons. $E_{c \text { (elétron) }}=h v-E_{b}$, onde $h v$ é a energia do fóton incidente, e $E_{b}$ é a energia de ligação do elétron. O foto-elétron ejetado percorre uma determinada distância perdendo sua energia através de ionizações secundárias. Desta forma, a energia toda do fotón incidente é depositada na matéria irradiada. Como resultado, um átomo que participou da interação fotoelétrica é ionizado. O defeito criado devido à ejeção do elétron é imediatamente preenchido por um elétron de um orbital externo do mesmo átomo, 
atingindo o equilíbrio da energia como um fóton entre as respectivas órbitas com baixo consumo de energia característica ${ }^{94}$.

\subsubsection{Efeito Compton}

O processo de deposição de energia chamado de Efeito Compton FIG. 13 ocorre quando há interação do fóton incidente com os elétrons dos orbitais mais externos, cuja energia de ligação é muito baixa se comparada à do fóton incidente. Nesta interação, o fóton incidente transfere energia para o elétron atômico causando a sua exclusão do átomo. O fóton é disperso com a energia resídual original numa direção diferente daquela de incidência do fóton. Assim a dispersão Compton provoca a ionização do átomo de absorção, devido à perda de um elétron. O elétron disperso (partícula secundária carregada) percorre uma determinada distância na matéria e eventualmente, perde energia por eventos de ionização e excitação para se tornar parte do material. A probabilidade de Espalhamento Compton diminui com o aumento da energia dos fótons. Este é o principal mecanismo de absorção por raios-X e raios- $\gamma$ na faixa de energia intermediária de $100 \mathrm{keV}$ a $10 \mathrm{MeV}^{94,97}$. 


\section{Dispersão Compton}

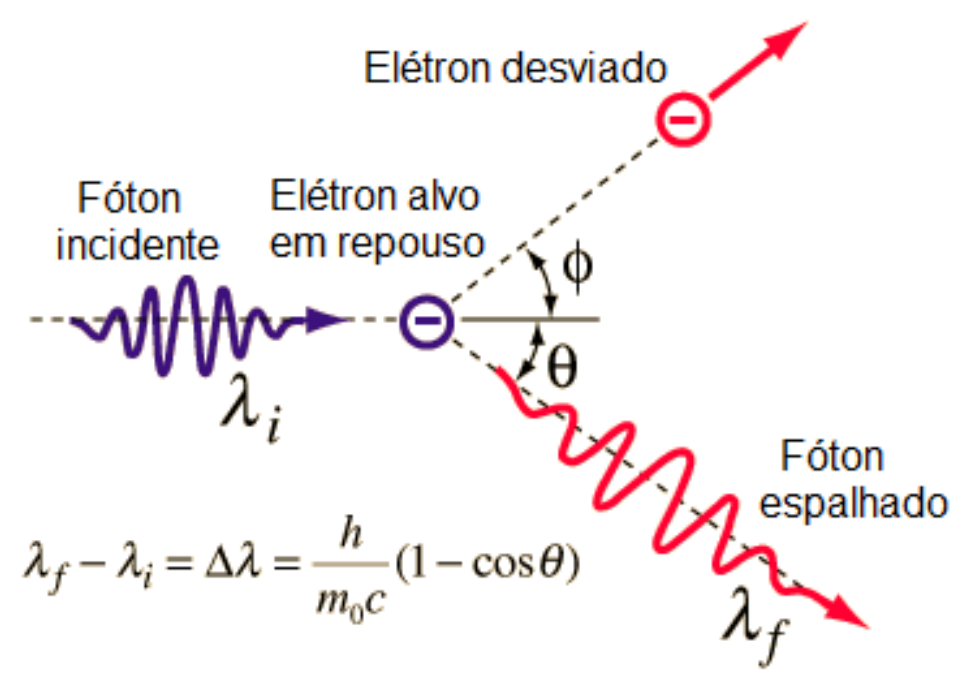

FIGURA 13 - Diagrama esquemático do Efeito Compton ${ }^{100-102}$.

No diagrama da FIG. 13 um fóton incidente colide com um elétron atômico e transmite energia para este, o fóton e o elétron que foram desviados da trajetória do fóton incidente em ângulos $\phi$ e $\boldsymbol{\theta}$, respectivamente ${ }^{100-102}$.

\subsubsection{Produção de pares}

O fotón pode ser convertido espontaneamente em massa de um elétron e de um par de pósitrons pela interação da força de Coulomb na proximidade do núcleo. As partículas carregadas são emitidas em direções opostas umas às outras e provocam danos na forma de partículas de carga secundária. Um pósitron é o equivalente de antimatéria do elétron e tem a mesma massa de um elétron, mas tem uma carga positiva igual em módulo à carga negativa de um elétron. A produção de pares ocorre quando fótons de energia igual ou superior a 1,02 MeV passam próximos a núcleos de elevado número atômico. Nesse caso, a radiação $X$ interage com o núcleo e desaparece, dando origem a um par elétron-pósitron com energia cinética. $O$ pósitron e o elétron 
perderão sua energia cinética pela ionização e excitação. O positron tem um tempo de vida muito curto e, no final do seu alcance combina-se com um elétron livre. Toda massa destas duas partículas é então convertida em um fóton de 1,02 MeV, FIG. 14. Os elétrons secundários (ou pósitrons) produzidos em qualquer um destes três processos frequentemente têm energia suficiente para produzir muitas ionizações adicionais, até o fim do seu alcance ${ }^{94,103}$.
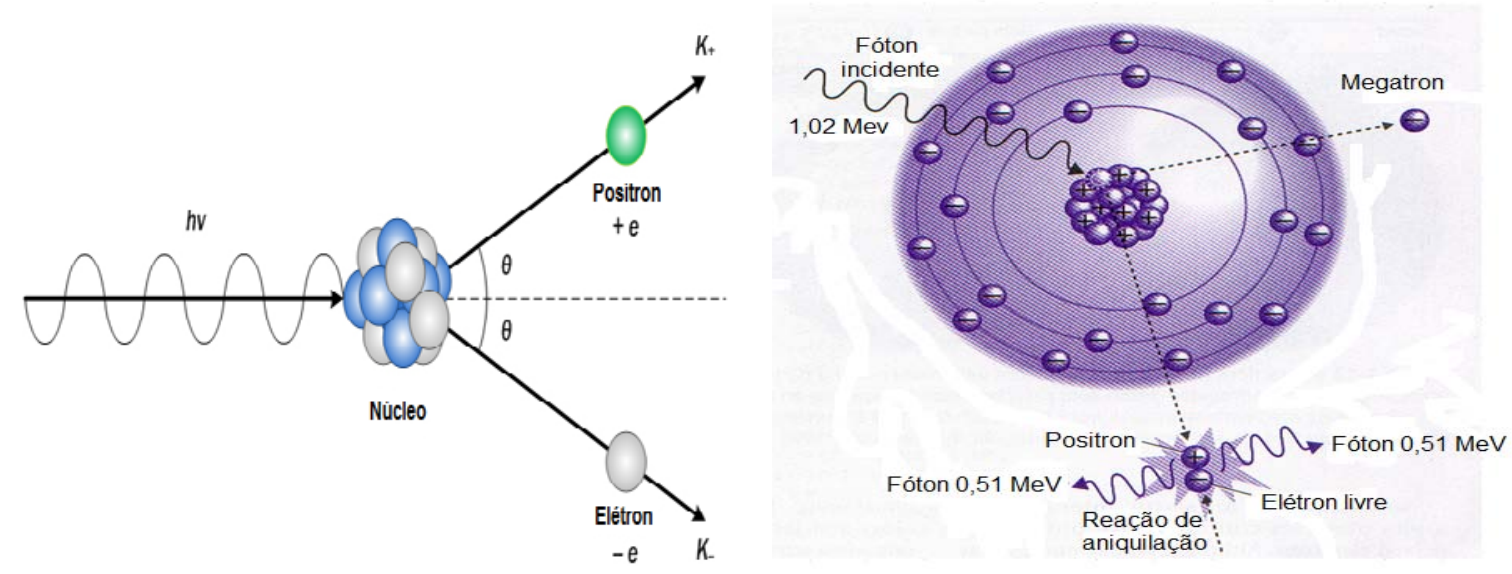

FIGURA 14 - Produção de pares ${ }^{103}$

\subsection{Materiais antimicrobianos}

Materiais antimicrobianos e biocidas são compostos que matam ou impedem o crescimento de organismos patogénicos e outros micro-organismos indesejáveis ${ }^{104}$.

O 2,4,4-tricloro-2-hidroxi difenil éter, normalmente referido como Triclosan (TCS), FIG. 15, é um agente antimicrobiano que foi inicialmente desenvolvido pela empresa Ciba-Geigy na década de 1960 e que apresenta uma vasta utilização em produtos de cuidado pessoal ${ }^{105}$.

TCS foi formulado para uso em sabonetes, esfoliantes cirúrgicos, géis de banho, desodorantes, cremes dentais, loção de mão, enxaguatórios bucais. Foi também incorporado em tecidos e plásticos, como brinquedos para crianças, tecidos cirúrgicos, tábuas de corte, escova dental, e até mesmo infundido em 
concreto para pisos ${ }^{106}$. Extensas investigações foram realizadas sobre a toxicidade do TCS, quando foi constatado não ser oralmente tóxico, bem como não demonstrou ser mutagênico e carcinogênico ${ }^{107,108}$.

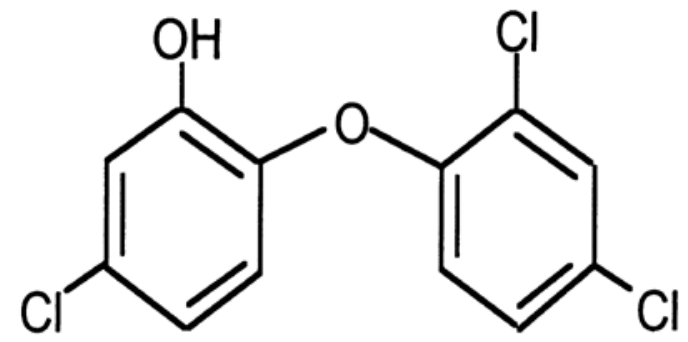

Triclosan

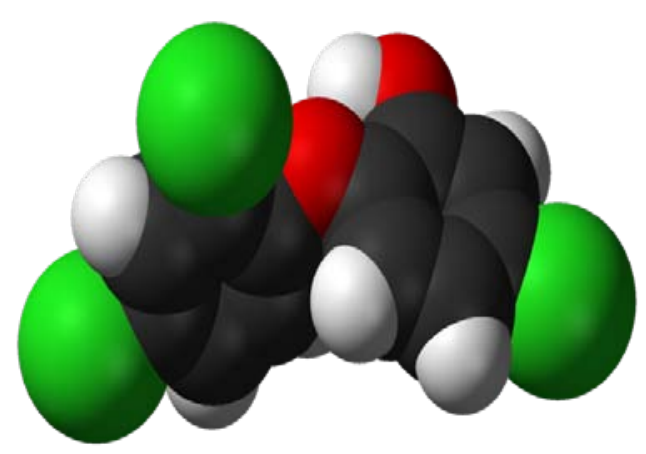

FIGURA 15 - Estrutura do biocida da família do bisfenol, Triclosan ${ }^{29}$ ou Irgasan DP300R - Ciba-Geigy 109-111

Bonilla e García ${ }^{112}$ descrevem o estado da arte no campo dos sistemas poliméricos antimicrobianos durante a última década. Tendo em mente a multiplicidade de sistemas existentes, a classificação de diferentes materiais é efetuada dividindo basicamente os polímeros sintéticos: (a) nos que apresentam uma atividade antimicrobiana, (b) naqueles cuja atividade biocida é conferida pela sua modificação química, (c) naqueles que incorporam os compostos orgânicos com antimicrobianos de peso molecular baixo ou elevado, e (d) nos que envolvem a adição de sistemas ativos inorgânicos. Esta classificação não é absolutamente única e em algumas ocasiões, os sistemas poliméricos descritos poderiam pertencer a mais de uma seção. Nesta publicação os polímeros com compostos orgânicos antimicrobianos, como é o caso do Triclosan foram incorporados ao PVC com sucesso. Procederam-se medições antimicrobianas contra Escherichia Coli (E. coli) e Staphylococcus Aureus (S. aureus) que foram analisadas e comparadas com as amostras contendo agentes inorgânicos, tais como Ag+ (prata iônica). Este estudo sugeriu que a hidrofilicidade da superfície de PVC é um fator importante para adesão de bactérias na superfície do PVC. 
Polímeros sintéticos antimicrobianos apresentam uma grande variedade de aplicações nas áreas de medicina, farmácia, alimentos, aeronáutica, etc. Isto é devido a suas propriedades não tóxicas e não irritantes, combinadas a atividade antimicrobiana prolongada, comparada com agentes antibacterianos de baixo peso molecular, que apresentam algumas desvantagens, tais como, toxicidade e curto prazo de capacidade antimicrobiana. Além disso, o aumento do uso de antibióticos em animais destinados à alimentação e medicina é um fator da resistência microbiana, provocando um sério impacto na saúde pública. O aumento exponencial no desenvolvimento/desempenho destes materiais antimicrobianos forneceu uma medida do seu grande potencial e o significado de reforçar a pesquisa sobre a melhoria da sua síntese, bem como a sua atividade e os mecanismos de ação. É importante obter materiais inócuos, não citotóxicos a seres humanos com faixa potente e ampla de atividade antimicrobiana. Nesta revisão existem muitas estratégias para projetar polímeros sintéticos antimicrobianos, com diversos modos de ação. A sua atividade pode ser inerente à sua estrutura original, como consequência de uma modificação química, ou da introdução de agentes orgânicos ou inorgânicos ao antimicrobiano para conferir um comportamento resultante biocida ${ }^{112}$.

\subsubsection{Resistência a Antibióticos}

Os antibióticos são, geralmente, pequenas moléculas produzidas por bactérias ou fungos que matam as bactérias, sem prejudicar as pessoas ou animais a serem tratados. Compostos quimicamente sintetizados são, muitas vezes, chamados de agentes antibacterianos. O rápido desenvolvimento da resistência aos antibióticos conduziu a uma contínua necessidade de se desenvolverem novos antibióticos, como representado na TAB.1. 
TABELA 1 - Data em que um antibiótico tornou-se disponível e quando a resistência a bactérias foi relatada ${ }^{113}$

\begin{tabular}{lcc}
\hline Antibióticos & Ano de Produção & $\begin{array}{c}\text { Ano da Ocorrência da } \\
\text { Resistência }\end{array}$ \\
\hline 1 - Sulfonamida & 1930 & 1940 \\
2 - Penicilina & 1943 & 1946 \\
3 - Tetraciclina & 1948 & 1953 \\
4 - Vancomicina & 1956 & 1988 \\
5 - Meticilina & 1960 & 1961 \\
6 - Amplicilina & 1961 & 1973 \\
7 - Amoxicilina & 1972 & 1975 \\
8 - Ciprofloxacina & 1987 & 1987 \\
9 - Linezolida & 2000 & 2002 \\
\hline
\end{tabular}

Conforme Guilfoile $^{113}$ relata em seu livro, os antibióticos são tipicamente muito eficientes para matar as bactérias, no entanto, cientistas têm isolado bactérias mutantes que não são capazes de crescer na ausência de um antibiótico específico.

Guilfoile alerta que a $S$. aureus é um importante agente patogênico humano. Inicialmente a penicilina foi um tratamento eficaz, mas cepas resistentes à penicilina desenvolveram-se rapidamente. Isso levou à busca de novos antibióticos, como a meticilina, que inicialmente era eficaz contra S. aureus resistente. A resistência à meticilina desenvolveu-se também, bem como, deixou o antibiótico Vancomicina como a última linha de defesa contra esse micróbio tenaz. Em Michigan no ano de 2002, os médicos relataram o primeiro caso de $S$. aureus resistente a Vancomicina. Este desenvolvimento ameaçador da resistência a antibióticos, mostra a dificuldade de se manter à frente de micróbios na corrida de resistência aos antibióticos. O desenvolvimento de novos antibióticos sempre se faz presente. Antibióticos disponíveis para o tratamento de S. aureus 
resistentes existem, mas, pode ser apenas uma questão de tempo até que a resistência generalizada para eles se desenvolva também ${ }^{113}$.

A S. aureus causa infecções de pele e tecidos e pode invadir muitos outros órgãos. Algumas cepas de $S$. aureus produzem toxinas que causam intoxicação alimentar, outras cepas produzem toxinas que causam a síndrome do choque tóxico. Este organismo comumente reside na pele, não causando problemas até que um ferimento por corte permita que o mesmo entre no tecido normalmente protegido. S. aureus resulta em infecções de pele na produção de espinhas ou furúnculos. Febre e arrepios podem ocorrer, juntamente com vermelhidão e inchaço no local da infecção. A S. aureus continua a ser um importante patógeno, particularmente entre as pessoas que estão hospitalizadas. Nos Estados Unidos, entre 1999 e 2000, aproximadamente um por cento dos pacientes do hospital tiveram infecção por $S$. aureus, e quase metade destas infecções foram causadas por cepas resistentes a múltiplos antibióticos ${ }^{113}$.

Segundo $\mathrm{Neu}^{114}$ em 1941, praticamente todas as cepas de S. aureus em todo o mundo eram sensíveis à penicilina G, mas em 1944 a S. aureus foi capaz de destruir a Penicilina. Hoje em dia, mais de 95\% dos S. aureus em todo o mundo é resistente à Penicilina, Ampicilina, e às Penicilinas antipseudomonas. A síntese de um grande número de antibióticos nas últimas três décadas tem sido complacente com a ameaça de resistência bacteriana. Bactérias tornaram-se resistentes aos agentes antimicrobianos, como resultado de alterações cromossômicas ou da troca de material genético. S. pneumoniae, Streptococcus pyogenes, Staphylococcus, organismos que causam infecções respiratórias e da pele, e membros da família Enterobacteriaceae e família das Pseudomonas, organismos que causam diarréia, infecções urinárias, e sepse (pele avermelhada) são agora resistentes a praticamente todos os antibióticos mais antigos. O uso extensivo de antibióticos na comunidade e em hospitais tem alimentado esta crise. Mecanismos como programas de controle de antibióticos, melhor higiene, e síntese de agentes antimicrobianos com melhor atividade têm sido adotados a fim de limitar a resistência bacteriana. 
Rai et al. ${ }^{115}$ discutiram neste trabalho os desafios enfrentados pelos profissionais da área da saúde perante a resistência das susperbactérias aos antibióticos, com o aumento contínuo da tuberculose multi-resistente (MDR) por micróbios patogênicos humanos. A re-emergência de micróbios MDR é facilitada pela droga e/ou resistência aos antibióticos, que é adquirida pelos micróbios para a sua sobrevivência e multiplicação em ambientes desagradáveis. Infecções bacterianas MDR levam ao aumento significativo da morbidade, mortalidade e custo dos tratamentos prolongados. Portanto, a pesquisa de compostos antimicrobianos com potencial contra bactérias MDR é uma área prioritária de pesquisa. Os autores indicam que a prata, sob a forma de vários compostos, usada em Ayurveda (medicina indiana) para tratar várias infecções bacterianas graves tem sido usada desde tempos imemoriáveis. Como várias bactérias patogênicas estão desenvolvendo resistência aos antibióticos, as nanopartículas de prata são a nova esperança para tratá-las.

Russell et al. ${ }^{116}$ estudaram a prata iônica que apresenta atividade antimicrobiana contra uma ampla gama de micro-organismos. Como consequência, a prata é incluída entre muitos produtos de saúde disponíveis comercialmente. No entanto, existe a preocupação associada com o uso excessivo de prata e a consequente resistência bacteriana. $O$ entendimento da base bioquímica e molecular da resistência de prata é documentado desde 1998. Apesar da evidência esporádica de resistência bacteriana à prata, existem poucos estudos realizados e documentados para comprovar este fato. Propõe-se que a higiene deva ser enfatizada e orientada para as aplicações que têm benefícios comprovados no tratamento de feridas. Neste trabalho foi avaliada a probabilidade de resistência generalizada à prata e ao potencial da prata para induzir a resistência aos antibióticos, na evidência de seu uso crescente no ambiente da saúde.

\subsection{Aspectos Históricos e Ação Biocida da Prata}

O entusiasmo inicial para a utilização de prata em próteses ósseas, suturas, agulhas e instrumentos cirúrgicos, aparelhos dentários e de terapia para 
ferimentos pode ter sido derivado de valores estéticos enquanto um metal precioso. Porém, a evidência clínica acumulada ao longo dos últimos 150 anos estabeleceu que a prata metálica e compostos de prata ionizável podem fornecer um meio seguro e eficaz de proteção do organismo humano contra doenças infecciosas $^{117}$. Avanços na ciência dos materiais e instrumentação conduziram à sua inclusão em uma ampla faixa de dispositivos industriais, médicos, domésticos e instrumentais com prata, FIG. 16A, como um meio de controlar ou prevenir infecções ${ }^{117}$.
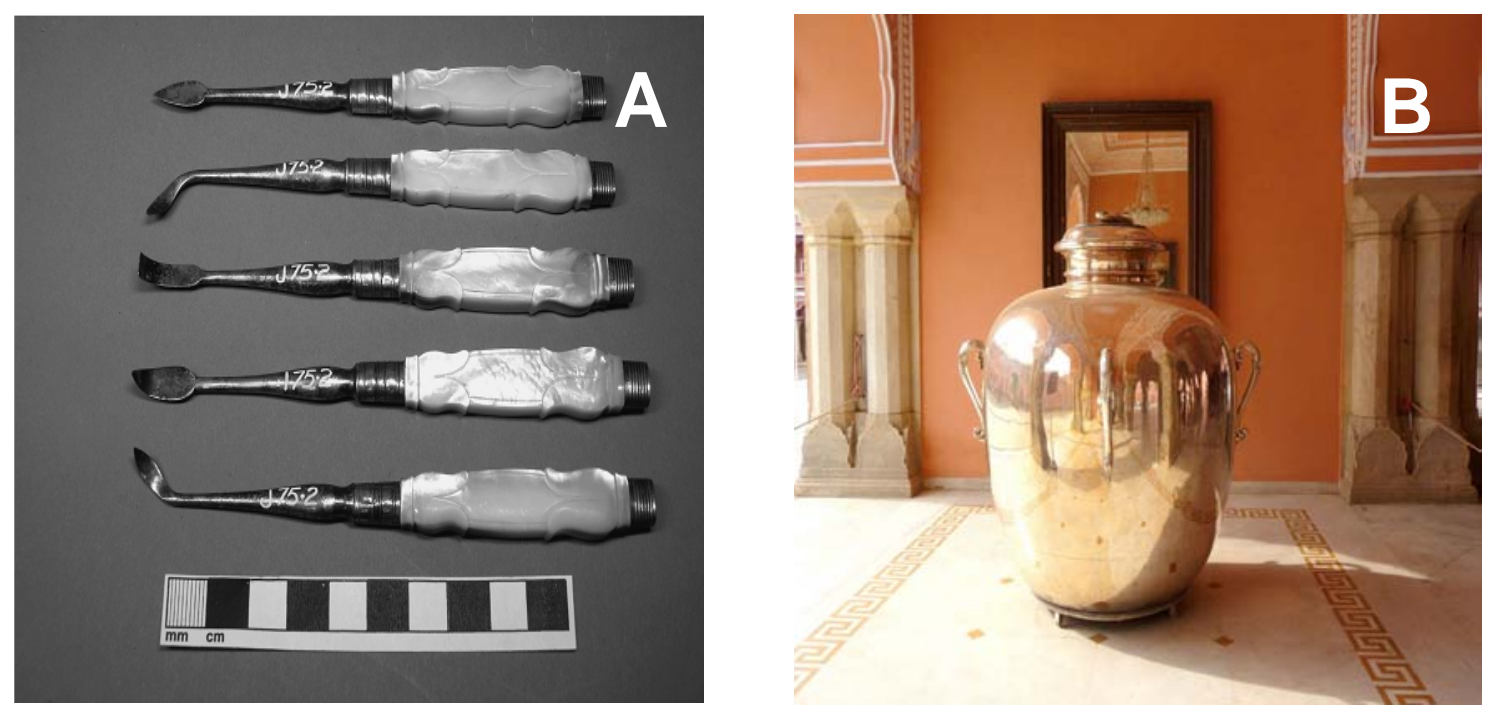

FIGURA 16 - (A) Instrumentos dentários em prata do século XVIII ${ }^{117}$; (B) Urna gigante de prata em Diwan-i-klas: que conserva a água sagrada do rio Ganges $^{117}$

A prata tem uma longa história na purificação de água. A primeira prova disso vem de evidências de que moedas de prata foram colocadas na água de monarcas e nobres das dinastias antigas do Egito e do Oriente Médio e, quando era moda reter água potável em urnas de prata e taças. Mesmo em tempos mais recentes, o Marajá de Jaipur (Índia) usava urnas de prata maciça para transportar as águas sagradas do rio Ganges em suas viagens para a Europa, FIG. 16B. Atualmente, filtros prata-cobre estão em uso em muitos hospitais para controlar os riscos de Legionella e $S$. aureus resistente à meticilina (MRSA) em sistemas de água quente ${ }^{117}$. 
A propriedade antimicrobiana da prata e de seus compostos é a base principal de sua aplicação medicinal desde o século XIX. Desde então seu enorme potencial para o tratamento de lesões foi descoberto e a prata teve diversas utilizações.

Moyer et al. ${ }^{118}$ foram provavelmente os primeiros a abordar o uso tópico da prata no cuidado de feridas. Desenvolveu-se um tratamento eficaz contra queimaduras infectadas utilizando-se um creme à base de nitrato de prata a 0,5\%. Seus estudos concluíram que o mesmo era eficaz contra S. aureus, Pseudomonas aeruginosa ( $P$. aeruginosa) e Streptococcus hemolyticus (S. hemolyticus) sem causar resistência por conta da prata.

\subsection{História das Nanopartículas de Prata}

Alguns historiadores poderiam estar inclinados a argumentar que um dos primeiros exemplos de nanotecnologia poderia ser creditado para alguns vidreiros da época do império romano. Esses antigos artesãos foram capazes de incorporar partículas metálicas coloidais em suas obras para melhorar a qualidade do brilho ${ }^{119}$.

O copo de Licurgo é um cálice romano feito de vidro rubi. Este cálice é ilustrado na FIG.17A e 17B e mostra o mito do rei Licurgo que é visto arrastando a ninfa Ambrósia, que está disfarçada como videira no submundo grego ${ }^{120}$. 

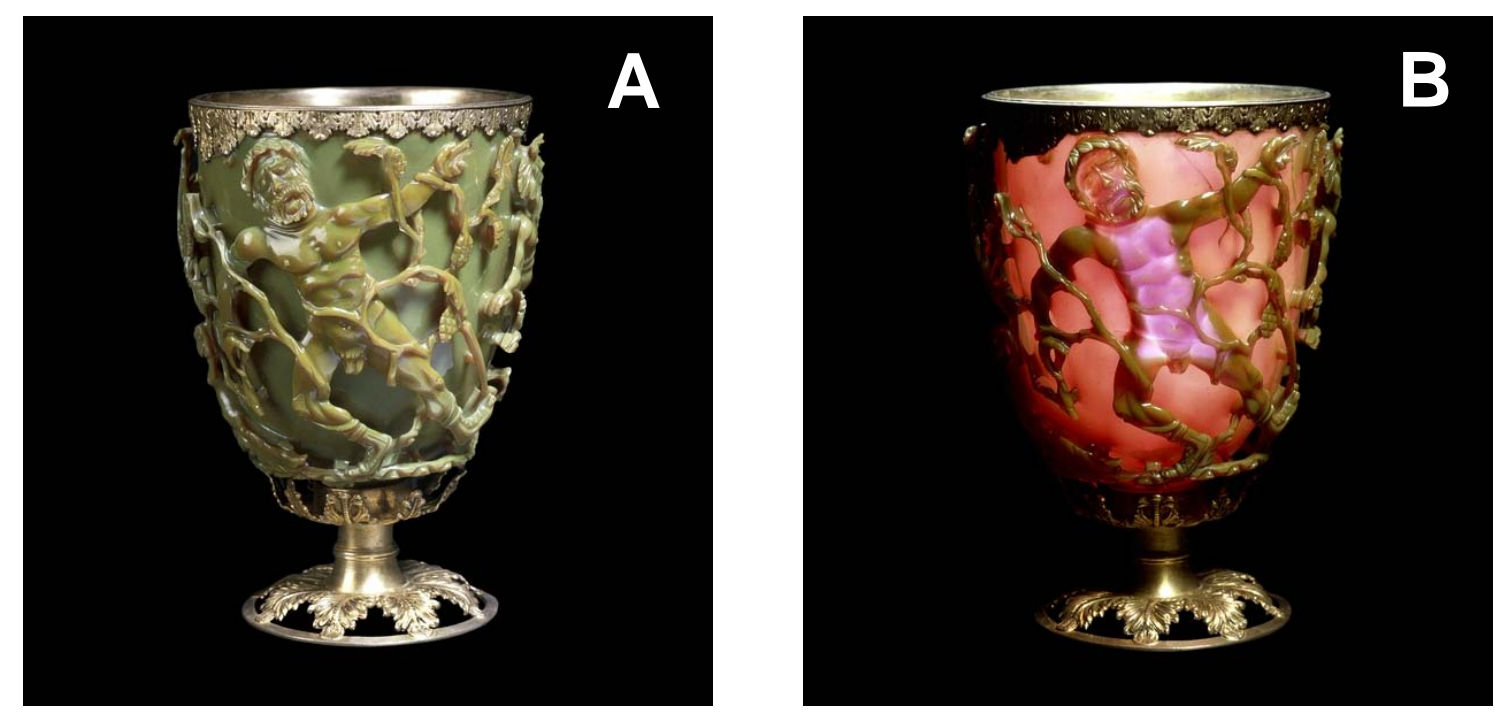

FIGURA 17- Cálice de Licurgo (A) que apresenta diferentes colorações em função da luz refletida ou $(B)$ transmitida devido à presença de NPs metálicas $^{121-123}$

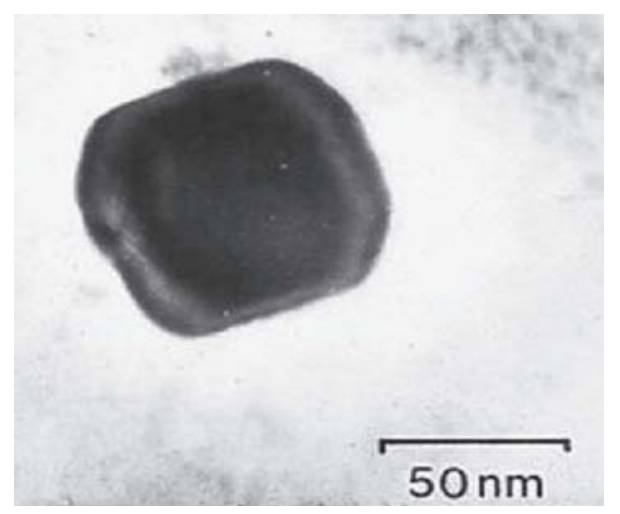

FIGURA 18 - Microscopia eletrônica de transmissão (TEM) de uma liga prataouro, partícula dentro do vidro do Cálice de Lycurgus ${ }^{122,123}$

Desde os tempos romanos (4 século AD) o famoso copo de vidro de Licurgo contém nanopartículas de prata e ouro com o diâmetro de cerca de 50 a $70 \mathrm{~nm}$, FIG. 18. A presença dessas nanopartículas metálicas provoca um efeito óptico colorido especial para o vidro. Quando visto pela luz refletida, durante o dia, parece verde. No entanto, quando a luz no copo é transmitida através do vidro aparece a cor vermelha ${ }^{123-125}$. 
Nanoprata é um nanomaterial que atualmente é muito pesquisado e os avanços da nanotecnologia abriram completamente novas áreas de aplicação para a prata. A nanoprata sob a forma de prata coloidal tem sido utilizada por mais de 100 anos $^{126}$ e foi registrada como um material biocida nos Estados Unidos desde 1954. Cinquenta e três por cento dos registros na EPA (Environmental Protection Agency) são de produtos biocidas de prata que, provavelmente contêm nanoprata. A maior parte destas aplicações são de prata impregnada em filtros de água, algicidas, e aditivos antimicrobianos que não alegam conter nanopartículas. Muitas normas de saúde humana a partir de 1930 para a prata são baseadas na análise de ocorrência de argiria (coloração azulada da pele $)^{127,128}$ e incluem estudos que consideram os materiais com nanoprata ${ }^{127}$.

\subsection{Processamento de Polímeros com NPsAg}

As nanopartículas metálicas tendem a se aglomerar com o tempo ou devido a pequenas perturbações no sistema, fato observado quando da dispersão de nanotubos de carbono (NTC) que também, tendem a se aglomerar devido a sua elevada área superficial específica ${ }^{129}$. Cho \& Danie ${ }^{130}$, utilizaram um método de processamento à base de solvente (dispersante) e ultrassom na mistura de nanotubos de carbono em uma matriz polimérica epoxi/carbono, obtendo um bom resultado na dispersão do material. Já Fages et al. ${ }^{131}$, misturaram nanopartículas de prata (NPsAg) utilizando diferentes surfactantes: polivinilpirrolidona (PVP) FIG. 19 e ácido oléico (AO) para facilitar a dispersão das NPsAg. Os compostos de polipropileno com NPsAg foram preparados pela mistura no fundido (melt mixing), e foram analisados os efeitos das condições de processamento na dispersão das nanopartículas. A eficiência antimicrobiana do PP-NPsAg para E.coli e S.aureus foi avaliada com sucesso. 

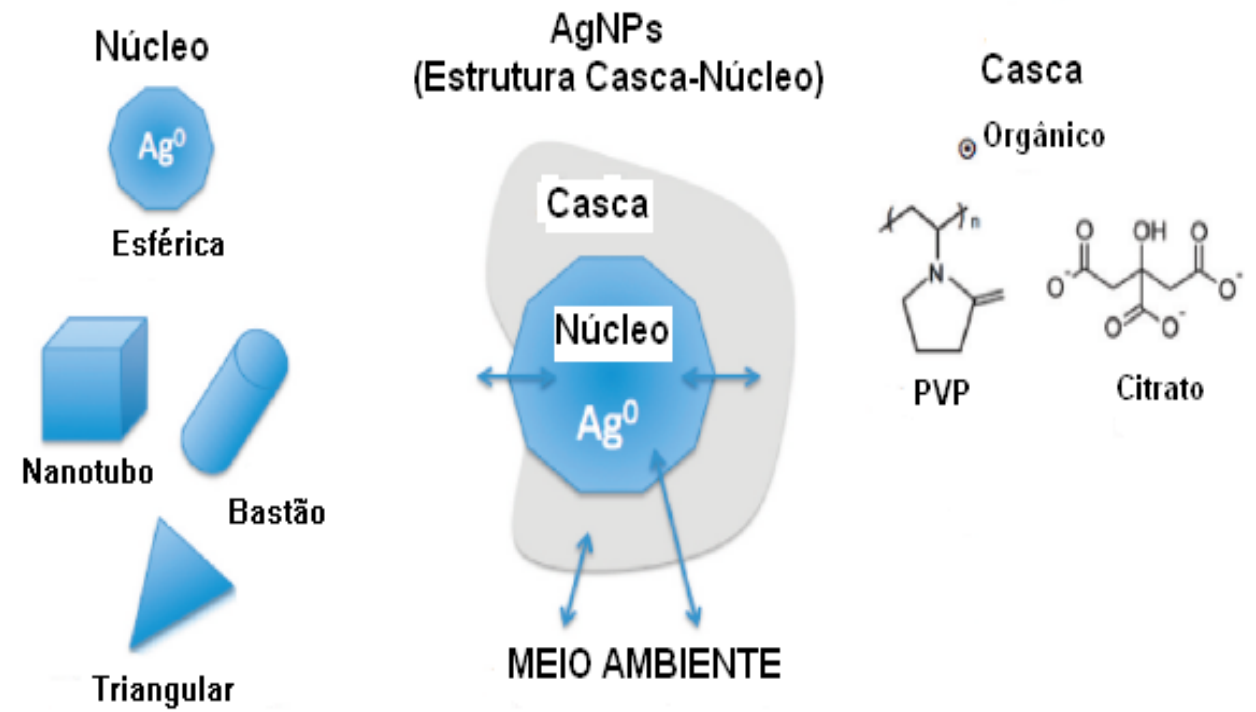

FIGURA 19 - Estrutura típica casca-núcleo de NPsAg (com diferentes formatos de prata), que podem ser liberadas para o ambiente ${ }^{134}$.

$\mathrm{Na}$ FIG. 19, as setas duplas representam as reações que podem ocorrer entre o reservatório ou núcleo com o meio ambiente e também na interface entre o núcleo e a concha ${ }^{134}$. Como concha têm a estrutura do PVP ${ }^{132,133}$ e Citrato ${ }^{134}$.

A TAB. 2 apresenta um panorama da aplicação de prata em diversos polímeros assim como os micro-organismos testados e metodologia de preparação das amostras. 
TABELA 2 - Polímeros com nanopartículas de prata com atividade mediante uma larga faixa de bactérias

\begin{tabular}{|c|c|c|c|c|}
\hline Polímeros & $\begin{array}{l}\text { Diferentes } \\
\text { formas de } \\
\text { prata }\end{array}$ & Micro-organismos & Método de preparação & Referências \\
\hline PP/PE & $\mathrm{Ag}^{\circ}$ & $\begin{array}{l}\text { S. aureus; Klebsiella } \\
\text { pneumoniae e E. coli }\end{array}$ & $\begin{array}{l}\text { - método de imersão e } \\
\text { secagem }\end{array}$ & Jeong et al. ${ }^{135}$ \\
\hline PP & $\mathrm{Ag}^{\circ}$ & $\begin{array}{l}\text { S. aureus e Klebsiella } \\
\text { pneumoniae }\end{array}$ & $\begin{array}{l}\text { - Fiação no fundido } \\
\text { - Extrusão }\end{array}$ & Yeo et al. ${ }^{136}$ \\
\hline PP & $\mathrm{Ag}^{\circ}$ & S. aureus e E. coli & $\begin{array}{l}\text { - Sonificação por } \\
\text { ultrassom }\end{array}$ & Perkas et al. ${ }^{137}$ \\
\hline PEAD & $\mathrm{Ag}+$ & S.aureus; e E.coli & - Extrusão e Injeção & Ziabka et al. ${ }^{138}$ \\
\hline $\begin{array}{l}\text { Espuma } \\
\text { Borracha- } \\
\text { Látex }\end{array}$ & $\begin{array}{l}\text { NPsAg } \\
\text { (coloidal) }\end{array}$ & $\begin{array}{l}\text { S. aureus; E. coli e } \\
\text { Aspergilles niger }\end{array}$ & - Adição (In-situ) & $\begin{array}{l}\text { Rathnayake et al. } \\
139\end{array}$ \\
\hline PEBD & $\mathrm{Ag}+$ & S. aureus & $\begin{array}{l}\text { - Superfície do filme } \\
\text { tratado por corona/plasma } \\
\text { e imersão em solução com } \\
\text { prata }\end{array}$ & Dehnavi et al. ${ }^{140}$ \\
\hline $\begin{array}{l}\text { PS, PET e } \\
\text { PVC }\end{array}$ & $\begin{array}{l}\text { NPsAg } \\
\text { (coloidal) }\end{array}$ & E. coli & $\begin{array}{l}\text { - Recobrimento espreiado } \\
\text { e blenda no fundido }\end{array}$ & Pongnop et al. ${ }^{141}$ \\
\hline PE/PA6 & $\mathrm{Ag}+\mathrm{e} \mathrm{Ag}^{\circ}$ & $\begin{array}{l}\text { A. niger (fungo) e } P \text {. } \\
\text { oleovorans }\end{array}$ & $\begin{array}{l}\text { - Derramamento; } \\
\text { espreiamento; laminação } \\
\text { (extrusão) }\end{array}$ & Valdes et al. ${ }^{142}$ \\
\hline PP & $\mathrm{Ag}+$ & S. aureus e E. coli & $\begin{array}{l}\text { - Dopagem na superfície } \\
\text { do PP }\end{array}$ & Wu et al. ${ }^{143}$ \\
\hline PP & $\mathrm{Ag}+/ \mathrm{TiO}_{2}$ & S. aureus & $\begin{array}{l}\text { - Extrusão utilizando dupla } \\
\text { rosca }\end{array}$ & Dastjerdi et al. ${ }^{144}$ \\
\hline PP & $\mathrm{Ag}+$ & S. epidermidis & $\begin{array}{l}\text { - Revestimento do Catéter } \\
\text { com Ag+ }\end{array}$ & Hazer et al. ${ }^{145}$ \\
\hline PA 6 & $\mathrm{Ag}+$ & E. coli & - Extrusão & Damm et al. ${ }^{146}$ \\
\hline $\begin{array}{l}\text { Nailon/PET/ } \\
\text { algodão }\end{array}$ & $\mathrm{Ag}+\mathrm{e} \mathrm{Ag^{ \circ }}$ & S. aureus e E. coli & $\begin{array}{l}\text { - Revestimento } \\
\text { /Deposição }\end{array}$ & Perelshtein et al. ${ }^{147}$ \\
\hline PP & $\mathrm{Ag}^{\circ}$ & Não experimentado & - Extrusão & Jang et al. ${ }^{148}$ \\
\hline PEBD & $\begin{array}{l}\text { NPsAg } \\
\text { (coloidal) }\end{array}$ & S. aureus e C. albicans & $\begin{array}{l}\text { - Processo por fusão e } \\
\text { confecção de filmes em } \\
\text { prensa }\left(140^{\circ} \mathrm{C}\right)\end{array}$ & Jokar et al. ${ }^{149}$ \\
\hline PE & NPsAg & E. coli & - Polimerização In-situ & Zapata et al. ${ }^{150}$ \\
\hline
\end{tabular}


Dehnavi et al. ${ }^{140}$ elaboraram um novo método para a obtenção de filmes poliméricos de nanocompósitos antibacterianos, para uso em embalagens de alimentos. No primeiro passo, uma solução coloidal estável de nanopartículas de prata foi preparada por redução química de sal de prata utilizando-se a frutose como um agente redutor. No segundo passo foi realizado um pré-tratamento na superfície do filme de PEBD utilizando-se tratamento corona, para aumentar a aderência das nanopartículas de prata à superfície da película. No terceiro passo, as nanopartículas de prata foram aplicadas sobre a superfície de PEBD por imersão dos filmes tratados nas soluções de prata coloidal. A morfologia da superfície do nanocompósito de prata/PEBD foi caracterizada por MEV-EC e análise AFM. A quantidade de prata do revestimento e a liberação de íons de prata para a superfície do nanocompósito foram determinadas, além da atividade antibacteriana eficiente dos filmes fabricados.

A TAB. 3 apresenta um panorama da contribuição brasileira na pesquisa e síntese de nanopartículas de prata com algumas aplicações. 
TABELA 3- Contribuição da pesquisa brasileira referente ao estudo com nanopartículas de prata e algumas aplicações

\begin{tabular}{|c|c|c|c|c|}
\hline Polímeros & $\begin{array}{l}\text { Diferentes formas } \\
\text { de prata }\end{array}$ & Micro-organismos & $\begin{array}{l}\text { Métodos de } \\
\text { preparação de } \\
\text { NPsAg }\end{array}$ & Referências \\
\hline Resina acrílica & NPsAg & C. albicans & $\begin{array}{l}\text { - Nitrato de prata } \\
\text { com borohidreto de } \\
\text { sódio e PVA }\end{array}$ & Wady et al. ${ }^{151}$ \\
\hline $\begin{array}{l}\text { Biosíntese com } \\
\text { NPsAg }\end{array}$ & $\mathrm{Ag}^{+}$ & $\begin{array}{l}\text { Fusarium } \\
\text { oxysporum (fungo) }\end{array}$ & $\begin{array}{l}\text { - Nitrato de prata } \\
\text { com agente redutor }\end{array}$ & Durán et al. ${ }^{152}$ \\
\hline $\begin{array}{l}\text { Síntese de NPsAg } \\
\text { e estudo da } \\
\text { toxicidade }\end{array}$ & $\mathrm{Ag}^{+}$e $\mathrm{Ag}^{\circ}$ & E. coli & $\begin{array}{l}\text { - Nitrato de prata } \\
\text { com ácido } \\
\text { ascórbico e solução } \\
\text { de amônia }\end{array}$ & Durán et al. ${ }^{153}$ \\
\hline $\begin{array}{l}\text { Síntese de NPsAg } \\
\text { com PVP }\end{array}$ & $\mathrm{Ag}^{+}$ & $\begin{array}{l}\text { E. coli; S. aureus; } \\
\text { S. epidermidis e M. } \\
\text { Iysodeikticus }\end{array}$ & $\begin{array}{l}\text { - Nitrato de prata } \\
\text { com Etileno glicol e } \\
\text { PVP }\end{array}$ & Lago et al. ${ }^{154}$ \\
\hline $\begin{array}{l}\text { Nova síntese de } \\
\text { filamentos de } \\
\text { prata metálica }\end{array}$ & $\mathrm{Ag}^{\circ}$ & $\begin{array}{l}\text { Não experimentado } \\
\text { (expectativa de alto } \\
\text { teor bactericida) }\end{array}$ & $\begin{array}{l}\text { - Óxido de prata } \\
\text { com irradiação de } \\
\text { elétrons em } \\
\text { tungstato }\end{array}$ & Longo et al. ${ }^{155}$ \\
\hline $\begin{array}{l}\text { PMMA Poli(metil- } \\
\text { metacrilato) }\end{array}$ & $\begin{array}{l}\mathrm{Ag}^{+} \text {e Prata } \\
\text { Coloidal }\end{array}$ & Não experimentado & $\begin{array}{l}\text { Nitrato de prata e } \\
\text { citrato }\end{array}$ & Monteiro et al. ${ }^{156}$ \\
\hline PVA & $\mathrm{Ag}^{+}$ & Não experimentado & $\begin{array}{l}\text { Nitrato de prata } \\
\text { com borohidreto de } \\
\text { sódio e PVA }\end{array}$ & Zucolotto et al. $^{67}$ \\
\hline
\end{tabular}

Empresas brasileiras que sintetizam e comercializam NPsAg são: Nanox, TNS e Khemia.

A Nanox ${ }^{157}$, de São Carlos, surgiu em 2004 com a colaboração de dois institutos de química, um da Universidade Federal de São Carlos (UFSCar) e outro da Universidade Estadual Paulista (Unesp), em Araraquara. 
A TNS Nanotecnologia ${ }^{158}$ depois de muitos anos de pesquisa em parceria com laboratórios da Universidade Federal de Santa Catarina, desenvolveu aditivos antimicrobianos a base de nanopartículas de prata.

Também a empresa Khemia ${ }^{159}$ que está localizada no CIETECIPEN/USP desenvolve pesquisas de nanotecnologia de metais, sendo as nanopartículas de prata o foco para desenvolvimento de produtos.

\subsection{Mecanismo de ação das nanopartículas de prata}

O efeito bactericida dos compostos de prata é bem conhecido, mas seu mecanismo de ação permanece parcialmente obscuro ${ }^{160,161}$. As nanopartículas de prata têm grande afinidade com grupos que possuem os elementos enxofre e fósforo, que são encontrados tanto nas membranas como no interior das bactérias. Sua interação ocorre com a membrana celular das bactérias causando danos no processo de respiração e no interior das mesmas, com o DNA, impedindo a divisão celular ${ }^{162}$.

As bactérias têm diferentes estruturas de membrana que permitem uma classificação geral delas como gram-negativos ou gram-positivos. As diferenças estruturais encontram-se na organização de um componente essencial da membrana, o peptidoglicano. As bactérias gram-negativas exibem apenas uma fina camada de peptidoglicano ( 2-3 nm) entre a membrana citoplasmática e a membrana externa ${ }^{163}$, em contraste, bactérias gram-positivas não possuem a membrana exterior, mas têm uma camada de peptidoglicano de cerca de $30 \mathrm{~nm}$ de espessura ${ }^{164}$.

A prata tem diferentes modos de ação com a célula bacteriana, tal como apresentado na FIG. 20. O modo de ação é diferente no caso de bactéria gram-positiva e gram-negativa. Tanto $P$. aeruginosa e $E$. coli são bactérias gramnegativas e seguem quase o mesmo padrão de inativação quando desinfectadas com prata. Os íons de prata $\left(\mathrm{Ag}^{+}\right)$ligam-se ao peptidoglicano carregado negativamente na parede célula/membrana prejudicando a respiração celular pelo 
bloqueio do sistema de transferência de energia, resultando na morte celular $^{165,166}$.

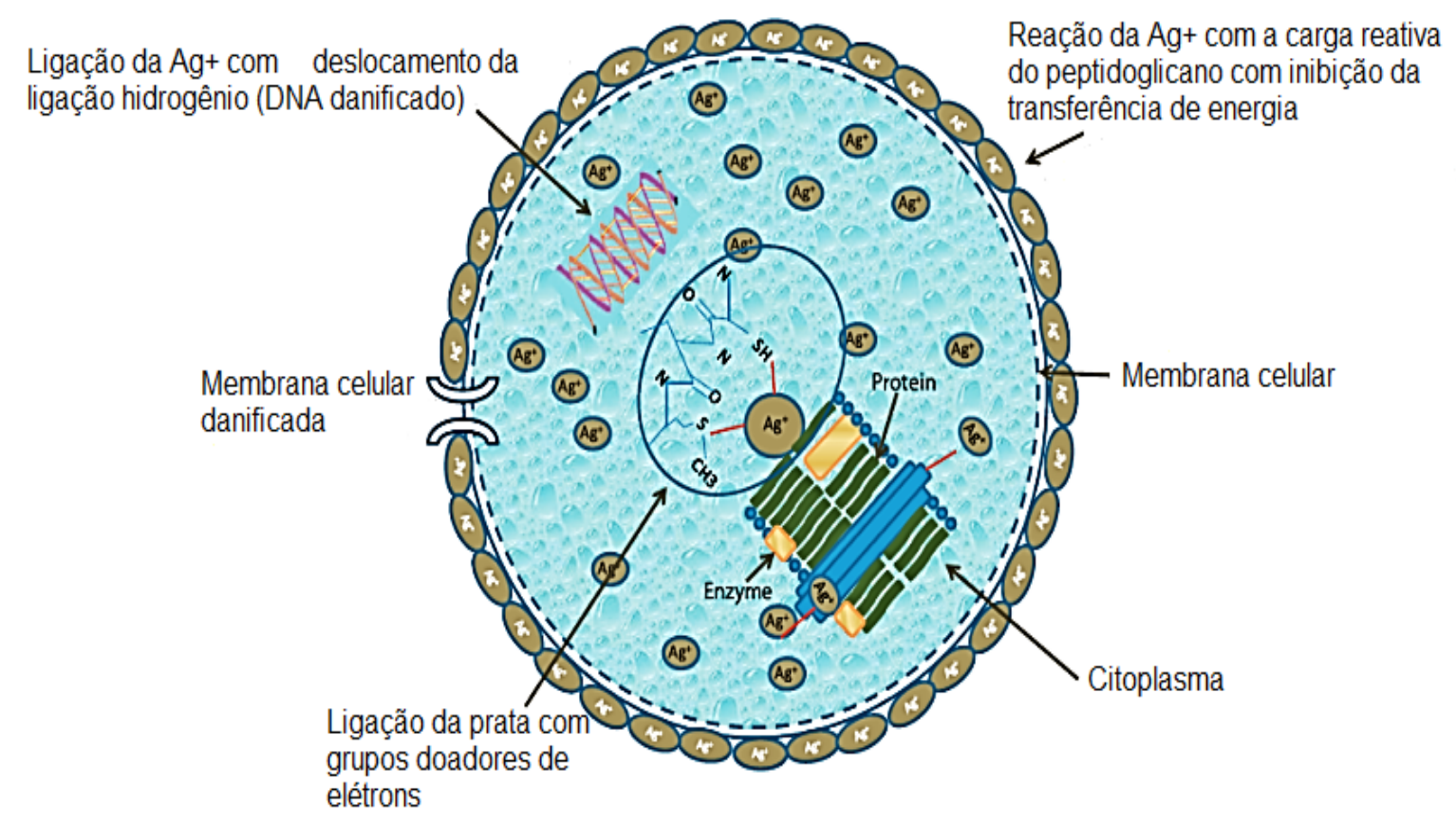

FIGURA 20 - Diferentes maneiras de ação da prata na célula bacteriana ${ }^{166}$

A prata tem a capacidade de marcar as proteínas que reagem com grupos tiois $(-\mathrm{SH})$ na célula bacteriana, enquanto presentes nas proteínas (enzimas) favorecem a sua inativação ${ }^{162,165-168}$. A prata também se liga a grupos doadores de elétrons que contêm nitrogênio, oxigênio, e enxofre, tais como aminas, hidroxilas, fosfatos das células ${ }^{165,169,170}$. A ligação da prata com o ácido desoxiribonucléico (DNA) é também uma das ações da prata nas bactérias ${ }^{165}$. A prata desloca as ligações de hidrogênio entre átomos adjacentes de nitrogênio de bases de purina e pirimidina, o que pode estabilizar a hélice do DNA e impedir a sua replicação e a divisão celular subsequente ${ }^{171-173}$.

\subsection{Algumas aplicações das NPsAg nos seres humanos}

As nanopartículas de prata têm despertado o interesse para aplicações biomédicas e isto se deve à sua potente atividade antibacteriana. A nano-prata tem aplicações anti-inflamatórias e consequente melhoria da cicatrização de 
feridas, o que deve ser explorado no desenvolvimento de curativos mais eficientes para feridas e queimaduras, FIG. 21. A chave da sua ampla atuação e atividade antibacteriana é o entendimento do mecanismo de atuação da nano-prata sobre os micróbios. A nano-prata é utilizada em revestimentos antibacterianos de dispositivos médicos para reduzir as taxas de infecção hospitalar. A toxicidade da nano-prata também é uma questão discutida sobre potenciais problemas antes generalizados para a aplicação no campo da medicina ${ }^{174}$.

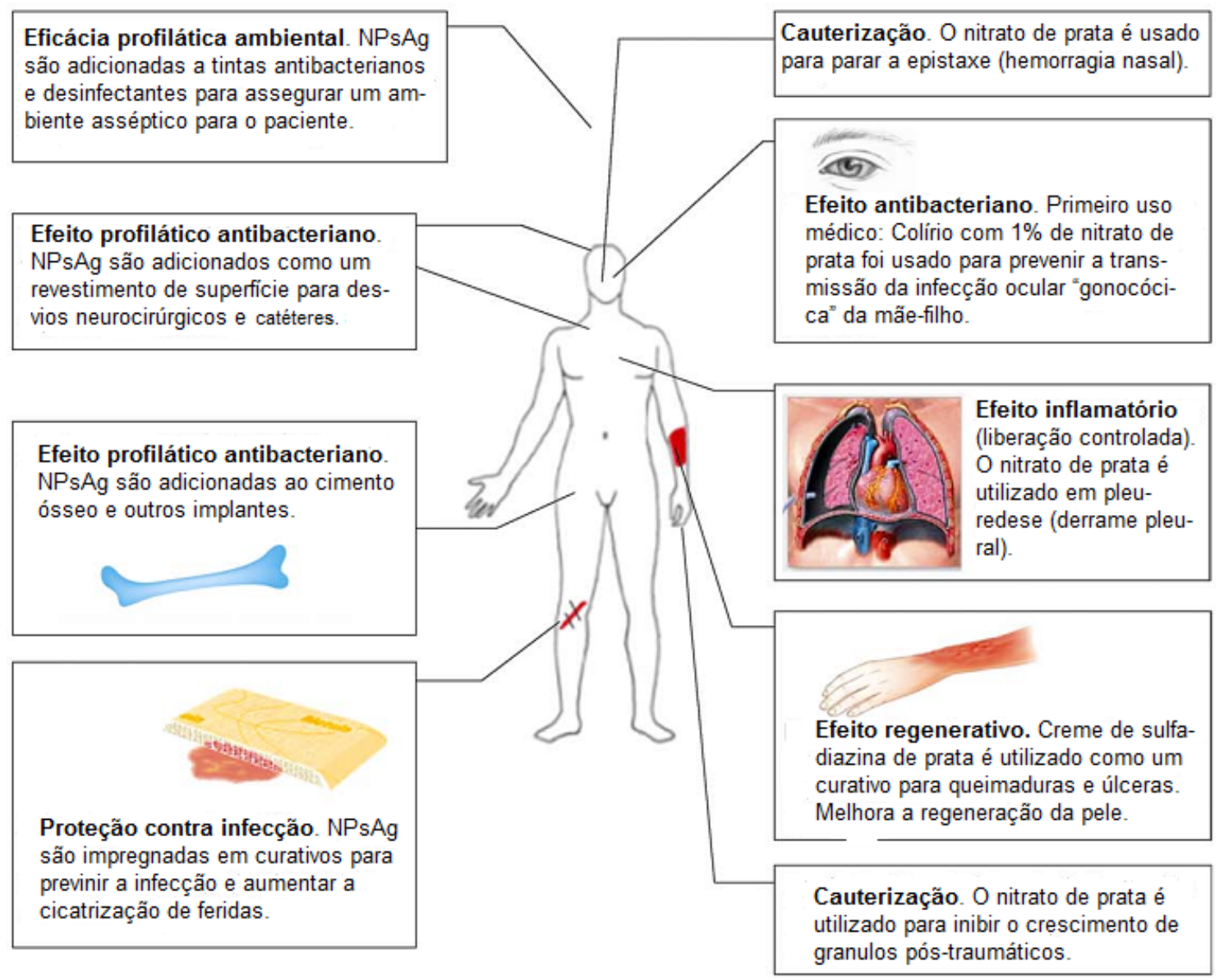

FIGURA 21 - Aplicações da prata (lado direito) e de nanopartículas de prata NPsAg (lado esquerdo) em medicina ${ }^{174}$

\subsection{Aspectos ambientais das nanopartículas de prata}

Devido a uma série de produtos em que as NPsAg são usadas atualmente, devemos nos preocupar quanto aos aspectos ambientais $\mathrm{e}$ nocividade. Os nanomateriais de prata são os principais componentes de 
produtos de proteção à saúde devido ao efeito antimicrobiano. Os mecanismos de toxicidade para os organismos biológicos não são bem entendidos. Em trabalho recente Kashiwada et al. ${ }^{175}$ utilizando embriões do peixe de origem japonesa "medaka fish" (Oryzias latipes) investigaram os efeitos tóxicos e mecanismos correspondentes de nanocolóides de prata (NCS, tamanho de partículas 3,8 \pm 1,0 $\mathrm{nm})$. Os NCS foram inseridos ao experimento e causaram mudanças na morfologia dos embriões, tais como, má formação cardiovascular, isquemia, subdesenvolvimento do sistema nervoso central e olhos. NCS foram observados dentro dos ovos e na superfície com 786,1 $\pm 32,5 \mathrm{pg} \mathrm{mg}^{-1}$ em peso de ovo, e na análise por TEM mostrou-se que NCS aderem à superfície e interior do clorion (membrana do embrião). A respeito da toxicidade das NPsAg, muito pouco é conhecido do seu mecanismo especifico e modo de ação. Entretanto, pequena quantidade de NPsAg, que têm elevada área superficial, produz eficiente meio tóxico, que é o efeito antibacteriano.

Interessante estudo de toxicologia utilizou NPsAg e o zebrafish (peixe zebra) ${ }^{176}$, no qual foram sintetizadas, purificadas, caracterizadas e estabilizadas as nanopartículas de prata (NPsAg, 41,6 = 9,1 nm de diâmetro médio). Utilizaramse embriões de zebrafish como modelo de organismos "in vivo" para sondar a difusão e toxicidade de NPsAg. Descobriu-se que só NPsAg (30-72 nm) difundem passivamente nos embriões através de poros. Por movimento Browniano permaneceram dentro dos embriões ao longo do seu desenvolvimento (120 horas-pós-fecundação). Efeitos tóxicos observados no desenvolvimento embrionário dependeram da dose e do tamanho das NPs mostrando a possibilidade de biocompatibilidade e toxicidade das nanopartículas. Em concentração mais baixa das NPs ( $\leq$ 0,02 nM), 75-91\% dos embriões de zebrafish se desenvolveram normalmente. Nas concentrações mais elevadas de Nखs ( 0,20 nM), 100\% dos embriões morreram. Nas concentrações entre (0,02-0,2 nM), ocorreram deformações nos embriões de zebrafish. Comparando-se com NPsAg de $(11,6 \pm 3,5 \mathrm{~nm})$ a nanotoxicidade foi impressionantemente dependente do tamanho, na mesma concentração molar, as NPsAg maiores $(41,6 \pm 9,1 \mathrm{~nm})$ são mais tóxicas do que as NPsAg menores (11,6 \pm 3,5 nm). 


\section{MATERIAIS E MÉTODOS}

\subsection{Materiais}

O polipropileno isotático com MFI = 1,5 dg $\mathrm{min}^{-1}$, ASTM D $1238-04{ }^{177} \mathrm{e}$ $\overline{\boldsymbol{M}}_{w}=338.000 \mathrm{~g} \mathrm{~mol}^{-1}$ foi fornecido na forma de grânulos pela Braskem - Brasil. Para sintetizar o polipropileno modificado por irradiação cujo acrônimo é HMSPP (Polipropileno com Alta Resistência do Fundido), foi utilizado o polímero iPP em grânulos, sendo acondicionado em recipiente de nylon com gás acetileno 99,8\%, fornecido pela White Martins, sob pressão de $110 \mathrm{kPa}^{178}$. A irradiação dos grânulos foi realizada utilizando-se uma fonte de ${ }^{60}$ Co a uma taxa de dose de 5 kGy $h^{-1}$. As doses de radiação utilizadas foram 5; 12,5 e 20 kGy sendo monitoradas por um dosímetro Perspex Red Harwell 4034. Após a irradiação, os grânulos foram submetidos a tratamento térmico a $90{ }^{\circ} \mathrm{C}$ durante 1 hora para promover a recombinação e a aniquilação de radicais residuais ${ }^{179,180}$.

As nanopartículas de prata (NPsAg) foram adquiridas da Sigma Aldrich, referência 576832, lote MKBF5701V. O agente dispersante (surfactante) utilizado foi o Poli(N-vinil-2-pirrolidona) (PVP) (Plasdone ${ }^{\circledR} \mathrm{K}-90 \mathrm{D}-\bar{M}_{w}=1.300 .000 \mathrm{~g} \mathrm{~mol}^{-1}$, viscosidade $55 \mathrm{mPa} . \mathrm{s}$ - sol. aquosa $5 \%$ a $25{ }^{\circ} \mathrm{C}$ e $\operatorname{Tg} 174{ }^{\circ} \mathrm{C}$ ) e o antioxidante Irganox B 215 ED fornecido pela BASF.

\subsubsection{Géis}

Os géis (nanogéis e microgéis) foram determinados a partir da extração em xileno, fração sol, processo "Settling" do polipropileno modificado por irradiação.

\subsubsection{Géis com Nanopartículas de Prata (NPsAg)}

A partir dos géis de polipropileno modificado foram adicionadas nanopartículas de prata. Na FIG. 22 é apresentado um fluxograma das atividades 
experimentais desenvolvidas para obtenção e caracterização dos géis de polipropileno com NPsAg.

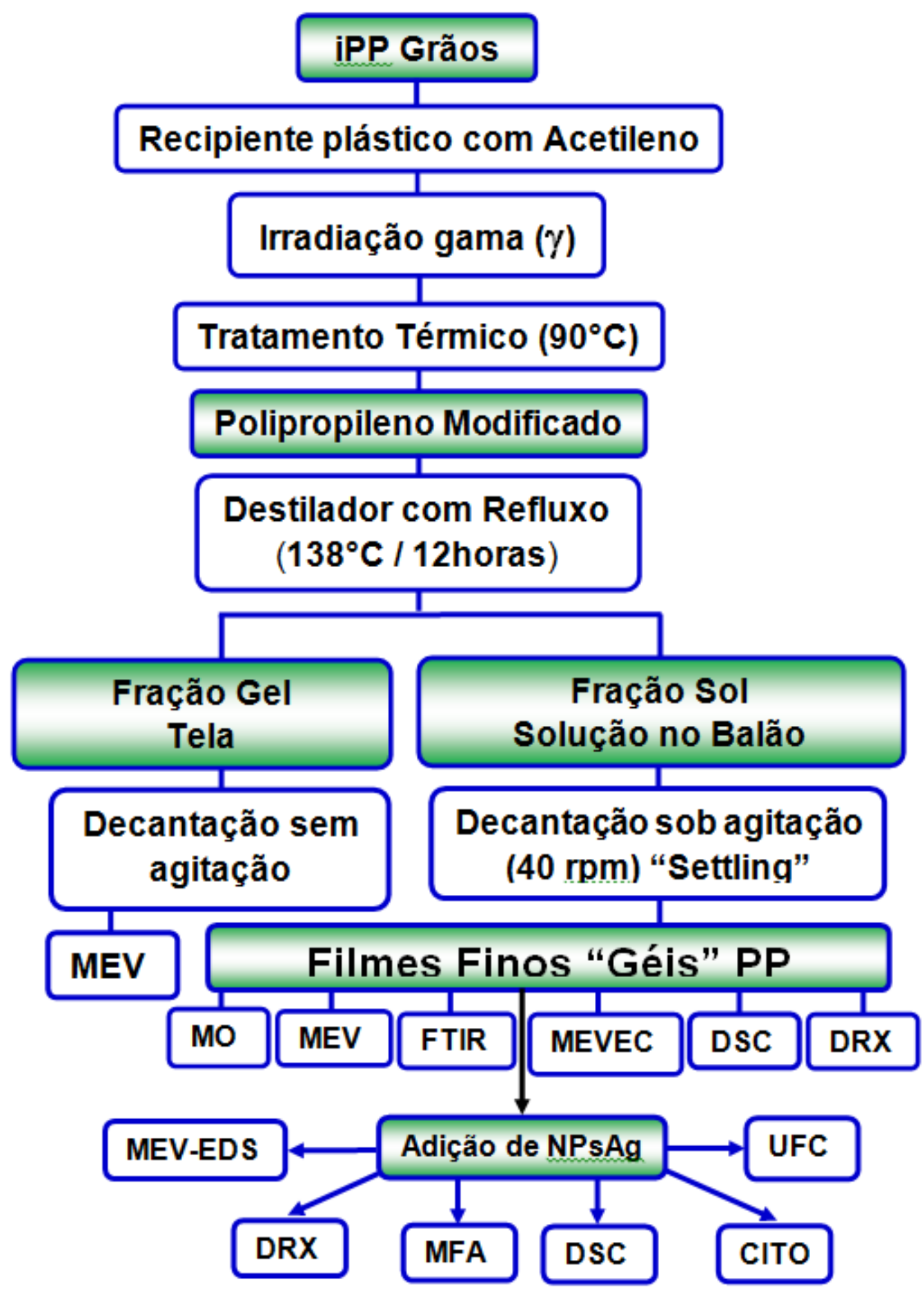

FIGURA 22 - Fluxograma das atividades da etapa experimental (géis de polipropileno com NPsAg) 


\subsubsection{Filmes de Polipropileno com Nanopartículas de Prata (NPsAg)}

A blenda polimérica consiste da mistura de iPP e PP 12,5 kGy que foi preparada na proporção de 50/50 (grânulos) e a seguir misturada às NPsAg com estabilizante fenólico Irganox B215 ED, utilizando-se um misturador rotativo por um período de 24 horas. Transcorrido este tempo, a mistura foi processada em uma extrusora co-rotatória Haake, modelo Rheomax PTW 16/25, com as seguintes condições de processamento: temperaturas das zonas foram de 180 a $195{ }^{\circ} \mathrm{C}$ e a $100 \mathrm{rpm}$, FIG. 22A-C. Logo após a extrusão o material foi transformado em grânulos, FIG. 22D. Os filmes de polipropileno foram obtidos por moldagem por compressão a $190{ }^{\circ} \mathrm{C}$ por 10 min sem pressão, em seguida submetido à pressão de 80 bar por 5 min, e logo após, mergulhados em um tanque com água a $23^{\circ} \mathrm{C}$, o que evita a formação da fase cristalina. 

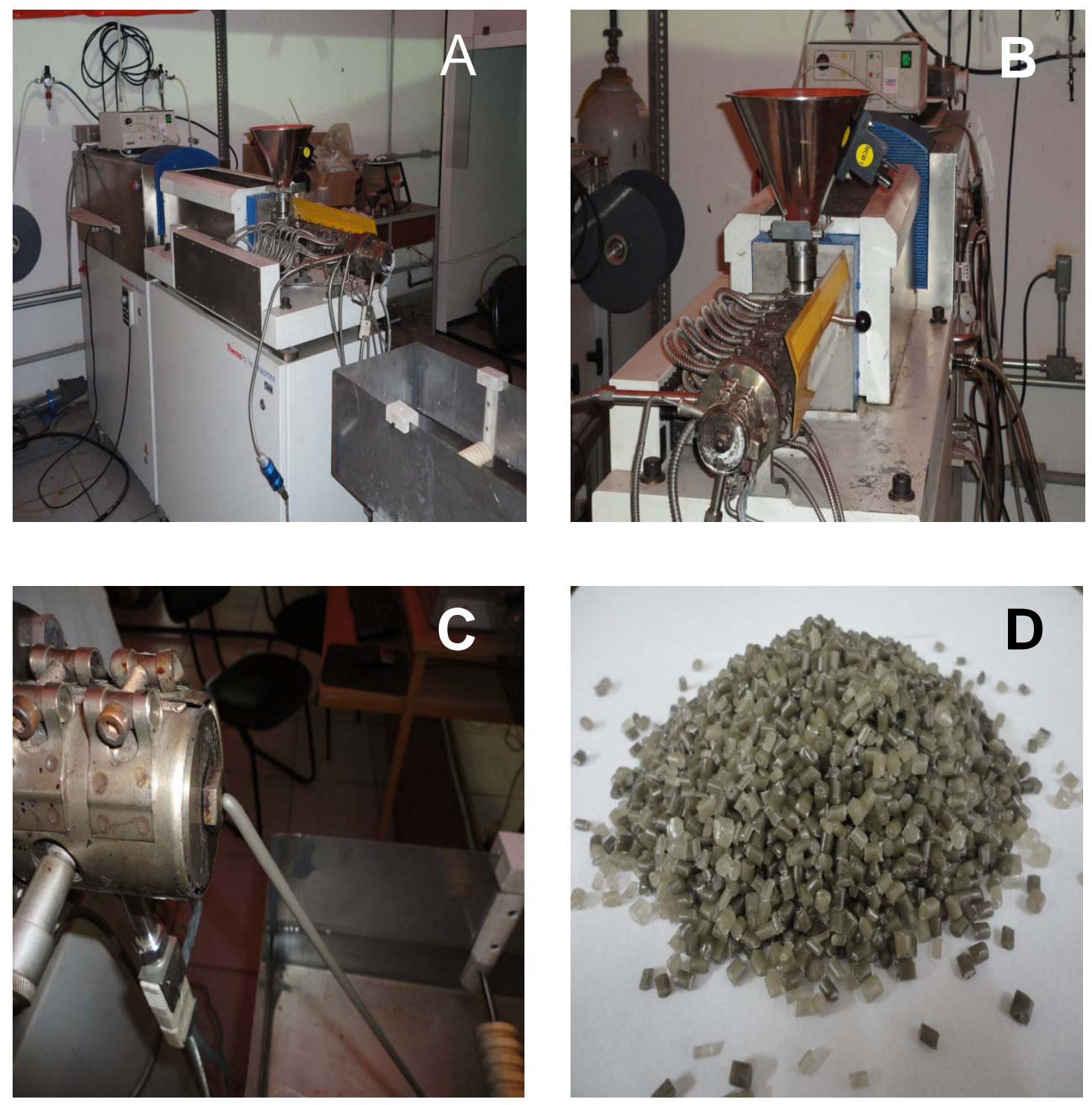

FIGURA 23 - (A-B) Extrusora co-rotatória Haake; (C) Extrusão da mistura na forma de macarrão; (D) Nanocompósito de polipropileno com NPsAg na forma de grãos

$\mathrm{Na}$ FIG. 24, é apresentado um fluxograma das atividades experimentais desenvolvidas como filmes de polipropileno com NPsAg. 


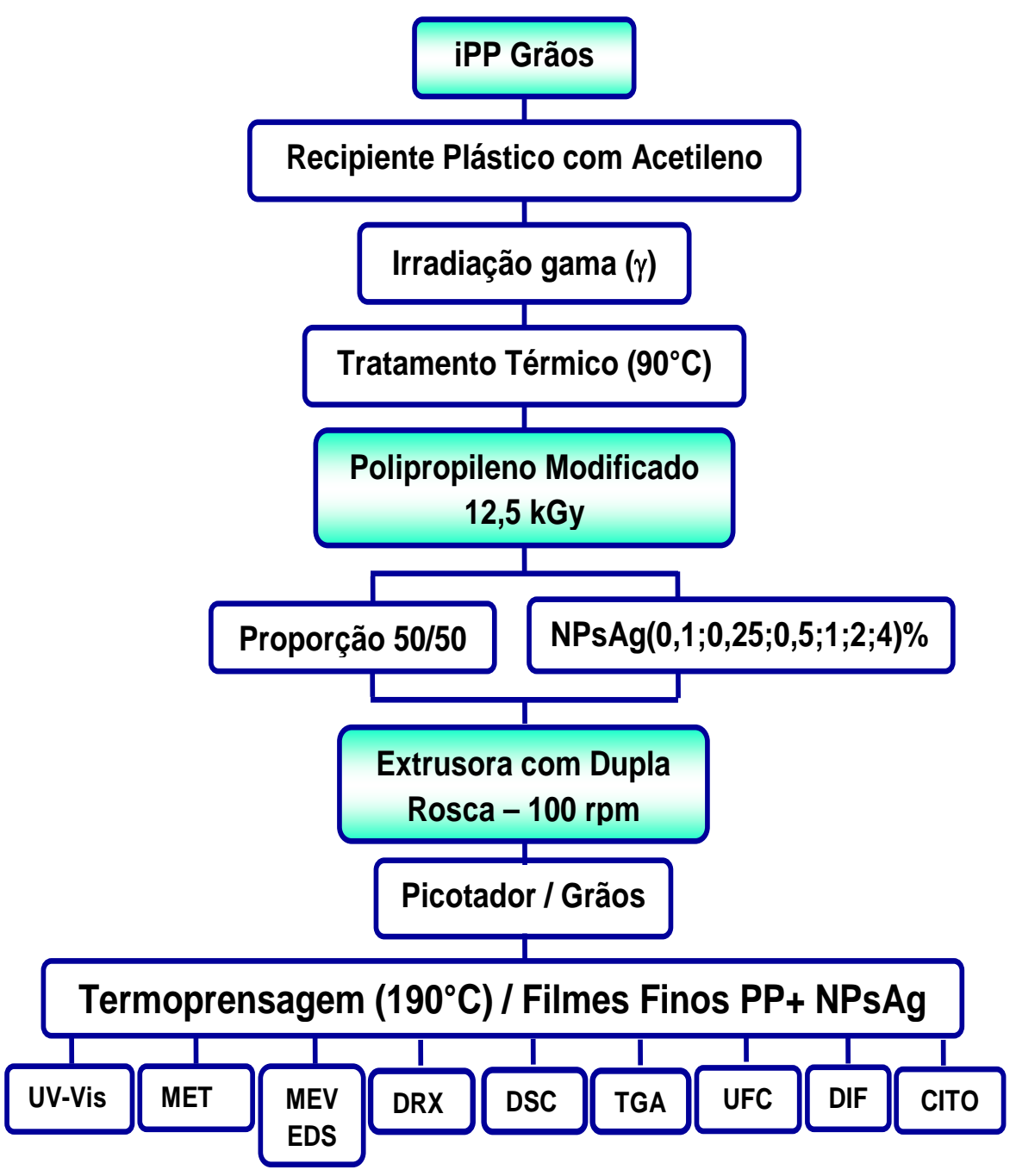

FIGURA 24 - Fluxograma das atividades da etapa experimental (filmes de polipropileno com NPsAg)

Os filmes obtidos como produto final foram caracterizados pelas técnicas físicas e biológicas. 


\subsection{Métodos}

\subsubsection{Fração Gell Fração Sol e Índice de Fluidez do Fundido (MFI)}

A fração gel constitui a parte insolúvel e é determinada por pesagem a partir da extração da amostra em xileno, após eliminação do solvente por secagem a vácuo.

Para elaboração das análises de fração gel foi utilizado um sistema de balões acoplados a destiladores de refluxo FIG. 25A. As amostras de PP foram envolvidas em uma malha de aço inoxidável de 500 mesh e imersas em xileno sob ebulição a $138^{\circ} \mathrm{C}$ por 12 horas $^{181-183}$, conforme ASTM D 2765-06 ${ }^{184}$. A fração gel é determinada pela relação entre a massa do gel seco e a massa inicial da amostra multiplicada por 100. As concentrações utilizadas das amostras de PP

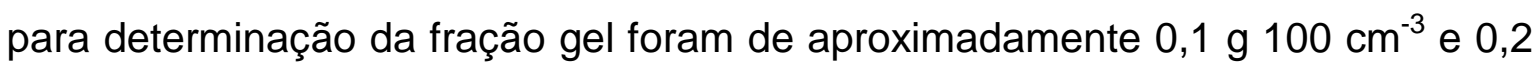
g $100 \mathrm{~cm}^{-3}$.

A fração sol, ou seja, a parte solúvel das amostras foi obtida pela decantação do material em solução em um béquer à temperatura ambiente de 25 ${ }^{\circ} \mathrm{C}$. Com a volatilização total do xileno ocorre a deposição gradual de um filme do material seco sobre finas lâminas de vidro, apropriadas para o uso em microscopia.

O índice de fluidez do fundido (MFI), ASTM D 1238-04 ${ }^{177}$; das amostras de iPP e PP modificado foram obtidos utilizando-se um plastômetro da Ceast FIG. 25B. 

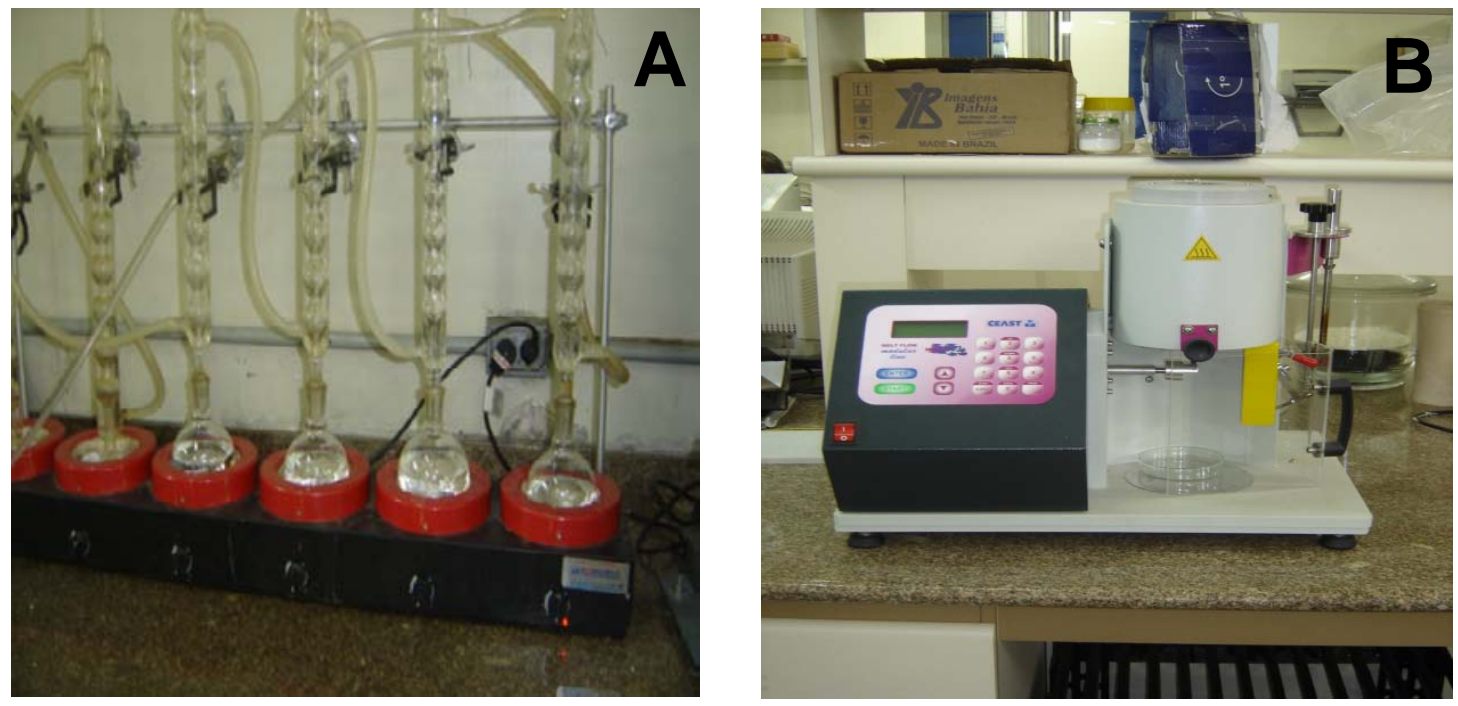

FIGURA 25 - (A) Sistema de balões acoplados a destiladores de refluxo; (B) Plastômetro da Ceast

\subsubsection{Microscopia Óptica}

O microscópio óptico utilizado foi da marca Olympus BX 51, FIG. 26, com luz polarizada permitindo observar a superfície das amostras de géis com escala de $100 \mu \mathrm{m}$.

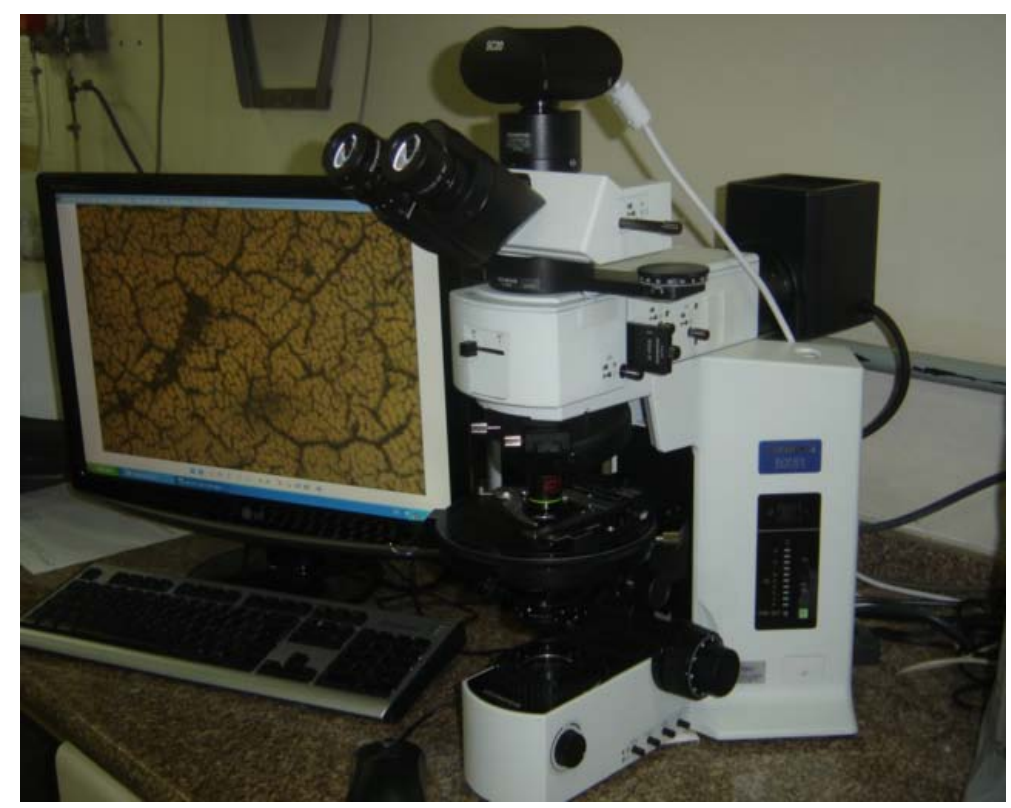

FIGURA 26 - Microscópio óptico Olympus BX51, com luz polarizada 


\subsubsection{Microscopia Eletrônica de Varredura (MEV) e Table Top (MEVIEDS) Espectroscopia de Energia Dispersiva (EDS)}

Para a visualização de detalhes da morfologia do polímero foi utilizada microscopia eletrônica de varredura, equipamento da marca EDAX Philips modelo XL-30, FIG. 27A. As amostras foram fixadas sobre suporte metálico adequado e recobertas com ouro pela técnica de sputtering. Para os filmes de PP modificado com 12,5 kGy e com adição de NPsAg foi obtido o espectro de EDS, assim como os géis com NPsAg, FIG. 27B.
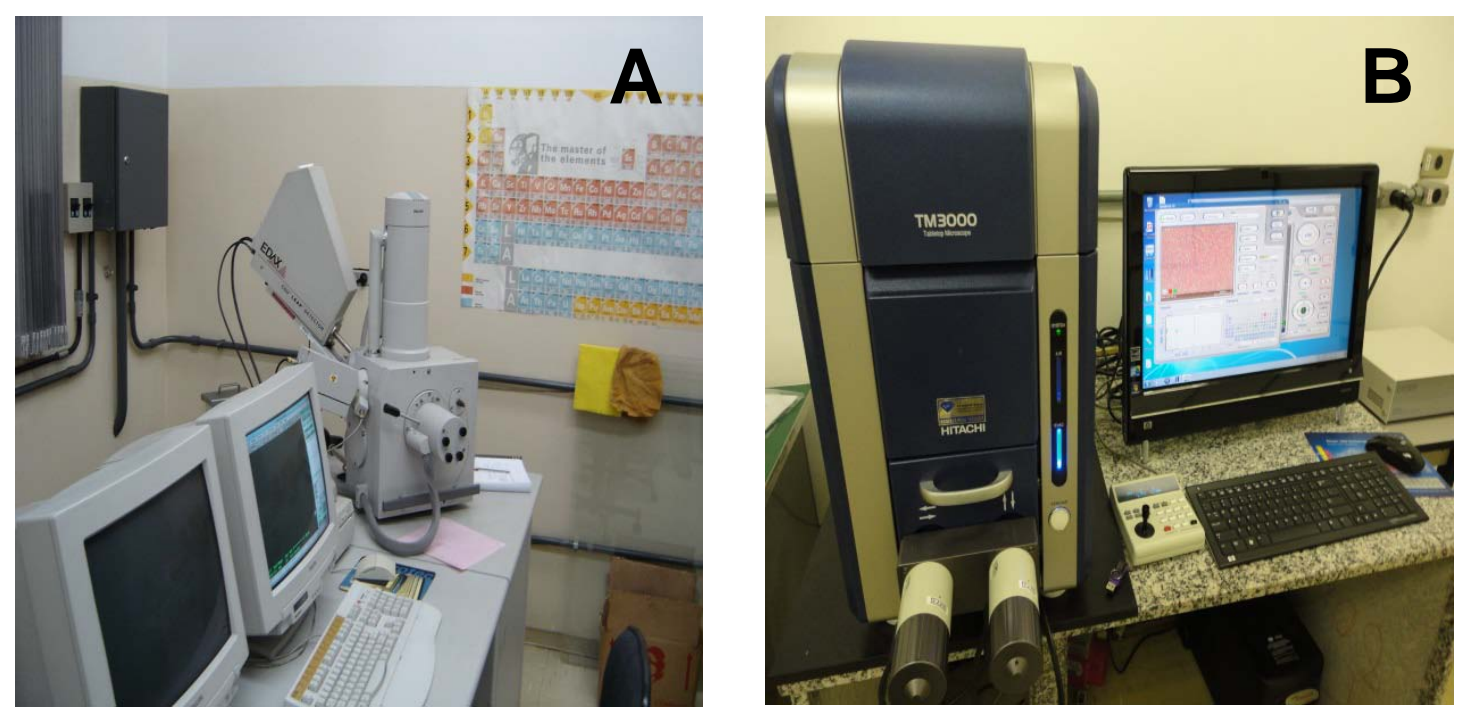

FIGURA 27 - (A) Microscopia Eletrônica de Varredura (MEV), equipamento marca EDAX Philips modelo XL-30 (B) Table Top (MEV/EDS), equipamento marca Hitachi modelo TM 3000

\subsubsection{Espectroscopia no Infravermelho (FT-IR)}

Os espectros de infravermelho foram obtidos no aparelho da Thermo Nicolet, modelo 380 FT-IR com acessório Smart Orbit (cristal de diamante), FIG. 28. Os espectros foram registrados à temperatura de $23{ }^{\circ} \mathrm{C}$ utilizando-se 64 varreduras na região de 4000 a $400 \mathrm{~cm}^{-1}$, com resolução de $2,0 \mathrm{~cm}^{-1}$. 


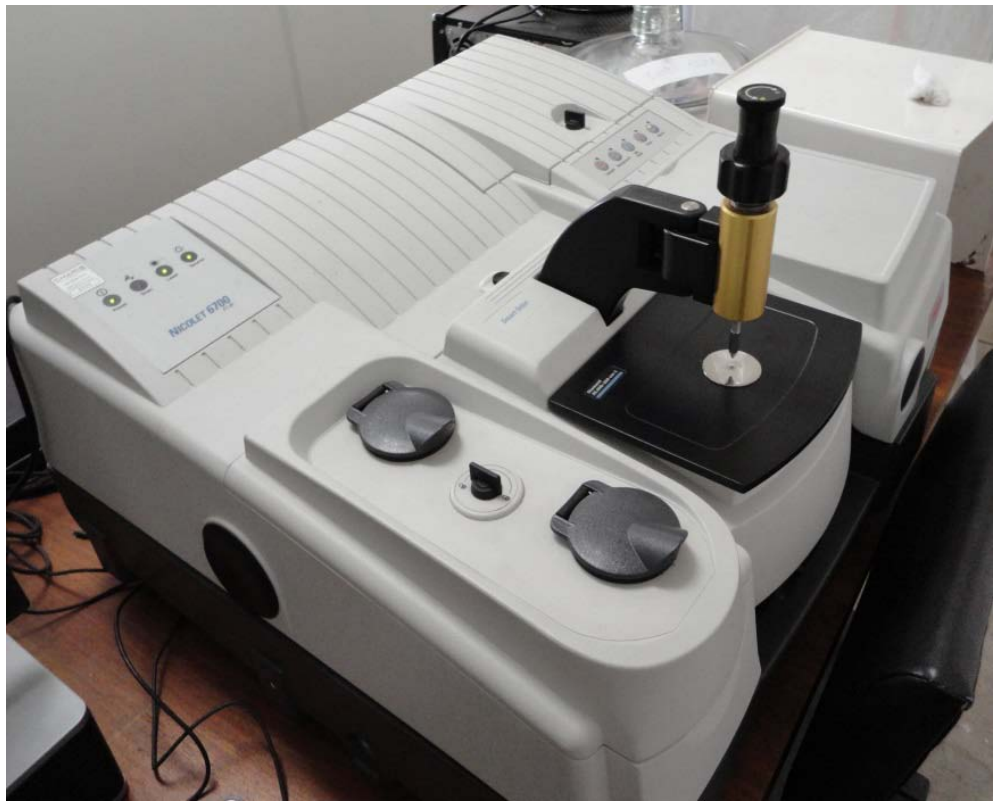

FIGURA 28 - Aparelho da Thermo Nicolet, modelo 380 FT-IR

\subsubsection{Microscopia de Força Atômica (MFA)}

As medidas de microscopia de força atômica foram executadas em um microscópio Nanoscope III A da Veeco, equipado com Multi-Modo, FIG. 29. A ponta de prova usada para a aquisição das imagens foi da modalidade comercial de Si, com frequência de ressonância de aproximadamente $250 \mathrm{kHz}$. As imagens foram obtidas usando-se 512 x 512 pixel e os experimentos foram realizados na modalidade de contato intermitente utilizando-se um scanner tipo $\mathrm{E}$. 


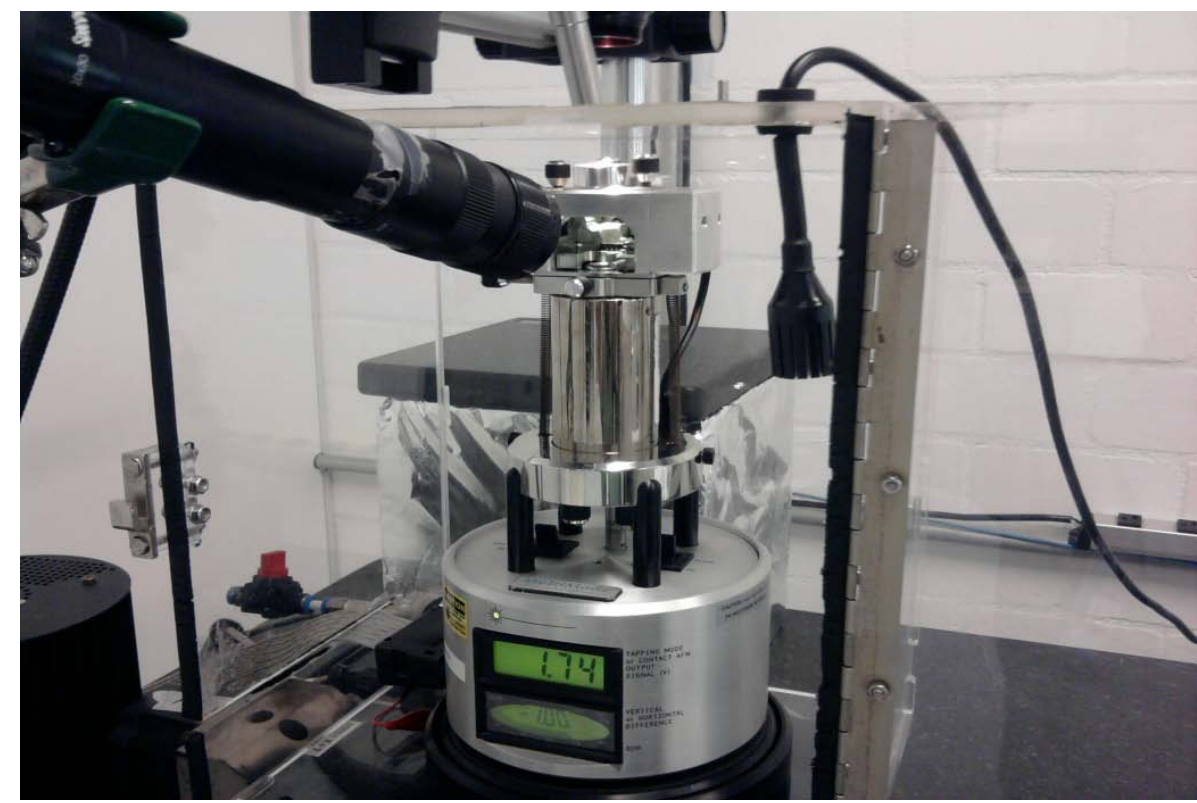

FIGURA 29 - Microscópio de Força Atômica (MFA) Nanoscope III A

\subsubsection{Microscopia Eletrônica de Varredura com Emissão de Campo (MEV-EC)}

Os filmes obtidos a partir da fração sol do polipropileno (géis) foram fixados em porta-amostra e recobertos com uma fina camada de carbono. As amostras foram analisadas por microscopia eletrônica de varredura com emissão de campo (MEV-EC), FE-SEM (Field Emission Scanning Electron Microscope), JEOL FE-SEM, JSM-6701F - Japão, FIG. 30. A tensão de aceleração usada foi de 5,0 kVa. O aparelho JSM-6701F está alocado no Centro de Ciência e Tecnologia de Materiais (CCTM) do IPEN-CNEN/SP. 


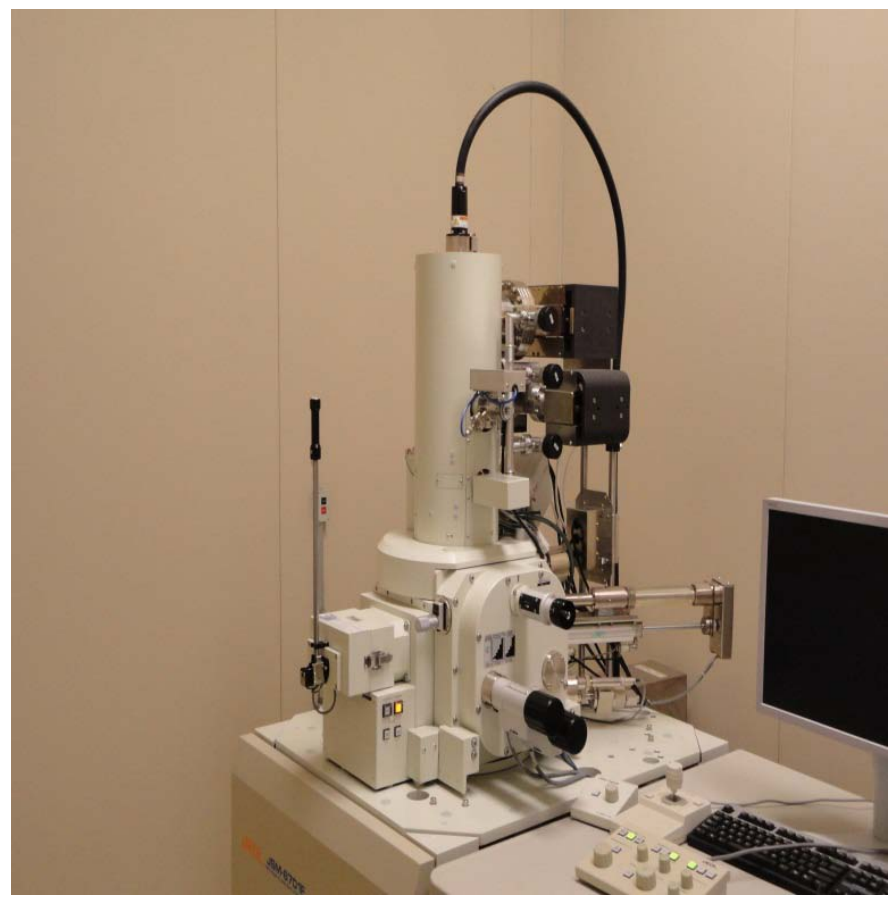

FIGURA 30 - Microscópio eletrônico de varredura com emissão de campo (MEVEC), JEOL FE-SEM, JSM-6701F

\subsubsection{Espectroscopia UV-Vis}

O espectro de UV-Vis foi obtido utilizando-se o equipamento Spectrometer Shimadzu, modelo UV-2401, faixa de 200-800nm.

\subsubsection{Microscopia Eletrônica de Transmissão (MET) e Ultramicrótomo}

Os filmes foram examinados por MET no equipamento JEOL JEM 2100 operando com uma voltagem de aceleração de 80 kV, FIG. 31A. Os cortes ultrafinos (80nm) foram preparados usando-se um ultramicrótomo Leica EM FC6 com navalha de diamante, FIG. 31B. 

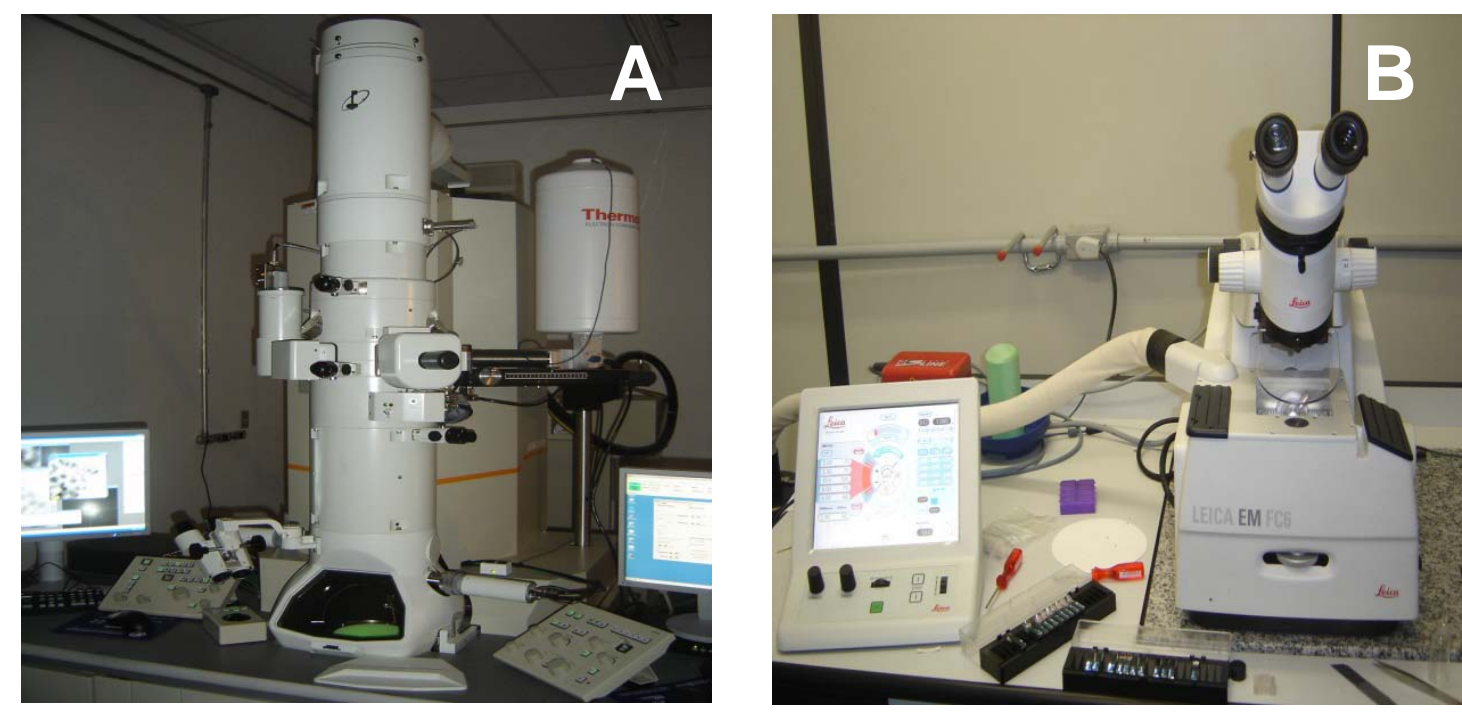

FIGURA 31 - (A) Microscópio eletrônico de transmissão (MET) equipamento da marca JEOL, modelo JEM 2100F (B) Ultramicrótomo Leica EM FC6

\subsubsection{Calorimetria Exploratória Diferencial (DSC)}

Os ensaios foram realizados no equipamento Mettler Toledo DSC 822 sob a atmosfera de nitrogênio, FIG. 32. O programa utilizado foi o seguinte: aquecimento de -50 a $280{ }^{\circ} \mathrm{C}$ a razão de $10{ }^{\circ} \mathrm{C} \mathrm{min}{ }^{-1}$, mantendo-se a $280{ }^{\circ} \mathrm{C}$ por 5 minutos; resfriamento de 280 a $-50{ }^{\circ} \mathrm{C}$ a uma razão de $-5{ }^{\circ} \mathrm{C} \mathrm{min}^{-1}$; e reaquecimento de -50 a $280{ }^{\circ} \mathrm{C}$ a $10{ }^{\circ} \mathrm{C} \mathrm{min}{ }^{-1}$. As amostras foram pesadas apresentado massa de 10 a $15 \mathrm{mg}$ e foram acondicionadas em cadinhos com tampas em alumínio, conforme ASTM D 3418-08 ${ }^{185}$. Com esta técnica foram determinados o percentual de cristalinidade, temperatura de fusão e temperatura de cristalização, referentes aos filmes de géis e filmes de polipropileno com NPSAg. 
A cristalinidade foi calculada conforme a equação:

$$
X_{C}(\%)=\frac{\Delta H_{f} \times 100}{\Delta H_{0}}
$$

Onde:

$\Delta \mathrm{H}_{f}=$ Entalpia de fusão da amostra $\Delta \mathrm{H}_{0}=$ Entalpia de fusão do PP $100 \%$ cristalino $209 \mathrm{~kJ} \mathrm{~kg}^{-1} 186,187$.

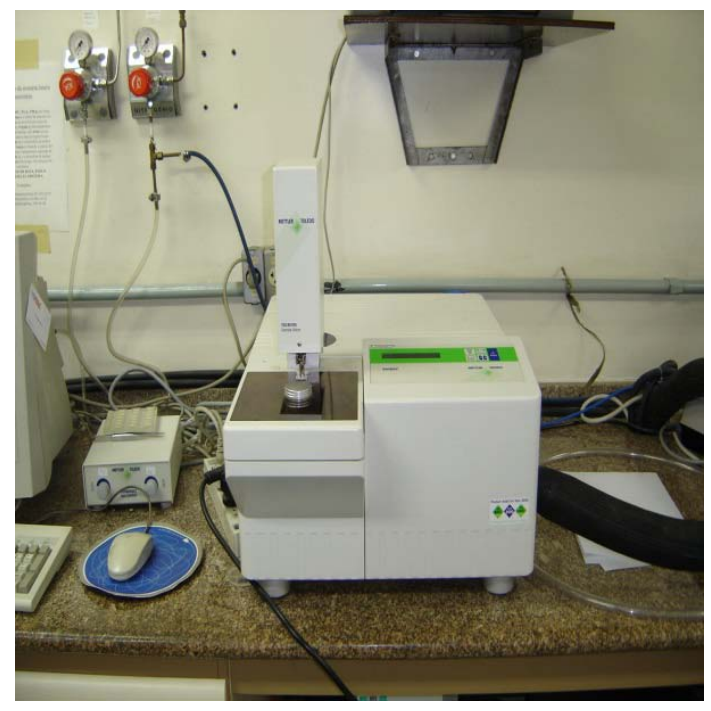

FIGURA 32 - Equipamento da Mettler Toledo DSC 822

\subsubsection{Análise de Termogravimetria (TGA)}

Análise de termogravimetria foi efetuada em equipamento da marca Mettler-Toledo - TGAISDTA 851 com termobalança, FIG. 33. Os testes foram programados para atmosfera de nitrogênio com fluxo de $50 \mathrm{~mL} \mathrm{~min}^{-1}$, na faixa entre 25 a $600^{\circ} \mathrm{C}$ com razão de aquecimento de $10^{\circ} \mathrm{C} \mathrm{min}^{-1}$. As amostras foram colocadas em cadinhos de alumina de $40 \mu \mathrm{L}$, conforme ASTM D $6370{ }^{188}$. O gás nitrogênio utilizado nas análises possui grau de pureza 99,999\% com nível de oxigênio menor que 1 ppm da empresa White Martins. 


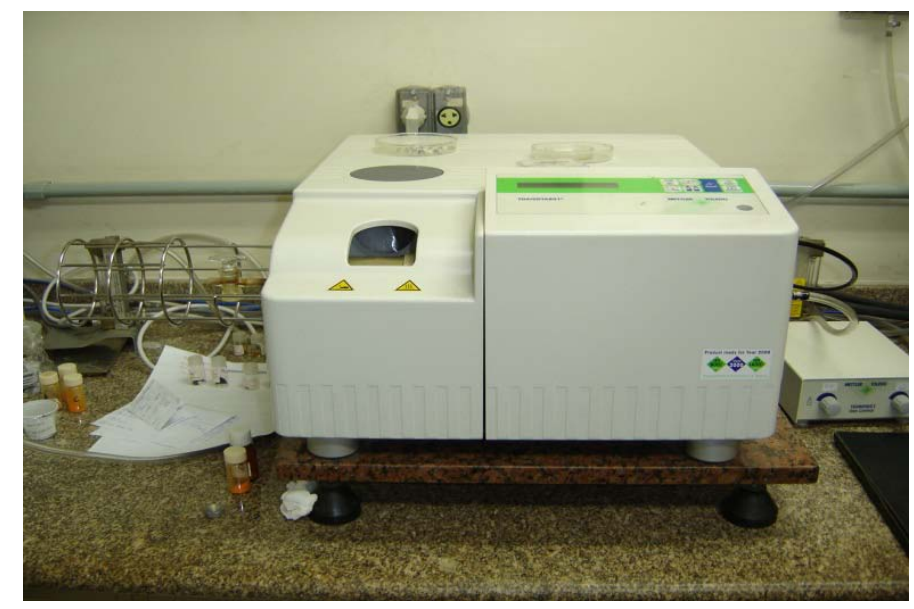

FIGURA 33 - Equipamento da marca Mettler-Toledo - TGA/SDTA 851

\subsubsection{Difração de Raios X (DRX)}

As medidas de difração de Raios $X$ foram efetuadas no modo refletância em um Difratômetro MiniFlex II da Rigaku (Japan), operando em uma voltagem de $30 \mathrm{kV}$ e corrente de $15 \mathrm{~mA}$, com radiação $\mathrm{K} \alpha$ de $\mathrm{Cu}(\lambda=1,541841$ A), FIG. 34.
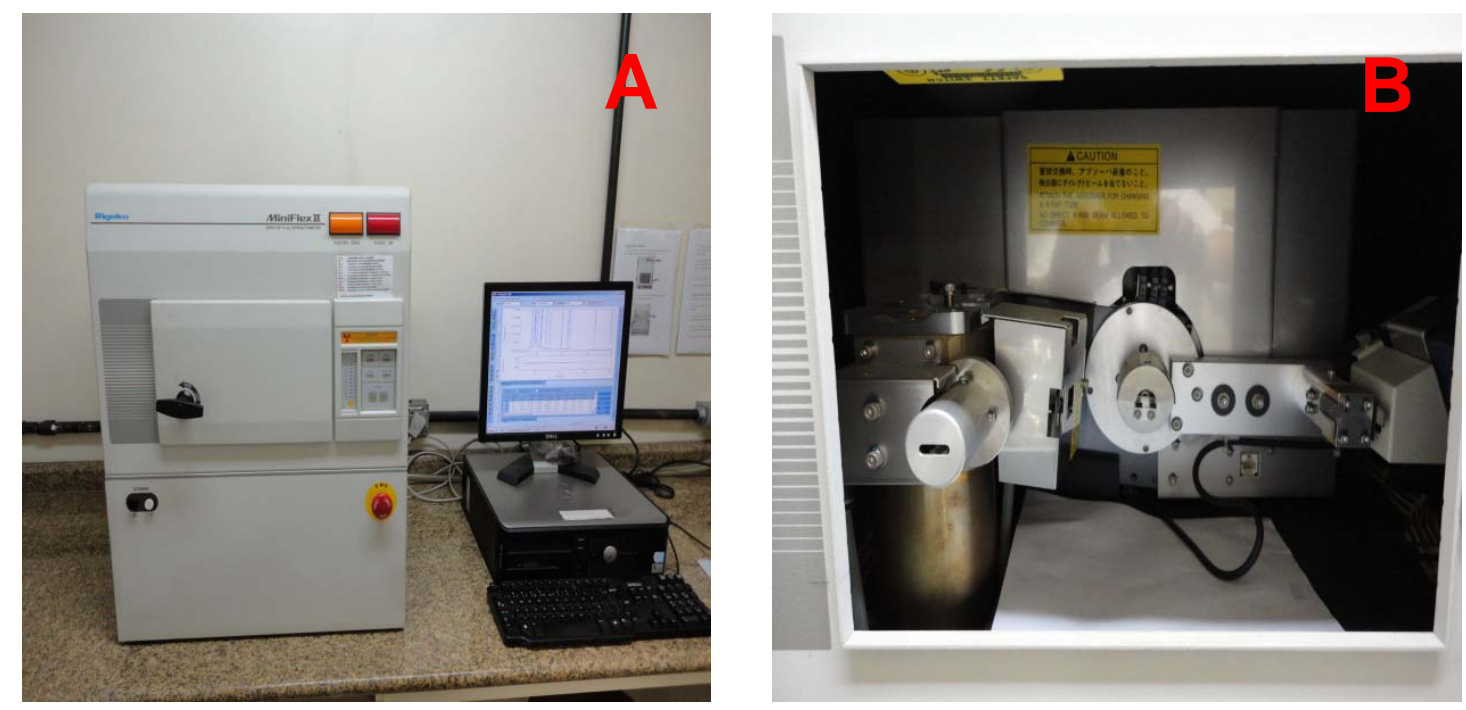

FIGURA 34 - (A) Difratômetro de Raios X marca Rigaku (B) Visão interna do Miniflex II (suporte de amostras) 


\subsubsection{Avaliação da Atividade Bactericida}

\subsubsection{Redução da unidade formadora de colônias (UFC) (\%) - Método 1 UNESC (Universidade do Extremo Sul Catarinense)}

Foi utilizada a norma "JIS Z 2801: $2010^{189}$ (adaptada) - Antimicrobial products. Test for antimicrobial activity and efficacy. JIS Japanese Industrial Standart". Cada um dos micro-organismos utilizados foram ativados das respectivas culturas estoque em meio de cultura apropriado para obtenção dos inóculos. Os micro-organismos testados foram: Staphylococcus aureus (ATCC 6538) e Escherichia coli (ATCC 10536). A suspensão de células obtidas para cada etapa testada foi padronizada a fim de se obter uma concentração final no inóculo de $900 \times 10^{6}$ UFC $\mathrm{mL}^{-1}$.

O procedimento brevemente descrito foi executado separadamente para cada cultura/amostra a ser testada: $100 \mu \mathrm{L}$ de suspensão do inóculo foram inserido sobre o corpo de prova, previamente esterilizado com álcool 70\%, espalhando sobre uma área correspondente a 40×40 $\mathrm{mm}^{2}$. Em seguida foi coberto por uma lamínula estéril e incubado em placa de Petri, estéril, por aproximadamente 4 horas a $37^{\circ} \mathrm{C}$. Após o tempo de incubação procederam-se 5 diluições para possibilitar a contagem das colônias. Para isso, com o auxilio de um swab (cotonete) efetuou-se a limpeza de todo o corpo de prova que teve contato com a suspensão bacteriana, inclusive a lamínula. Para facilitar, utilizaram-se $10 \mathrm{~mL}$ de solução salina 0,9\% para lavar o corpo de prova, com objetivo de efetuar o recolhimento do número máximo possível de células, correspondendo à $1^{\mathrm{a}}$ diluição. Em seguida, cortou-se a ponta do cotonete e juntamente com a solução salina $0,9 \%$, colocou-se em um tubo de ensaio a agitou-se em vórtex por aproximadamente 30 segundos. Posteriormente foram realizadas mais 4 diluições, 10x, 100x, 1000x e 10000x, respectivamente. Para cada diluição realizou-se o plaqueamento utilizando-se placa de Petri contendo ágar PCA e a incubação em estufa a $37^{\circ} \mathrm{C}$ por 24 horas. 
O percentual da redução do crescimento bacteriano foi calculado a partir da quantidade de bactérias sobreviventes encontrada na placa de Petri após a incubação por 24 horas a $37^{\circ} \mathrm{C}$ multiplicado pelo valor da diluição e comparouse com o número de colônias da amostra controle. Esta metodologia foi utilizada em amostras de géis e de polipropileno processado com NPsAg.

\subsubsection{Redução da unidade formadora de colônias (UFC) (\%) - Método 2 (ICB - Instituto de Ciências Biológicas - USP)}

Para testar a atividade bactericida dos filmes de polipropileno com NPsAg, realizou-se o procedimento a partir da unidade formadora de colônias UFC. As colônias individuais das cepas de $P$. aeruginosa e $S$. aureus foram suspensas em meio nutritivo - Müeller-Hinton deixando-as crescendo no período de 2 horas, em seguida foram feitas lavagens das bactérias com o uso de tampão isotônico de glicose/fosfato - IGP $1 \mathrm{mM}$ com o objetivo de manter as bactérias "vivas". Na sequência, a suspensão das colônias foi levada à concentração de $1 \times 10^{5}$ UFC $\mathrm{mL}^{-1}$, a partir da escala 0,5 de McFarland, $\left(1 \times 10^{8}\right.$ UFC $\left.\mathrm{mL}^{-1}\right)$.

A partir da concentração final $\left(1 \times 10^{5}\right.$ UFC $\left.\mathrm{mL}^{-1}\right)$ 0,06 mL da suspensão de cada uma das bactérias foram adicionados sobre cada um dos filmes com NPsAg. Em seguida foi feita a diluição seriada onde $0,1 \mathrm{~mL}$ de cada diluição foram espalhados em placas contendo ágar Müeller-Hinton (MHA), com auxílio de alça de Drigalsky, incubando-se por 24 horas a $37{ }^{\circ} \mathrm{C}$, na presença de $\mathrm{O}_{2}$ para controle da contagem de colônias.

Após 24 horas, foi colhida uma alíquota de 0,01 $\mathrm{mL}$ das amostras de $P$. aeruginosa e $S$. aureus e novamente realizaram-se diluições 1:100 que foram semeadas, cada diluição, em placas com ágar Müeller-Hinton com auxilio da alça de Drigalsky. Incubou-se na estufa bacteriológica a $37^{\circ} \mathrm{C}$ por 24 horas. Esta metodologia foi utilizada em amostras de géis e filmes de polipropileno processados com NPsAg, sendo que, apenas para amostras de filmes de polipropileno com NPsAg foi possível a realização do teste. 


\subsubsection{Teste de sensibilidade a antimicrobianos por disco de difusão - Método de Kirby-Bauer - Método 3 (ICB - Instítuto de Ciências Biológicas - USP)}

O objetivo do ensaio é avaliar resultados de difusão das NPsAg contidas nos filmes de polipropileno, utilizando-se os procedimentos padronizados pelo NCCLS - National Commitee for Clinical Laboratory Standard e ANVISA ${ }^{190}$.

Bactérias e Preparação do inóculo: As amostras bacterianas para 0 ensaio foram P. aeruginosa (Gram - negativa) ATCC 25923 e S. aureus (Gram positiva) ATCC 27853. As colônias foram suspensas em meio nutritivo (MüellerHinton) até se obter uma concentração de 0,5 da escala MacFarland $\left(1 \times 10^{8}\right.$ UFC $\left.\mathrm{mL}^{-1}\right)$.

Com um cotonete estéril embebido no caldo realizou-se a semeadura em todas as direções na placa com ágar Müeller-Hinton, após a secagem da superfície do ágar as amostras com prata e o controle (sem prata) foram adicionados sobre a superfície do meio inoculado. As placas foram incubadas em estufa bacteriológica a $37{ }^{\circ} \mathrm{C}$ pelo período de 18 a 24 horas. Para obter um controle positivo utilizou-se o teste de sensibilidade antimicrobiano, com as mesmas cepas, com disco de antibiótico (CIP 5) Ciprofloxacina, em que $P$. aeruginosa e S. aureus possuem sensibilidade. Esta metodologia foi utilizada em filmes de polipropileno com NPsAg.

\subsubsection{Teste de Citotoxicidade}

O teste foi realizado com base na International Standard Organization (ISO 10993) $^{191}$ e na literatura ${ }^{192}$, por método de incorporação de vermelho neutro. O ensaio foi realizado a partir do uso da linhagem celular: NCTC Clone 929, da American Type Culture Collection (ATCC). O cultivo em meio mínimo de Eagle (MEM) suplementado com $10 \%$ de soro fetal bovino (SFB) e 0,1 mM de piruvato de sódio (MEM-uso). Polietileno de alta densidade (HDPE) foi utilizado como controle negativo e filme de látex de borracha natural, como controle positivo 
(tóxico às células). Em placa de poços foram distribuídos $200 \mu \mathrm{L}$ da suspensão celular contendo $\left(5 \times 10^{5}\right.$ células $\left.\mathrm{mL}^{-1}\right)$ em cada poço e a placa foi incubada em estufa úmida a $37^{\circ} \mathrm{C}$ com $5 \%$ de $\mathrm{CO}_{2}$ por 24 horas.

As amostras e os extratos controle foram preparados por imersão em MEM-uso e incubadas durante 24 horas a $37^{\circ} \mathrm{C}\left(1 \mathrm{~cm}^{2} \mathrm{~mL}^{-1}\right)$. A diluição em série foi feita para se obter as seguintes diluições: 100; 50; 25; 12,5 e 6,25 \%. O meio de cultura da microplaca foi substituído por extratos diluídos de controles e amostras, em triplicatas. As microplacas foram incubadas em meio de $\mathrm{CO}_{2}$ por 24 horas. Os extratos foram substituídos por solução de vermelho neutro e a placa foi incubada por 3 horas. Depois, a microplaca foi lavada duas vezes com PBS e uma vez com solução de lavagem e cada poço recebeu $200 \mu \mathrm{L}$ de solução de extração. As absorbâncias foram lidas em leitor de ELISA, Sunrise-Tecan em 540 $\mathrm{nm}$ com filtro de referência $620 \mathrm{~nm}$ e as porcentagens de viabilidade celular foram calculadas em relação ao controle de células ${ }^{193}$. 


\section{RESULTADOS E DISCUSSÃO}

\subsection{Géis de Polipropileno}

\subsubsection{Fração Gel/Fração Sol e Índice de Fluidez do Fundido (MFI)}

Os resultados da fração gel e do índice de fluidez estão apresentados na TAB.4.

TABELA 4 - Conteúdo de gel e índice de fluidez das amostras de iPP e PP modificado

\begin{tabular}{lcc}
\hline Amostras & Fração Gel (\%) & Índice de Fluidez $\left(\mathrm{dg} \mathrm{\text {min } ^ { - 1 } )}\right.$ \\
\hline 1 - IPP & 1,14 & 1,5 \\
2 - PP 5 kGy & 1,01 & 0,9 \\
3 - PP 12,5 kGy & 2,27 & 0,9 \\
4 - PP 20 kGy & 16,00 & 0,5 \\
\hline
\end{tabular}

Observa-se o aumento abrupto do teor percentual de gel conforme o aumento da dose de irradiação das amostras. Nas amostras 2 e 3 houve um decréscimo na média dos valores de índice de fluidez passando a 0,9 dg $\mathrm{min}^{-1} \mathrm{e}$ para PP $20 \mathrm{kGy}$ o menor valor, 0,5 dg $\mathrm{min}^{-1}$, cujo indicativo é de reticulação do material.

\subsubsection{Microscopia Óptica (MO)}

A análise por microscopia óptica com luz polarizada foi realizada na fração sol seca, isto é, a parte solúvel das amostras que formaram uma película de gel depositada sobre o substrato de vidro pelo processo de sedimentação chamado "settling". 

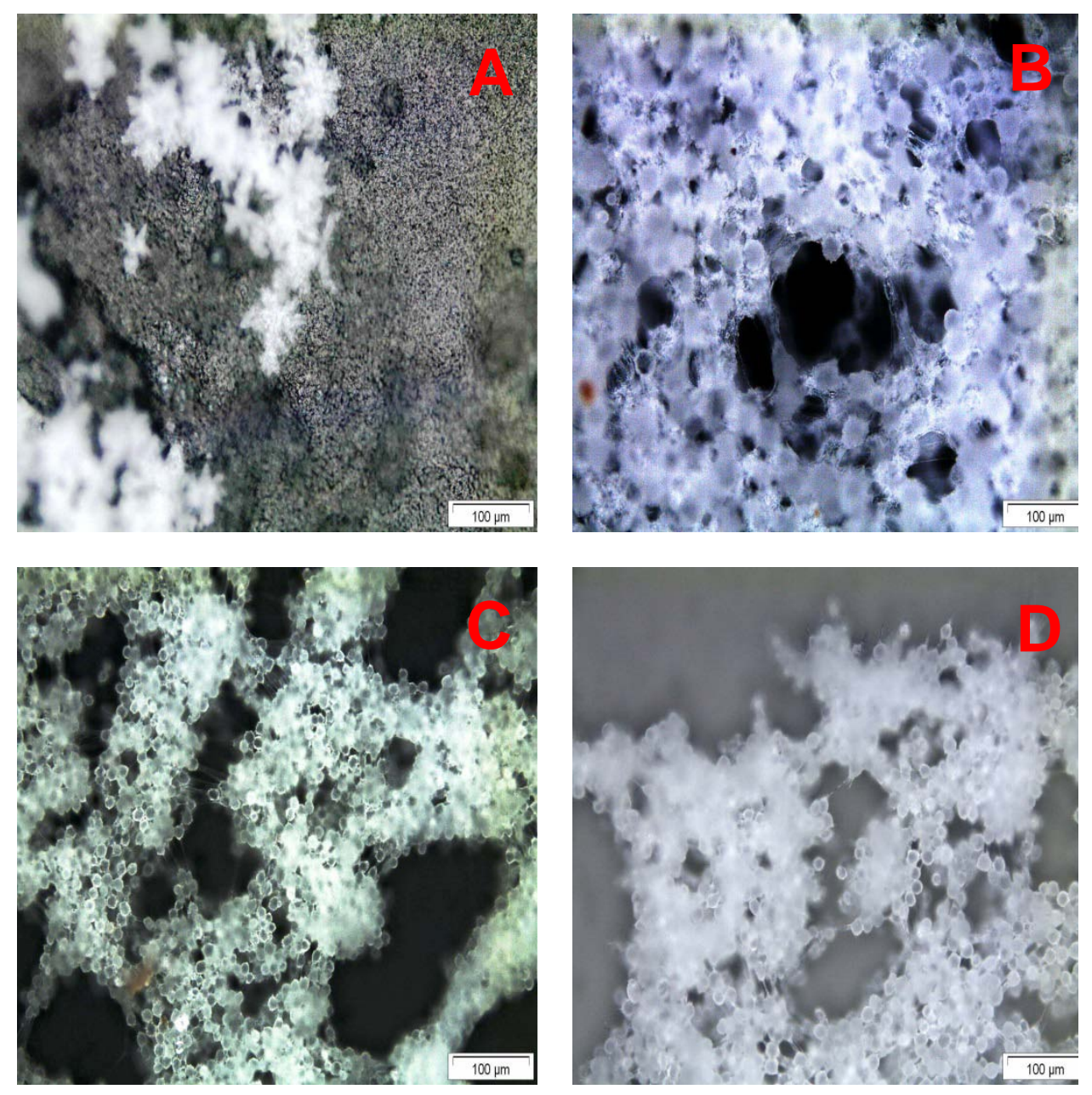

FIGURA 35 - Fotomicrografias obtidas por MO de géis de polipropileno: A) Pristine, B) PP 5 kGy, C) PP 12,5 kGy e D) PP 20 kGy, escala=100 $\mu \mathrm{m}$

O exemplo apresentado na FIG. 35 (A) mostra esferulitos irregulares ou

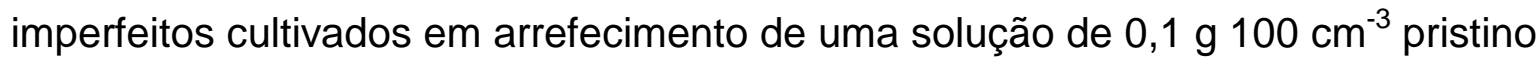
PP em xileno ${ }^{194,182}$. Na FIG. 35 (B) - (D), existe uma elevada concentração de esferulitos com forma esférica obtida da mesma maneira, indicativo da presença de microgéis de polipropileno. Em um trabalho semelhante Nedkrov et al. ${ }^{195}$ em uma película fina obtida a partir de solução descobriram esferulitos de PP não irradiado e irradiado. O PP irradiado quando cristalizado em solução sob condições não isotérmica tende a formar facilmente agregados lamelares esféricos com diferentes tamanhos. 
5.1.3 Microscopia Eletrônica de Varredura (MEV) da Fração Gel/Fração Sol

\subsubsection{MEV da Fração Gel}

A visualização de microgéis pode ser realizada por várias técnicas microscópicas, dentre elas o MEV, que é uma técnica importante para o estudo de estruturas mais complexas de microgéis, multicamadas e de características superficiais dos géis ${ }^{196}$. 

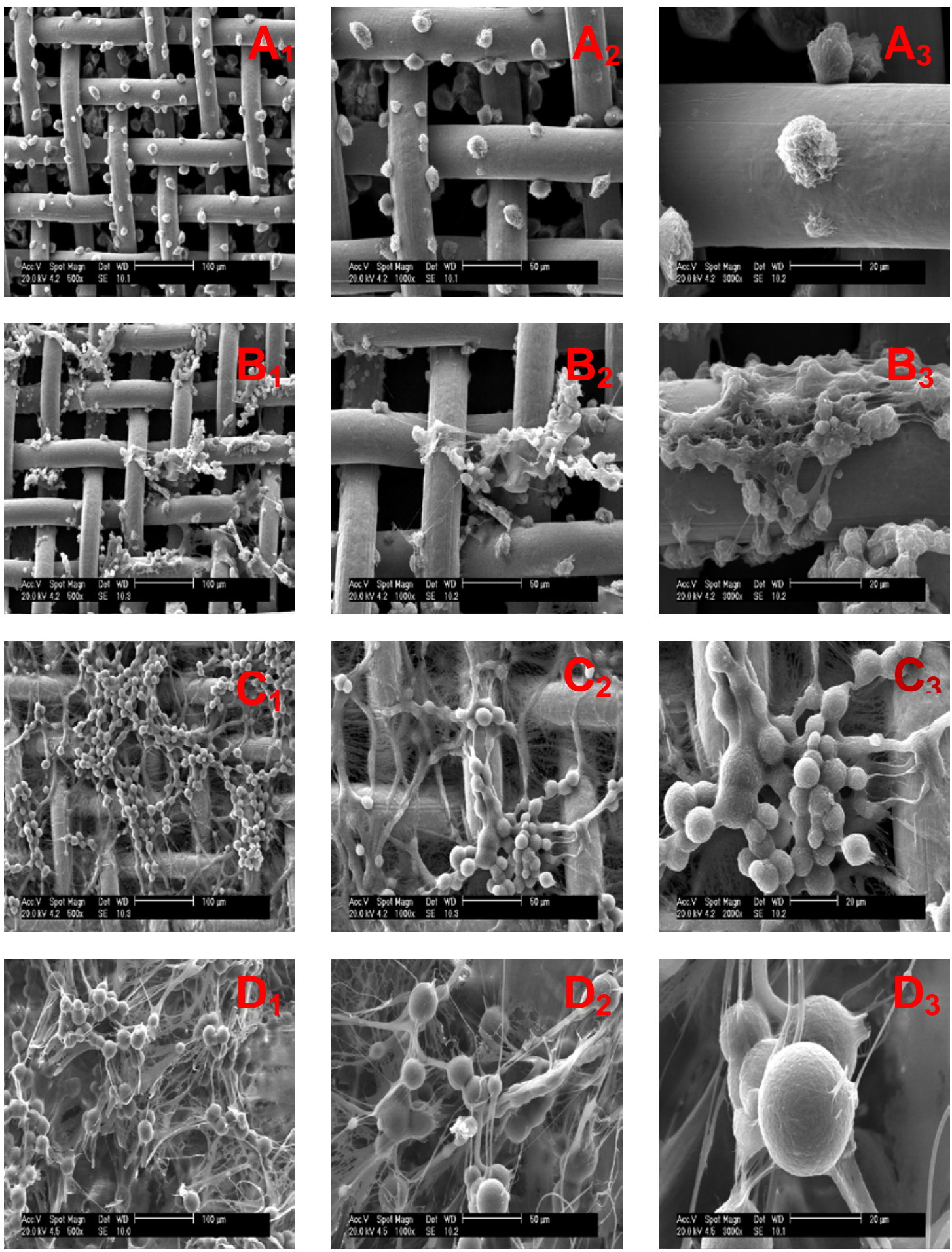

FIGURA 36 - MEV de géis de polipropileno em tela de aço inoxidável: A) iPP, B) 5 kGy, C) PP 12,5 kGy e D) 20 kGy. Índice (1) barra de 100 m; índice (2) barra de $50 \mu \mathrm{m}$ e índice (3) barra de $20 \mu \mathrm{m}$ 
Na FIG. 36 está representada a fração gel das amostras de PP depositada em uma malha de aço inoxidável de 500 mesh.
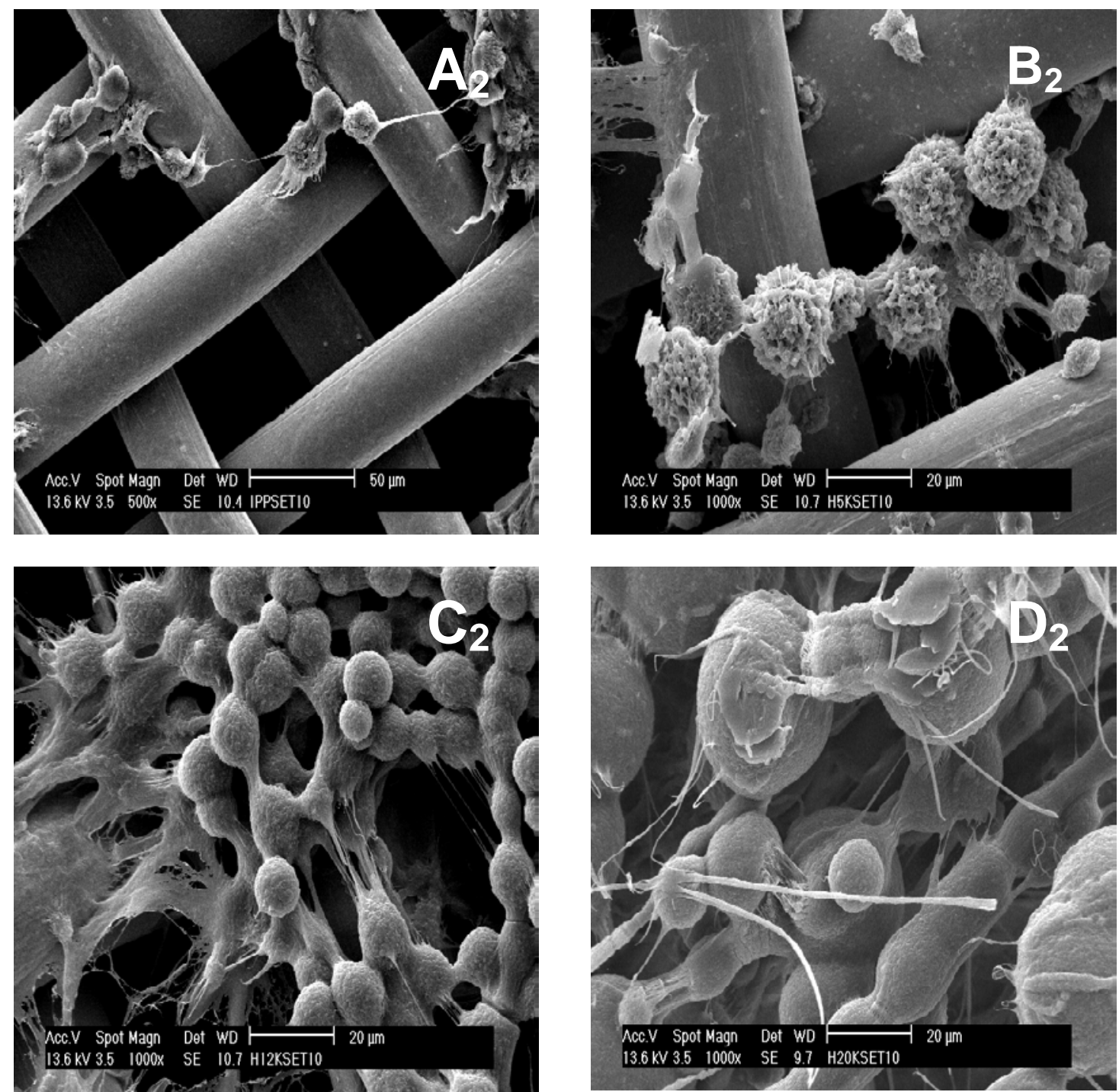

FIGURA 37 - MEV de géis de polipropileno em tela de aço inoxidável: $A_{2}$ ) iPP,

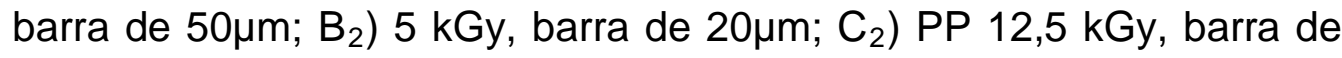

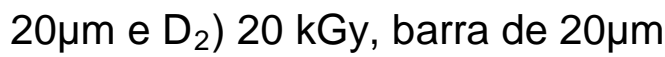

Constatou-se que a fração gel da amostra de PP 20 kGy é a maior sendo seguida pela PP 12,5 kGy, superiores a iPP e PP 5 kGy, ou seja, o material está mais reticulado e com muitas fibrilas interligando os esferulitos retidos na malha de aço da amostra PP 20 kGy, conforme FIG. $37 D_{2}$. 


\subsubsection{MEV da Fração Sol (Sob Agitação)}

A FIG. 38 representa a fração sol que consiste na parte solúvel do PP, cuja solução foi depositada em finas lâminas de vidro com gradual volatilização de todo o solvente. Neste caso foi utilizada uma mesa agitadora microprocessada (Quimis) com controle de agitação (40 rpm). 

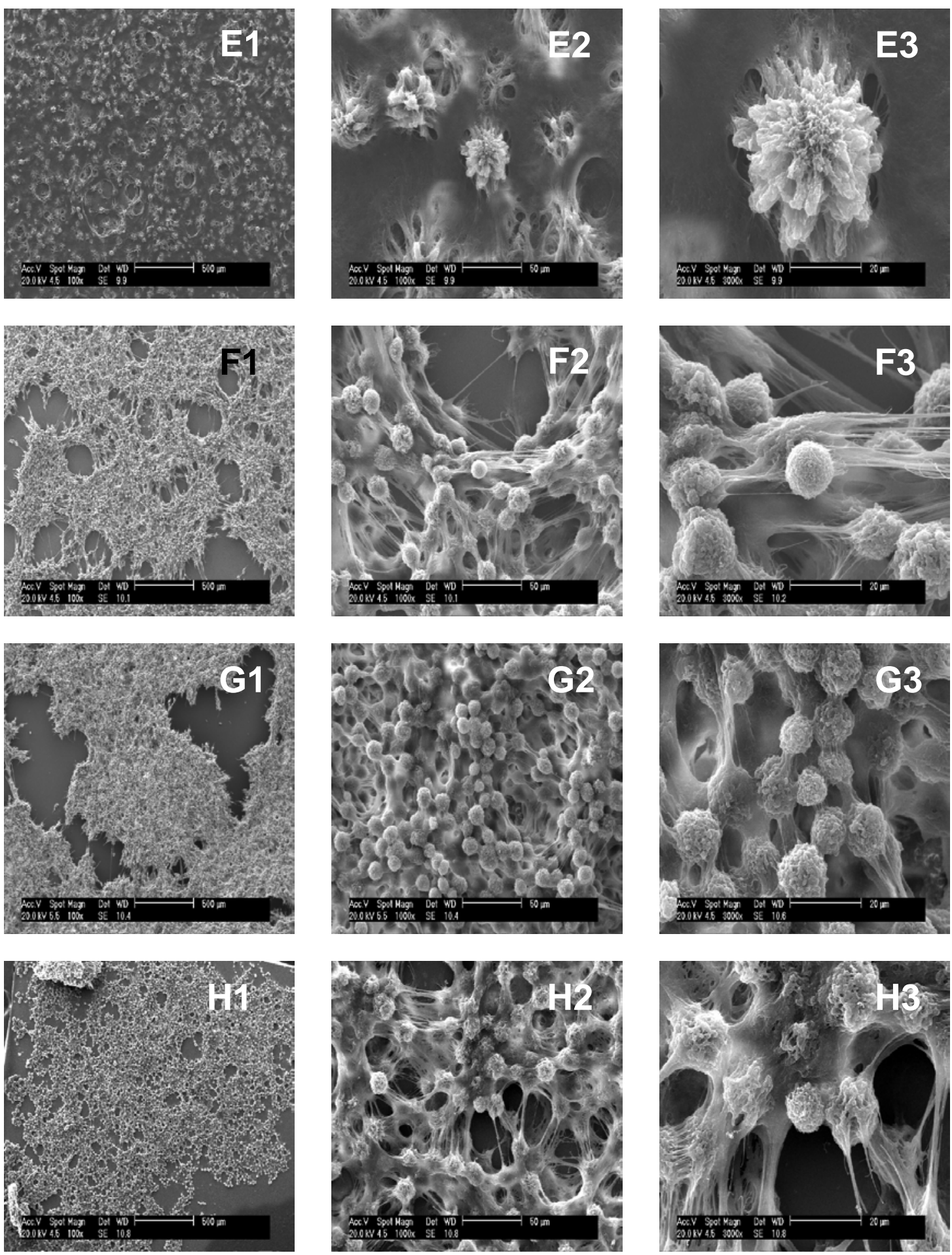

FIGURA 38 - MEV de géis de polipropileno em substrato de vidro: E) iPP, F) PP 5

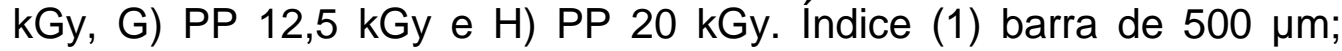
índice (2) barra de $50 \mu \mathrm{m}$ e índice (3) barra de $20 \mu \mathrm{m}$ 
Observa-se o aumento da concentração de estruturas esféricas que são esferulitos (microgéis), conforme se aumenta a dose de irradiação das amostras. As estruturas esféricas são microgéis de esferulitos que se apresentam interligados por fibrilas, constituídas por fases amorfa e cristalina. Essa ligação se processa por meio de moléculas de interligação também chamadas de "tie molecules", formando uma estrutura tridimensional. O tamanho dos esferulitos formados foi influenciado pelo processo de irradiação com o qual foi obtido o PP modificado (HMSPP).

\subsubsection{MEV da Fração Sol (Sem Agitação)}

A FIG. 39 representa a fração sol do PP, cuja solução foi depositada em finas lâminas de vidro com gradual volatilização de todo o solvente. 

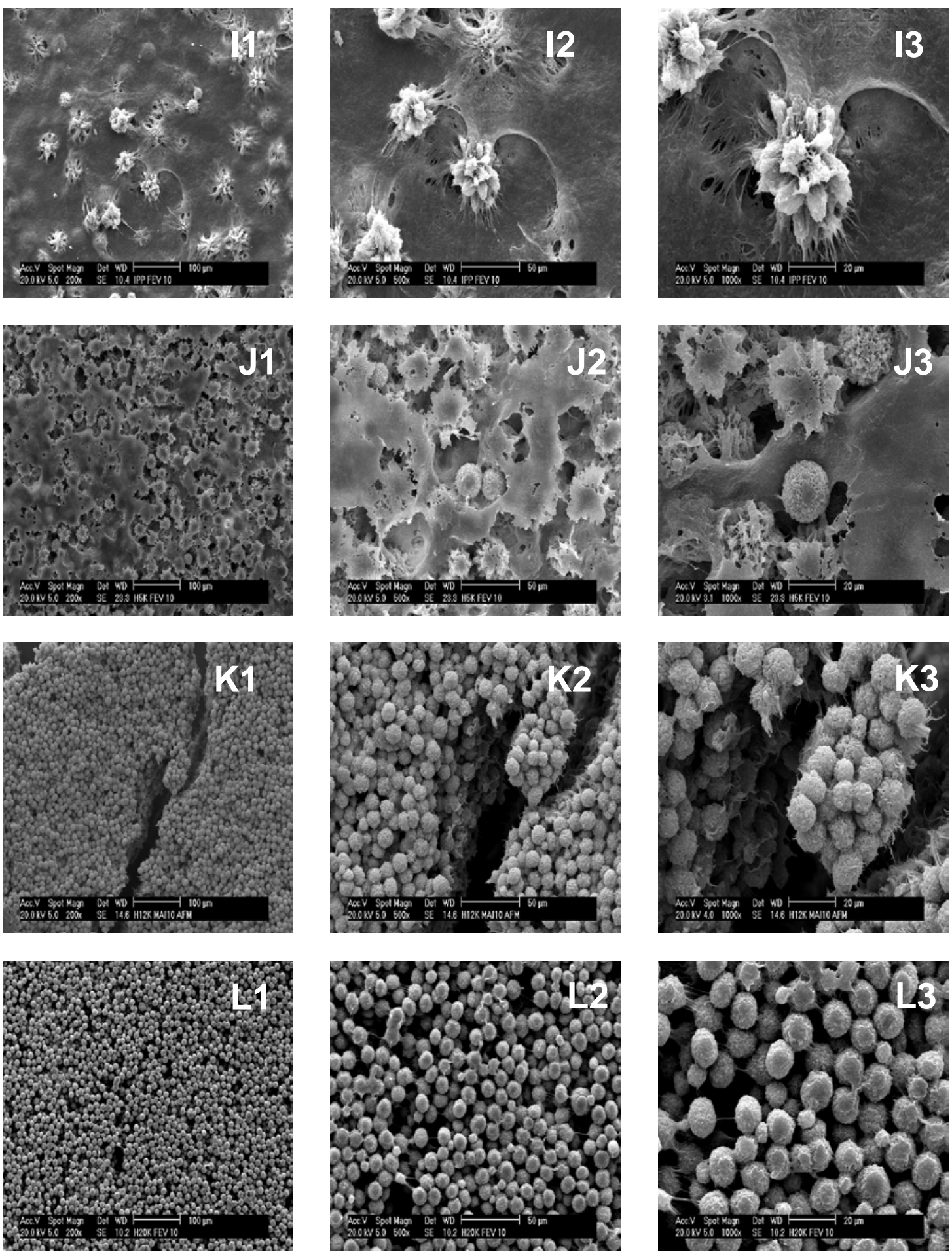

FIGURA 39 - MEV de géis de polipropileno em substrato de vidro: I) iPP, J) PP 5 kGy, K) PP 12,5 kGy e L) PP 20 kGy. Índice (1) barra de 100 m; índice (2) barra de $50 \mu \mathrm{m}$ e índice (3) barra de $20 \mu \mathrm{m}$

Observa-se na FIG. 39 (I), a formação de filmes finos em torno de poucos esferulitos, também em (J), em doses baixas a organização dos 
esferulitos é deficiente. Quando as amostras são expostas a doses maiores de radiação (12,5 kGy e 20 kGy) observa-se nas FIG. 39 (K-L), que devido ao efeito de nucleação, são formados muito esferulitos os quais podemos afirmar que são microgéis de polipropileno.

\subsubsection{Espectroscopia no Infravermelho (FT-IR)}

A espectroscopia de infravermelho, IR, é o método mais sensível e versátil para acompanhar modificações químicas em um material polimérico. Modificações que envolvem grupos oxidados aparecem no espectro de IR como uma banda intensa, por volta de $1700 \mathrm{~cm}^{-1}$ atribuída à vibração da ligação $\mathrm{C}=\mathrm{O}$ de cetonas (estiramento) ${ }^{197}$. Estudos realizados por alguns pesquisadores ${ }^{198,199}$ apresentaram a formação de grupos carbonílicos com absorção máxima entre $1755 \mathrm{~cm}^{-1}$ e $1714 \mathrm{~cm}^{-1}$ acompanhada de fraca absorção próximo de $1780 \mathrm{~cm}^{-1}$. Campbell et al. ${ }^{200}$ estabeleceram uma faixa ainda maior de modos de vibração característicos em polímeros, no caso de estiramento de grupos carbonílicos, ou seja, $1820-1680 \mathrm{~cm}^{-1}$.

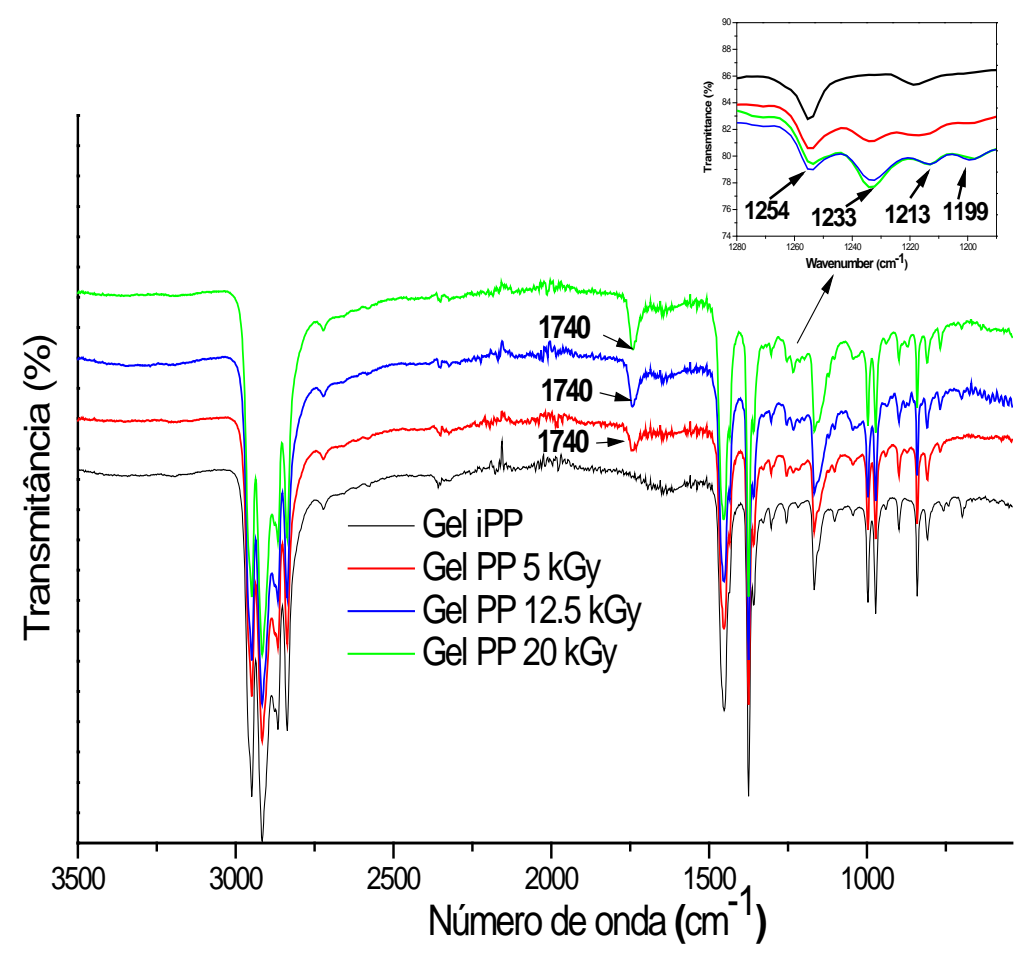

FIGURA 40 - Espectros de FTIR-ATR, de géis de polipropileno 
A vibração da ligação $\mathrm{C}=\mathrm{O}$ atribuída ao estiramento de grupos carbonílicos de produtos oxidados aparece no espectro de IR como uma banda intensa, por volta de $1740 \mathrm{~cm}^{-1}$, conforme indicado na FIG. 40. Como esta banda só aparece nas amostras modificadas, a irradiação em atmosfera de acetileno permitiu a formação de grupos oxidados a partir de reações de cisão de cadeia em consequência de presença mínima de oxigênio. Diferentemente da amostra pura, o espectro de PP modificado apresentou três picos de absorção em 1233, 1213 e $1199 \mathrm{~cm}^{-1}$, respectivamente. Estas bandas fracas foram atribuídas ao modo de deformação $(=\mathrm{CH} 2)$ de grupos de vinila. Conforme descrito por Jones \& Ward ${ }^{201}$ grupos vinílicos são formados como uma reação em cadeia na fase amorfa do PE irradiado em acetileno e são prováveis pontos de nucleação.

\subsubsection{Microscopia Eletrônica de Varredura com Emissão de Campo (MEV-EC)}

As FIG. 41 e 42 representam a fração sol, cuja solução foi depositada em finas lâminas de vidro com gradual volatilização de todo o solvente.

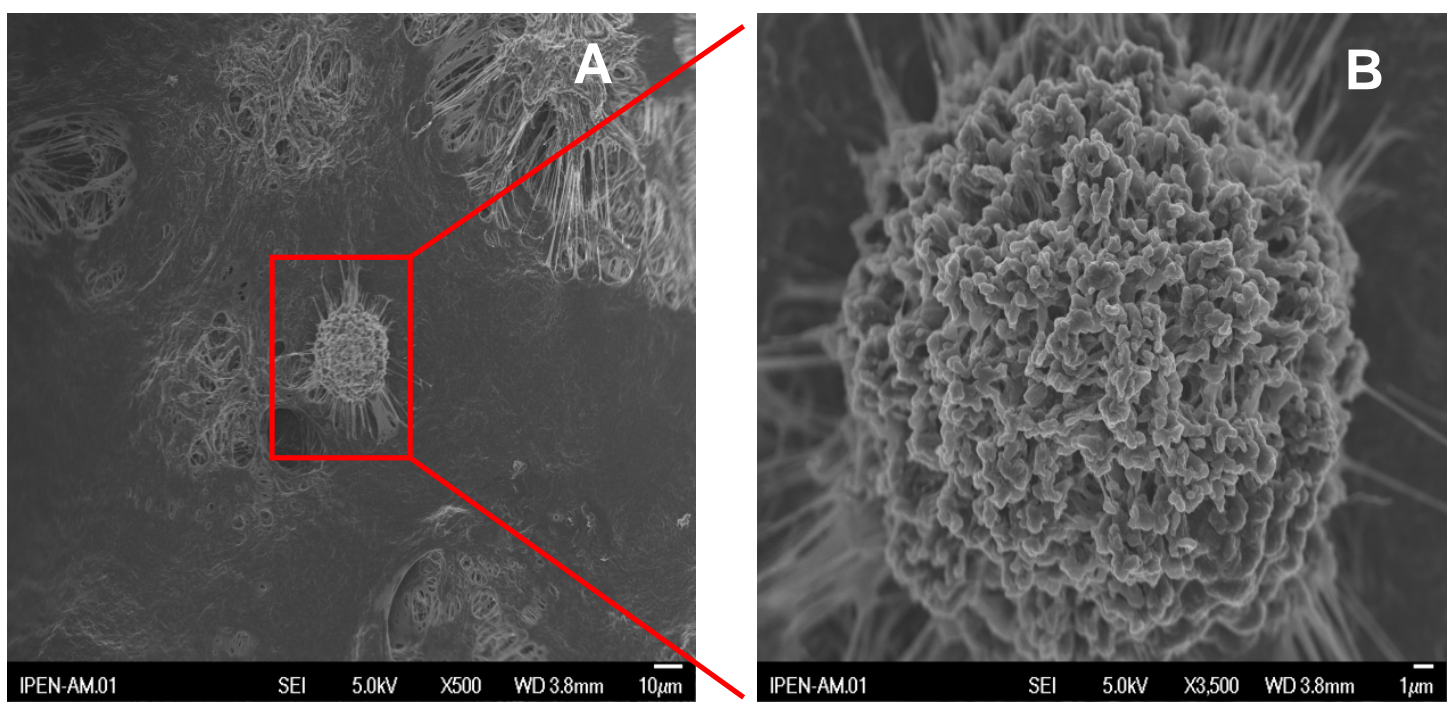

FIGURA 41 - Imagem MEV-EC em amostra de Gel de iPP. A) barra de $10 \mu \mathrm{m}$ e B) $1 \mu \mathrm{m}$

Na FIG. 41 A e B, está apresentado um esferulito na forma de gel com aproximadamente $28 \mu \mathrm{m}$ de câmetro, obtido de uma amostr a da fração sol do iPP solubilizado. 

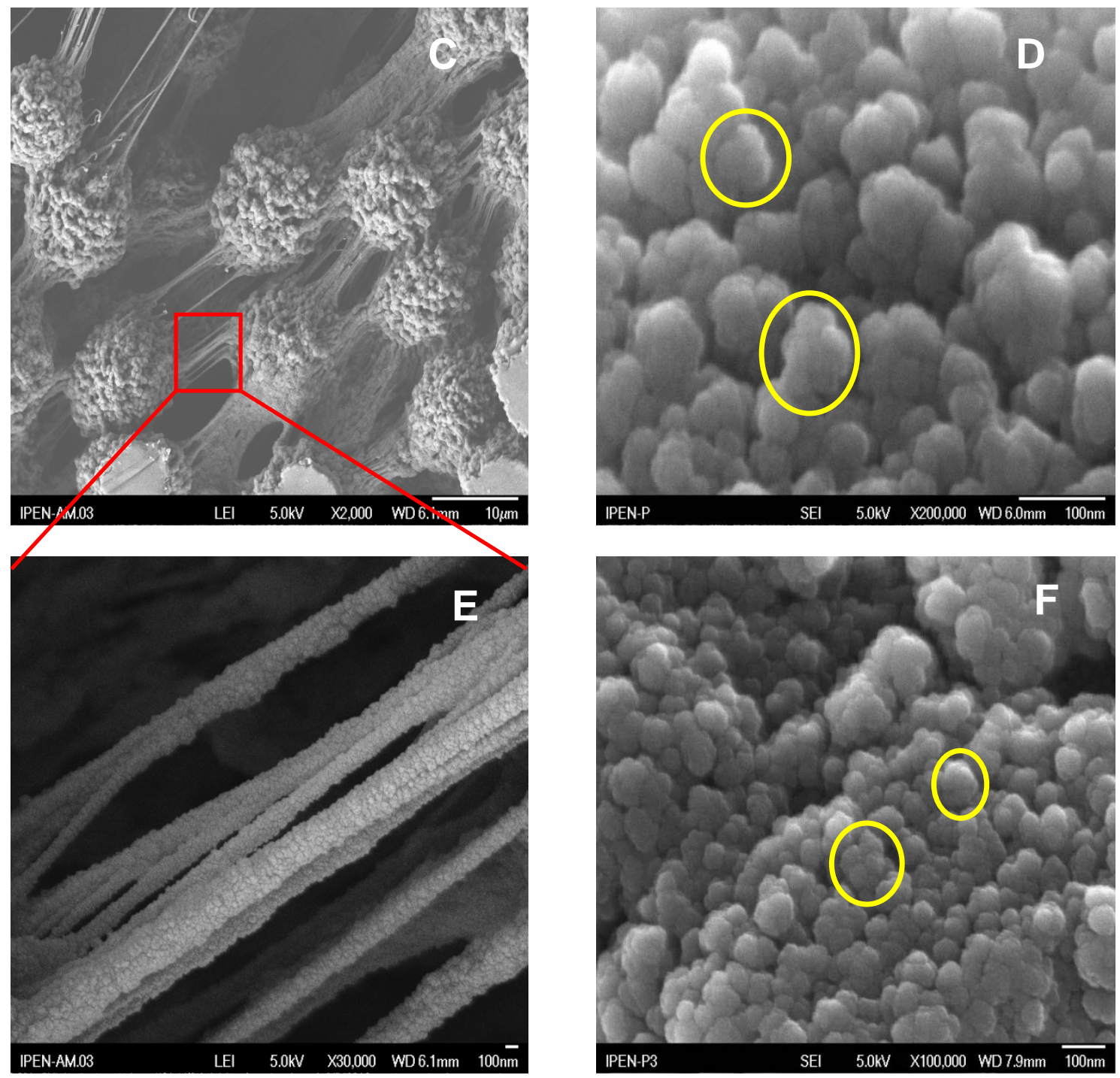

FIGURA 42 - Imagens MEV-EC da formação de nanogéis em filmes finos de polipropileno, Fs = fração solúvel do PP modificado. C) Microgéis de

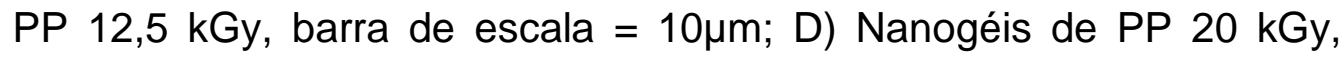
barra de escala = $100 \mathrm{~nm}$; E) Nanofibras de PP 12,5 kGy, barra de escala =100 nm; F) Nanogéis de PP 12,5 kGy, barra de escala $=100$ $\mathrm{nm}$

Nas FIG. 42D e F, observam-se estruturas nanométricas de géis PP com o diâmetro de cada unidade variando entre 42 a $50 \mathrm{~nm}$, obtidas de uma amostra da fração sol do PP modificado com 20 e 12,5 kGy. A FIG. 42C apresenta esferulitos com diâmetro de 10m ligados por nanofibras e com a ampliação temos a FIG. 42E com detalhes das nanofibras, que apresentam um diâmetro aproximado de $200 \mathrm{~nm}$. 
Nanogéis de polipropileno são estruturas nanométricas. São obtidos por irradiação e foram constatados nas doses de 12,5 e 20 kGy. Os nanogéis são formações reticuladas, ramificadas, e emaranhadas, nucleadas em regiões de incidência de alta concentração de energia (spurs) em uma amostra irradiada.

\subsubsection{Calorimetria Exploratória Diferencial (DSC)}

Os resultados de DSC das amostras de géis de iPP e PP irradiados estão ilustrados nas FIG. 43 e 44.

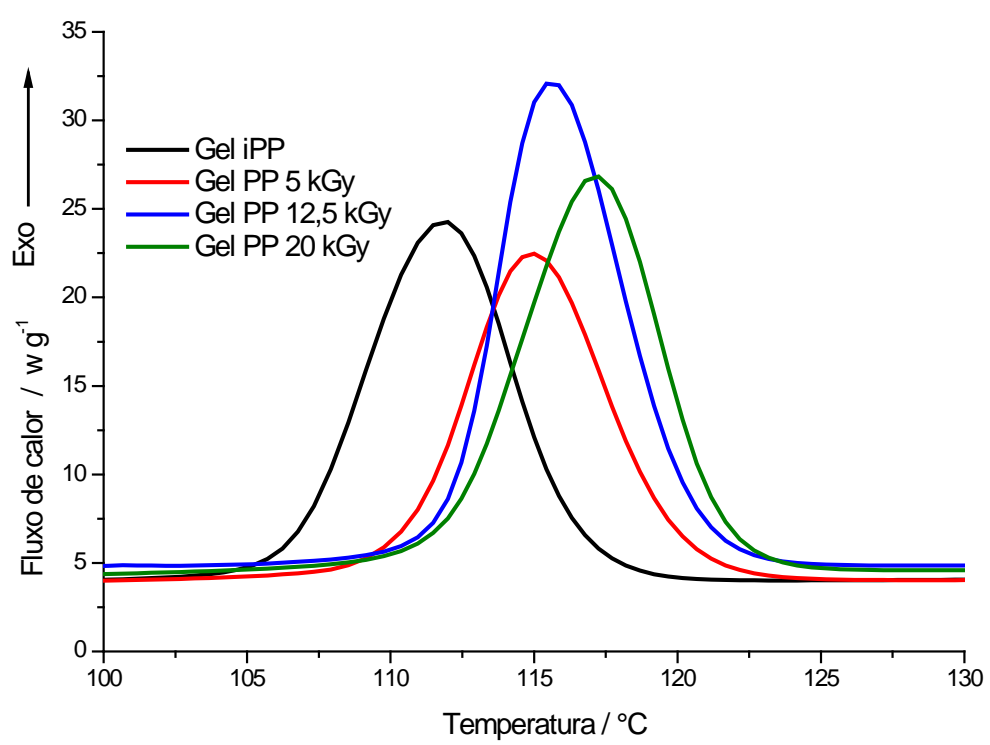

FIGURA 43 - DSC curvas de cristalização do Gel iPP; Gel PP 5kGy; Gel PP 12,5kGy e Gel PP 20kGy (resfriamento), aquecimento a $10{ }^{\circ} \mathrm{C} \mathrm{min}^{-1}$ 


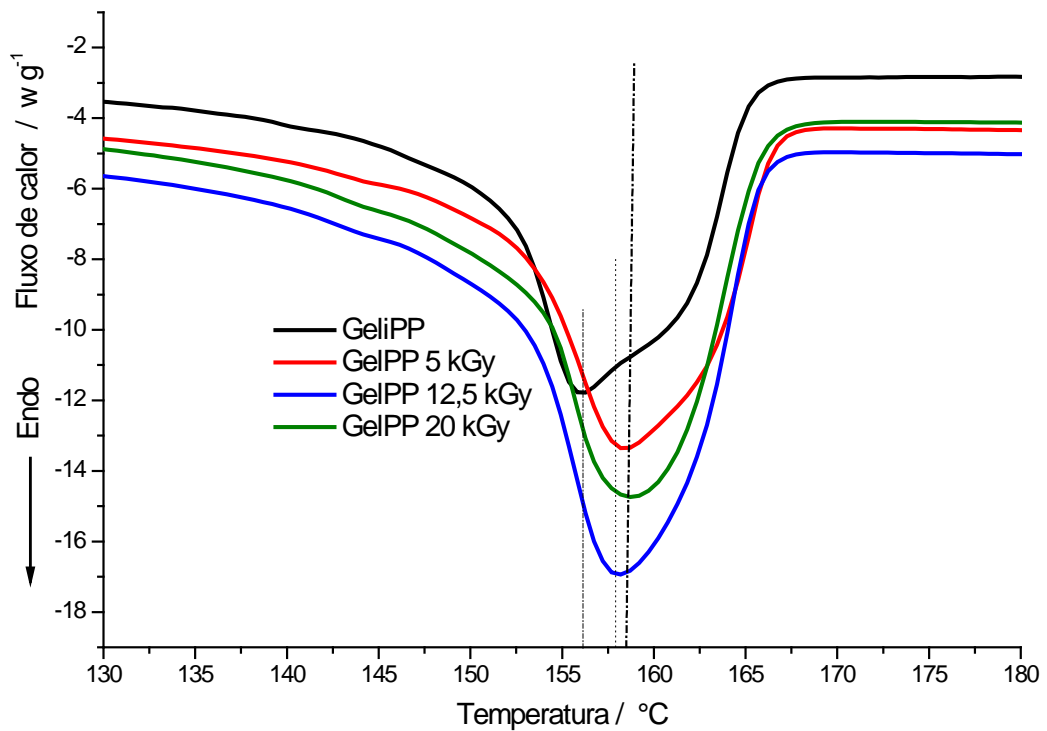

FIGURA 44 - DSC de Gel de PP obtido com diferentes doses de irradiação, no decurso da fusão no reaquecimento, aquecimento a $10{ }^{\circ} \mathrm{C} \mathrm{min}^{-1}$

Os resultados da temperatura de cristalização, temperatura de fusão e cristalinidade estão apresentados na TAB.5.

TABELA 5 - Valores obtidos na análise de DSC, temperatura de cristalização $\left(T_{C}\right)$, temperatura de fusão $\left(T_{m 2}\right)$ e cristalinidade $\left(X_{C}\right)( \pm 5 \%)$, das amostras de géis de iPP e PP modificado

\begin{tabular}{llll}
\hline Amostras & $\mathrm{Tc}\left({ }^{\circ} \mathrm{C}\right)$ & $\mathrm{Tm}_{2}\left({ }^{\circ} \mathrm{C}\right)$ & $\mathrm{Xc}(\%)$ \\
\hline GeliPP & 111,8 & 156,3 & 43,0 \\
GelPP 5 kGy & 115,4 & 158,5 & 44,7 \\
GelPP 12,5 kGy & 116,5 & 158,2 & 45,6 \\
GelPP 20 kGy & 117,3 & 158,8 & 42,1 \\
\hline
\end{tabular}

A TAB.5 refere-se ao cálculo de cristalinidade, observa-se que as temperaturas para as amostras pristine, indicado como iPP, são inferiores aos correspondentes para as amostras irradiadas. A cristalinidade do PP irradiado com 20 kGy é o único valor inferior ao do iPP. 
As micrografias MEV mostraram uma diferença significativa entre as amostras pura e modificada de PP. A radiação é responsável pela formação de núcleos de cristalitos com a evolução subsequente de uma rede de esferulitos. Por outro lado, no iPP puro existem poucos núcleos, resultantes do emaranhamento e praticamente não há esferulitos. Outra razão para a ausência de esferulitos nesta amostra é a baixa temperatura de cristalização que dificulta o arranjo dos cristais grandes e pequenos para formá-los. Essa diferença no tamanho dos cristais pode ser vista na curva de fusão, que apresenta um pico e um ombro em temperatura mais elevada. Nas amostras irradiadas os cristalitos reorganizam-se para formar esferulitos.

A respeito da cristalinidade das amostras é sabido que a cisão de cadeias favorece esta propriedade. Este efeito pode ser observado na TAB. 5 para doses baixas. Por outro lado, a cristalinidade diminui para a amostra de 20 kGy, devido ao efeito de aumento de reticulação, confirmado pelo valor de $16 \%$ obtido pela fração gel, TAB. 4.

Finalmente, a menor temperatura de fusão da amostra iPP denota a existência de cristalitos pequenos e imperfeitos, mas também há cristalitos maiores e perfeitos, correspondentes ao ombro em $160,5{ }^{\circ} \mathrm{C}$ na FIG. 44. A temperatura de fusão mais elevada $\left(158,2\right.$ a $\left.158,8{ }^{\circ} \mathrm{C}\right)$ para as amostras irradiadas denota cristais maiores e mais perfeitos do que os cristais correspondentes à amostra pura.

\subsubsection{Difração de Raios X (DRX)}

As curvas de difração de raios-X, FIG. 45, indicam a contribuição de duas fases, cristalina e amorfa. Os picos da fase cristalina são identificados pelos índices de Miller e correspondem à estrutura cristalina $\alpha$ cuja célula unitária monoclínica apresenta $\left(a=6,66 ; b=20,78 ; c=6,495 \AA\right.$ e $\left.\beta=99,6^{\circ}\right)$, de acordo com Burgt $^{202}$. 


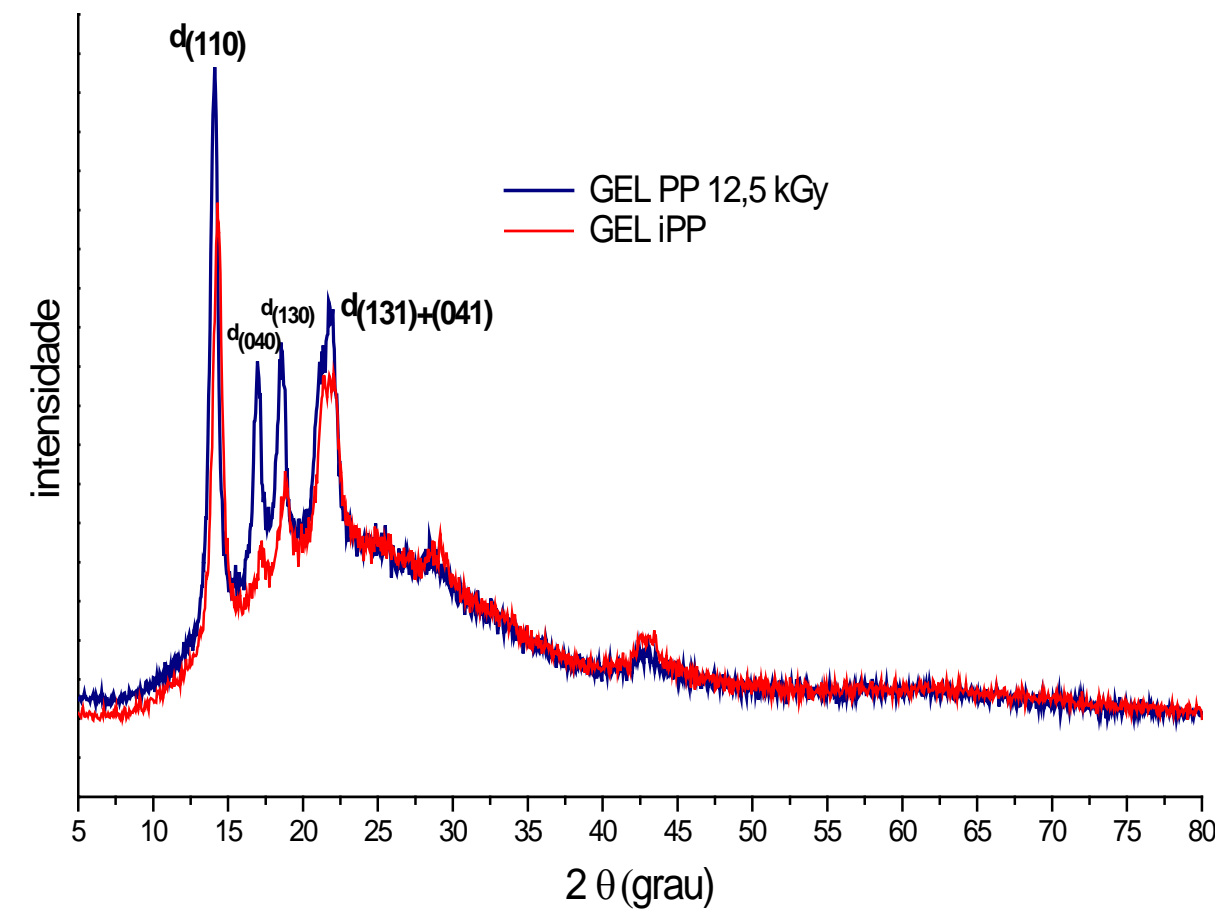

FIGURA 45 - Difração de Raios-X de gel de polipropileno e gel PP 12,5 kGy

Os ângulos de difração, FIG. 45, estão associados às distâncias interplanares: $d_{(110)}=6,28 \AA, d_{(040)}=5,18 \AA, d_{(130)}=4,74 \AA$ e d $_{(131)+(041)}=4,06 \AA$.

\subsection{Géis com Nanopartículas de Prata (NPsAg)}

5.2.1 Microscopia Eletrônica de Varredura da Fração Sol e Espectroscopia de Energia Dispersiva

As FIG. 46-51, mostram imagens de MEV e espectro de EDS com identificação e quantificação dos componentes químicos. 

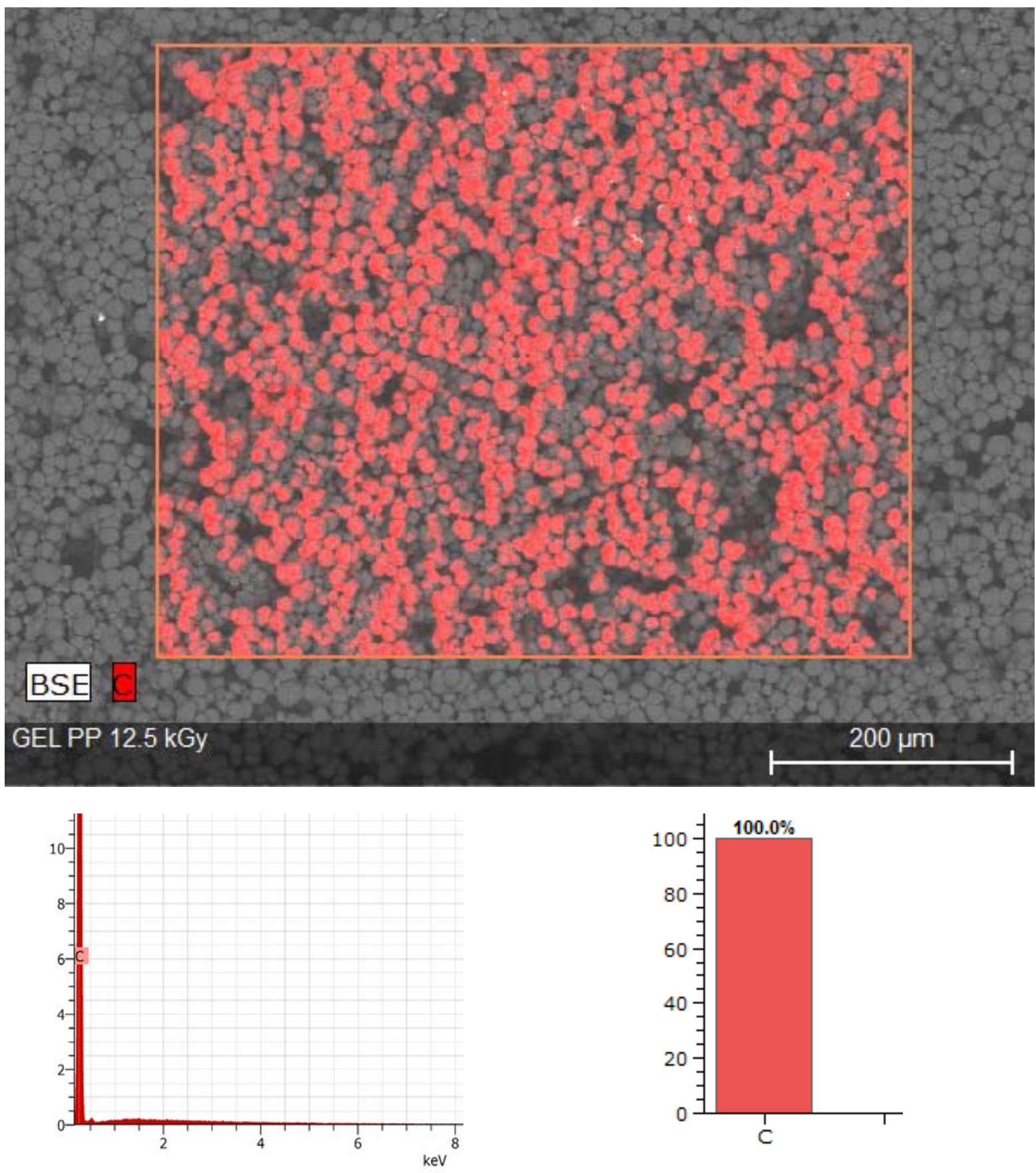

FIGURA 46 - Micrografia de géis de polipropileno (12,5 kGy) e espectro de EDS de géis de polipropileno sem prata 

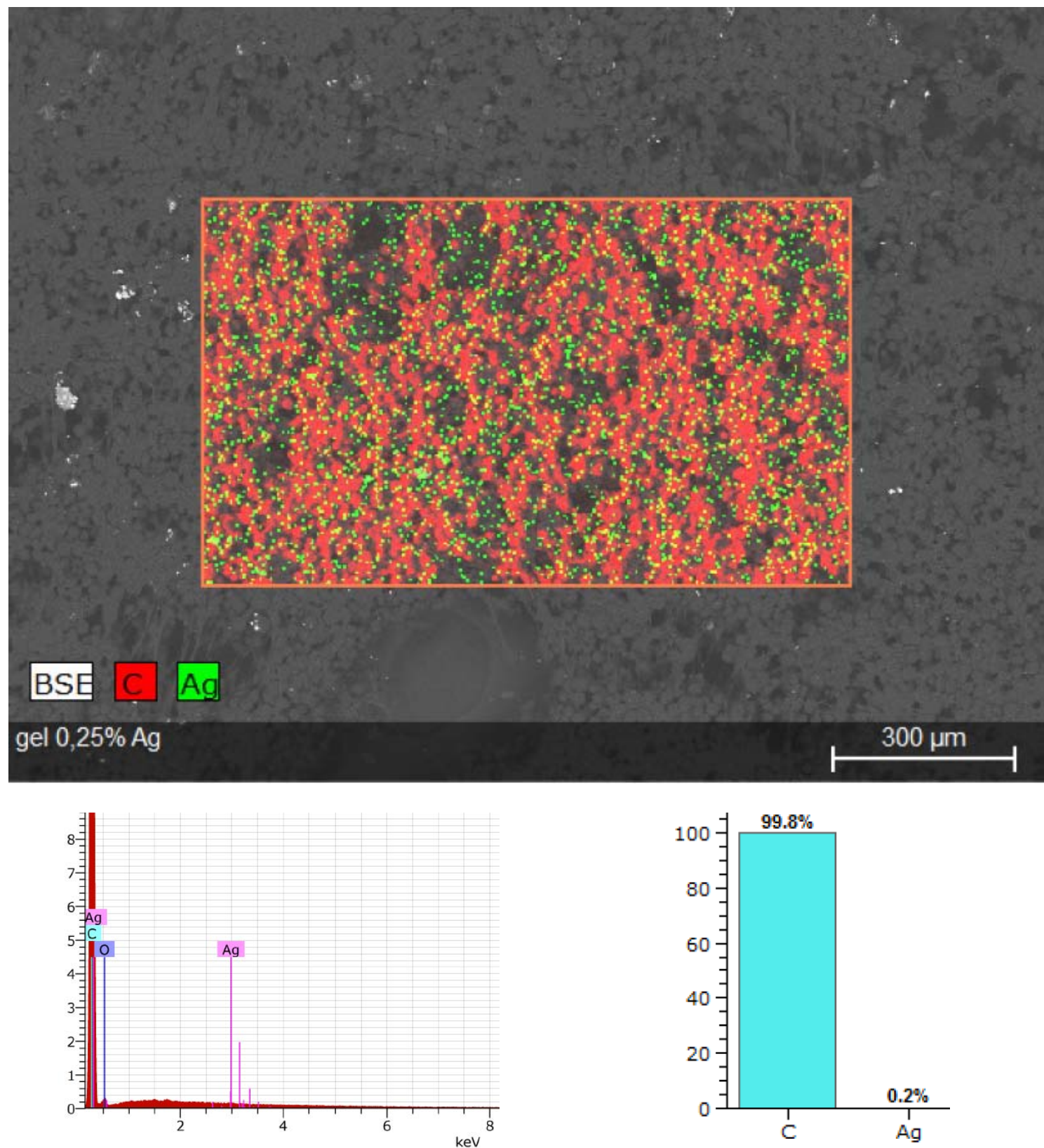

FIGURA 47 - Micrografia de géis de polipropileno com NPsAg e espectro de EDS de PP Gel 0,25\%NPsAg 

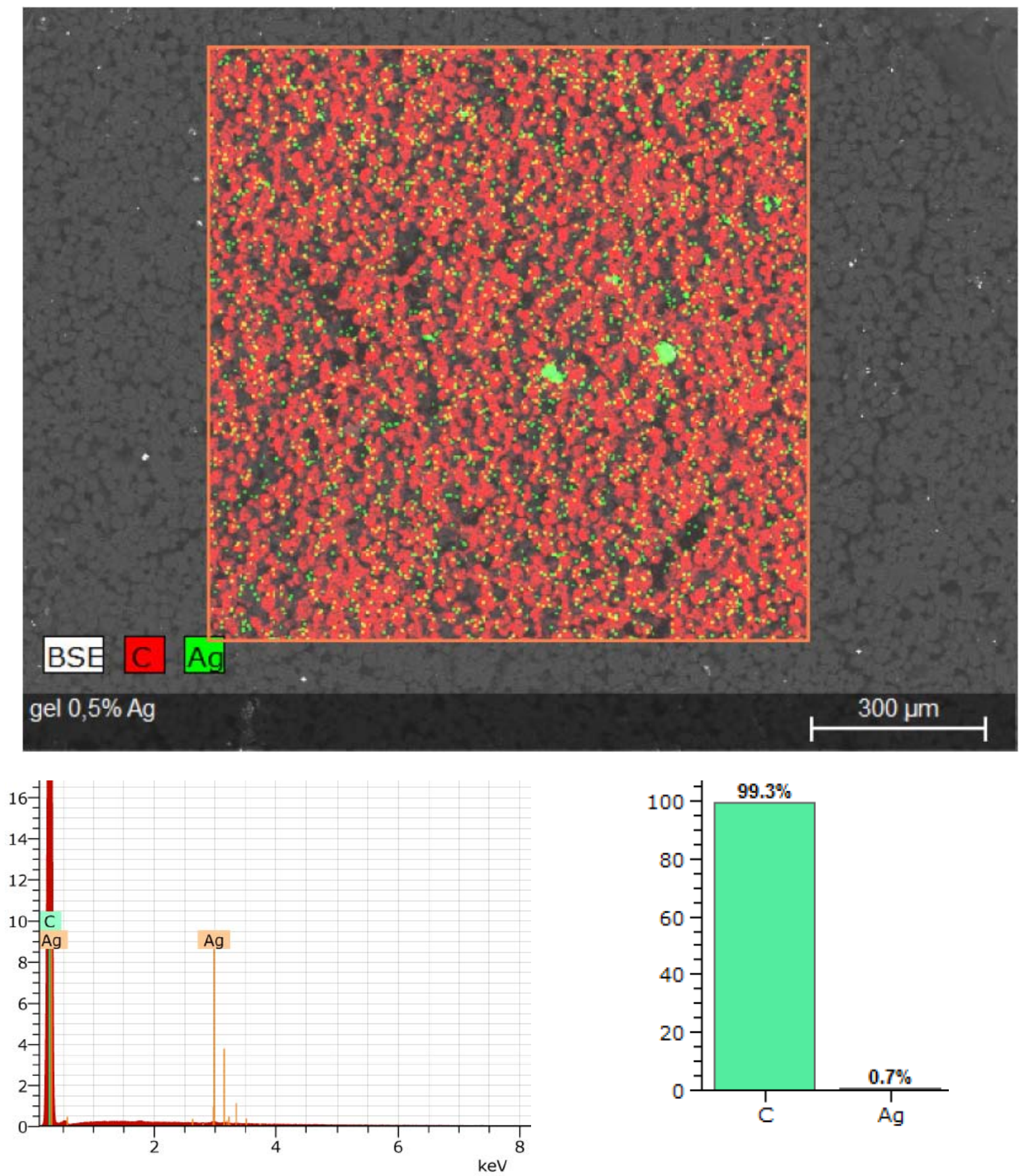

FIGURA 48 - Micrografia de géis de polipropileno com NPSAg e espectro de EDS de PP Gel 0,5\%NPsAg 

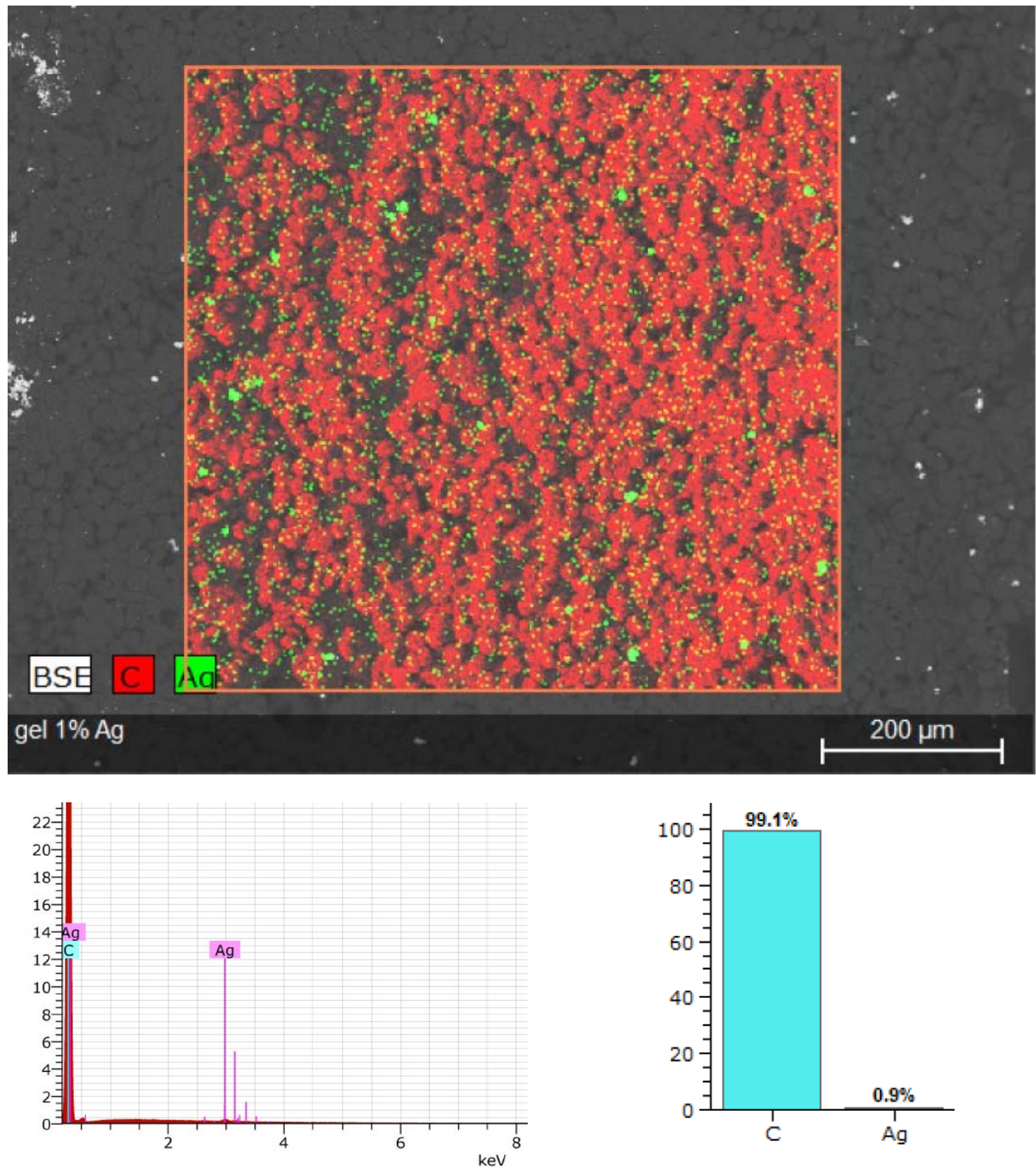

FIGURA 49 - Micrografia de géis de polipropileno com NPSAg e espectro de EDS de PP Gel 1\%NPsAg 

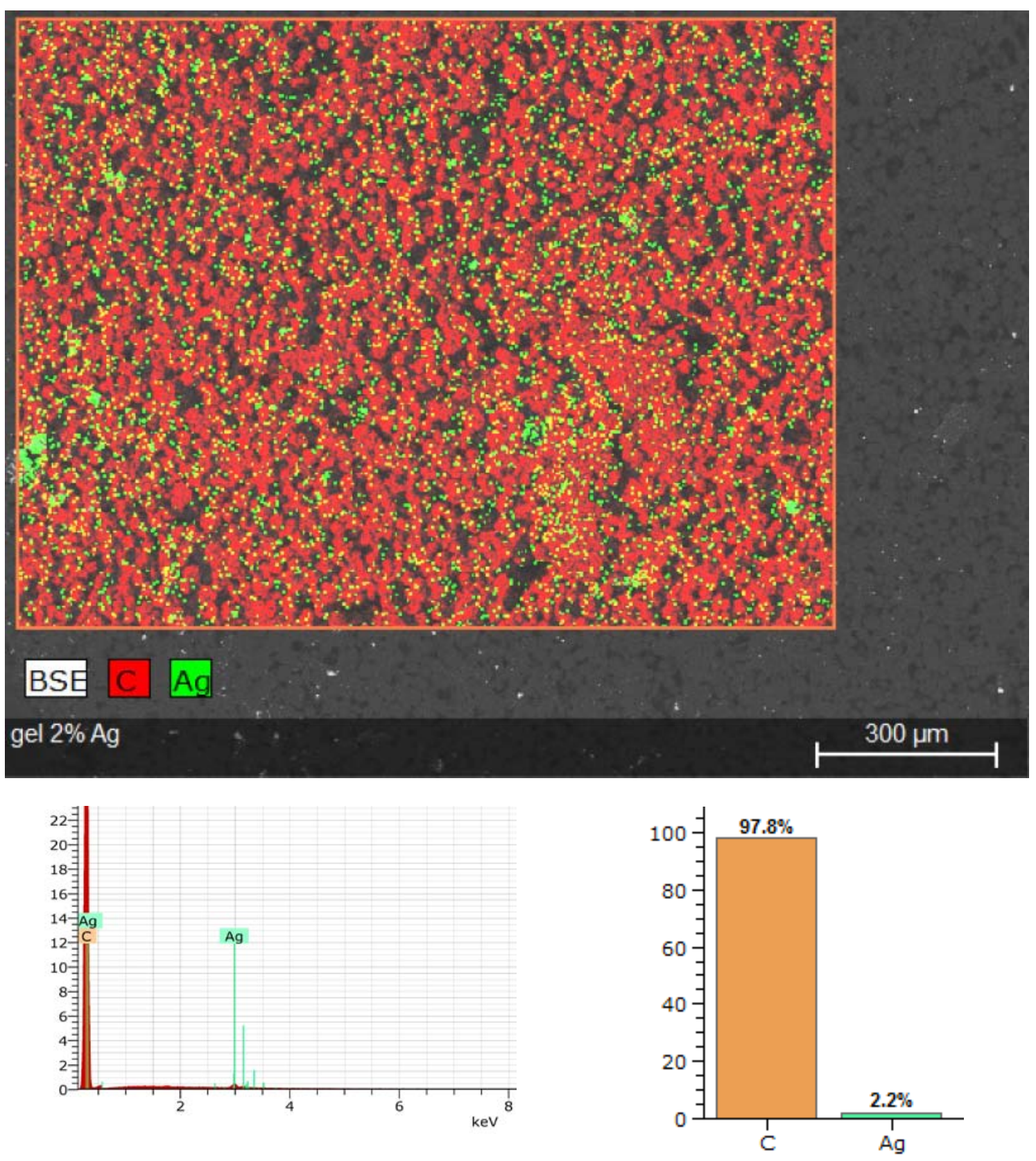

FIGURA 50 - Micrografia de géis de polipropileno com NPSAg e espectro de EDS de PP Gel 2\%NPsAg 

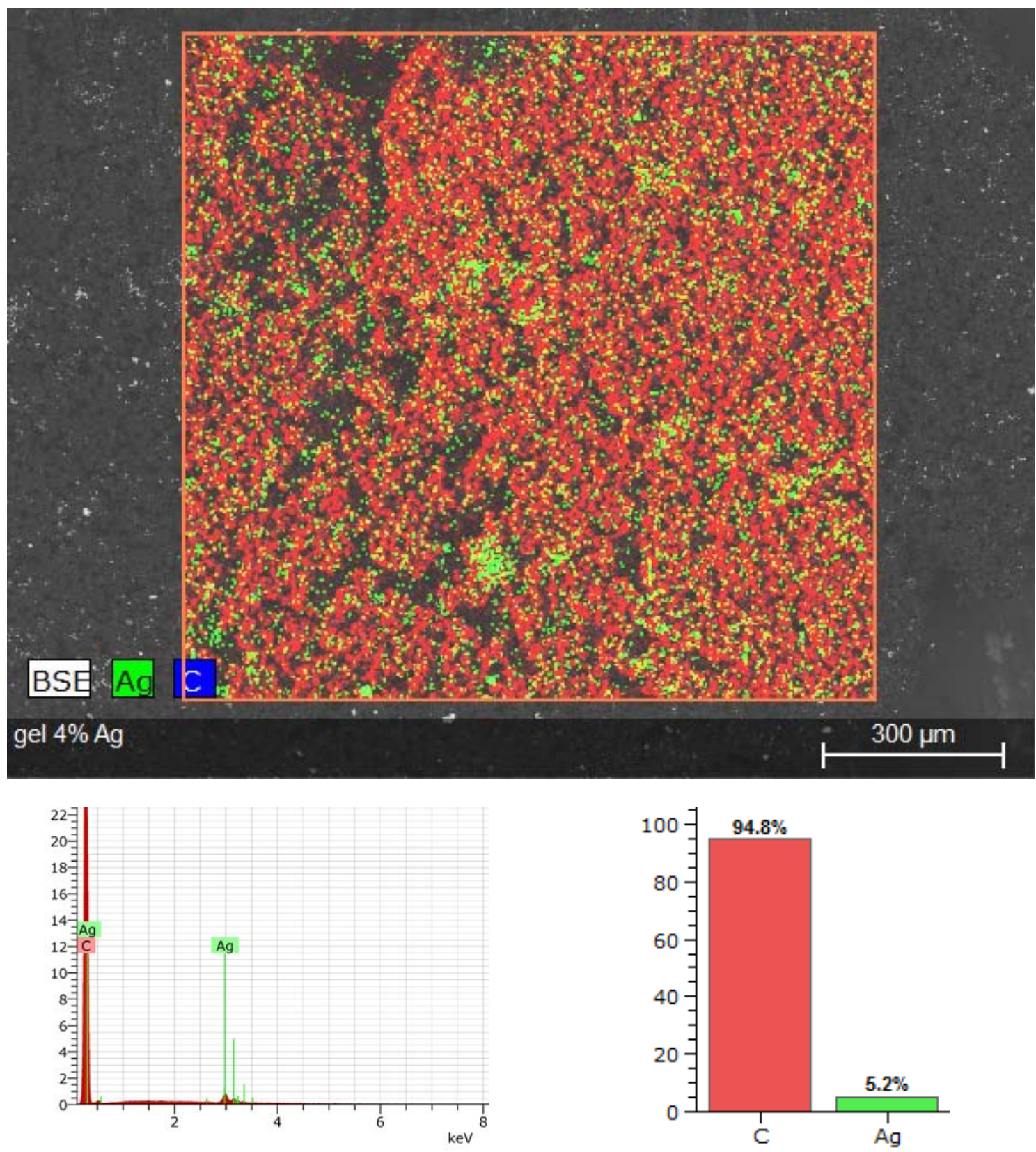

FIGURA 51 - Micrografia de géis de polipropileno com NPSAg e espectro de EDS de PP Gel 4\%NPsAg

Observa-se nas amostras de géis de polipropileno com NPsAg FIG. 4751 nas proporções de $(0,25 ; 0,5 ; 1 ; 2$ e 4\%) a identificação dos componentes químicos, carbono e prata, realizada por EDS. Encontrou-se na superfície das amostras de géis, distribuição homogênea de NPsAg e a presença de 
aglomerados de prata em diferentes regiões. Conforme determinação quantitativa constatou-se nas amostras de géis com NPsAg as seguintes proporções: $(0,2$; 0,$7 ; 0,9 ; 2,2$ e 5,2\%) de NPsAg nas regiões selecionadas.

\subsubsection{Microscopia de Força Atômica (MFA)}

A microscopia de força atômica utiliza uma ponta muito fina como sonda para varrer a superfície da amostra. Esta ponta fica na extremidade livre de um cantilever que vibra sobre a superfície da amostra ou simplesmente toca sua superfície. Em ambos os casos haverá forças de interação entre ponta e amostra gerando informações topográficas da superfície, como pode ser visto nas FIG.52 e 53.

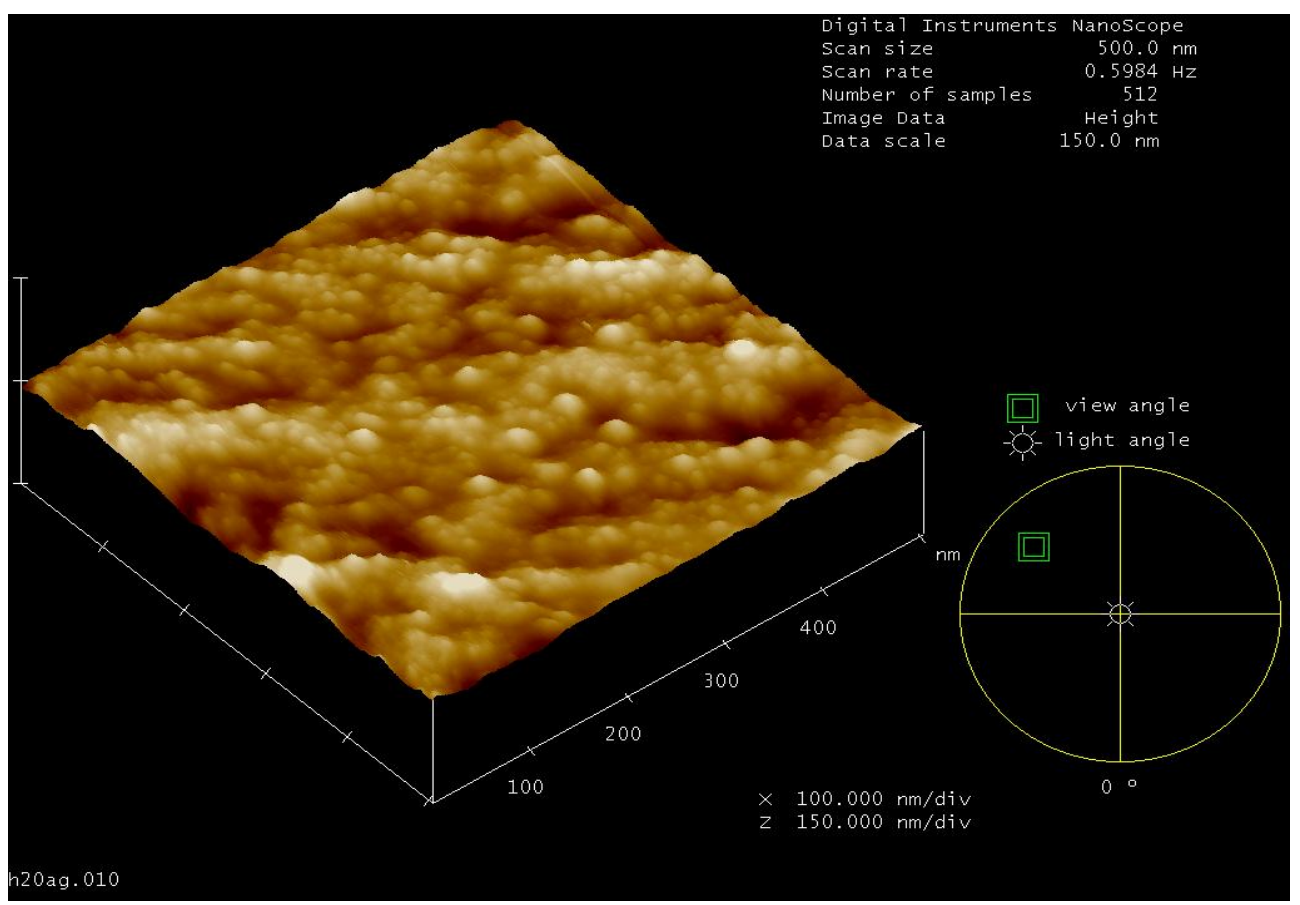

FIGURA 52 - Imagem 3D de MFA de PP Gel 20 kGy com NPsAg 


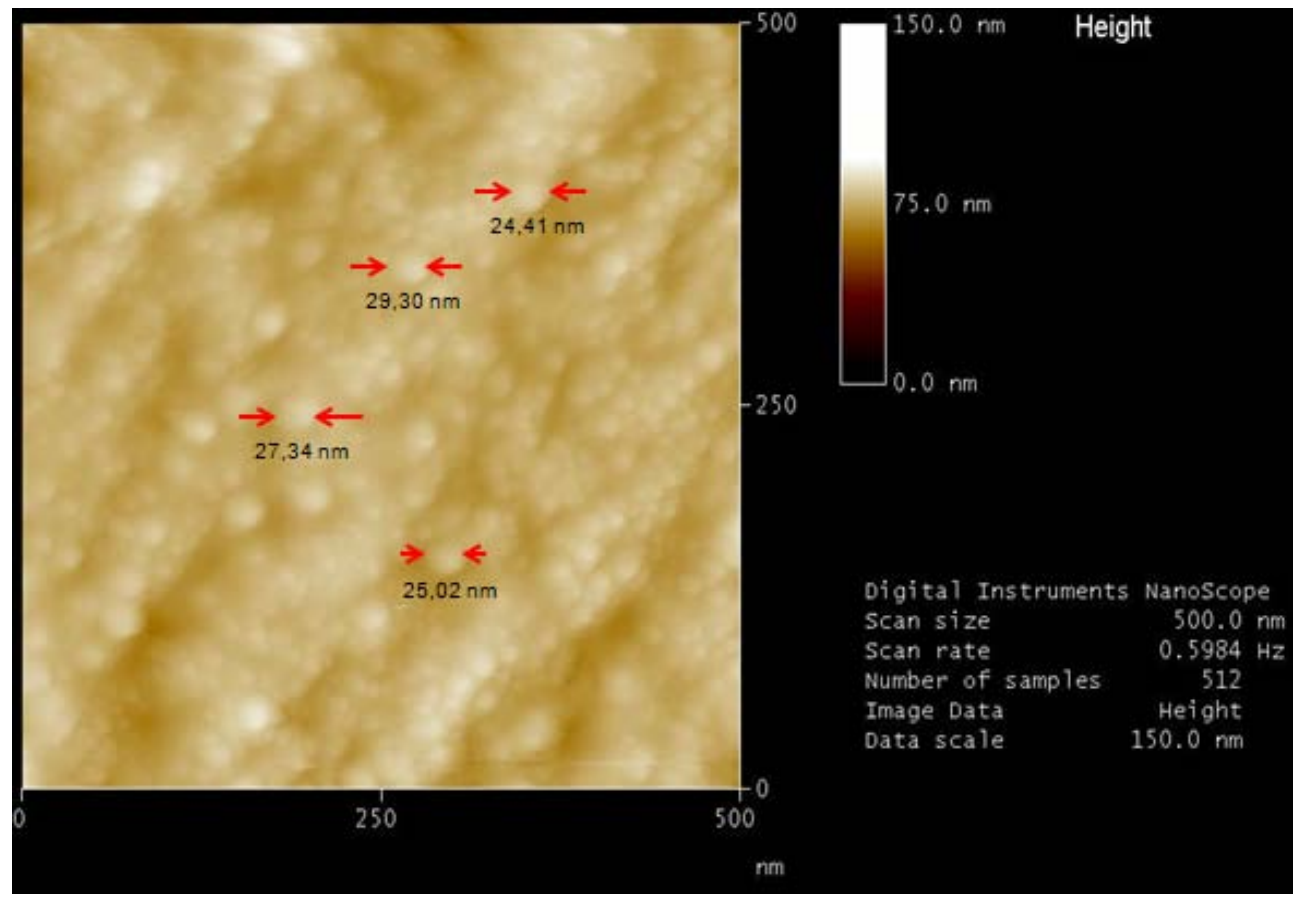

FIGURA 53 - Imagem de MFA obtida através do modo contato intermitente de PP Gel 20 kGy com NPsAg

As imagens geradas por MFA no filme de géis de PP 20 kGy estão apresentadas na FIG. 52 e 53, onde, se verifica a topografia da superfície com nanopartículas de prata. Através da análise de seção foi possível determinar o tamanho médio das partículas de prata entre 24,4 e 29 nm no formato esférico.

As FIG 54 e 55 apresentam imagens por MFA de géis de PP 12,5 kGy com NPsAg. 


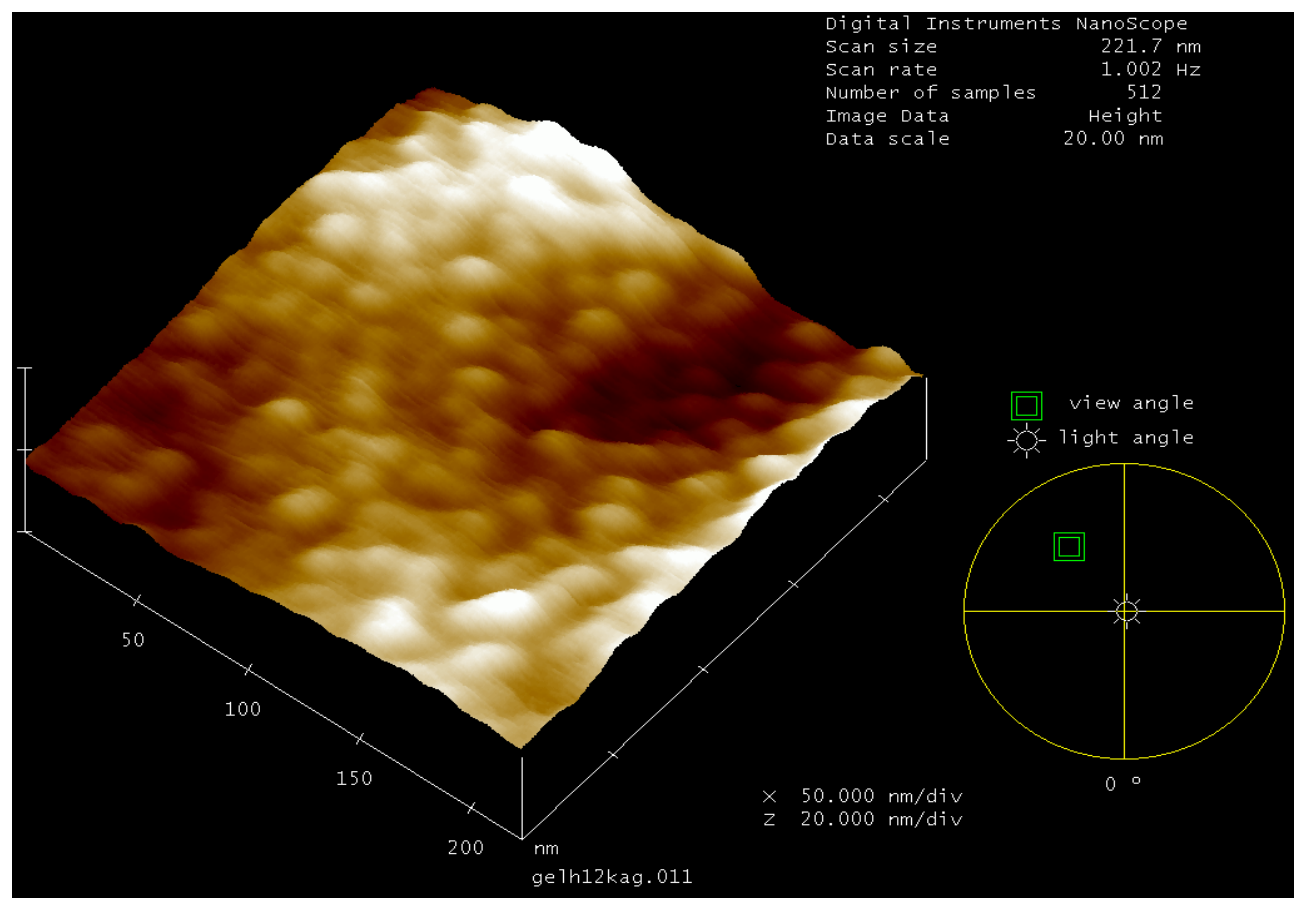

FIGURA 54 - Imagem 3D de MFA de PP Gel 12,5 kGy com NPsAg

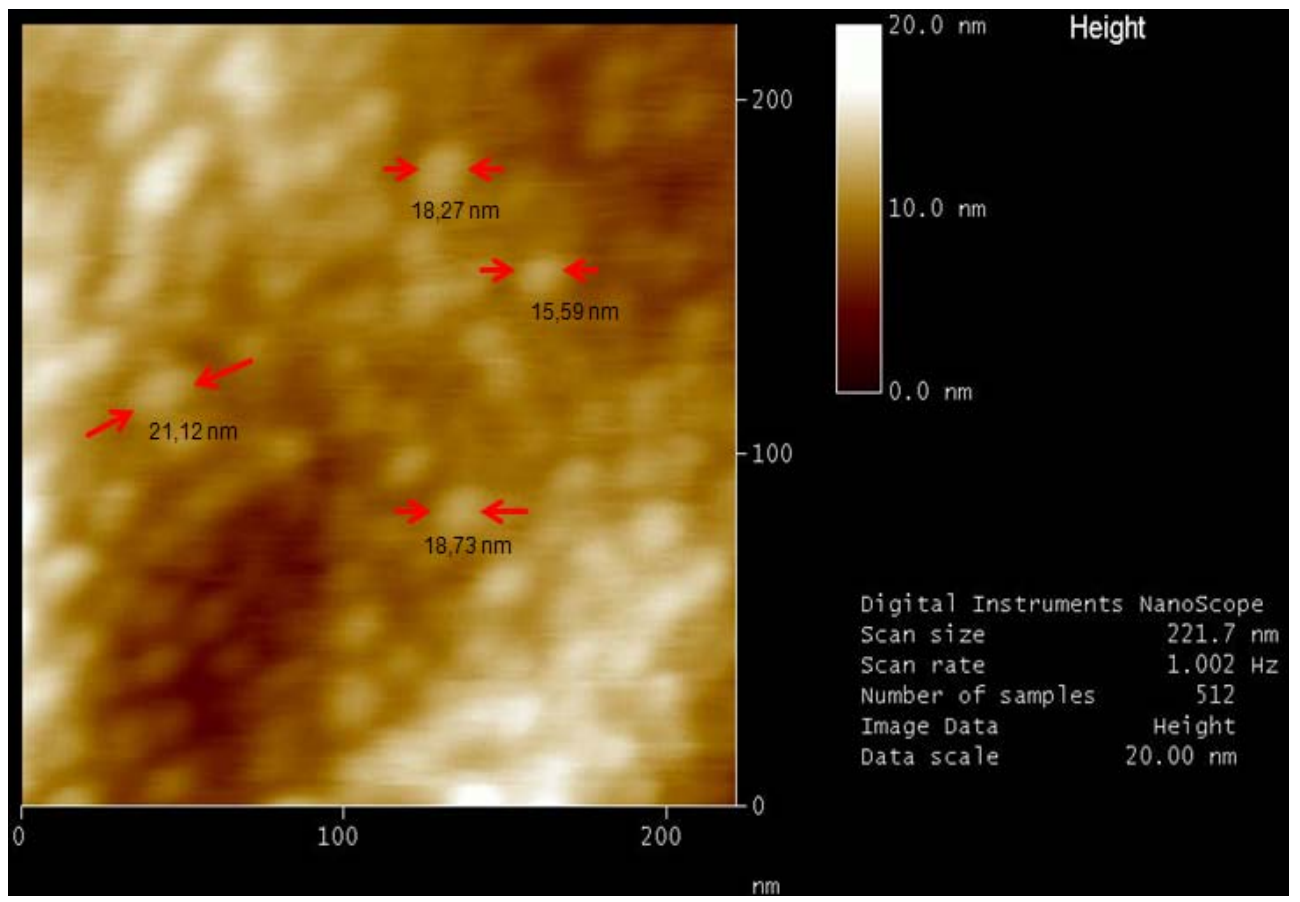

FIGURA 55 - Imagem de MFA obtida por modo contato intermitente de PP Gel 12,5 kGy com NPsAg 
A topografia da superfície dos géis de polipropileno com NPSAg FIG.55 apresenta a ampliação lateral de 221,7 nm e a escala de altura (eixo Z) é dada pela variação de tons na figura. Na imagem, a variação em altura (Z) é de $20 \mathrm{~nm}$, conforme indicado pela variação de cor. Pela análise de seção foi possível determinar o tamanho médio das nanopartículas de prata entre 15 e 21 nm com formato esférico.

\subsubsection{Difração de Raios X (DRX)}

A FIG. 56 mostra a difração de raios-X (DRX) de PPGel-1\%NPsAg. Os picos a $2 \theta=14.2^{\circ} ; 16.2^{\circ} ; 17.0^{\circ} ; 18.6^{\circ} ; 21.4^{\circ} ; 22.0^{\circ} ; 25.6^{\circ} ;$ e $28.7^{\circ}$, correspondem aos planos (110), (040), (130), (111), (150)+(060), (220), respectivamente, da forma $\alpha$-PP. Para o PP e compósitos fabricados sob condições experimentais, a forma $\beta$-PP, plano (300) pico em $2 \theta=16.2^{\circ}$ e plano $(131)+(041)$ pico em $2 \theta=22^{\circ}$, foram detectados e estão de acordo com a literatura ${ }^{203}$. 


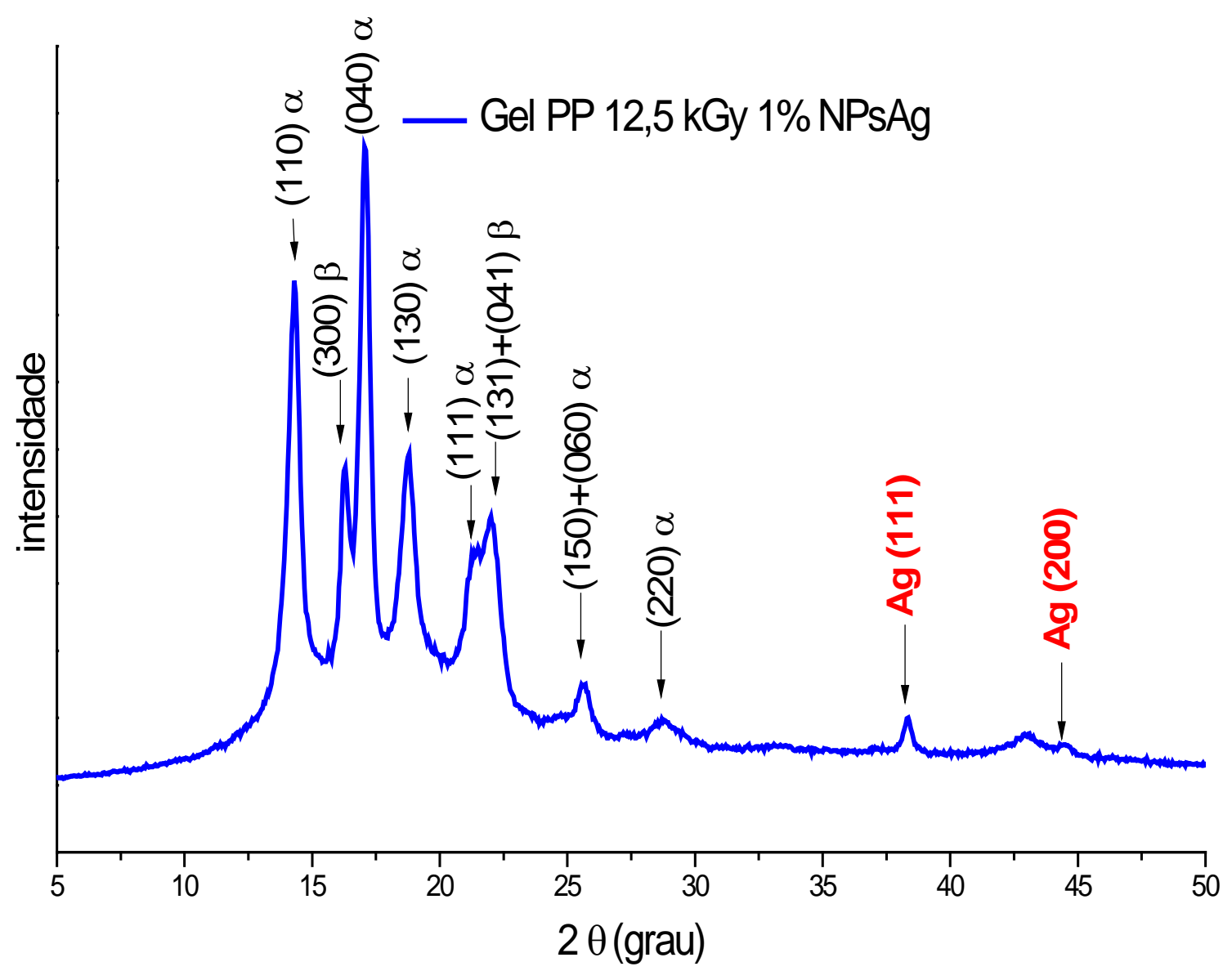

FIGURA 56 - Difração de raios X em PPGel-AgNPs

Neste resultado, as distâncias interplanares foram obtidas a partir de: $\mathrm{d}_{(110)}=6.18 \AA, \mathrm{d}_{(300)}=5.46 \AA, \mathrm{d}_{(040)}=5.19 \AA, \mathrm{d}_{(130)}=4.73 \AA, \mathrm{d}_{(111)}=4.18 \AA$, $\mathrm{d}(131)+(041)=4.03 \AA, \mathrm{d}_{(150)+(060)}=3.57 \AA, \mathrm{d}_{(220)}=3.10 \AA$. O padrão de raios- $\mathrm{X}$ das nanopartículas de prata corresponde à estrutura cúbica de face centrada (cfc) de prata com picos identificados em $38.4^{\circ}$ e $44.5^{\circ}$ correspondendo a $\mathrm{d}_{(111)}=2,35$ $\AA$ e $_{(200)}=2.03 \AA$, respectivamente ${ }^{204,205}$.

O polipropileno modificado por irradiação (12.5 kGy) não apresenta nucleação de $\beta$-cristais ${ }^{183}$ enquanto que a fase- $\beta$ ocorreu quando da adição de NPsAg. 


\subsubsection{Calorimetria Exploratória Diferencial (DSC)}

As análises de DSC são apresentadas na FIG. 57. A curva correspondente ao Gel PP 12,5 kGy mostrou um pico de fusão enquanto são observados para amostras de Gel PP-AgNPs dois picos. O pico de fusão a $158{ }^{\circ} \mathrm{C}$ corresponde à forma $\alpha$-cristal do Gel PP 12,5 kGy. Os dois picos de fusão do PPGel-AgNPs foram observados a 160 e $174{ }^{\circ} \mathrm{C}$ e correspondem respectivamente, a fusão das faseß e $\alpha$ que são semelhantes aos valores encontrados por Zhang ${ }^{206}$. Observa-se que a inclusão de prata causou o deslocamento de pico da temperatura da fase $\alpha$ para temperatura mais elevada $\mathrm{e}$ induziu a formação da fase $\beta$. A área deste pico aumentou com a concentração de NPsAg até $1 \%$ em peso e, em seguida, diminui para concentrações mais elevadas. Este comportamento confirmou a agregação das nanopartículas de prata, tal como se vê nas FIG. 50 e 51. Neste caso, foi demonstrado a sua capacidade de nucleação em função da redução da área de superfície específica. Estes efeitos foram observados antes por $\mathrm{Liu}^{207}$, utilizando como agente de nucleação HNTs (Nanotubos de Haloisita) de PP. Os resultados de DSC relativos ao $\mathrm{T}_{m 2}$ e $\mathrm{X}_{C}$ estão representados na TAB. 5. Na FIG. 57, os picos duplos de fusão foram observados para GelPP-AgNPs e atribuídos a organização de cristais diferentes. Os valores da temperatura de cristalização $T_{C}$ (curvas não mostradas em gráficos) estão apresentados na TAB. 5. 


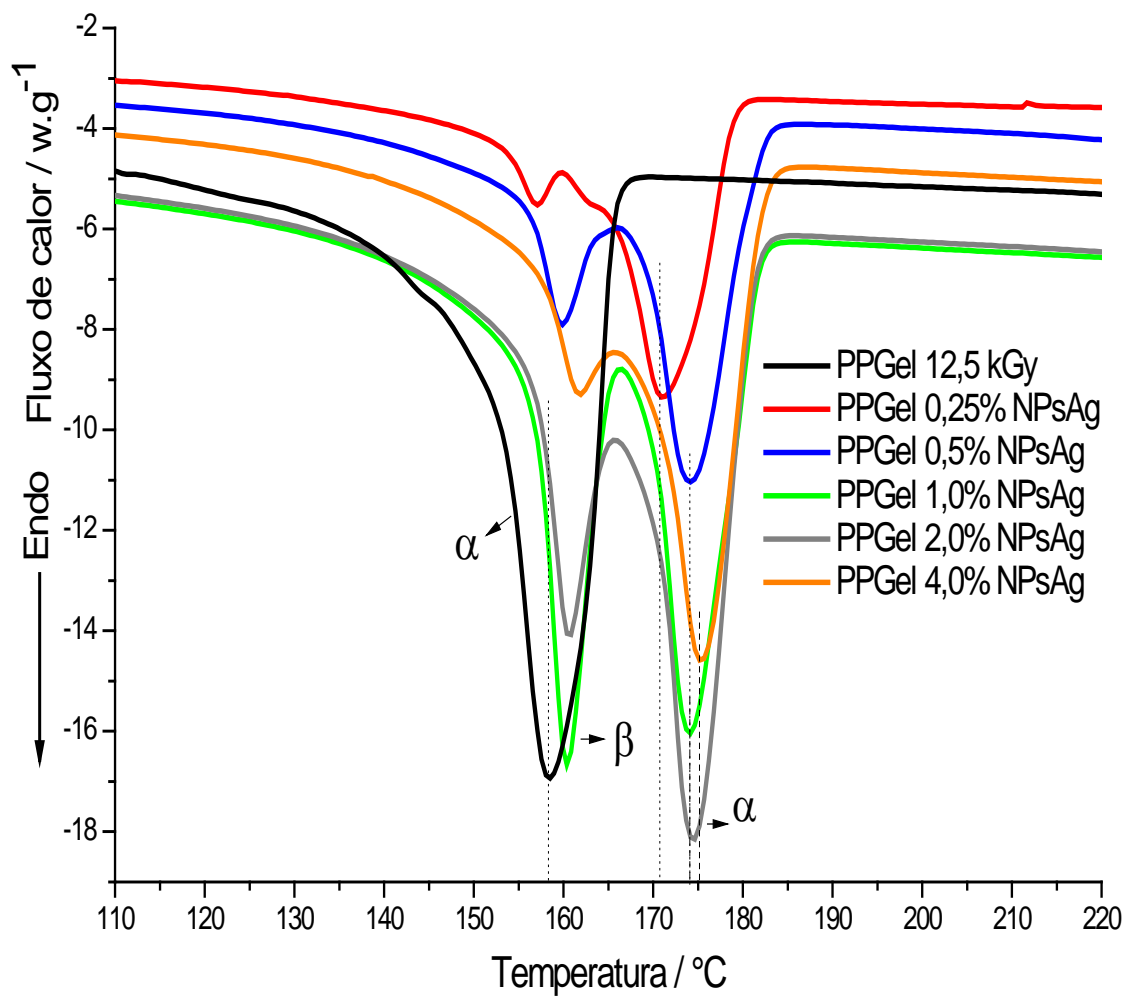

FIGURA 57 - Curvas de DSC (segunda fusão) de PPGel 12,5 kGy e PPGel 12,5 kGy-NPsAg com diferentes porcentagens em massa de prata, aquecimento $10^{\circ} \mathrm{C} \mathrm{min}^{-1}$

TABELA 6 - Valores obtidos na análise de DSC em amostras de PPGel-NPsAg

\begin{tabular}{|c|c|c|c|c|}
\hline \multirow[t]{2}{*}{ Amostras } & \multirow[t]{2}{*}{$\begin{array}{c}\text { Temperatura de } \\
\text { Cristalização, } T_{C}\left({ }^{\circ} \mathrm{C}\right)\end{array}$} & \multicolumn{2}{|c|}{$\begin{array}{l}\text { Temperatura de } \\
\text { Fusão, } \mathrm{T}_{m 2}\left({ }^{\circ} \mathrm{C}\right)\end{array}$} & \multirow[t]{2}{*}{$\begin{array}{c}\text { Grau de } \\
\text { Cristalinidade, } \mathrm{X}_{C}(\%)\end{array}$} \\
\hline & & $\mathrm{T} \beta$ & $\mathrm{T} \alpha$ & \\
\hline PPGel 12,5 kGy & 116,5 & - & 158,2 & 45,6 \\
\hline PPGel 0,25\% NPsAg & 130,8 & 157,0 & 171,2 & 50,0 \\
\hline PPGel 0,5\% NPsAg & 135,9 & 160,0 & 174,5 & 48,4 \\
\hline PPGel 1,0\% NPsAg & 135,4 & 160,2 & 174,1 & 48,7 \\
\hline PPGel 2,0\% NPsAg & 136,5 & 160,6 & 174,5 & 48,0 \\
\hline PPGel 4,0\% NPsAg & 136,5 & 161,9 & 175,5 & 43,5 \\
\hline
\end{tabular}


Os valores de cristalinidade apresentado na TAB. 6, foram calculados considerando-se a entalpia da fase $\alpha$. A nucleação de novos cristais pode ser considerada, de modo a exibir vários segmentos móveis moleculares produzidos por cisão de cadeia e/ou adição das NPsAg na vizinhança próxima. Os $\beta$-cristais não foram observados em PP modificado por irradiação. Na presença de NPsAg, como observado na FIG. 57, a fase $\beta$ é constatada para as curvas de fusão GelPP-NPsAg, sugerindo a capacidade de $\beta$ nucleação, como discutido no trabalho de Romankiewicz ${ }^{208}$, e Liang ${ }^{209}$. A quantidade da fase $\beta$ no iPP depende da concentração de aditivos e das condições de resfriamento durante a cristalização do fundido ${ }^{208}$. A formação de $\beta$-PP em condições não-isotérmicas de cristalização é também confirmada em experimentos de DRX. A FIG. 56 mostra o padrão de DRX do nanocompósito de PPGel-NPsAg em cristalização não isotérmica.

\subsubsection{Teste de ação bactericida nos géis com NPsAg}

\subsubsection{Redução da unidade formadora de colônias (UFC) (\%)}

As amostras com bactérias testadas por contato (método 1) com géis foram incubadas por 24 horas à temperatura de $37^{\circ} \mathrm{C}$. Na FIG. 58, apresentam-se resultados de micro-organismos sobreviventes da amostra controle e de quatro amostras de géis de polipropileno com proporções variáveis de NPsAg $(0,5 ; 1 ; 2$ e 4\%). Verificou-se para cada proporção um limite da ação biocida das NPsAg frente às bactérias. 


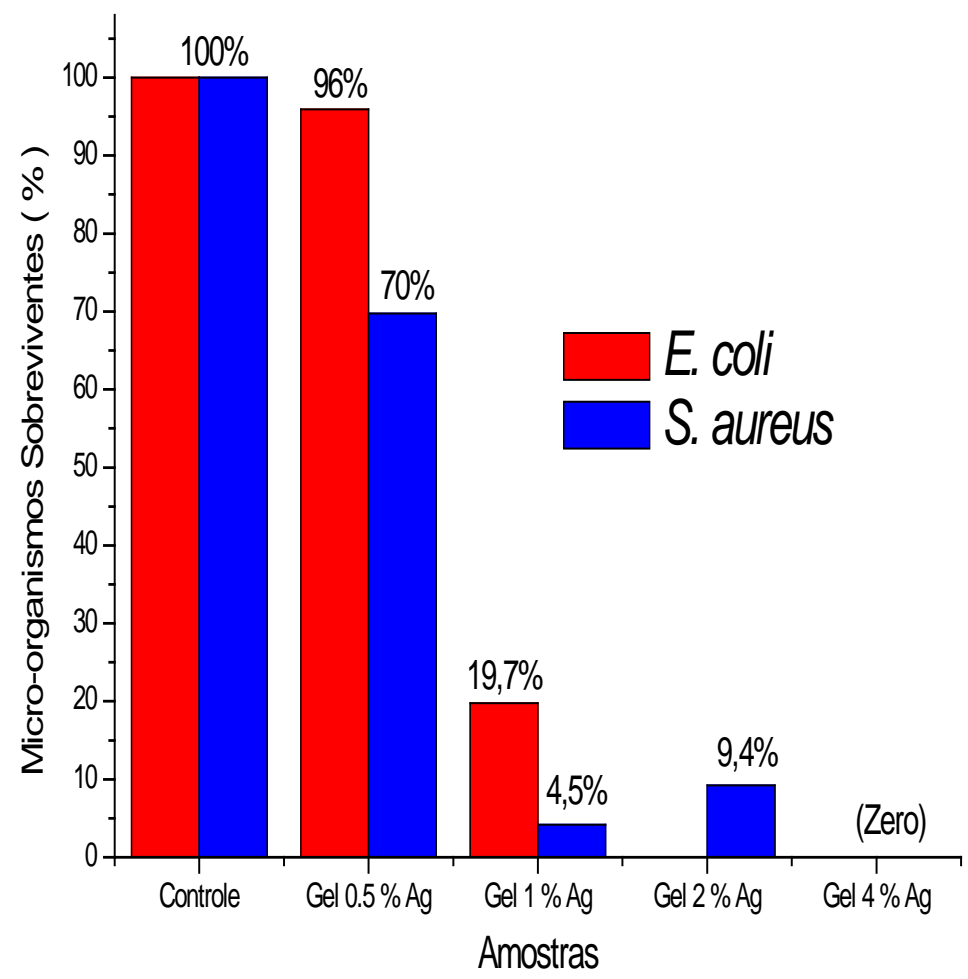

FIGURA 58 - Porcentagem (\%) de micro-organismos sobreviventes frente a E.coli e S.aureus em diferentes amostras de géis com NPsAg

A redução da \% de unidade formadora de colônias para os géis de polipropileno com NPSAg, FIG. 58, demonstrou um excelente efeito para as amostras de géis a partir da adição de 1\% de NPsAg. Na amostra com 1\% de NPsAg, os resultados de micro-organismos sobreviventes foram aproximadamente de $20 \%$ para a E. coli e $5 \%$ para S. aureus, o que denota um bom resultado. Com a proporção de $2 \%$ de NPsAg ocorreu o extermínio total das E. coli, entretanto, $9 \%$ de S. aureus sobreviveram. Finalmente, a proporção de 4\% de NPsAg dizimou os dois tipos de bactérias, tanto a gram-negativa (E.coli) como a gram-positiva (S.aureus).

\subsubsection{Teste de Citotoxicidade}

As curvas de viabilidade celular foram obtidas em um gráfico traçado com as percentagens de viabilidade celular em função da concentração do extrato. O índice de citotoxicidade $\mathrm{IC}_{50 \%}$ é identificado no gráfico e significa a concentração de extrato, que danifica a 50\% da população de células no ensaio. 
A amostra com curva de viabilidade celular acima da linha $I C_{50 \%}$ é considerada não citotóxica e sob ou cruzando a linha $I_{50 \%}$ é considerada tóxica.

A FIG. 59 representa a curva de viabilidade celular em géis de polipropileno com proporções de 0,25 a 4,0\% de NPsAg.

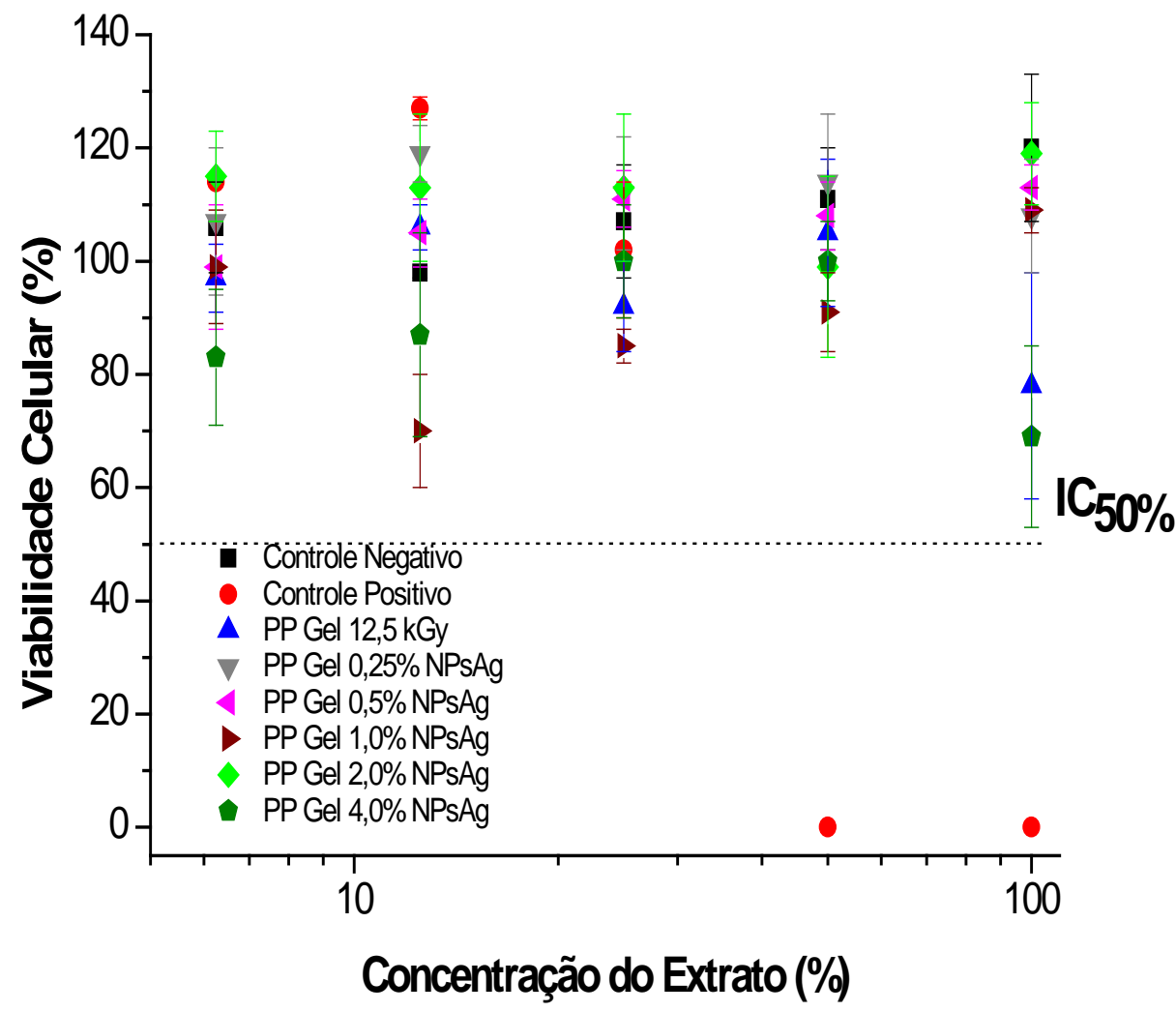

FIGURA 59 - Curvas de viabilidade celular das amostras de PPGel-NPsAg pela incorporação do vermelho neutro

Os géis de polipropileno com NPsAg no teste de citotoxicidade mostraram um comportamento semelhante ao controle negativo, isto é, os filmes testados não apresentaram toxicidade, como pode ser observado na FIG. 59. Por conseguinte, as películas de PP Gel 12,5 kGy-NPsAg foram caracterizadas como não citotóxicas neste ensaio. 
5.3 Filmes de Polipropileno com Nanopartículas de Prata (NPsAg) Extrusão

Os filmes obtidos a partir de grãos do extrudado estão apresentados na FIG. 60.

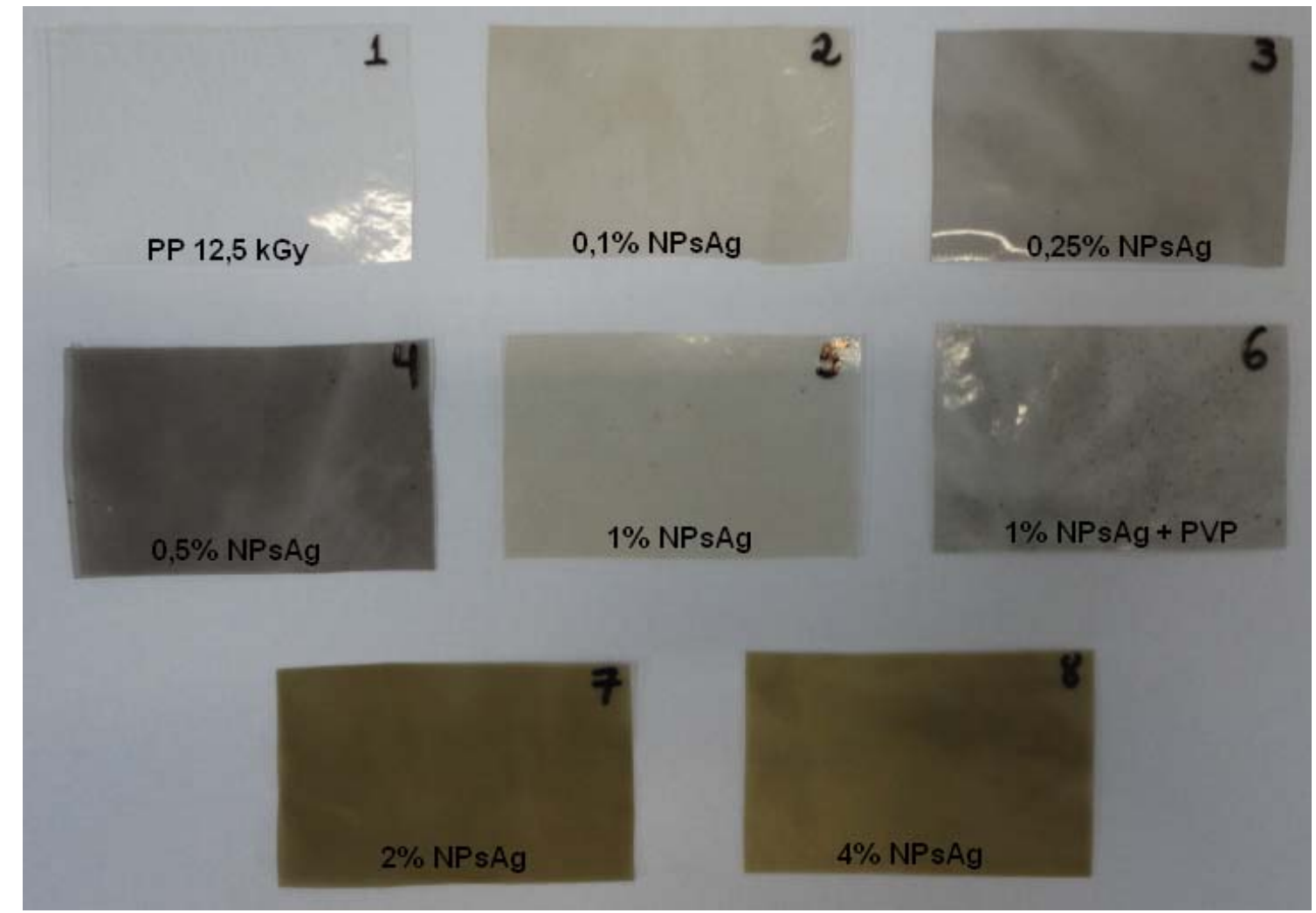

FIGURA 60 - Filmes de polipropileno com nanopartículas de prata em diferentes proporções

A FIG. 60 apresenta oito filmes processados por extrusão de polipropileno, sendo que, os filmes de $n^{\circ} 2$ ao $n^{\circ} 8$ contêm nanopartículas de prata.

\subsubsection{Calorimetria Exploratória Diferencial (DSC)}

Os resultados de DSC dos filmes de polipropileno com NPSAg estão ilustrados na FIG. 61. 


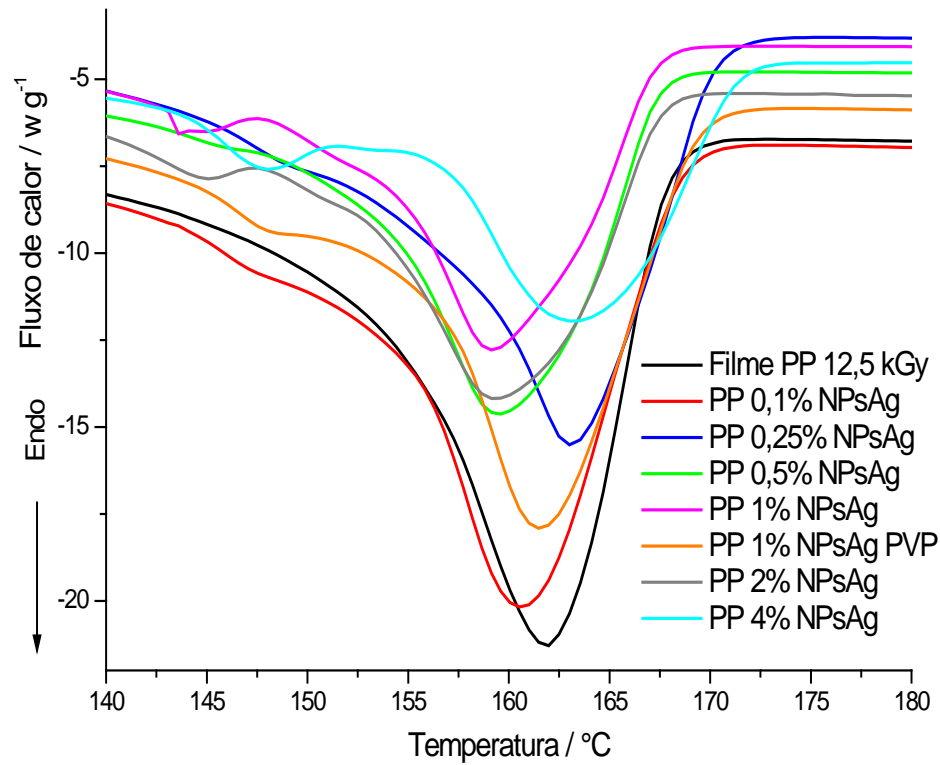

FIGURA 61 - Curvas de DSC de filmes de PP 12,5 kGy e PP-NPsAg com diferentes porcentagens em peso de prata (segunda fusão), aquecimento $10^{\circ} \mathrm{C} \mathrm{min}^{-1}$

TABELA 7- Valores obtidos da análise de DSC em amostras de filmes extrudados de PP-NPsAg

\begin{tabular}{llll}
\hline Filmes & $\mathrm{T}_{c}\left({ }^{\circ} \mathrm{C}\right)$ & $\mathrm{T}_{m 2}\left({ }^{\circ} \mathrm{C}\right)$ & $\mathrm{Xc}(\%)$ \\
\hline PP 12,5 kGy & 116,5 & 161,8 & 50,6 \\
PP 0,1\%NPsAg & 120,6 & 160,5 & 50,1 \\
PP 0,25\%NPsAg & 125,4 & 163,4 & 48,4 \\
PP 0,5\%NPsAg & 117,2 & 159,7 & 50,8 \\
PP 1\%NPsAg & 117,0 & 159,6 & 50,1 \\
PP 1\%NPsAg PVP & 120,9 & 161,6 & 47,5 \\
PP 2\%NPsAg & 116,7 & 159,5 & 50,2 \\
PP 4\%NPsAg & 116,5 & 163,3 & 44,2 \\
\hline
\end{tabular}

Pode-se afirmar pelos valores de $\mathrm{T}_{m 2}$ apresentados na TAB. 7 que não está havendo criação da fase $\beta$. Existe a tendência de redução da cristalinidade em presença de maior concentração de NPsAg como pode ser constatado na TAB. 7. 


\subsubsection{Análise de Termogravimetria (TGA)}

Os termogramas obtidos de filmes de PP-NPsAg estão ilustrados na FIG. 62.

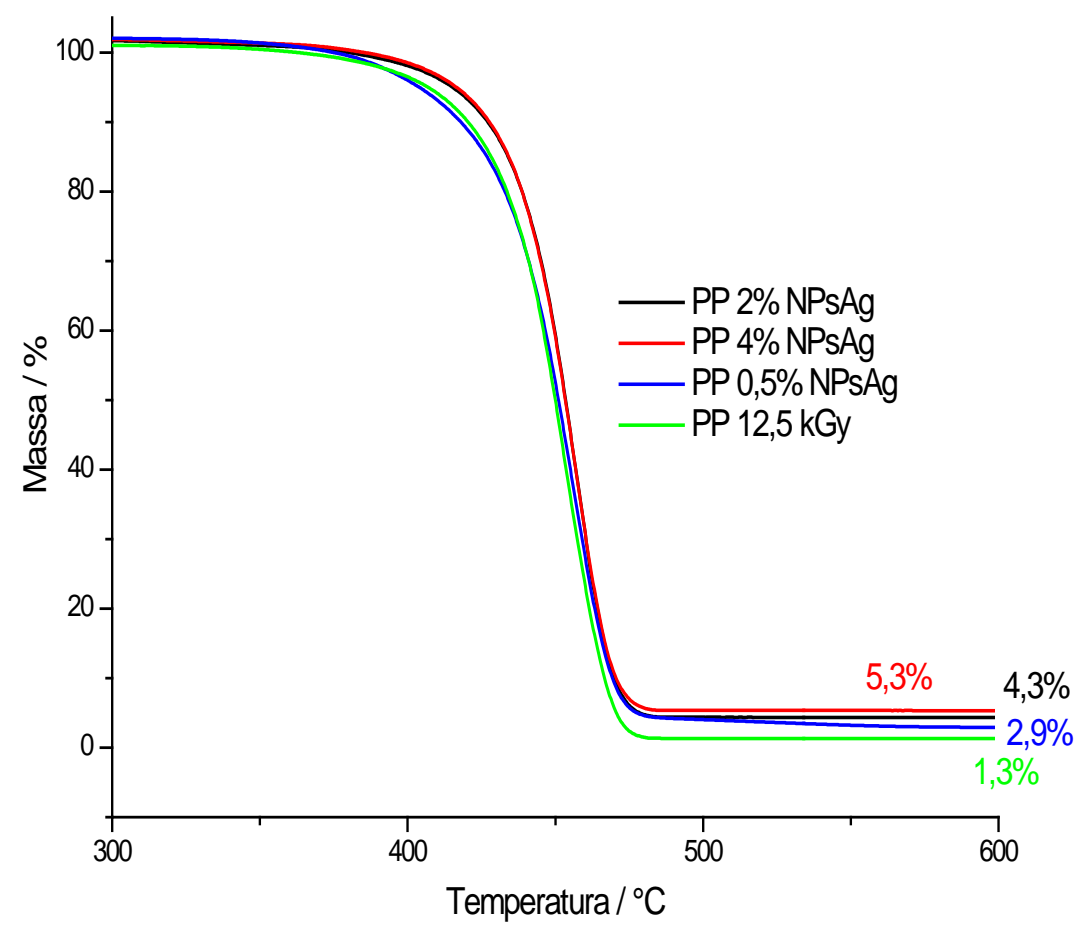

FIGURA 62 - Curvas de perda de massa em atmosfera inerte de filmes de PPNPsAg, taxa de aquecimento de $10^{\circ} \mathrm{C} \mathrm{min}^{-1}$

Na FIG. 62 observam-se os termogramas de 4 filmes de polipropileno com nanopartículas de prata. O filme de PP 12,5 kGy, único que não contém NPsAg possui valor de resíduo de 1,3\%, já no filme de PP 0,5\% NPsAg foi de 2,9\%, seguido do filme de PP 2\%NPsAg que foi de 4,3\% e finalmente no filme de PP 4\%NPsAg o valor residual obtido foi de 5,3\%.

Estes valores comprovam a presença de resíduo de NPsAg na forma de óxido de prata, nos filmes obtidos por extrusão e são mais precisos em conformidade com as formulações processadas. Entretanto a prata localizada internamente nos filmes não manifesta a atividade biocida, conforme constatado nas amostras de PP 2\%NPsAg e PP 4\%NPsAg. 


\subsubsection{Difração de Raios X (DRX)}

O polimorfismo é um fenômeno comum em polímeros cristalinos e, portanto, também no polipropileno. Os tipos de fase cristalina encontrados no polipropileno isotático (iPP) são $\alpha, \beta$ e $\gamma$ e a estrutura cristalina mesomórfica. Nesta pesquisa do iPP e PP 12,5 kGy a fase $\alpha$ é a mais comum com célula unitária monoclínica $\left(a=6,66 ; b=20,78 ; c=6,495 \AA \text { e } \beta=99,6^{\circ}\right)^{202}$.

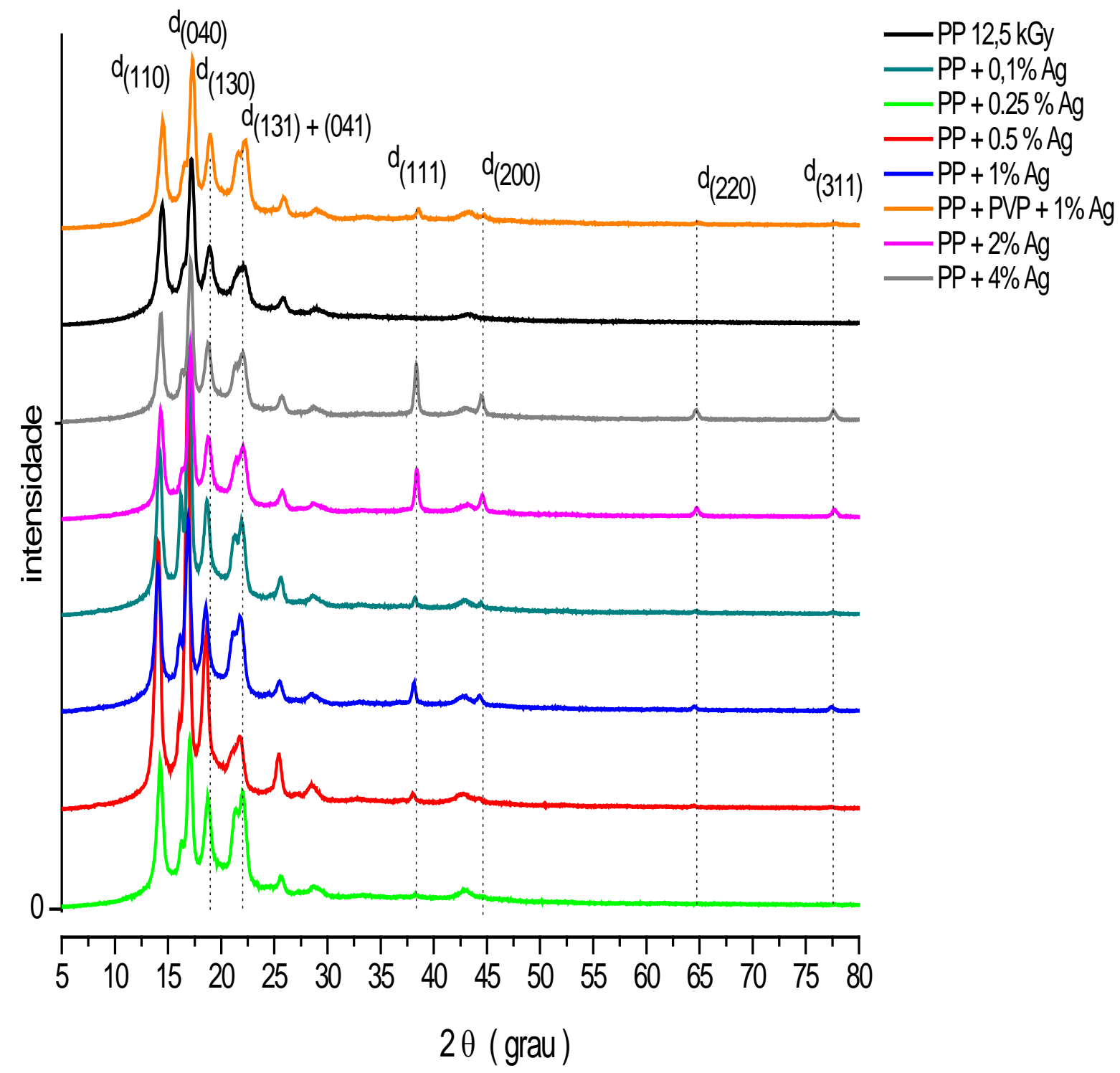

FIGURA 63 - Difratogramas de Raios-X (DRX) em filmes de polipropileno PP 12,5 kGy e nanocompósitos de PP com NPsAg 
A estrutura do cristal e natureza das NPsAg formadas foram analisadas por DRX. Os perfis de DRX apresentados na FIG. 63 apresentam os picos característicos de ângulos de espalhamento $(\notin)$ de 38,1 e 44,3, 64,5, e 77,3 correspondentes ao espalhamento de (111), (200), (220), e (311) planos cristalográficos, respectivamente. Estes picos de difração representam a estrutura cristalina cúbica de face centrada das NPsAg ${ }^{210}$. 


\subsubsection{Microscopia Eletrônica de Varredura (MEV) e EDS}

As FIG. 64-71, mostram imagens de MEV e espectro de EDS com identificação e quantificação dos componentes químicos.
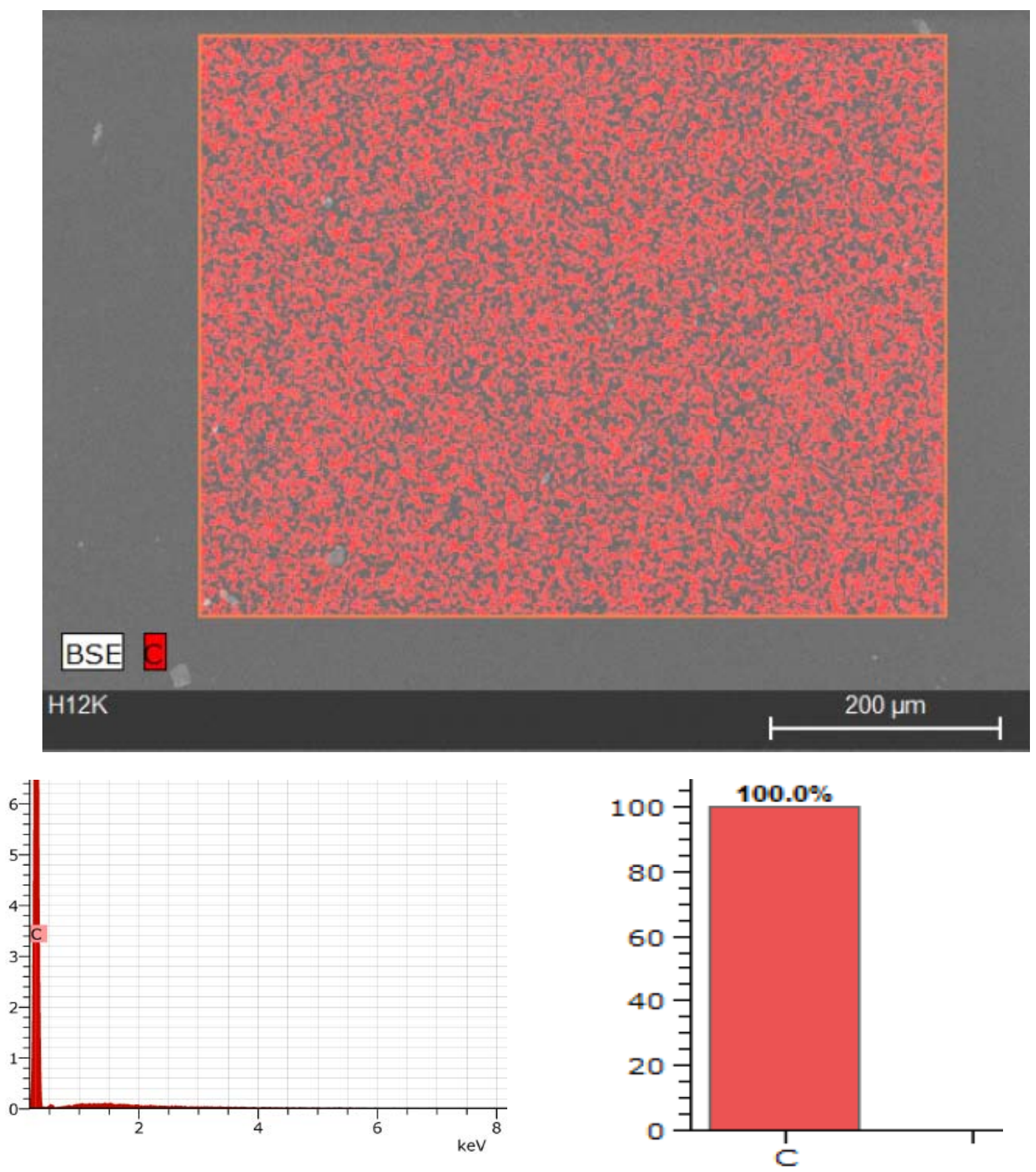

FIGURA 64 - Micrografia do filme de polipropileno e espectro de EDS do filme de polipropileno sem prata 

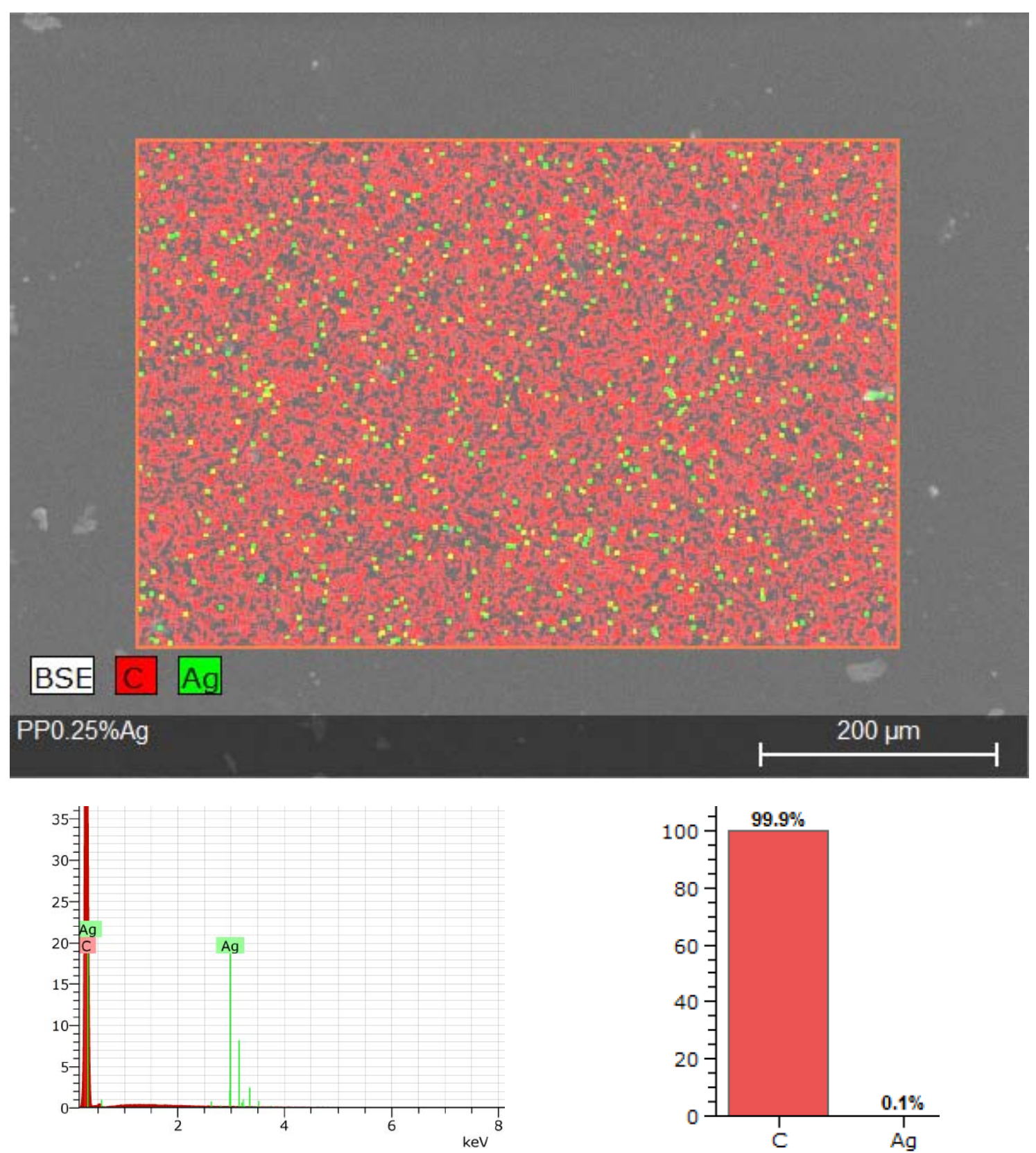

FIGURA 65 - Micrografia do filme de polipropileno com NPsAg e espectro de EDS do filme de PP 0,25\%NPsAg 

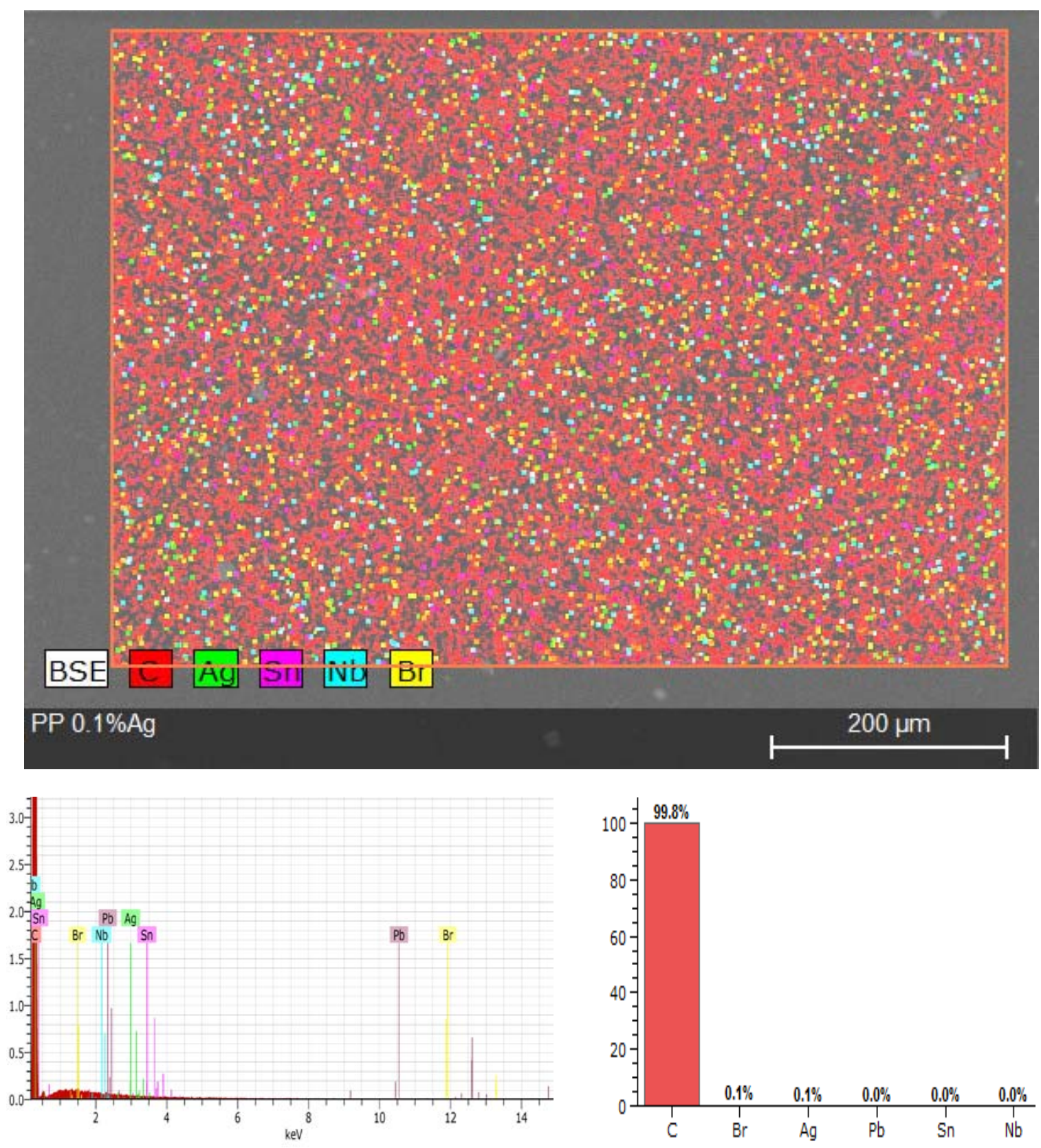

FIGURA 66 - Micrografia do filme de polipropileno com NPsAg e espectro de EDS do filme de PP 0,1\%NPsAg. 

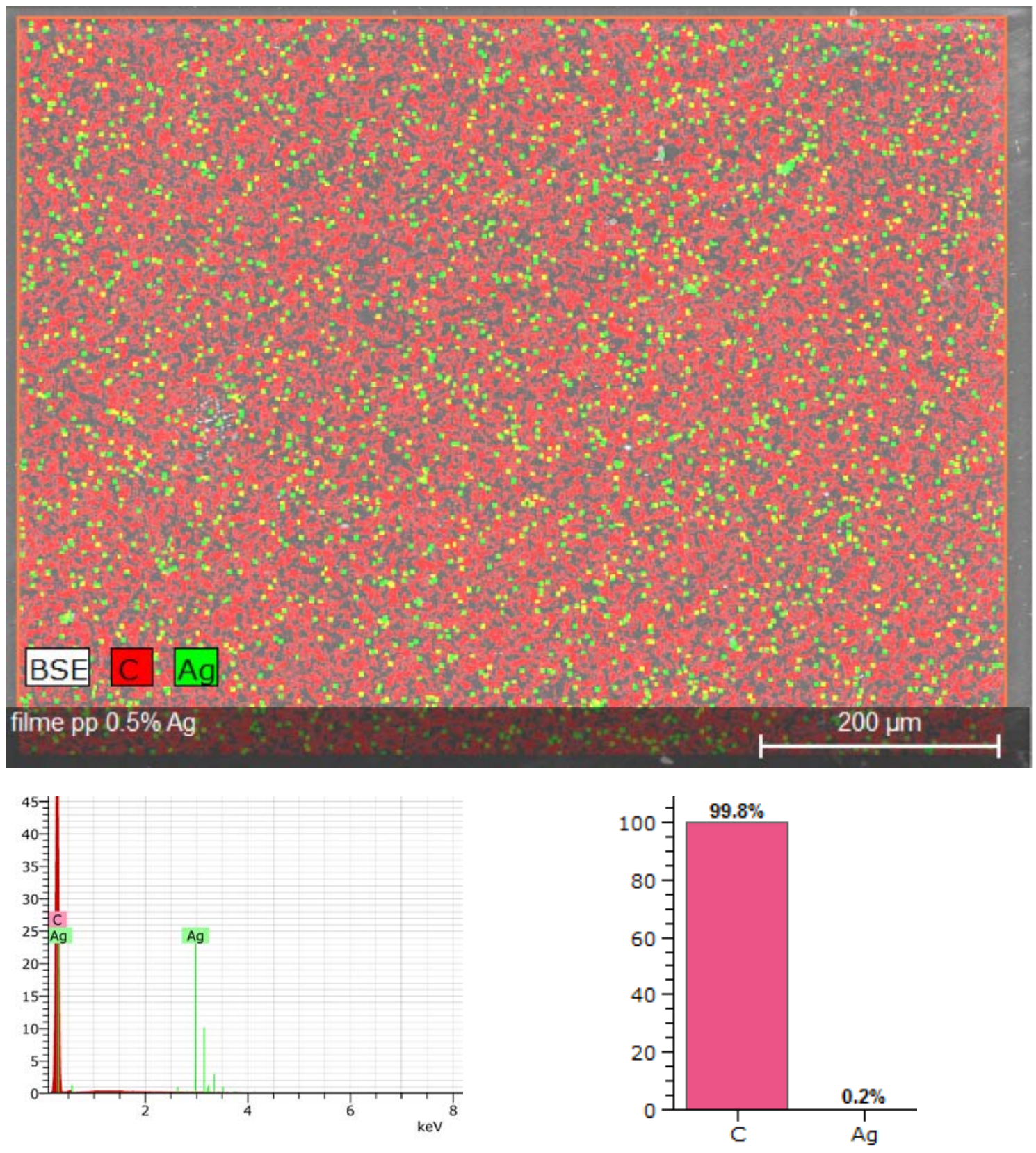

FIGURA 67 - Micrografia do filme de polipropileno com NPsAg e espectro de EDS do filme de PP 0,5\%NPsAg 

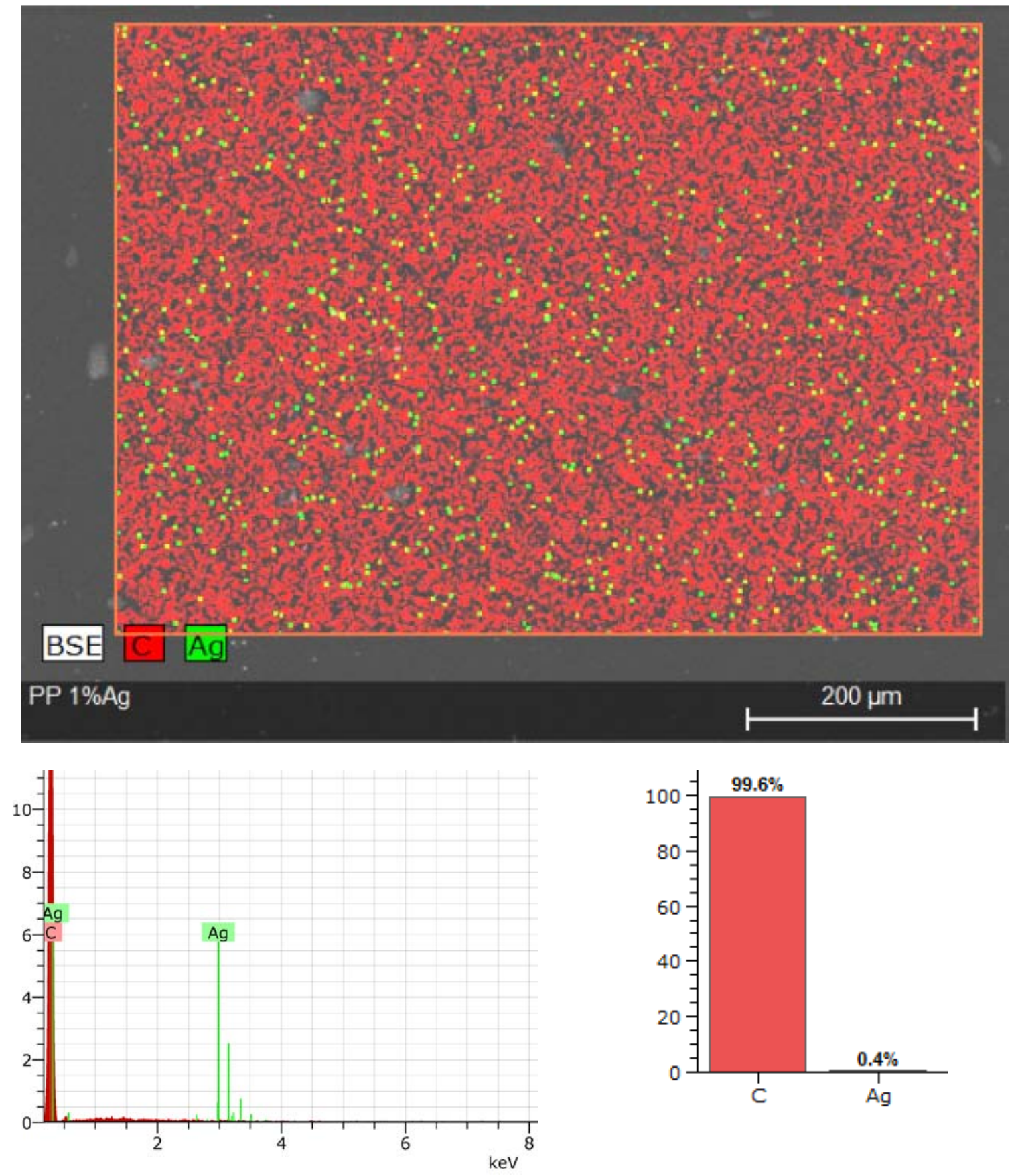

FIGURA 68 - Micrografia do filme de polipropileno com NPsAg e espectro de EDS do filme de PP 1\%NPsAg 

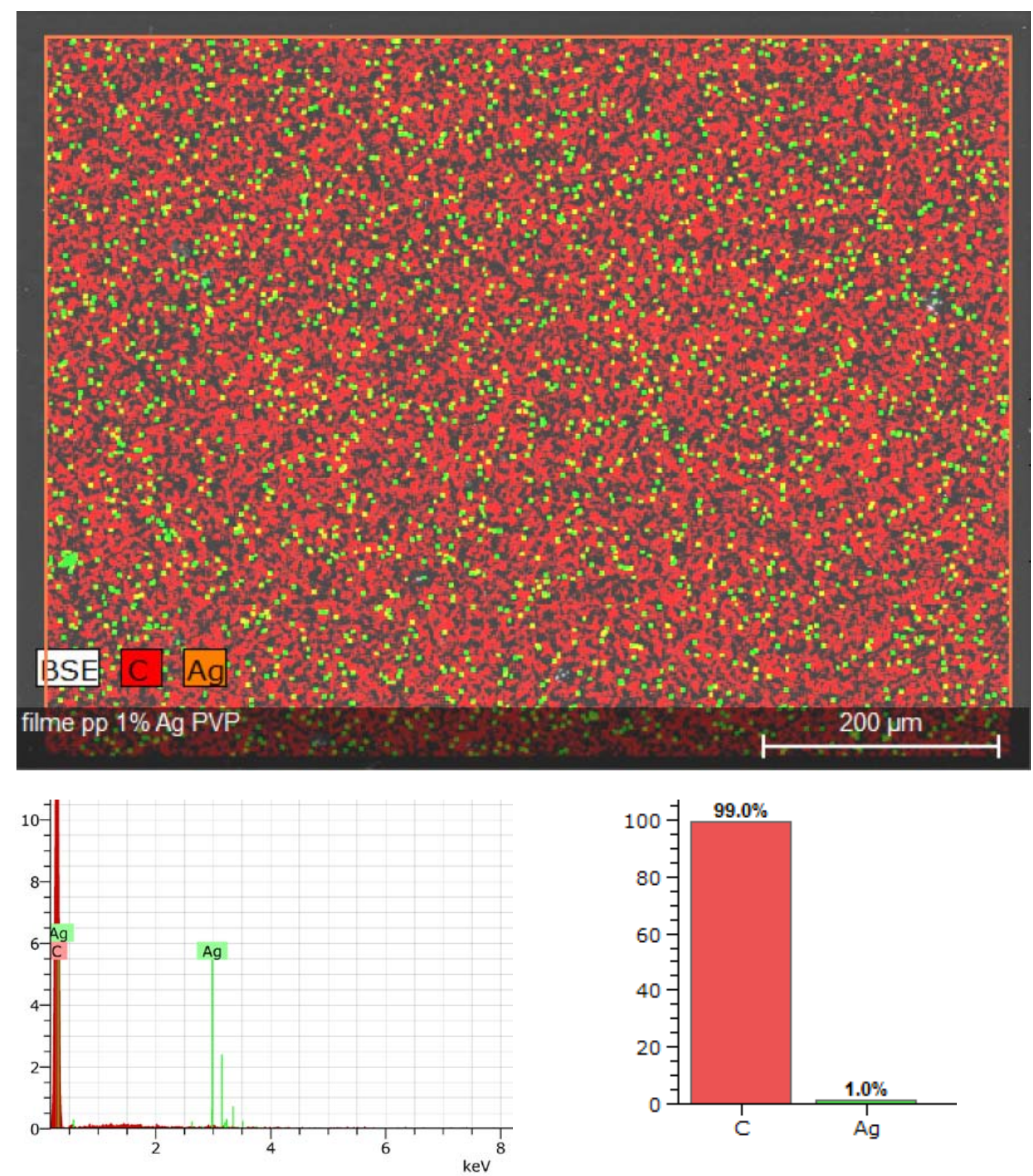

FIGURA 69 - Micrografia do filme de polipropileno com NPsAg e espectro de EDS do filme de PP 1\%NPsAg com PVP 


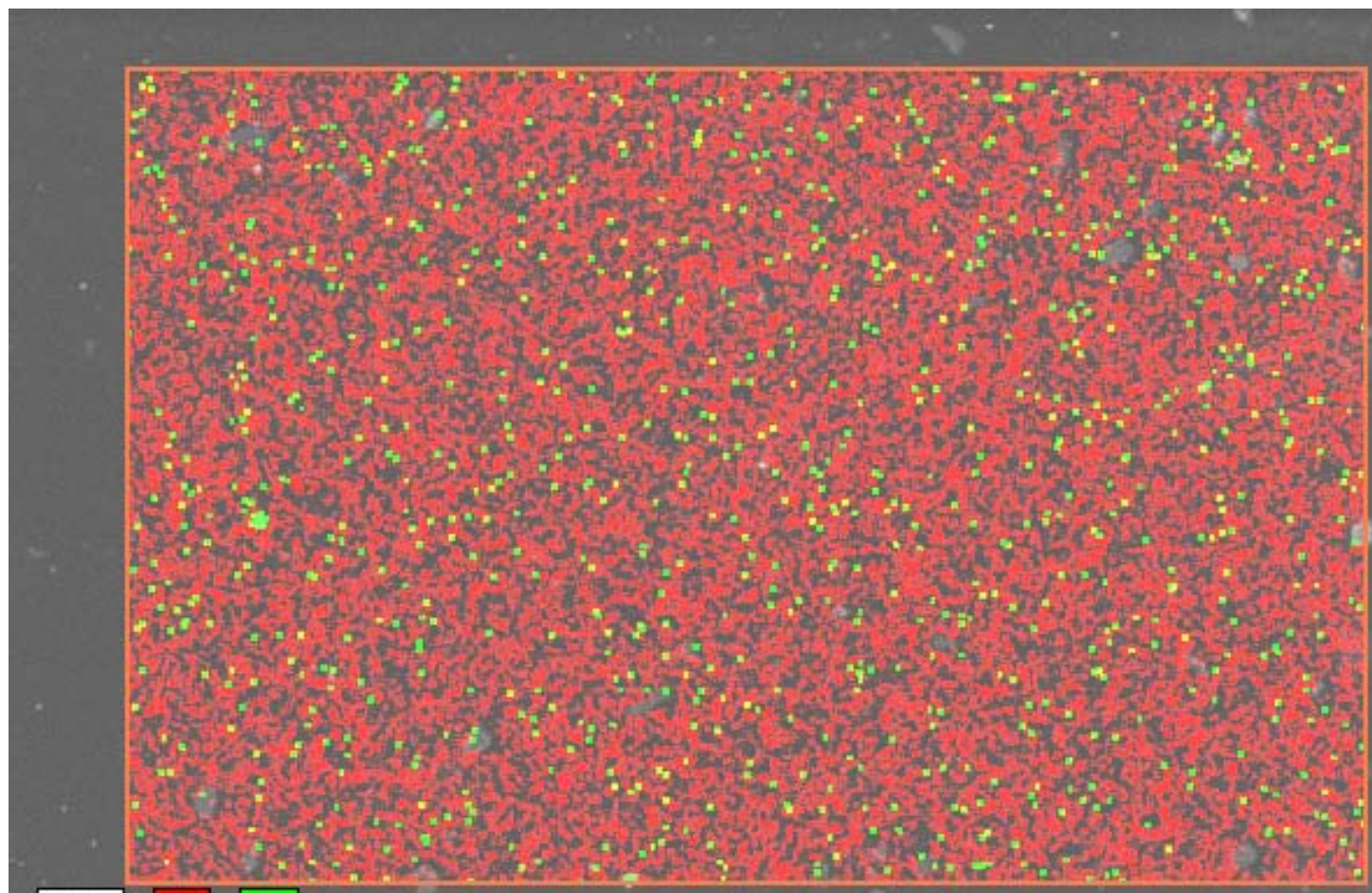

BSE C] $\mathrm{Ag}$ $\mathrm{PP} 2 \%$ Ag
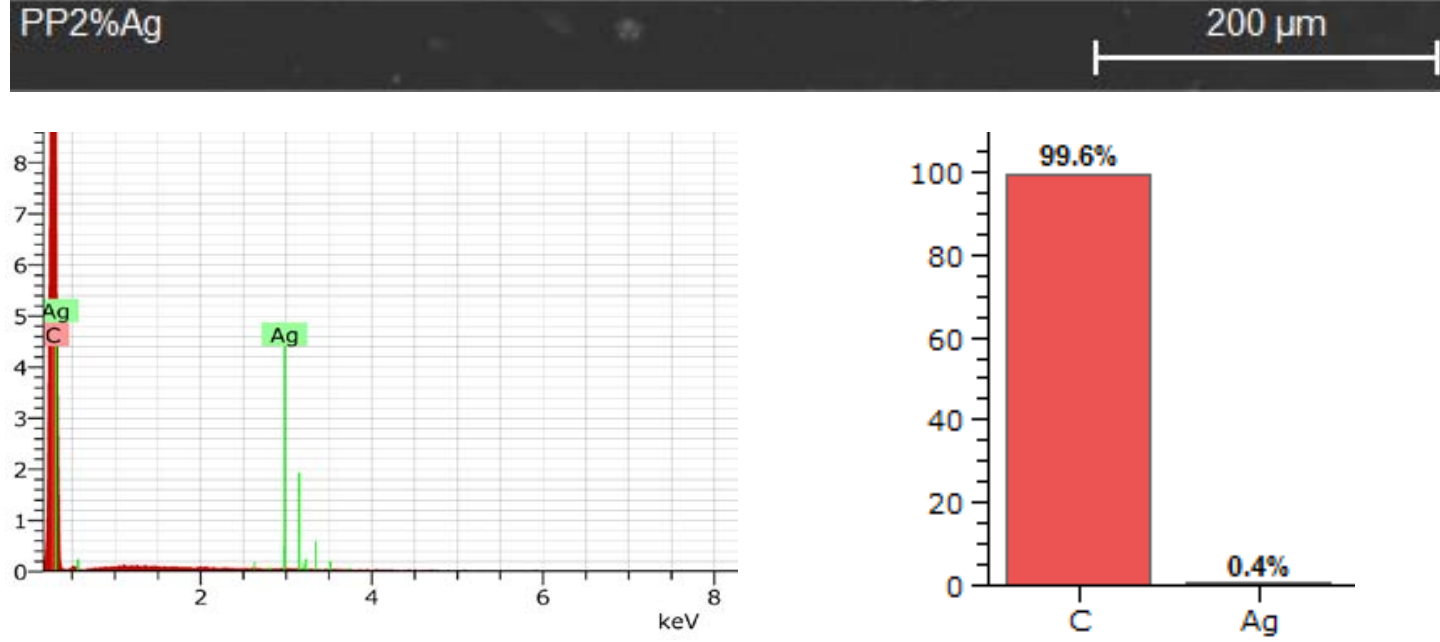

FIGURA 70 - Micrografia do filme de polipropileno com NPsAg e espectro de EDS do filme de PP 2\%NPsAg 

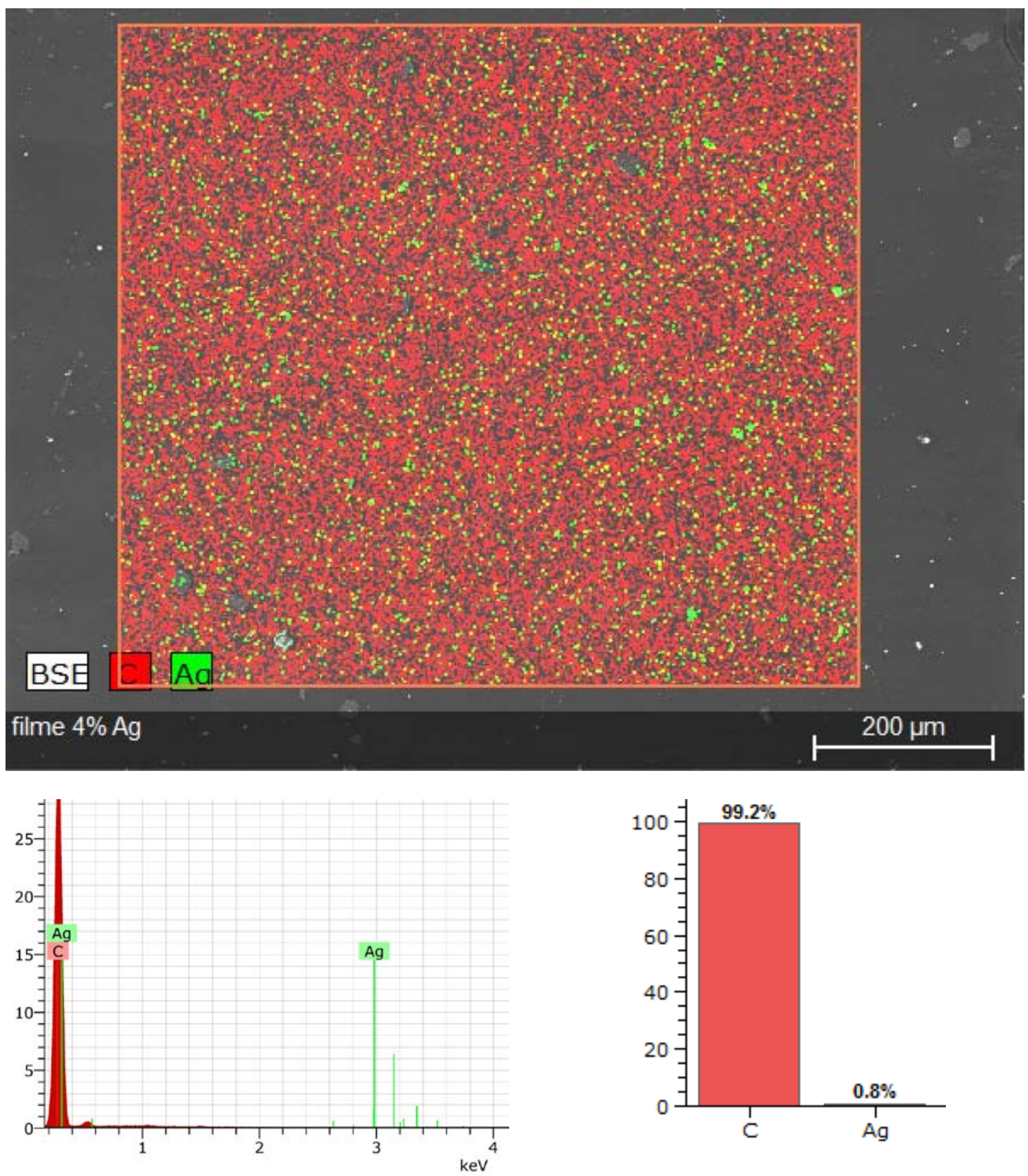

FIGURA 71 - Micrografia do filme de polipropileno com NPsAg e espectro de EDS do filme de PP 4\%NPsAg

Para a análise elementar das NPsAg utilizaram-se filmes com espessura variando de 0,39 a 0,56 mm. Nas micrografias das FIG. 64-71, estão apresentados filmes onde se nota a incidência de pontos vermelhos referentes ao carbono e pontos verdes que são aglomerados de nanopartículas de prata. Nessas mesmas (FIG.65-71) estão apresentados os espectros de EDS, nos quais 
se observam picos por volta de 3,40 KeV correspondentes às bandas de energia $\mathrm{AgL}^{211-215}$, o que confirma a presença de prata.

Deve-se ressaltar que na amostra com 0,1\% de NPsAg a solução de prata foi fornecida pela empresa "TNS Nanotecnologia" o que justifica a presença de outros componentes químicos ( $\mathrm{Br}, \mathrm{Pb}, \mathrm{Sn}, \mathrm{Nb})$.

Encontrou-se na superfície dos filmes, distribuição homogênea de NPsAg e a presença de aglomerados de prata em diferentes regiões. Conforme determinação quantitativa constataram-se nos filmes com NPsAg as seguintes proporções: $(0,1 ; 0,1 ; 0,2 ; 0,4 ; 1 ; 0,4 ;$ e $0,8 \%)$ de NPsAg nas regiões selecionadas.

\subsubsection{Espectroscopia UV-Vis}

A solução de PVP com 1\% de NPsAg foi feita utilizando-se um dispersor com velocidade de rotação de 2000 rpm, por 15 minutos.

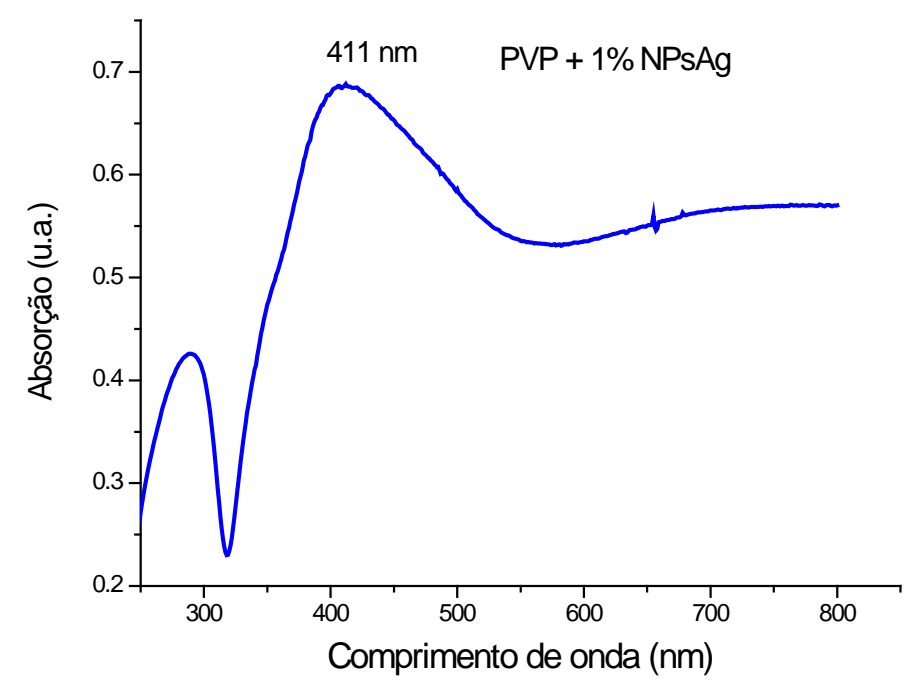

FIGURA 72 - Espectro de absorção no UV-Vis da solução de PVP com nanopartículas de prata (PVP com 1\% NPsAg) 
O espectro UV-Vis da solução está apresentado na FIG. 72, na qual se observa o pico centrado por volta de $411 \mathrm{~nm}$, característico de nanopartículas de prata com formato esférico. A análise de MET confirmou o formato esférico das NPSAg.

\subsubsection{Microscopia Eletrônica de Transmissão (TEM)}

A microscopia eletrônica de transmissão foi feita em amostras de filme de PP-1\% NPsAg, FIG. 73 (A-B).
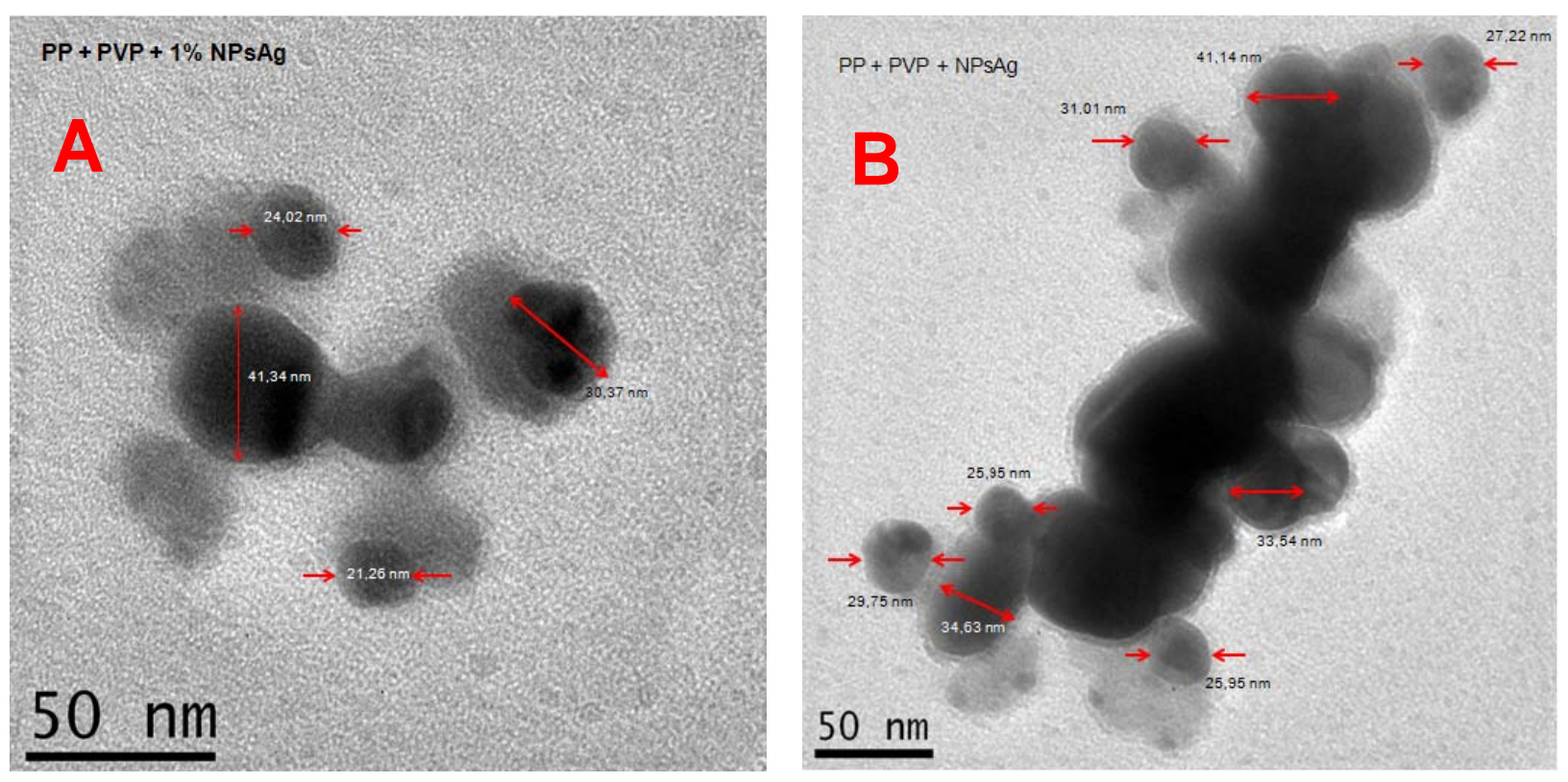

FIGURA 73 - Imagens obtidas por MET de amostras de filmes de PP 1\%NPsAg

Observa-se a presença de nanopartículas de prata (NPsAg) com formato esférico, FIG. 73A, assim como a formação de aglomerados de NPsAg, FIG 73B, nos filmes de polipropileno. O tamanho da NPsAg variam de $21 \mathrm{~nm}$ a 41 nm de diâmetro.

A dispersão das nanopartículas de prata não foi totalmente completa e a presença de aglomerados é observada. A utilização do agente tensoativo (PVP) melhora a dispersão das NPsAg. 


\subsubsection{Teste de ação bactericida nos filmes de PP-NPsAg}

\subsubsection{Redução da unidade formadora de colônias (UFC) (\%)}

Os filmes de PP-NPsAg foram testados para redução de unidade formadora de colônias (Método 1).

Amostras dos filmes em contato com solução de bactérias foram lavadas e, em seguida, a solução foi replaqueada em meio de cultura e incubadas por 24 horas.

Na FIG. 74 verifica-se um excelente efeito da atividade do filme de PP 1\%NPsAg sobre a S. aureus (gram positiva ATCC 6538).

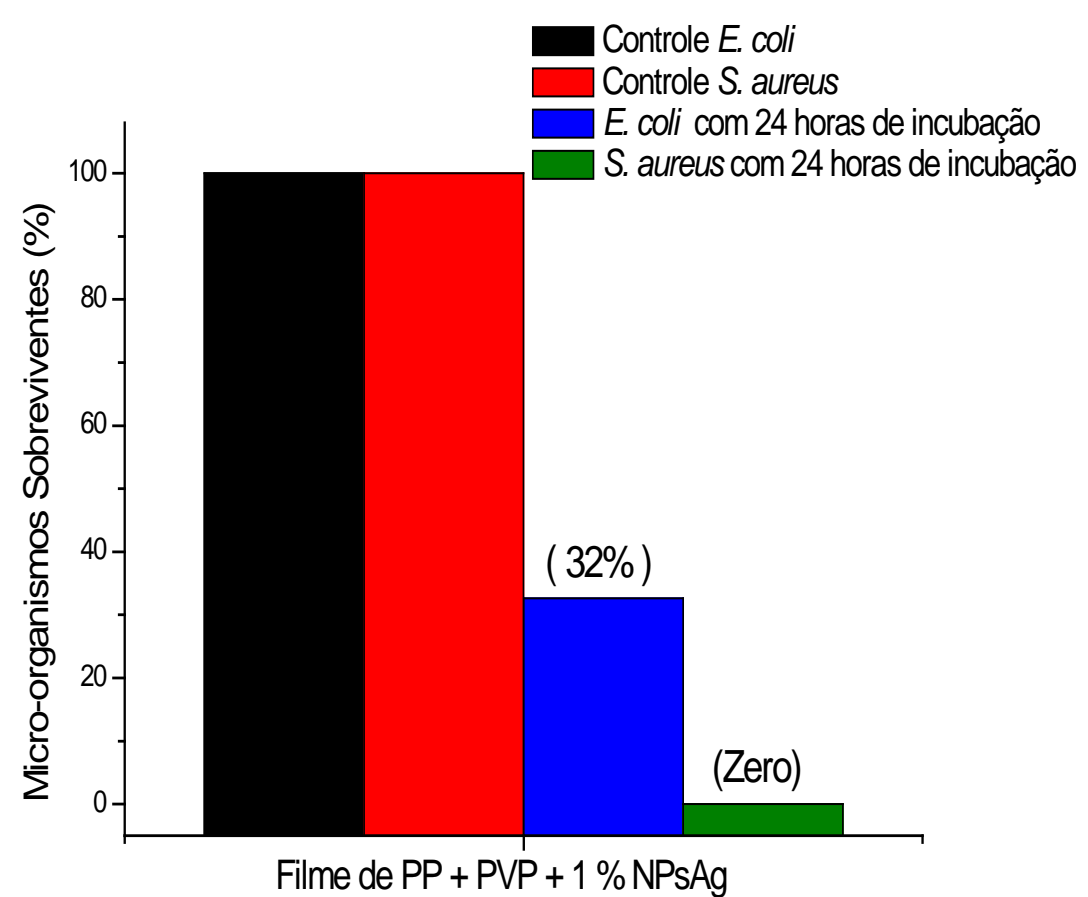

FIGURA 74 - Porcentagem de micro-organismos sobreviventes (\%) frente a $E$. coli e S. aureus 
Para E. coli, após a incubação, restaram 32\% de micro-organismos sobreviventes. Pode-se concluir que o principio ativo do filme apresenta efeito sobre as bactérias quando em contato.

Deve-se ressaltar que os mesmos testes foram efetuados nos outros filmes de PP com NPsAg, nas proporções já citadas, e a atividade antimicrobiana foi muito baixa (insuficiente) ou não ocorreu atividade antimicrobiana nos filmes, pelo método 1.

No teste realizado no ICB, método 2, os resultados confirmaram a ausência de atividade antimicrobiana dos filmes de PP com NPsAg ou pouca atividade antimicrobiana, exceto no filme de PP 1\%NPsAg (PVP). Para esse filme foi obtido o resultado relevante com $100 \%$ de morte das bactérias $P$. aeruginosa (Gram - negativa) ATCC 25923 e S. aureus (Gram - positiva) ATCC 27853.

\subsubsection{Teste de halo, sensibilidade a antimicrobianos por disco de difusão (Método 3)}

Utilizando-se discos de amostras de PP 1\%NPsAg foi feito o teste de difusão (método de Kirby-Bauer) para $P$. aeruginosa e $S$. aureus em comparação ao controle positivo, composto de antibiótico (Ciprofloxacina). Conforme ilustrado na FIG. 75 não houve formação de halo, portanto não houve a morte das bactérias distintamente do controle. 


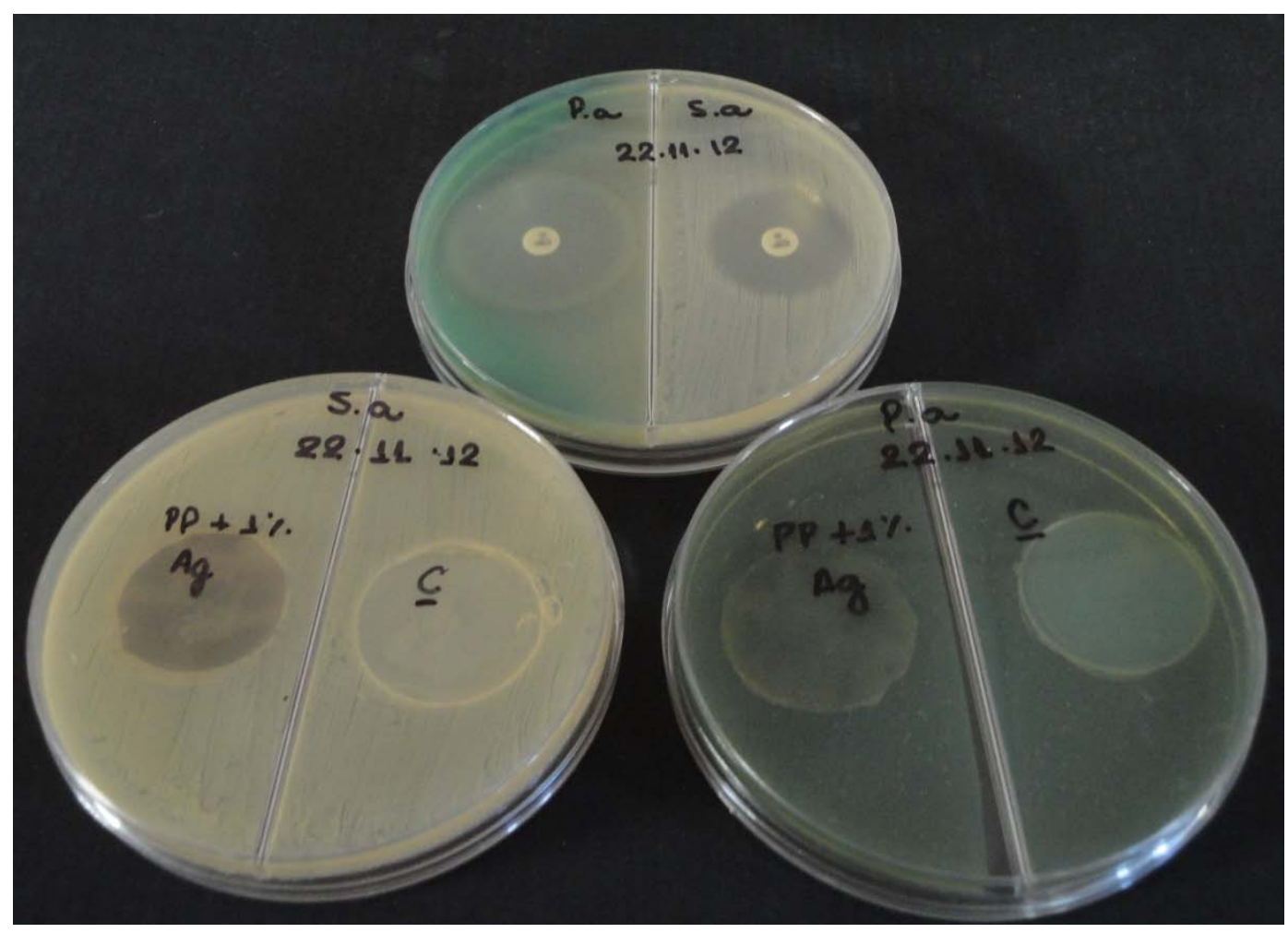

FIGURA 75 - Teste de sensibilidade a antimicrobianos por disco de difusão em amostra de filme de PP com 1\%NPsAg

O resultado obtido sugere que não houve difusão da prata para o meio de cultura.

Sobre os mesmos discos (PP 1\%NPsAg e PP) deste ensaio foram adicionados gotas de solução com bactérias e retiradas após 2 horas sendo novamente cultivadas em meio de ágar, FIG.76. 


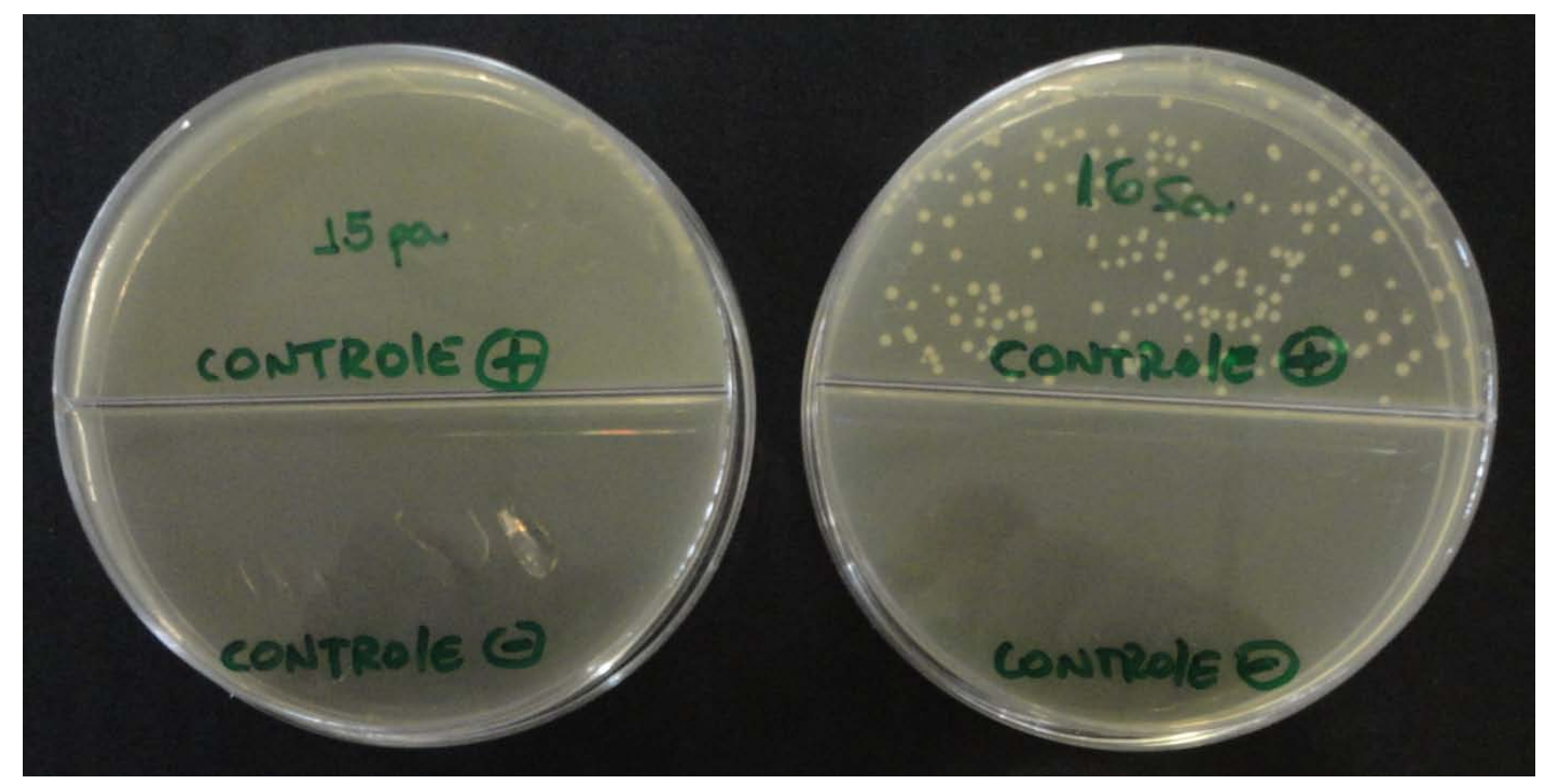

FIGURA 76 - Teste de proliferação em meio de ágar em amostra de filme de PP e PP 1\%NPsAg, controle positivo e negativo

Após o tempo de incubação, o resultado obtido indica a formação de colônias, tanto para $P$. aeruginosa quanto para $S$. aureus, para as amostras retiradas da superfície do PP. Entretanto amostras retiradas da superfície do disco de PP 1\%NPsAg não apresentaram crescimento de nenhuma das colônias indicando que o filme com prata apresentou $100 \%$ de atividade biocida.

\subsubsection{Teste de Citotoxicidade}

A FIG. 77 representa a curva de viabilidade celular em filmes de polipropileno com proporções 0,1 e 1\% de NPsAg. 


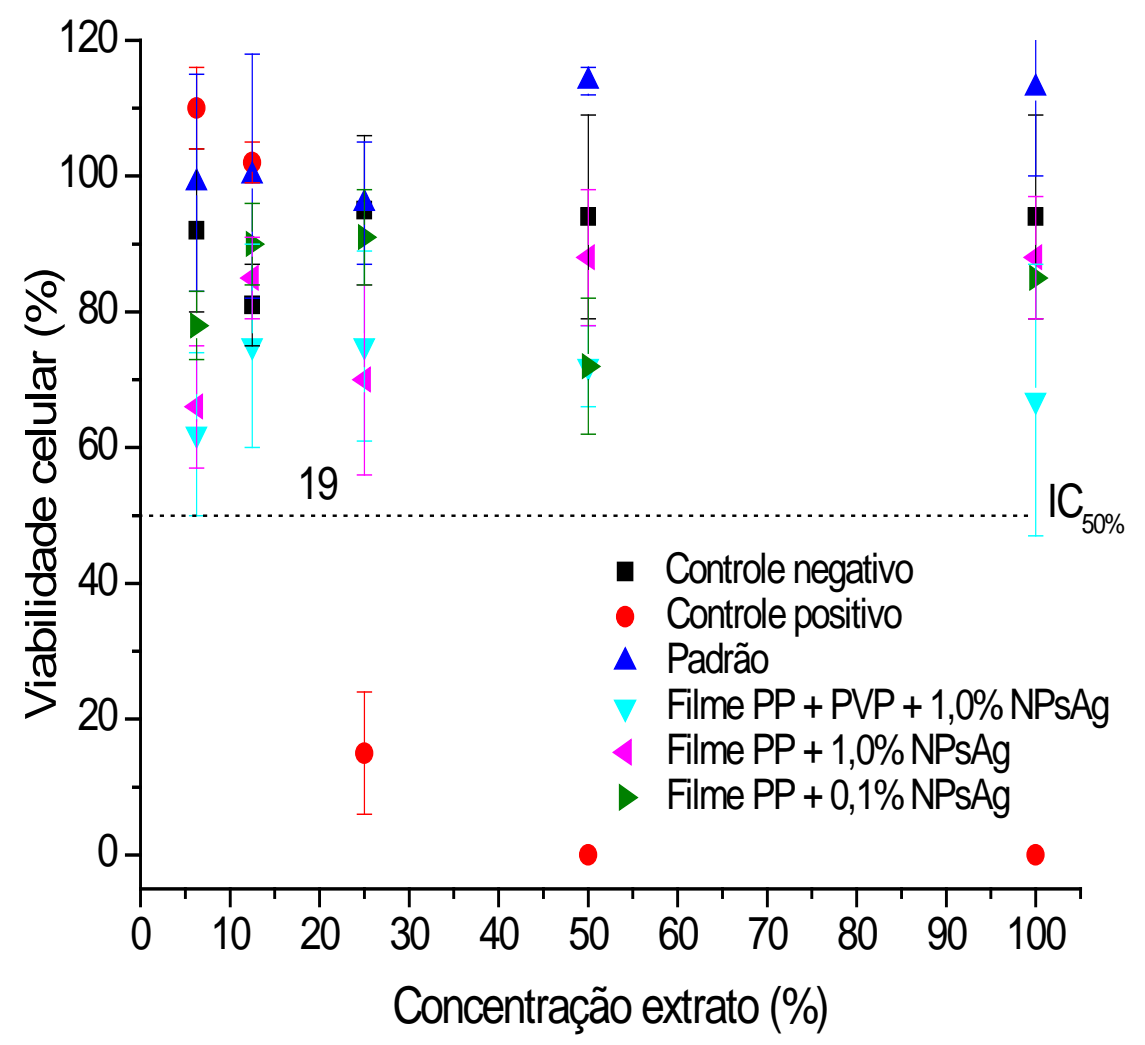

FIGURA 77 Curvas de viabilidade celular dos filmes de polipropileno contendo 0,1 e 1\% de NPsAg pela incorporação do vermelho neutro

Nos testes de citotoxicidade observou-se comportamento semelhante ao controle negativo, ou seja, os filmes testados não apresentaram toxicidade, como pode ser observado na FIG. 77 pelo resultado negativo. Portanto é possível afirmar que os filmes de PP-NPsAg são caracterizados como não citotóxicos mediante células de camundongos.

A FIG. 78 representa a curva de viabilidade celular em filmes de polipropileno com proporções de 2 e $4 \%$ de NPsAg. 


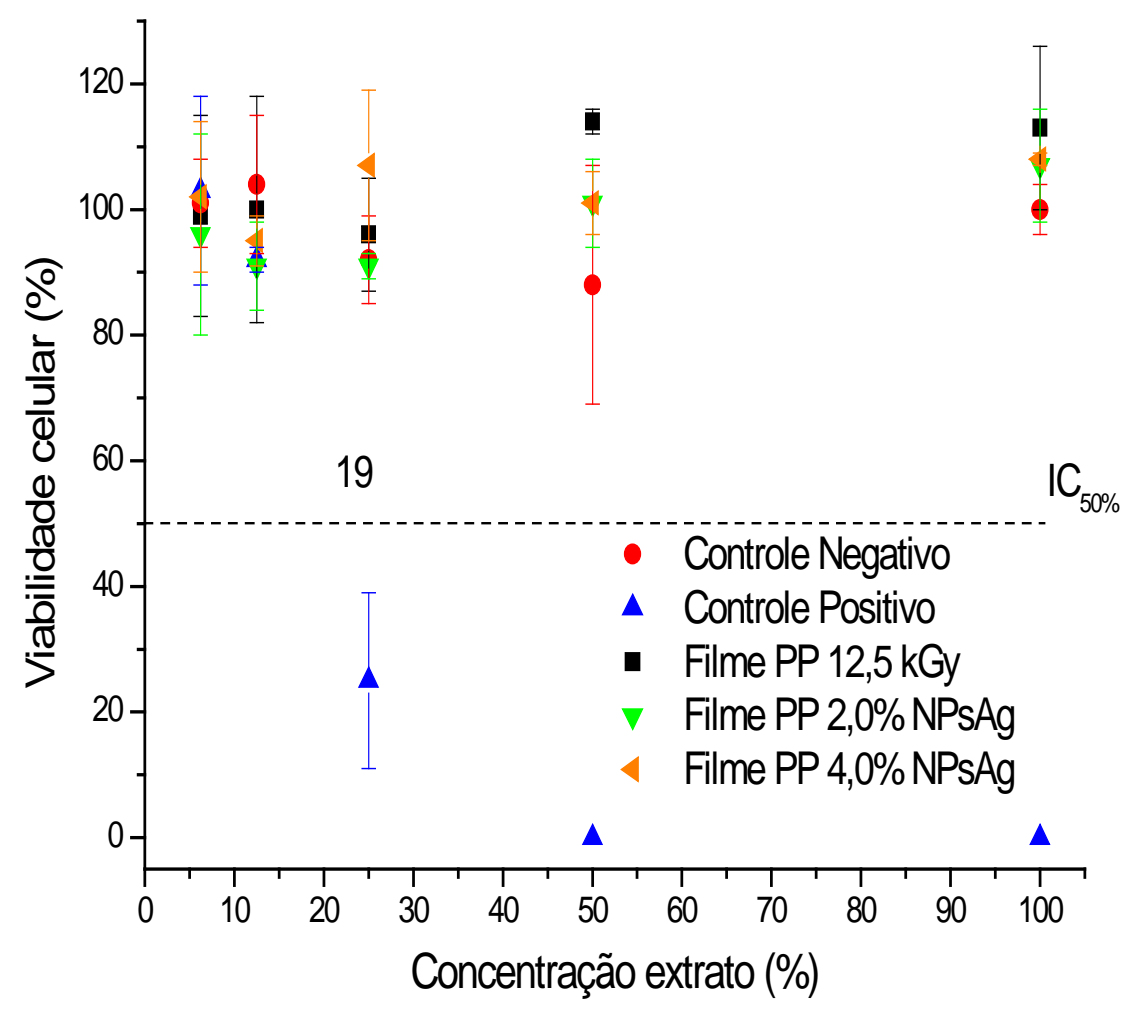

FIGURA 78 - Curvas de viabilidade celular dos filmes de polipropileno variando-se entre 2 e 4\% de NPsAg pela incorporação do vermelho neutro

Nos testes de citotoxicidade observou-se comportamento semelhante ao controle negativo, ou seja, os filmes testados variando-se entre 2 e $4 \%$ de NPsAg não apresentaram toxicidade, como pode ser observado na FIG. 78 pelo resultado negativo. Portanto é possível afirmar que os filmes de PP-NPsAg são caracterizados como não citotóxicos enquanto ensaiados em células de camundongo. 


\section{CONCLUSÕES}

A formação de nanogéis vem de sítios de irradiação que antecedem a formação de ligações cruzadas (reticulação) e de pequenos segmentos provenientes da cisão. A evolução do tamanho dos nanogéis depende da criação de domínios intersticiais com menor densidade de reticulação e um grande número de defeitos provenientes da irradiação. A irradiação é responsável pela formação de núcleos de cristalitos na fase amorfa com a evolução de uma rede de esferulitos. A formação de nanogéis foi observada em filmes depositados a partir de soluções de PP irradiado. Os nanogéis são compostos por uma fase cristalina e uma fase amorfa cuja formação se dá a partir de núcleos de reticulação causados pela radiação.

O estudo da formação de géis no PP modificado por radiação ionizante demonstrou a relação da sua formação com a dose de radiação. A morfologia dos géis é de nanogéis ligados por moléculas de interligação (tie molecules).

Nanogéis de polipropileno são estruturas nanométricas. São obtidos por irradiação e foram constatados nas doses de 12,5 e 20 kGy. Os nanogéis são formações reticuladas, ramificadas, e emaranhadas, nucleadas em regiões de incidência de alta concentração de energia (spurs) em uma amostra irradiada.

A nanoprata mostrou-se homogeneamente (ou não) dispersa nos géis obtidos com NPsAg. A cristalização dos géis se dá na presença da nanoprata com a indução da fase $\beta$ no polipropileno. Resultado importante foi o obtido com a utilização de filmes de géis de PP com a adição de diferentes proporções de NPsAg $(0,5 \%, 1 \%, 2 \%$ e $4 \%)$, em que foi evidenciado a eficácia da ação biocida da prata nos géis a partir da concentração de 1\% NPsAg.

Resultados positivos de atividade bactericida dos géis e a elaboração de filmes de PP com PP modificado e adição de nanopartículas de prata visando 
à ação biocida foram alcançados. Pelos testes realizados, o melhor resultado obtido foi no filme preparado com a utilização do surfactante (PVP) e 1\% de NPsAg. Apenas para este filme o resultado biocida foi positivo tanto para E. coli , $P$. Aeruginosa como para $S$. aureus. Nos testes de citotoxicidade os filmes de polipropileno com NPsAg demonstraram não serem tóxicos ao meio.

Deve-se buscar o aprimoramento do processo com a redução do tamanho dos aglomerados e melhoria na distribuição das NPsAg no filme polimérico, com o intuito de se obter um resultado ainda mais expressivo da ação biocida da prata.

Tanto os filmes como os géis contendo nanoprata demonstraram ser não citotóxicos em meio de células de camundongos. 


\section{REFERÊNCIAS BIBLIOGRÁFICAS}

1. PASQUINI, N. Polypropylene Handbook. 2nd ed. Hanser Gardner Publications. p. 1-12, 2005.

2. LONKAR, S. P.; MORLAT-THERIAS, S.; CAPERAA, N.; LEROUX, F.; GARDETTE, J. L.; SINGH, R.P. Preparation and nonisothermal crystallization behavior of polypropylene/layered double hydroxide nanocompósitos. Polymer, 50, p. 1505-1515, 2009.

3. ABIPLAST. Associação Brasileira da Indústria do Plástico -. Perfil 2011. Disponível em:<http://www.abiplast.org.br>. Acesso em: 25 fev. 2013.

4. ABIPLAST. Associação Brasileira da Indústria do Plástico. Disponível em: $<$ http://www.abiquim.org.br/resinastermoplasticas/estatisticas_32.asp>. Acesso em: 01 set. 2012.

5. ARLMAN, E. J. Ziegler-Natta Catalysis II. Surface Structure of Layer-Lattice Transition Metal Chlorides. J. Catalysis, v.3, p. 89-98, 1964.

6. NATTA, G.; CORRADINI, P.; ALLEGRA, G. The different crystalline modifications of $\mathrm{TiCl}_{3}$, a catalysis component for the polymerization of $\alpha$ olefins. I: $\alpha-, \beta-, \gamma-\mathrm{TiCl}_{3}$. II $-\delta-\mathrm{TiCl}_{3}$. J. Polym. Sci., v.51, n¹56, p.399-410, 1961.

7. MARQUES, M.F.V.; JUNIOR, P.A.C.; GUIMARÃES, M.J.C.; COUTINHO, F.M.B. Catalisadores Metalocênicos: Aspectos Gerais e Heterogeneização. Polímeros: Ciência e Tecnologia, v.8, n³, p.26-40, 1998.

8. MANRICH, S. Processamento de Termoplásticos. Capítulo 5 - Exemplo de Extrusão de um Produto Fabricado com Polímero Termoplástico. Artliber, p. 231-275, 2005.

9. OTAGURO, H.; ARTEL, B. W. H.; PARRA, D. F.; CARDOSO, E. C. L.; LIMA, L. F. C. P.; LUGAO, A. B. The behavior in the melt state of polypropylene (PP) in the presence of trifunctional monomers and their influence in PP morphology. Polímeros: Ciência e Tecnologia, v.14, n², p. 99-104, 2004.

10. RÄTZSCH, M.; ARNOLD, M.; BORSIG, E.; BUCKA, H.; REICHELT, N. Radical reactions on polypropylene in the solid state. Prog. Polym. Sci., v.27, p. 1195-1282, 2002. 
11. YOSHII, F.; MAKUUCHI, K.; KIKUKAWA, S.; TANAKA, T.; SAITOH, J.; KOYAMA, K. High-Melt-Strength Polypropylene with Electron Beam Irradiation in the presence of Polyfunctional Monomers. J. Appl. Polym. Sci., v.60, p. 617-623, 1996.

12. LUGAO, A.B.; HUTZLER, B.; OJEDA, T.; TOKUMOTO, S.; SIEMENS, R.; MAKUUCHI, K.; VILLAVICENCIO, A.L.C.H. Reaction mechanism and rheological properties of polypropylene irradiated under various atmospheres. Radiat. Phys. Chem., v.57, p. 389-392, 2000.

13. OJEDA, T. M.; TOKUMOTO, S.; BRACANCA, A. L. D.; CASSINELLI, L. F.; LUGAO, A. B.; HUTZLER, B. W. Patent US 2004/0171712. Process for preparing high melt strength polypropylene and crosslinked prepared therewith.

14. LUGÃO, A. B. Estudo da síntese por irradiação, da estrutura e do mecanismo de formação de polipropileno com alta resistência do fundido. 2004. Tese (Doutorado) - Instituto de Pesquisas Energéticas e Nucleares, São Paulo.

15. OliANI, W. L.; PARRA, D. F.; LIMA, L. F. C. P.; LUGAO, A. B. Morphological characterization of branched PP under stretching. Polym. Bull., v.68, p. 2121-2130, 2012.

16. CLOUGH, R. L.; SHALABY, S. W. Radiation Effects on Polymers. In: Williams, j. I. Chapter 35 - Stability of Polypropylene to Gamma Irradiation, ACS, p. 554-568, 1991.

17. OLIANI, W. L. Estudo do comportamento de HMS-PP (Polipropileno com Alta Resistência do Fundido) sob condições de degradação ambiental e acelerada. 2008. Dissertação (Mestrado) - Instituto de Pesquisas Energéticas e Nucleares, São Paulo.

18. ROSIAK, J. M. Gel/Sol Analysis of Irradiated Polymers. Radiat. Phys. Chem., v.51, $n^{\circ} 1$, p. 13-17,1998.

19. KADLUBOWSKI, S.; ULANKI, P.; ROSIAK, J. M. Synthesis of tailored nanogels by means of two-stage irradiation. Polymer, v.53, p. 1985-1991, 2012.

20. CHAPIRO, A. Radiation Chemistry of Polymeric Systems. Chapter IX Radiation Effects in Polymers of the Cross-linking Type. Wiley-Interscience, p. 385, 1962.

21. FUNKE, W.; OKAY, O.; JOOS-MULLER, B. Microgels-Intramolecularly Crosslinker Macromolecules with a Globular Structure. Adv. Polym. Sci., v.136, p. 139-234, 1998. 
22. ZAGÓRSKI, Z. P. Modification, degradation and stabilization of polymers in view of the classification of radiation spurs. Radiat. Phys. Chem., v.63, p. 919, 2002.

23. CHANDA, M.; ROY, S. K. Plastics Fundamentals, Properties, and Testing. CRC Press, p. 1-38, 2009.

24. ODIAN, G. Principles of Polymerization. Canada - Wiley-Interscience. Fourth Edition. p. 17, 2004.

25. SPERLING, L.H. Introduction to Physical Polymer Science. WileyInterscience, fourth edition, p. 18-53, 2006.

26. BRADLEY, R. Radiation Technology Handbook. Chapter 5 - Irradiation Polymers: Crosslinking. Marcel Dekker, INC. p. 59-83, 1984.

27. Encyclopedia of Polymer Science and Technology. HILL, D. J. T. \& WHITTAKER, A. K. Radiation Chemistry of Polymers, John Wiley \& Sons, p. 1-55, 2005.

28. Irradiation Effects on Polymers. Chapter 3 - Radiation of Polymers and Composites, CLOUGH, R. L.; GILLEN, K. T. Edited by D. W. Clegg \& A. A. Collyer, p. 80, 1991.

29. MAKUUCHI, K.; CHENG, S. Radiation Processing of Polymer Materials and Its Industrial Applications. Chapter 1 - Basic Concepts of Radiation Processing. John Wiley \& Sons, p. 19, 2012.

30. SARCINELLI, L. VALENZA, A.; SPADARO, G. Inverse response of polypropylene to gamma radiation under vacuum. Polymer, v.38, n¹0, p. 2307-2313, 1997.

31. LUGAO, A. B., ARTEL, B. W. H., YOSHIGA, A., LIMA, L. F. C. P., PARRA, D. F., BUENO, J. R., LIBERMAN, S., FARRAH, M., TERÇARIOL, W. R.; OTAGURO, H. Production of high melt strength polypropylene by gamma irradiation. Radiat. Phys. Chem., v.76, p. 1691-1695, 2007.

32. GLOOR, P. E., TANG, Y., KOSTANSKA, A. E.; HAMIELEC, A. E. Chemical modification of polyolefin's by free radical mechanisms: a modelling and experimental study of simultaneous random scission, branching and crosslinking. Polymer, v.35, n5, p. 1012-1030, 1994.

33. TOBITA, H. Molecular weight development during simultaneous chain scission, long-chain branching and crosslinking. Macromol. Theory. Simul., v.12, p. 24-31, 2003. 
34. CHARLESBY, A. Atomic Radiation and Polymers. Chapter 11 Alternative methods of network formation. Pergamon Press. p. 171-181, 1960.

35. BOVEY, F. A. The effects of ionizing radiation on natural and synthetic high polymers. Chapter IV - Statistical treatment of crosslinking and scission occurring under ionizing radiation. Interscience Publishers, INC., New York, p. 90-91, 1958.

36. ROMANI, F.; CORRIERI, R.; BRAGA, V.; CIARDELLI, F. Monitoring the chemical crosslinking of propylene polymers through rheology. Polymer, v.43, p.1115-1131, 2002.

37. PAUL, D. R.; ROBESON, L. M. Polymer Nanotechnology: Nanocomposites. Polymer, v.49, p. 3187-3204, 2008.

38. KUMAR, A. P.; DEPAN, D., TOMER, N. S.; SINGH, R. P. Nanoscale particles for polymer degradation and stabilization - Trends and future perspectives. Prog. Polym. Sci., v.34, p. 479-515, 2009.

39. DUNCAN, T. V. Applications of nanotechnology in food packing and food safety: Barrier materials, antimicrobials and sensors. J. Colloid. Interf. Sci., v.363, p. 1-24, 2011.

40. ZHANG, L.; WEBSTER, T. J. Nanotechnology and Nanomaterials: Promises for improved tissue regeneration. Nano. Today., v.4, p. 66-80, 2009.

41. MAMALIS, A. G. Recent advances in nanotechnology. J. Mater. Process. Technol., v.181, p. 52-58, 2007.

42. DURÁN, N.; MATTOSO, L. H. C.; DE MORAIS, P. C. Nanotecnologia. Capítulo 1 - Nanotecnologia. Artliber, p. 13-29, 2006.

43. GUPTA, R. K.; KENNEL, E.; KIM, K-J. Polymer Nanocomposites Handbook. Chapter 3 - The incorporation of Nanomaterials into polymer media. CRC Press-Taylor \& Francis Group. p. 22, 2010.

44. ANDRADE, C. T.; COUTINHO, F. M. B.; DIAS, M. L.; LUCAS, E. F.; OLIVEIRA, C. M. F.; TABAK, D. Dicionário de Polímeros. Interciência, p. 107, 2001.

45. WORK, W.J.; HORIE, K.; HESS, M.; STEPTO, R.F.T. Definitions of Terms related to Polymer Blends, Composites, and Multiphase Polymeric Materials.

Pure Appl. Chem., v.76, 11, p. 1985-2007, 2004. 
46. GOESMANN, H.; FELDMANN, C. Nanoparticulate Functional Materials. Angew. Chem. Int. Ed., v.49, p. 1362-1395, 2010.

47. CAPEK, I. Nanocomposite Structures and Dispersions - Science and Nanotechnology - Fundamental Principles and Colloidal Particles. Chapter 1 - Nanotechnology and Nanomaterials. Elsevier, v. 23, p. 1-69, 2006.

48. SCHWARTZ, M. New Materials Processes, and Methods Technology. Chapter 2 - Nanotechnology. CRC Press - Taylor \& Francis Group, USA. p. 15, 2006.

49. MITTAL, V. Advances in Polyolefin Nanocomposites. Chapter 1 Polyolefin Nanocomposites Technology. Edited by Vikas Mittal. CRC PressTaylor \& Francis Group. p. 1-24, 2011.

50. MAGDASSI, S.; GROUCHKO, M.; KAMYSHNY, A. Structure and Functional Properties of Colloidal Systems. Chapter 15- Colloidal Dispersion of Metallic Nanoparticles: Formation and Functional Properties. CRC Press, p.343, 2010.

51. CASERI, W. Metal-Polymer Nanocomposites. Chapter 9 - Opticaly Anisotropic Metal-Polymer Nanocomposites. John Wiley \& Sons, p. 272, 2005.

52. KAMYSHNY, A.; MAGDASSI, S. Nanoscience Colloidal and Interfacial. Chapter 25 - Aqueous Dispersions of Metallic Nanoparticles: Preparation, Stabilization, and Application. CRC Press, p. 747-778, 2010.

53. HONG-BO, W.; JIN-YAN, W.; QU-FU, W.; JIAN-HAN, H. Nanostructured antibacterial silver deposited on polypropylene nonwovens. Surf. Rev. Lett., v. 14, nº 4 , p.553-557, 2007.

54. LIANG, G. D.; BAO, S. P.; TJONG, S. C. Microstructure and properties of polypropylene composites filled with silver and carbon nanotube nanoparticles prepared by melt-compounding. Mat. Sci. Eng. B., v.142, p.55-61, 2007.

55. YEO, S. Y.; JEONG, S. H. Preparation and characterization of polypropylene/silver nanocomposite fibers. Polym. Int., v.52, p.1053-1057, 2003.

56. JEONG, S. H.; YEO, S. Y.; YI, S. C. The effect of filler particle size on the antibacterial properties of compounded polymer/silver fibers. J. Mat. Sci., v.40, p. 5407-5411, 2005.

57. YEO, S. Y.; LEE, H. J.; JEONG, S. H. Preparation of nanocomposite fibers for permanent antibacterial effect. J. Mat. Sci., v.38, p. 2143-2147, 2003. 
58. PONGNOP, W.; SOMBATSOMPOP, K.; KOSITCHAIYONG. Effects of incorporating technique and silver colloid content on antibacterial performance for thermoplastic films. J. Appl. Polym. Sci., v.122, p. 34563465, 2011.

59. STARÁ, H.; STARY, Z.; MÜNSTEDT, H. Silver nanoparticles in blends of polyethylene and a superabsorbent polymer: Morphology and silver ion release. Macromol. Mater. Eng., v.296, p. 423-427, 2011.

60. RAI, M.; YADAV, A.; GADE, A. Silver nanoparticles as a new generation of antimicrobials. Biotechnol. Adv., v.27, p. 76-83, 2009.

61. SILVER, S.; PHUNG, L. T.; SILVER, G. Silver as biocides in burn and wound dressings and bacterial resistance to silver compounds. J. Ind. Microbiol. Biotechnol., v.33, p. 627-634, 2006.

62. HORSFALL, J.G. Principles of fungicidal action. Chron. Bot. Comp. Waltham, Mass., p. 166, 1956.

63. MATOLCSY, G. Y.; NÁDASY, M.; ANDRISKA, V. Pesticide Chemistry. Chapter 5 - In Nádasy, Fungicides, Elsevier, p. 272, 1988.

64. AYDIN, M.; YARKIN, F.; SERIN, M. S.; KIBAR, F. Morphological changes in Candida albicans induced by a silver anode. Ann. Med. Sci., v.6, p. 88-92, 1997.

65. BERGER, T.J.; SPADARO, J.A.; BIERMAN, R.; CHAPIN, S.E.; BECKER, R.O. Antifungal properties of electrically generated metallic ions. Antimicrob. Agents. Chemother., v.10, n5, p. 856-860, 1976.

66. SOMERS, E. The fungitoxicity of metal ions. Ann. Appl. Biol., v.49, p. 246253, 1961.

67. BERNI, E.; RIBEIRO, C.; ZUCOLOTTO. V. Síntese de Nanopartículas de Prata para Aplicação na Sanitização de Embalagens. ISSN 1517-4786, São Carlos, 2008.

68. ZHAO, G.; STEVENS, E. Multiple parameters for the comprehensive evaluation of the susceptibility of Escherichia coli to the silver ion. BioMetals., v.11, p. 27-32, 1998.

69. ANSARI, M.A.; KHAN, H.M.; KHAN, A.A.; MALIK, A.; SULTAN, A.; SHAHID, M.; SHUJATULLAH, F.; AZAM, A. Evaluation of antibacterial activity of silver nanoparticles against MSSA and MSRA on isolates from skin infections. Biol. Med., v.3, nº 2 , p. 141-146, 2011. 
70. JAISWAL, S.; MCHALE, P.; DUFFY, B. Preparation and rapid analysis of antibacterial silver, cooper and zinc doped sol-gel surfaces. Colloid. Surf. B., v.94, p. 170-176, 2012.

71. Disponível em: <http://www.ptonline.com/articles/no-2---polypropylene>. Acesso em: 12 jan. 2013.

72. MANRICH, S. Processamento de Termopláticos. São Paulo: Artliber, p. 230-275, 2005.

73. CANEVAROlO JR., S. V. Ciência dos Polímeros. São Paulo: Artliber, 2. ed., p. 57, 2006.

74. MARINHO, J. R. D. Macromoléculas e Polímeros. São Paulo: Manole, p. $27,2005$.

75. BRYDSON, J. A. Plastics Materials. Oxford: British Library, 7 ed, p. 68, 1999.

76. DEALY, J. M.; LARSON, R. G. Structure and Rheology of Molten Polymers: From Structure to Flow Behavior. Hanser, p. 28, 2006.

77. CHANDA, M.; ROY, S. Plastics Fundamentals, Properties, and Testing. United States of America. CRC Press - Taylor \& Francis Group. p. 25, 2009.

78. DE-PAOLI, M-A. Degradação e Estabilização de Polímeros. Capítulo 3 Formas independentes de iniciação das reações de degradação. São Paulo: Artliber, p. 69-112, 2008.

79. BUSFIELD, W. K.; APPLEBY, R. W. Crosslink enhancement in polypropylene film by gamma irradiation in the presence of acetylene. British. Polym. J., v.18, n5, p. 340-344, 1986.

80. MATSUDA, H., INOUE, T., OKABE, M.; UKAJI, T. Study of polyolefin gel in organic solvents I. Structure of isotactic polypropylene gel in organic solvents. Polym. J., v.19, n³, p. 323-329, 1987.

81. HU, G-H.; FLAT, J-J.; LAMBLA, M. Free radical grafting of monomers onto polymers by reactive extrusion: principles and applications. In: AlMalaika S. editor. Reactive modifiers for polymers. London: Blackie Academic and Professional Chapman and Hall. p. 1-77,1996.

82. PASSAGLIA, E.; COIAI, S.; AUGIER, S. Control of macromolecular architecture during the reactive functionalization in the melt of olefin polymers. Prog. Polym. Sci., v.34, p. 911-947, 2009. 
83. CHAPIRO, A. Chemical modifications in irradiated polymers. Nucl. Instrum. Meth. B., v.32, p. 111-114, 1988.

84. SCOTT, G. Mechanisms of Polymer Degradation and Stabilisation. In: Carlsson, D. J., Chmela, S. Chapter 4 - Polymers and High-Energy Irradiation: Degradation and Stabilization., Elsevier, p. 109-133, 1990.

85. KELEN, T. Polymer Degradation. Chapter 6 - Oxidative Degradation. Van Nostrand Reinhold Company, p. 107-136, 1983.

86. CHARLESBY, A. Atomic Radiation and Polymers. Chapter 28 Mechanism of Crosslinking and Degradation. Pergamon Press, p. 467-491, 1960.

87. HILL, D.J.; WHITTAKER, A. K. Encyclopedia of Polymer Science and Technology. Radiation Chemistry of Polymers., p. 39, 2005.

88. ROSA, D. S.; ANGELINI, J. M. G.; AGNELLI, J. A. M.; MEI, L. H. I. The use of optical microscopy to follow the degradation of isotactic polypropylene (iPP) subjected to natural and accelerated ageing. Polym. Test., v. 24, p. 1022-1026, 2005.

89. TAN, X.; XU, Y.; WANG, C. Pre-irradiation-induced graft reaction of maleic anhydride onto polypropylene. Radiat. Eff. Defect. S., v.161, no9, p. 529535, 2006.

90. BOCCHINI, S.; MORLAT-THERIAS, S.; GARDETTE, J. L.; CAMINO, G. Influence of nanodispersed hydrotalcite on polypropylene photooxidation. Eur. Polym. J., v.44, p. 3473-3481, 2008.

91. BERNSTEIN, R.; THORNBERG, S. M.; ASSINK, R. A.; MOWERY, D. M.; ALAM, M. K.; IRWIN, A. N.; HOCHREIN, J. M.; DERZON, D. K.; KLAMO, S. B.; CLOUGH, R. L.. Insights into oxidation mechanisms in gamma-irradiated polypropylene, utilizing selective isotopic labeling with analysis by GC/MS, NMR and FTIR. Nucl. Instrum. Meth. B., v.265, p. 8-17, 2007.

92. LUGÃO, A. B.; CARDOSO, E. C. L.; LIMA, L. F. C. P.; HUSTZLER, B.; TOKUMOTO, S. Characterization study of gamma-irradiated, high meltstrength polypropylene. Nucl. Instrum. Meth. B., v.208, p. 252-255, 2003.

93. YOSHIGA, A.; OTAGURO, H.; LIMA, L.F.C.P.; ARTEL, B. W. H.; PARRA, D. F.; BUENO, J. R.; SHINZATO, R.; FARRAH, M.; LUGÃO, A. B. Study of polypropylene/polybutene blends modified by gamma irradiation and (high melt strength polypropylene)/polybutene blends. Nucl. Instrum. Meth. B., v.265, p. 130-134, 2007. 
94. Radiation Biology: A Handbook for Teachers and Students. Training Course Series 42. IAEA - International Atomic Energy Agency, Vienna, Austria. p. 13-22, 2010.

95. CLEGG, D. W.; COLLYER, A. A. Irradiation effects on polymers. In: GILLEN, K. T.; CLOUGH, R. L. Accelerated aging methods for predicting long-term mechanical performance of polymers. Elsevier, England. p.157-223, 1991.

96. CLEGG, D. W.; COLLYER, A. A. Irradiation effects on polymers. In: HALLS, N. A. Gamma-irradiation processing. Elsevier, England. p. 253-273, 1991.

97. O'DONNELL, J. H.; SANGSTER, D. F. Principles of Radiation Chemistry. Chapter 2 - Interaction of Radiation with Matter. Edward Arnold Publishers, London. p. 9-30, 1970.

98. DROBNY, J. G. Radiation Technology for Polymers. Second Edition. CRC Press. p. 21-58, 2010.

99. BRADLEY, R. Radiation Technology Handbook. Chapter 5 - Irradiated Polymers: Crosslinking. Marcel Dekker, INC. New York - USA, p.59-84, 1984.

100. ELBARADEI, M. M.; BURKART, W. Handbook or Radioactivity analysis. Edited by Michael F. L'Annunziata, 2th ed., Elsevier - EUA, p. 57$77,2003$.

101. BAGLIN, C. M. Kirk-Othmer Encyclopedia of Chemical Technology. Radioisotopes., v.21, 5th ed., John Wiley \& Sons, Inc., Publication - EUA, p. 284-321, 2006.

102. KIRCHER, J. F.; BOWMAN, R. E. Effects of Radiation on Materials and Components. Chapter 1 - Basics Concepts of Radiation Effects. Reinhold Publishing Corporation. New York. p. 11-34, 1964.

103. SPINKS, J. W.; WOODS, R. J. An Introduction to Radiation Chemistry. Chapter 3 - The Interaction of Radiation with Matter. John Wiley \& Sons, Inc., USA. p. 53-54, 1964.

104. KENAWY, E. R.; WORLEY, S. D.; BROUGHTON, R. The chemistry and applications of antimicrobial polymers: A state-of-the-art review. Biomacromolecules., v.8, n5, p. 1360-1384, 2007.

105. JONES, R. D.; JAMPANI, H. B.; NEWMAN, J. L.; LEE, A. S. Triclosan: A review of effectiveness and safety in health care settings. AJIC. Am. J. Infect. Control., v.28, p.184-196, 2000. 
106. SCHWIZER, H. P. Triclosan: a widely used biocide and its link to antibiotics. FEMS. Microbiology. Letters., v.202, p. 1-7, 2001.

107. BHARGAVA, H. N.; LEONARD, P. A. Triclosan: Applications and safety. AJIC Am. J. Infect. Control., v.24, p. 209-218, 1996.

108. CAMPBELL, L.; ZIRWAS, M. J. Product allergen watch: Triclosan. Dermatitis., v.17, nº4, p. 204-207, 2006.

109. LU, J.; HILL, M. A.; HOOD, M.; GREESON, D. F.; HORTON, J. R.; ORNDORFF, P. E.; HERNDON, A. S.; TONELLI, A. E. Formation of antibiotic, biodegradable polymers by processing with Irgasan DP300R (Triclosan) and its inclusion compound with $\beta$-Cyclodextrin. J. Appl. Polym. Sci., v.82, p. 300-309, 2001.

110. KALYON, B. D.; OLGUN, U. Antibacterial efficacy of triclosan-incorporated polymers. AJIC. Am. J. Infect. Control., v.29, p. 124-126, 2001.

111. Disponível em: <http://en.wikipedia.org/wiki/File:Triclosan-3D-vdW.png>. Acesso em: 12 Jan. 2013.

112. BONILLA, A. M.; GARCÍA, M. F. Polymeric materials with antimicrobial activity. Prog. Polym. Sci., v.37, p. 281-339, 2012.

113. GUILFOILE, P. G. Antibiotic-Resistant Bacteria. Chesea House Publishers, EUA, p. 10-80, 2007.

114. NEU, H.C. The Crisis in Antibiotics Resistance. Science., v. 257, p. 10641073, 1992.

115. RAI, M. K.; DESHMUKH, S. D.; INGLE, A. P.; GADE, A. K. Silver nanoparticles: the powerful nanoweapon against multidrug-resistant bactéria. J. Appl. Microbiol., v.112, p. 841-852, 2012

116. PERCIVAL, S. L.; BOWLER, P. G.; RUSSEL, D. Bacterial resistance to silver in wound care. J. Hosp. Infect., v.60, p.1-7, 2005.

117. LANSDOWN, A. B. G. Silver in Healthcare: Its Antimicrobial Efficacy and Safety in Use. Published by Royal Society of Chemistry. Chapter 1., p. 1-7, 2010.

118. MOYER, C. A.; BRENTANO, L.; GRAVENS, D. L.; MARGRAF, H. W.; MOFANO, W. W. Treatment of large human burns with a $0.5 \%$ silver nitrate solution. Arch. Surg., v.90, p. 812-867, 1965. 
119. Nanoparticles - Building Blocks for Nanotechnology. Chapter 7 Plasmonic Nanomaterials. Wei A. Edited by Vincent Rotello - Spring, p. 173-174, 2004.

120. LEONHARDT, U. Invisibility Cup. Nat. Photonics., v.1, p. 207-208, 2007.

121. Disponível em: $<$ http://www.britishmuseum.org/explore/highlights/highlight_objects/pe_mla/t/ the_lycurgus_cup.aspx>, acesso em: 12 Jan. 2013.

122. FREESTONE, I. C.; MEEKS, N.; SAX, M.; HIGGITT, C. The Lycurgus Cup - A Roman Nanotechnology. Gold. Bulletin., v.40, nº4, p. 270-277, 2007.

123. BARBER, D. J.; FREESTONE, I. C. An investigation of the origin of the colour of the Lycurgus Cup by analytical transmission electron microscopy. Archaeometry., v.32, nº1, p. 33-45, 1990.

124. LEE, B. I.; COPELAND, T. Nanoparticles for materials design: present \& future. J. Ceram. Proces. Res., v.1, p. 31-40, 2005.

125. LIZ-MARZÁN, L. M. Nanometals formation and color. Mater. Today., p. 26-31, 2004.

126. LEA, M. C. On allotropic forms of silver. Am. J. Sci., v.37, p. 476-491, 1889.

127. NOWACK, B.; KRUG, H. F.; HEIGHT, M. 120 years of nanosilver history: implications for policy makers. Environ. Sci. Technol., v.45, p. 1177-1183, 2011.

128. PANYALA, N. R.; PEÑA-MÉNDEZ, E. M.; HAVEL, J. Silver or silver nanoparticles: a hazardous threat to the environment and human health? $\mathbf{J}$. Appl. Biom., v.6, p. 117-129, 2008.

129. ZLOCZOWER, I. M.; LOOS, M. R. Reinforcement Efficiency of Carbon Nanotubes - Myth and Reality. Macromol. Theory. Simul., v.21, p. 130137, 2012.

130. CHO, J.; DANIEL, I. M. Reinforcement of carbon/epoxy composites with multi-wall carbon nanotubes and dispersion enhancing block copolymers. Scripta. Mater., v.58, p. 533-536, 2008.

131. FAGES, E.; PASCUAL, J.; SANOGUERA, D. G.; BALART, R. Study of antibacterial properties of polypropylene filled with surfactant-coated silver nanoparticles. Polym. Eng. Sci., v.51, n4, p. 804-811, 2011. 
132. TSUJI, T.; THANG, D. H.; OKAZAKI, Y.; NAKANISHI, M.; TSUBOI, Y.; TSUJI, M. Preparation of silver nanoparticles by laser ablation in polyvinylpyrrolidone solutions. Appl. Surf. Sci., v.254, I.16, p. 5224-5230, 2008.

133. PARRANAIK, M.; BHAUMIK, S. K. Adsorption behaviour of polyvinyl pyrrolidone on oxide surfaces. Mater. Lett., v.44, p. 352-360, 2000.

134. LEVARD, C.; HOTZE, E. M.; LOWRY, G. V.; BROWN, G. E. Environmental transformations of silver nanoparticles impact on stability and toxicity. Environ. Sci. Technol., v. 46, p. 6900-6014, 2012.

135. JEONG, S. H.; HWANG, Y. H.; YI, S.C. Antimicrobial properties of padded PP/PE nonwovens incorporating nano-sized silver colloids. J. Mater. Sci., v.40, p. 5413-5418, 2005.

136. YEO, S. Y.; JEONG, S.H. Preparation and characterization of polypropylene/silver nanocomposite fibers. Polym. Int., v.52, p. 1053-1057, 2003.

137. PERKAS, N.; SHUSTER, M.; AMIRIAN, G.; KOLTYPIN, Y.; GEDANKEN, A. Sonochemical immobilization of silver nanoparticles on porous polypropylene. J. Polym. Sci: Part A: Polym. Chem., p. 1719-1729, 2008.

138. ZIABKA, M.; MERTAS, A.; KRÓL, W.; BOBROWSKI, A. High density polyethylene containing antibacterial silver nanoparticles for medical applications. Macromol. Symp., v.31, p. 218-225, 2012.

139. RATHNAYAKE, W. G.I.U.; ISMAIL, H.; BAHARIN, A.; DARSANASIRI, A. G. N. D.; RAJAPAKSE, S. Synthesis and characterization of nano silver based natural rubber latex foam for imparting antibacterial and anti-fungal properties. Polym. Test., v.31, p. 586-592, 2012.

140. DEHNAVI, A. S.; AROUJALIAN, A.; RAISI, A.; FAZEL, S. Preparation and characterization of polyethylene/silver nanocomposite films with antibacterial activity. J. Appl. Polym. Sci., v.127, n², p. 1180-1190, 2013.

141. PONGNOP, W.; SOMBATSOMPOP, K.; KOSITCHAIYONG, A.; SOMBATSOMPOP, N. Effects of incorporating technique and silver colloid content on antibacterial performance for thermoplastic films. J. Appl. Polym. Sci., v.122, p. 3456-3465, 2011.

142. VALDES, S. S.; ORTIZ, H. O.; VALLE, L. F. R.; RODRÍGUEZ, F. J. M.; MIRANDA, R. G. Mechanical and antimicrobial properties of multilayer films with a polyethylene/silver nanocomposite layer. J. Appl. Polym. Sci., v.111, I.2, p. 953-962, 2009. 
143. WU, J. J.; LEE, G.J.; CHEN, Y. S.; HU, T. L. The synthesis of nanosilver/polypropylene plastics for antibacterial application. Curr. Appl. Phys., v.12, p. s89-s95, 2012.

144. DASTJERDI, R.; MOJTAHEDI, M. R. M.; SHOSHTARI, A. M. Comparing the effect of three processing methods for modification of filament yarns with inorganic nanocomposite filler and their bioactivity against staphylococcus aureus. Macromol. Res., v.17, n6, p. 378-387, 2009.

145. HAZER, D. B.; MUT, M.; DINÇER, N.; SARIBAS, Z.; HAZER, B.; ÖZGEN, $\mathrm{T}$. The efficacy of silver-embedded polypropylene-grafted polyethylene glycol-coated ventricular catheters on prevention of shunt catheter infection in rats. Childs. Nerv. Syst., v.28, p. 839-846, 2012.

146. DAMM, C.; MÜNSTEDT, H.; RÖSCH, A. The antimicrobial efficacy of polyamide 6/silver-nano and microcomposites. Mater. Chem. Phys., v.108, p. 61-66, 2008.

147. PERELSHTEIN, I.; APPLEROT, G.; PERKAS, N.; GUIBERT, G.; MIKHAILOV, S.; GEDANKEN, A. Sonochemical coating of silver nanoparticles on textile fabrics (nylon, polyester and cotton) and their antibacterial activity. Nanotechnology., v.19, 245705, p. 1-6, 2008.

148. JANG, M. W.; KIM, J-Y.; IHN, J. Properties of polypropylene nanocomposites containing silver nanoparticles. J. Nanosci. Nanotechno., v.7, p. 3990-3994, 2007.

149. JOKAR, M.; RAHMAN, R. A.; IBRAHIM, N. A.; ABDULLAH, L. C.; TAN, C. $P$. Melt production and antimicrobial efficiency of low-density polyethylene (LDPE)-silver nanocomposite film. Food. Bioprocess. Technol., v.5, p. 719-728, 2012.

150. ZAPATA, P. A.; TAMAYO, L.; PÁEZ, M.; CERDA, E.; AZÓCAR, I.; RABAGLIATI, F. M. Nanocomposites based on polyethylene and nanosilver particles produced by metallocenic "in situ" polymerization: synthesis, characterization, and antimicrobial behaviour. Eur. Polym. J., v.47, p. 15411549, 2011.

151. WADY, A. F.; MACHADO, A. L.; ZUCOLOTTO, V.; ZAMPERINI, C. A.; BERNI, E.; VERGANI, C. E. Evaluation of Candida albicans adhesion and biofilm formation on a denture base acrylic resin containing silver nanoparticles. J. Appl. Microbiol., v.112, p. 1163-1172, 2012.

152. DURÁN, N.; MARCATO, P. D.; ALVES, O. L.; SOUZA, G. I. H.; ESPOSITO, E. Mechanistic aspects of biosynthesis of silver nanoparticles by several Fusarium oxysporum strains. J. Nanobiotechnol., v.3, p.1-7, 2005. 
153. DURÁN, N.; MARCATO, P. D.; CONTI, R.; ALVES, O. L.; COSTA, F. T. M.; BROCCHI, M. Potential use of silver nanoparticles on pathogenic bactéria, their toxicity and possible mechanisms of action. J. Braz. Chem. Soc., v.21, p.949-959, 2010.

154. LAGO, V. D.; OLIVEIRA, L. F.; GONÇALVES, K. A.; KOBARG, J.; CARDOSO, M. B. Size-selective silver nanoparticles: future of biomedical devices with enhanced bacterial properties. J. Mater. Chem., v. 21, p. 12267-12273, 2011.

155. LONGO, E.; CAVALCANTE, L. S.; VOLANTI, D. P.; GOUVEIA, A. F.; LONGO, V. M.; VARELA, J. A.; ORLANDI, M. O.; ANDRÉS, J. Direct in situ observation of the electron-driven synthesis of $\mathrm{Ag}$ filaments on $\alpha-\mathrm{Ag}_{2} \mathrm{WO}_{4}$ crystals. Sci Rep., v.3, p. 1-4, 2013.

156. MONTEIRO, D. R.; GORUP, L. F.; TAKAMIYA, A. S.; RUVOLLO-FILHO, A. C.; CAMARGO, E. R.; BARBOSA, D. B. The growing importance of materials that prevent microbial adhesion: antimicrobial effect of medial devices containing silver. Int. J. Antimicrob. Agents., v.34, p.103-110, 2009.

157. Disponível em: <http://uww.nanox.com.br>. Acesso em: 22 Abril 2013.

158. Disponível em: <http://uww.tnsolution.com.br>. Acesso em: 22 Abril 2013.

159. Disponível em: <http://www.khemia.com.br>. Acesso em: 22 Abril 2013.

160. MATSUMURA, Y.; YOSHIKATA, K.; KUNISAKI, S.; TSUCHIDO, T. Mode of bacterial action of silver zeolite and its comparation with that of silver nitrate. Appl. Environ. Microbiol., v.69, nº7, p. 4278-4281, 2003.

161. GRUPTA, A.; MAYNES, M.; SILVER. S. Effects of halides on plasmidmediated silver resistance in Escherichia coli. Appl. Environ. Microbiol., v.64, n¹2, p. 5042-5045, 1998.

162. FENG, Q. L.; WU, J.; CHEN, G. Q.; CUI, F. Z.; KIM, T. N.; KIM, J. O. A mechanistic study of the antibacterial effect of silver ions on Escherichia coli and staphylococcus aureus. J. Biomed. Mater. Res., v.52, p.662-668, 2000.

163. MURRAY, R. G. E.; STEED, P.; ELSON, H. E. The location of the mucopeptide in sections of the cell wall of Escherichia Colli and other gramnegative bacteria. Can. J. Microbiol., v.11, p. 547-560, 1965.

164. SHOCKMAN, G. D.; BARRET, J. F. Structure, Function, and Assembly of cell walls of gram-positive bacteria. Annu. Rev. Microbiol., v.37, p. 501527, 1983. 
165. THURMAN, R. B.; GERBA, C. P. The molecular mechanisms of copper and silver ion disinfection of bacteria and viruses. Crit. Rev. Environ. Contr., v.18, p. 295-315, 1989.

166. NAWAZ, M.; HAN, M. Y.; KIM, T.; MANZOOR, U.; AMIN, M. T. Silver disinfection of Pseudomonas aeruginosa and $E$. coli in rooftop harvested rainwater for potable purposes. Sci. total. Environ., v.431, p. 20-25, 2012.

167. SLAWSON, R. M.; VAN DYKE, M. I.; LEE, H.; TREVORS, J. T. Germanium and silver resistance, accumulation, and toxicity in microorganisms. Plasmid., v.27, p. 72-79, 1992.

168. LIAU, S. Y.; READ, D. C.; PUGH, W. J.; FURR, J. R.; RUSSEL, A. D. Interaction of silver-nitrate with readily identifiable groups: relationship to the antibacterial action of silver ions. Lett. Appl. Microbiol., v.25, p. 279-83, 1997.

169. MODAK, S. M.; FOX, Jr C. L. Binding of silver sulfadiazine to the cellular components of Pseudomonas aeruginosa. Biochem. Pharmacol., v.22, p. 2391-404, 1973.

170. RUSSELL, A. D.; HUGO, W. B.; AYLIFFE. In: Adam PF, Peter AL, JeanYves $\mathrm{M}$, editors. Principles and practice of disinfection, preservation and sterilization. 4th ed. Malden, Massachusetts: Blackwell Publishing. p. 61, 304-305, 2004.

171. KLUEH, U.; WAGNER, V.; KELLY, S.; JOHNSON, A.; BRYERS, J. D. Efficacy of silver-coated fabric to prevent bacterial colonization and subsequent device-based biofilm formation. J. Biomed. Mater. Res., v.53, p. 621-31, 2000.

172. CASTELLANO, J. J.; SHAFII, S. M.; KO, F.; DONATE, G.; WRIGHT, T. E.; MANNARI, R. J. Comparative evaluation of silver-containing antimicrobial dressings and drugs. Int. Wound. J., v.4, p. 114-22, 2007.

173. In: LAGARÓN, J.M.; OCIO, M. J.; RUBIO, A. L. Editors. Antimicrobial Polymer. Chapter 11 - Silver and nanosilver based plastic technologies. Antonio Marínez Abad. Wiley - New Jersey, p. 287-316, 2012.

174. CHALOUPKA, K.; MALAM, Y.; SEIFALIAN, A. M. Nanosilver as a new generation of nanoproduct in biomedical applications. Trends. Biotechnol., v.28, no11, p. 580-588, 2010.

175. KASHIWADA, S.; ARIZA, M. E.; KAWAGUCHI, T.; NAKAGAME, Y.; JAYASINGHE, B. S.; GÄRTNER, K.; NAKAMURA, H.; KAGAMI, Y.; SABOATTWOOD, T.; FERGUSON, P. L.; CHANDLER, G. T. Silver nanocolloids 
disrupt medaka embryogenesis through vital gene expressions. Environ. Sci. Technol., v.46, p. 6278-6287, 2012.

176. LEE, K. J.; BROWNING, L. M.; NALLATHAMBY, P. D.; DESAI, T.; CHERUKURI, P. K.; XU, X. H. N. In vivo quantitative study of sizeddependent transport and toxicity of single silver nanoparticles using zebrafish embryos. Chem. Res. Toxicol., v.25, p. 1029-1046, 2012.

177. ASTM D 1238-04 - Standard Test for Melt Flow Rates of Thermoplastics by Extrusion Plastometer.

178. YOSHIGA, A.; OTAGURO, H.; PARRA, D. F.; LIMA, L. F. C. P.; LUGAO, A. B. Controlled degradation and crosslinking of polypropylene induced by gamma radiation and acetylene. Polym Bull., v.63, p. 397-409, 2009.

179. OLIANI, W. L.; PARRA, D. F.; LUGAO, A. B. UV stability of HMSPP (high melt strength polypropylene) obtained by radiation process. Radiat Phys. Chem., v.79, p.383-387, 2010.

180. OLIANI, W. L.; LIMA, L. F. C. P.; PARRA, D. F.; LUGAO, A. B. Study of the morphology, thermal and mechanical properties of irradiated isotactic polypropylene films. Radiat Phys Chem., v.79, p. 325-328, 2010.

181. OTAGURO, H.; LIMA, L.F.C.P.; PARRA, D.F.; LUGAO, A.B.; CHINELATTO, M.A.; CANEVAROLO, S. V. High-energy radiation forming chain scission and branching in polypropylene. Radiat Phys Chem., v.79, p.318-324, 2010.

182. OLIANI, W. L.; PARRA, D. F.; RIELLA, H. G.; LIMA, L. F. C. P.; LUGAO, A. B. Polypropylene Nanogel: "Myth or reality" Radiat Phys Chem., v.81, p. 1460-1464, 2012.

183. OLIANI, W. L.; PARRA, D. F.; FERMINO, D. M.; LIMA, L.F.C.P.; RIELLA, H. G.; LUGAO, A. B. Study of gel formation by ionizing radiation in polypropylene. Radiat Phys Chem., v.84, p.20-25, 2013.

184. ASTM D 2765-06 - Standard Test Methods for Determination of Gel Content and Swell Ratio of Crosslinked Ethylene Plastics.

185. ASTM D 3418-08 - Standard Test Method for Transition Temperatures and Enthalpies of Fusion and Crystallization of Polymers by Differential Scanning Calorimetry.

186. MARK, J. E. Physical properties of polymers handbook. In.: Crystallization kinetics of polymers. Patki, R., Mezghani, K., Phillips, P.J. Springer, Second Edition. p.639, 2007. 
187. SILVESTRE, C.; DI-LORENZO, M. L.; DI-PACE, E. Handbook of Polyolefins. In.: Chapter 9 - Crystallization of Polyolefins. Second Edition, Edited by Cornelia Vasile. Marcel Dekker, INC, New York - USA, p. 242, 2000.

188. ASTM D6370 - 99(2009) - Standard Test Method for Rubber Compositional Analysis by Thermogravimetry (TGA).

189. JIS Z 2801:2010. Japanese Industrial Standard. Antimicrobial Products Test for antimicrobial activity and efficacy.

190. ANVISA - Agência Nacional de Vigilância Sanitária. Padronização dos Testes de Sensibilidade a Antimicrobianos por Disco-difusão. M2- A8, v. 23, n¹, 2003.

191. ISO 10993-5 : 2009 - Biological evaluation of medical devices. Pat 5: Tests for in vitro cytotoxicity.

192. ROGERO, S.O.; MALMONGE, S. M.; LUGAO, A.B.; IKEDA, T.I.; MIYAMARU, L.; CRUZ, A. S. Biocompatibility study of polymeric biomaterials. Artificial Organs. v.27, n5, p.424-427, 2003.

193. ROGERO, S. O.; LUGAO, A. B.; IKEDA, T. I.; CRUZ, A. S. Teste in vitro de Citotoxicidade: Estudo Comparativo entre Duas Metodologias. Materials Research, v.6, n³, p.317-320, 2003.

194. KHOURY, F. The spherulitic crystallization of isotactic polypropylene from solution: on the evolution of monoclinic spherulites from dentritic chainfolded crystal precursors. J. Res. Nat. Bur. Stand. A: Phys. Chem., v.70, n¹, p.29-61, 1966.

195. NEDKROV, E.; STOYANOV, A.; KRESTEV, V. Morphology of gammairradiated polypropylene gels crystallised from xylene solution-1. Optical microscopy and SALS. Radiat. Phys. Chem., v.37, n², p.299-304, 1991.

196. ULANSKI, P.; ROSIAK, J.M. Encyclopedia of Nanoscience and nanotechnology. In. Polymeric Nano/Microgels, Edited by H.S. Nalwa, California, v.8, p. 845-871, 2004.

197. DE PAOLI, M-A. Degradação e Estabilização de Polímeros. Capítulo 6 - Ensaios e Métodos de Acompanhamento dos Processos de Degradação, São Paulo: Artliber, p.183-214, 2009.

198. RIVATON, A.; LALANDE, D.; GARDETTE, J.-L. Influence of the structure on the $\gamma$-irradiation of polypropylene and on the post-irradiation effects. Nucl. Instrum. Meth. B., v.222, p.187-200, 2004. 
199. Polymer Durability - Degradation, Stabilization, and Lifetime Prediction. Edited by: CLOUGH, BILLINGHAN \& GILLEN. Chapter 35 Mechanisms of Photooxidation of Polyolefins: Prediction of Lifetime in Weathering Conditions. LEMAIRE,J., GARDETE,J-L., LACOSTE,J. DELPRAT,P., VAILLANT, p. 577-598, 1996.

200. CAMPBELL, D.; PETHRICK, R.A.; WHITE, J.R. Polymer Characterization - Physical Techniques. Chapter 5. Vibrational spectroscopy: infra-red and Raman spectroscopy, second edition, Stanley Thornes, p.73, 2000.

201. JONES, R.A.; WARD, I.M. Reactions of amorphous PE radical-pairs in vacuo and in acetylene: a comparison of gel fraction data with FloryStockmayer and atomistic modelling analyses. Polymer., v.37, p.3643-3657, 1996.

202. BURGT, F.P.T.J.VAN DER. Crystallization of Isotactic Polypropylene: The influence of Stereo - Defects. Edited by Frank P.T.J. van der Burgt. Eindhoven :Technische Universiteit Eindhoven, 2002.

203. THOMAS, S.; GIREU, S. A.; AL-JUHANI, A. A.; MEZGHANI, K.; DE, S. K.; ATIEH, M. A. Effect of phenol functionalized carbon nanotube on mechanical, dynamic mechanical, and thermal properties of isotactic polypropylene nanocomposites. Polym. Eng. Sci., v.52, p. 525-531, 2012

204. KIM, D.; JEONG, S.; MOON, J. Synthesis of silver nanoparticles using the polyol process and the influence of precursor injection. Nanotechnology, v.17, p. 4019-4024, 2006.

205. CHUDASAMA, B.; VALA, A. K.; ANDHARIYA, N.; MEHTA, R. V.; UPADHYAY, R. V. Highly bacterial resistant silver nanoparticles: synthesis and antibacterial activities. J. Nanopart. Res., v.12, p. 1677-1685, 2010.

206. ZHANG, B.; CHEN, J.; ZHANG, X.; SHEN, C. Crystal morphology and structure of the $\beta$-form of isotactic polypropylene under supercooled extrusion. J. Appl Polym Sci., v.120, I.6, p. 3255-3264, 2011.

207. LIU, M.; GUO, B.; DU, M.; CHEN, F.; JIA, D. Halloysite nanotubes as a novel $\beta$-nucleating agent for isotactic polypropylene. Polymer. v.50, p. 30223030, 2009.

208. ROMANKIEWICZ, A.; STERZYNSKI, T.; BROSTOW, W. Structural characterization of $\alpha$ - and $\beta$-nucleated isotactic polypropylene. Polym. Int., v.53, p. 2086-2091, 2004.

209. LIANG, G. D.; BAO, S. P.; TJONG, S. C. Microstructure and properties of polypropylene composites filled with silver and carbon nanotube 
nanoparticles prepared by melt-compounding. Mater. Sci. Eng. B., v.142, p. 55-61, 2007.

210. KAKKAR, R.; SHERLY, E.D.; MADGULA, K.; DEVI,D.K.; SREEDHAR, B. Synergetic Effect of Sodium Citrate and Starch in the Synthesis of Silver Nanoparticles. J. Appl. Polym. Sci., v.126, E154-E161, 2012.

211. AFREEN, R. A.; RANGANATH, E. Synthesis of monodispersed silver nanoparticles by Rhizopus Stolonifer and its antibacterial activity against MDR strains of Pseudomonas Aeruginosa from burnt patients. Int. $J$. Environ. Sci., v.1, 7, p.1582-1592, 2011.

212. QUANG, D.V.; SARAWADE, P. B.; HILONGA, A.; KIM, J. K.; CHAI, Y. G.; KIM, S. H.; RYU, J. Y.; KIM, H. T. Preparation of silver nanoparticles containing silica micro beads and investigation of their antibacterial activity. Appl. Surf. Sci., v.257, p. 6963-6970, 2011.

213. KIM, Y. H.; LEE, D. K.; KANG, Y. S. Synthesis and Characterization of Ag and $\mathrm{Ag}-\mathrm{SiO}_{2}$ Nanoparticles. Colloids Surf. A: Physicochem. Eng. Aspects., v. 257-258, p. 273-276, 2005.

214. GUZMAN, M. G.; DILLE, J.; GODET, S. Synthesis of silver nanoparticles by chemical reduction method and their antibacterial activity. Int. J. Chem. Biol. Eng., 2:3, p.104-111, 2009.

215. WEI, Q.; TAO, D.; DENG, B.; HUNG, F. Comparative studies of silver nanocomposite fibers. J. Ind. Text., v.38, 4, p. 1-8, 2009. 